\title{
Untersuchungen zur Biosynthese und Aktivität ausgewählter Plecomakrolide sowie chemisches Screening von Actinomyceten
}

\author{
Dissertation \\ zur Erlangung des Doktorgrades \\ der Mathematisch-Naturwissenschaftlichen Fakultäten \\ der Georg-August-Universität zu Göttingen
}

vorgelegt von

Tim Schuhmann

aus Marktredwitz 
D7

Referent: Prof. Dr. A. Zeeck

Korreferent: Prof. Dr. H. Laatsch

Tag der mündlichen Prüfung: 25.01.2005 
Die vorliegende Arbeit wurde im Institut für Organische und Biomolekulare Chemie der Universität Göttingen in der Zeit von Januar 2002 bis Dezember 2004 unter Anleitung von Prof. Dr. A. Zeeck durchgeführt.

Frau Dr. S. Grond und Herrn Prof. Dr. A. Zeeck danke ich für die interessante Themenstellung, das stete Interesse am Fortgang dieser Arbeit sowie für viele wertvolle Diskussionen und Anregungen. 
für Imelda 


\section{Inhalt}

A. Theoretischer Teil 1

I. Einleitung ...................................................................................................................................1 1

1. Empty Pipelines - Wirkstoffsuche in der Krise? ................................................... 1

2. Mikroorganismen als Quelle hochaktiver Wirkstoffe ............................................

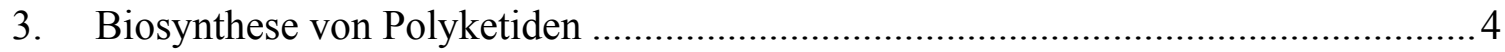

4. „Genetic engineering“ als zukünftiger Hoffnungsträger .......................................

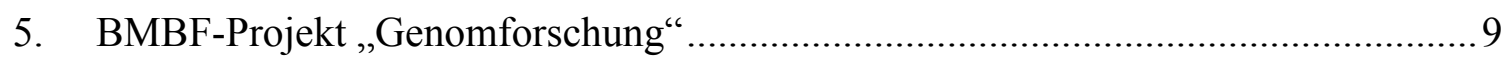

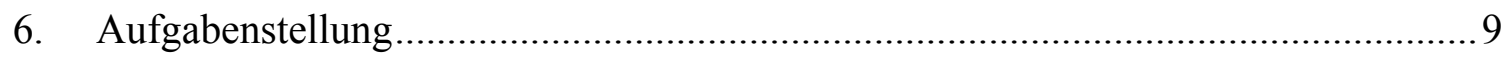

II. Biosyntheseuntersuchungen an den Plecomakroliden ..........................................11

1. Plecomakrolide - eine Klasse potenter ATPase-Inhibitoren.................................. 11

2. Einführende Aspekte zu Biogenesestudien ....................................................... 14

3. Die ,unusual extender unit“ - Biosynthetische Besonderheit der Plecomakrolide .. 15

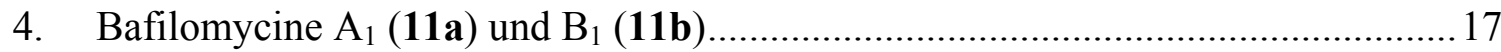

4.1. Überlegungen zur Biogenese der Bafilomycine (11) ................................... 17

4.2. Fermentation und Isolierung der Bafilomycine 11a und 11b.......................... 18

4.3. Aufnahme der Produktionskurve ................................................................20

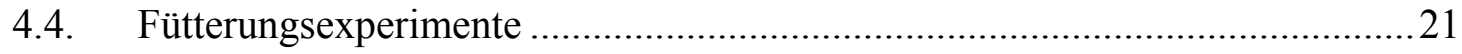

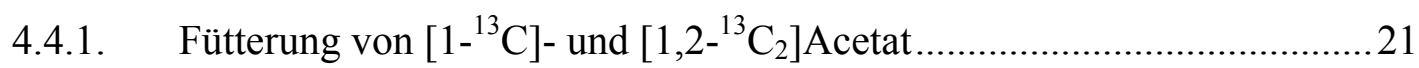

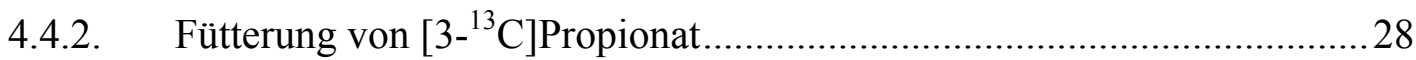

4.4.3. Fütterung von $\left[1-{ }^{13} \mathrm{C}\right]$ Isobutyrat und [Methyl- $\left.{ }^{13} \mathrm{C}\right] \mathrm{L}-$ Methionin .............. 29

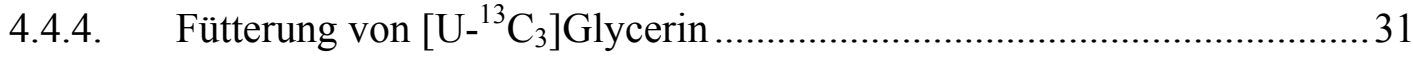

4.4.5. Fütterung von $\left[1-{ }^{13} \mathrm{C}\right]$ Malonyl-SNAC-Estern 31 und 32 ........................33

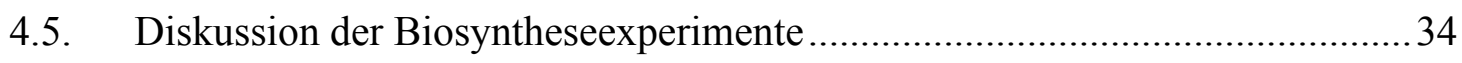

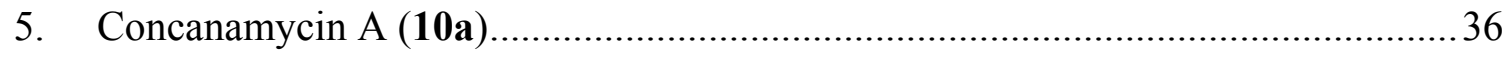

5.1. Bisherige Untersuchungen zur Biosynthese ….............................................. 36

5.2. Fermentationsbedingungen für Streptomyces sp. Stamm Gö 22/15 ..................37

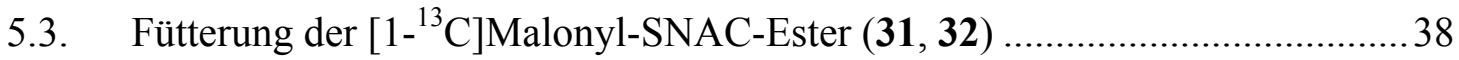

5.4. Fütterung von $\left[1,2-{ }^{13} \mathrm{C}_{2}\right]-(\mathbf{3 5})$ und $\left[2,3-{ }^{13} \mathrm{C}_{2}\right]-s n$-Glycerin $(\mathbf{3 7})$.....................39

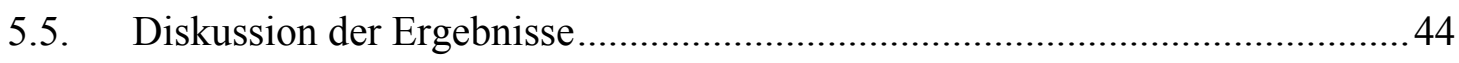

III. Putatives Biosynthese-Gencluster von Concanamycin A (10a) ...........................45

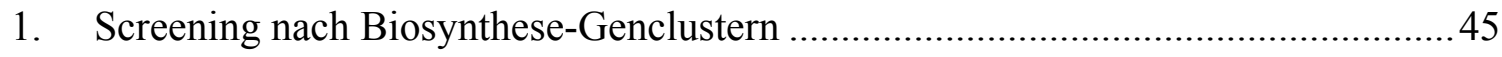

2. Arbeiten innerhalb des GenoMik-Projektes ......................................................... 45 


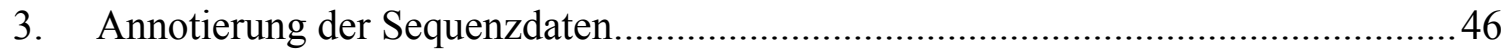

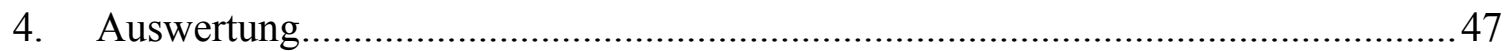

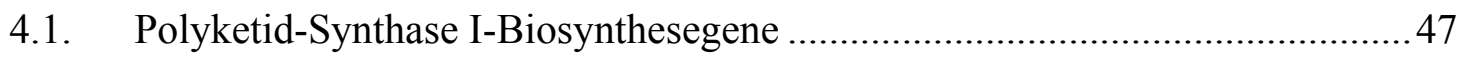

4.2. Biosynthesegene der , ungewöhnlichen $\mathrm{C}_{2}$-Einheit““...................................50

4.3. Biosynthesehypothese des Methoxymalonyl-Vorläufers ................................51

4.4. Biosynthesegene des 4-O-Carbamoyl-2-desoxy-D-rhamnosidbausteins..........52

4.5. Transformationsversuche an Streptomyces sp. Stamm Gö 22/15 .....................53

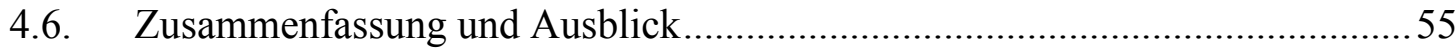

IV. Darstellung eines Bafilomycin-Derivates für Bindungsstudien an V-ATPasen ...56

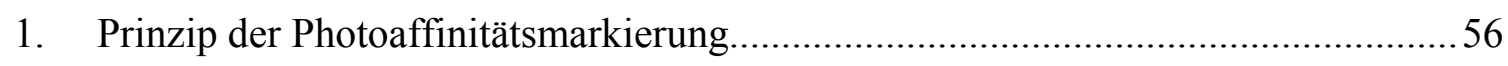

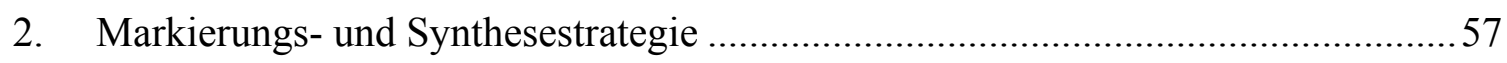

3. Bromierung von 4-[3-(Trifluormethyl)-3H-diazirin-3-yl]benzoesäure (41) ............58

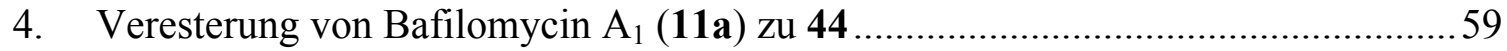

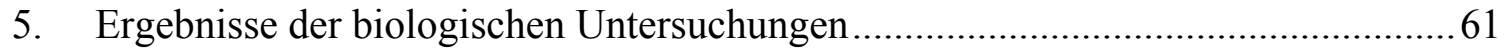

V. Isolierung von Sekundärmetaboliten aus Actinomyceten ...................................63

1. Isolierung und chemisches Screening der untersuchten Stämme ............................63

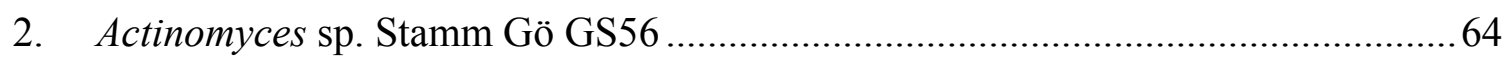

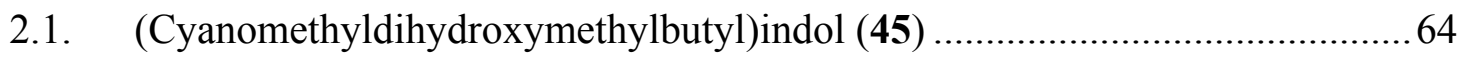

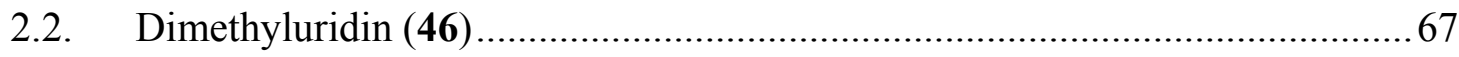

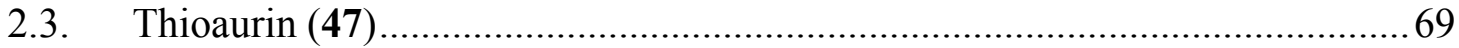

2.4. Biologische Aktivität der Metaboliten .......................................................... 71

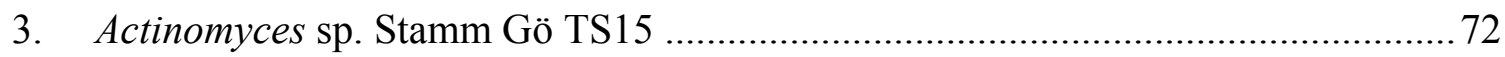

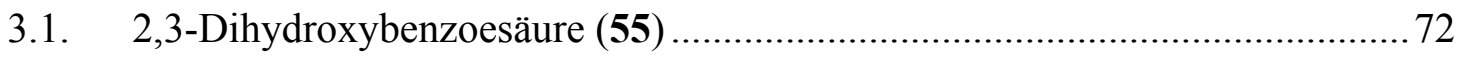

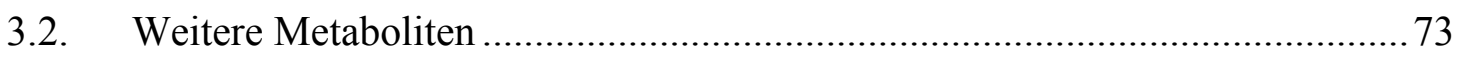

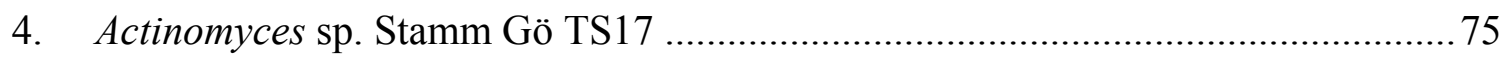

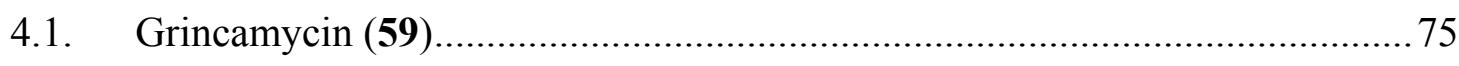

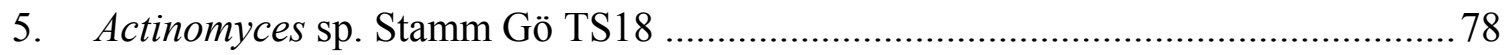

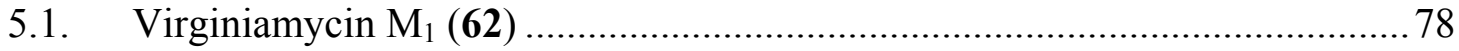

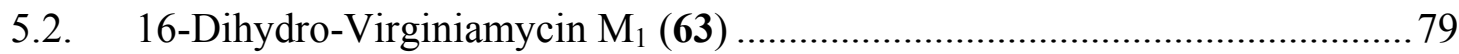

5.3. Dimethylaminophenylhydroxypropionsäureamid (64) ................................. 81

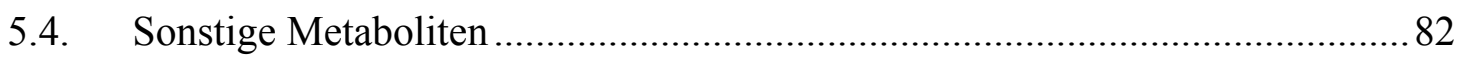

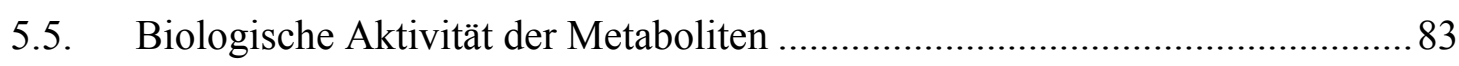

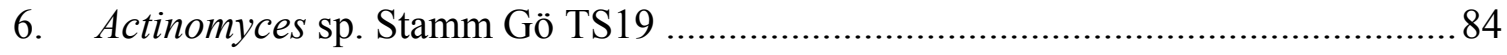

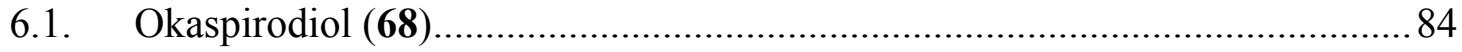




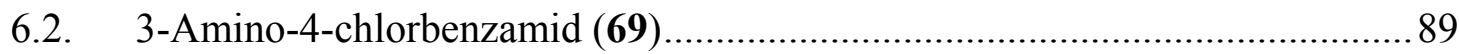

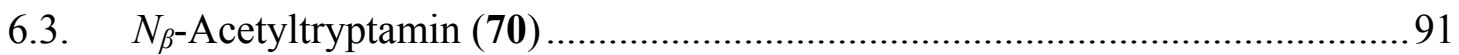

6.4. Biologische Aktivität der Metaboliten ..........................................................92

VI. Endosymbionten aus Aplidium lenticulum ..............................................................93

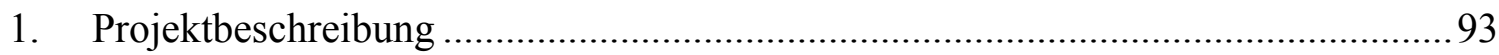

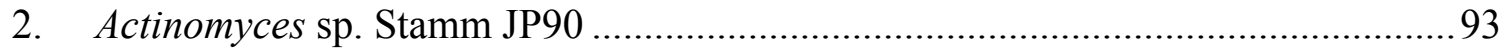

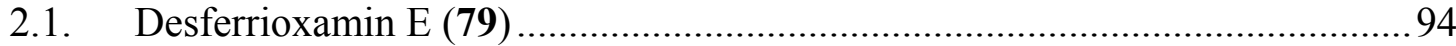

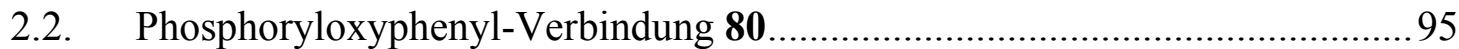

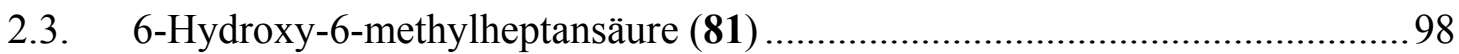

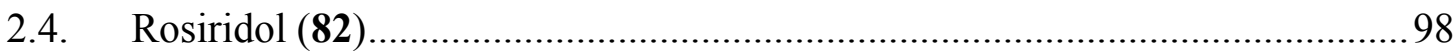

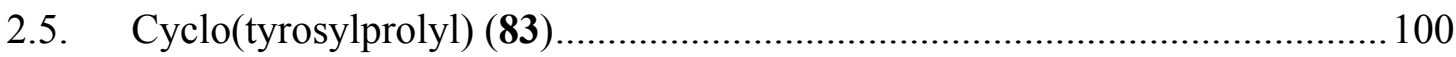

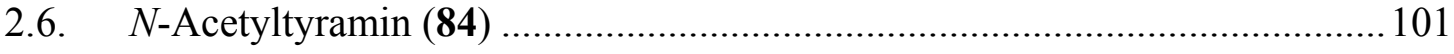

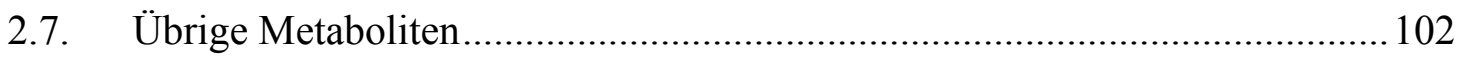

2.8. Biologische Aktivität der Metaboliten ......................................................... 102

VII. Zusammenfassung der Ergebnisse ....................................................................103

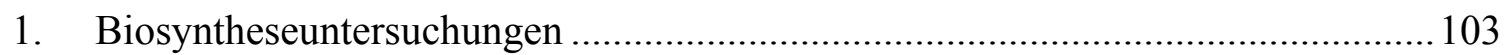

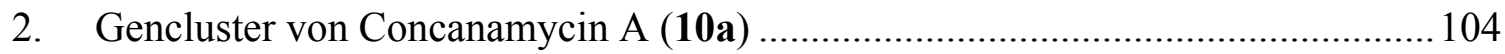

3. Darstellung eines photomarkierten Bafilomycin-Derivates ................................. 104

4. Isolierung von Sekundärmetaboliten aus Actinomyceten .................................... 105

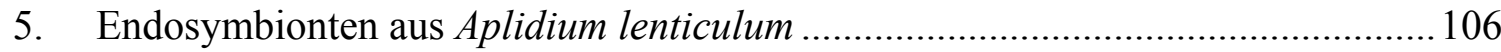

B. Experimenteller Teil .............................................................................................. 108

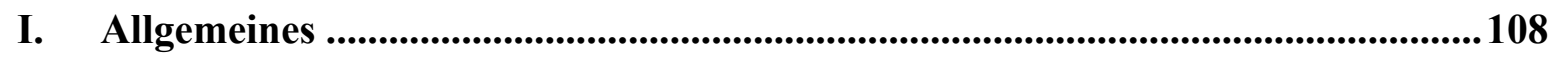

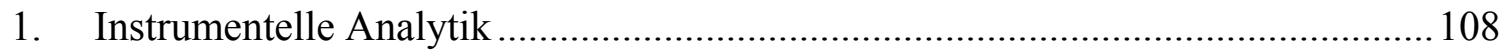

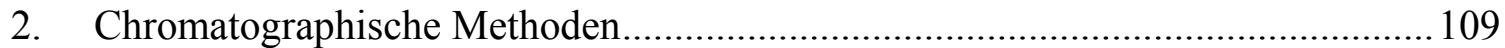

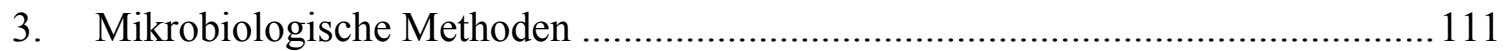

II. Biosyntheseuntersuchungen an Plecomakroliden ................................................ 114

1. Fütterungsexperimente am Bafilomycin-Produzenten ........................................ 114

1.1. Stammhaltung von Streptomyces griseus Stamm 3822-14F ......................... 114

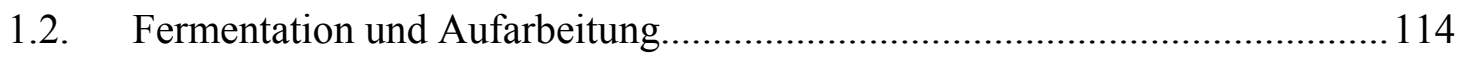

1.3. Erstellen der Fermentationskurve ............................................................ 114

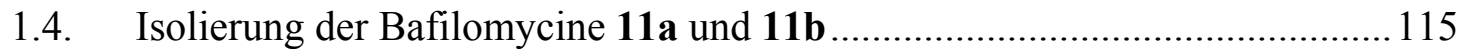

1.5. Durchführung der Fütterungsexperimente.............................................. 115

1.6. Charakterisierung der Metaboliten ............................................................. 115

2. Fütterungsexperimente am Concanamycin-Produzenten ..................................... 118 
2.1. Stammhaltung von Streptomyces sp. Stamm Gö 22/15_.............................. 118

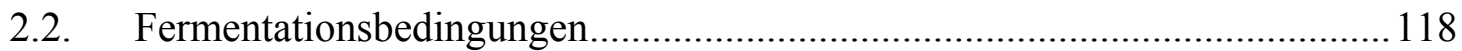

2.3. Aufarbeitung der Fermentationsansätze und Isolierung von 10a ................... 119

2.4. Durchführung der Fütterungsexperimente................................................ 119

III. Transformationsversuche an Stamm Gö 22/15 ............................................. 120

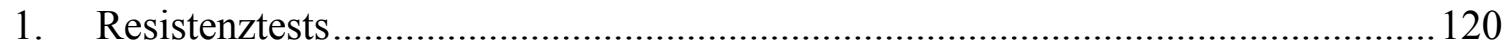

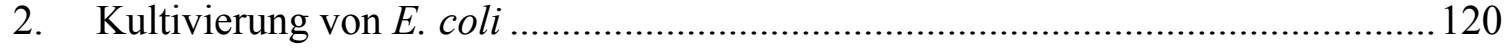

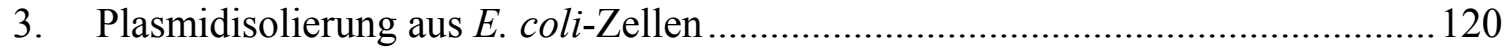

4. Isolierung des Plasmids pGM9 aus Streptomyces lividans Stamm Tü 32............. 121

5. Transformationsversuche an Streptomyces sp. Stamm Gö 22/15 ......................... 121

6. Konjugationsversuche mit Streptomyces sp. Stamm Gö 22/15 ............................ 122

IV. Darstellung eines photomarkierten Bafilomycin-Derivats ................................123

1. 2,5-Dibrom-4-[3-(trifluormethyl)-3H-diazirin-3-yl]benzoesäure (43).................. 123

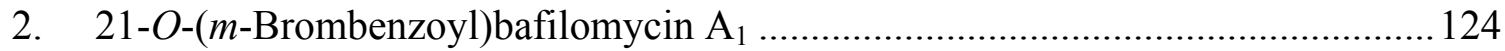

2.1. Darstellung durch Umsatz mit $m$-Brombenzoylchlorid............................... 124

2.2. Darstellung durch Veresterung mit $m$-Brombenzoesäure ............................. 124

3. 21-O-\{2',5'-Dibrom-4'-[3-(trifluormethyl)-3H-diazirin-3-yl]benzoyl $\}$ bafilomycin $\mathrm{A}_{1}$ (44) 126

V. Isolierung von Sekundärmetaboliten aus Actinomyceten ................................... 128

1. Isolierung der Actinomyceten-Stämme aus Erdproben........................................ 128

2. Stammhaltung und Langzeitkonservierung ..................................................... 128

3. Durchführung des chemischen Screenings...................................................... 128

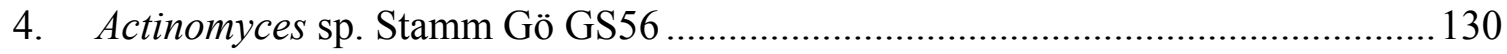

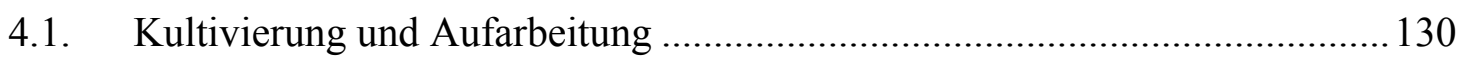

4.2. Isolierung und Charakterisierung der Metaboliten....................................... 130

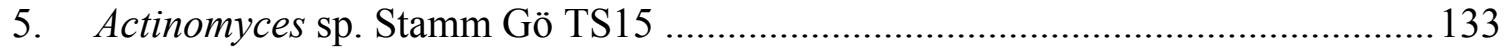

5.1. Kultivierung und Aufarbeitung ………....................................................... 133

5.2. Isolierung und Charakterisierung der Metaboliten........................................ 133

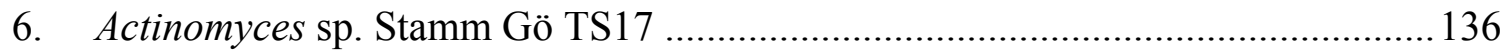

6.1. Kultivierung und Aufarbeitung .................................................................. 136

6.2. Isolierung und Charakterisierung der Metaboliten....................................... 136

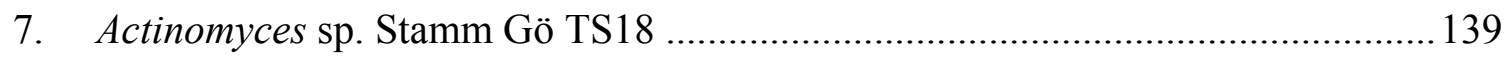

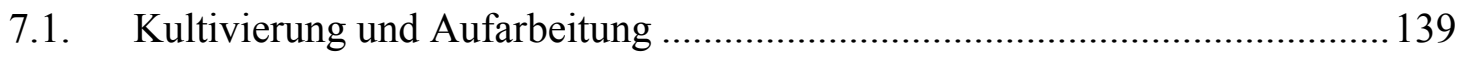

7.2. Isolierung und Charakterisierung der Metaboliten..........................................139 


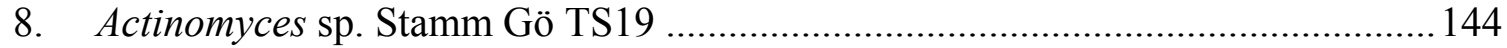

8.1. Kultivierung und Aufarbeitung ................................................................. 144

8.2. Isolierung und Charakterisierung der Metaboliten....................................... 144

VI. Endosymbionten aus Aplidium lenticulum ..................................................... 148

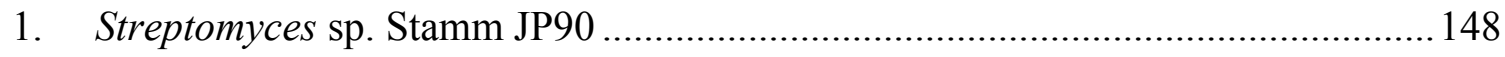

1.1. Kultivierung und Aufarbeitung ….......................................................... 148

1.2. Isolierung und Charakterisierung der Metaboliten....................................... 148

C. Literaturverzeichnis...................................................................................... 154 


\section{A. THEORETISCHER TEIL}

\section{Einleitung}

\section{Empty Pipelines - Wirkstoffsuche in der Krise?}

Die enormen Fortschritte in der biochemischen und genetischen Forschung der letzten Jahrzehnte haben der Menschheit zu einem tief greifenden Verständnis der für die Abläufe des Lebens verantwortlichen, molekularen Zusammenhänge verholfen. So wurde mit der epochalen Entdeckung des strukturellen Aufbaus der DNA durch WATSON und CRICK ${ }^{1}$ vor nunmehr 50 Jahren der Grundstein für das heute als Genomics bezeichnete Forschungsfeld gelegt. Große Anstrengungen in dieser wissenschaftlichen Disziplin führten zur Aufklärung der kompletten Genomsequenzen zahlreicher Spezies, darunter Bakterien ${ }^{2}$ sowie Pflanzen, ${ }^{3}$ und gipfelten in der Entschlüsselung der Basenabfolge des menschlichen Erbguts. ${ }^{4,5}$ Insbesondere hiervon erhoffte man sich tiefere Einblicke in die komplexen biochemischen Zusammenhänge, welche dem Metabolismus des Menschen zugrunde liegen und deren Störung zur Entstehung von Krankheiten führen kann.

So konnten mit diesem Ansatz bislang unbekannte Proteine anhand ihrer Gensequenz als mögliche Ziele für neu zu entwickelnde Medikamente gefunden werden. ${ }^{6}$ Eine Bewertung hinsichtlich der pharmakologischen Relevanz dieser Zielstrukturen ist jedoch äußerst schwierig. Somit konnten die großen Hoffnungen, welche die Industrie zur Entwicklung neuer Wirkstoffe in diese Strategie gesetzt hatte, laut einer aktuellen Analyse von R. F. SERVICE ${ }^{7}$ bislang nicht erfüllt werden. Dies hat mit dazu geführt, dass sich ein beträchtlicher Anteil der Pharmakonzerne weltweit trotz drastischer Erhöhung der für Forschung und Entwicklung aufgewendeten Mittel derzeit in einer schwierigen Lage befindet. So sinkt die Zahl an Neuzulassungen bei Medikamenten, wobei ein Großteil an Krankheiten nach wie vor nur symptomatisch behandelbar ist, da ursächlich wirkende Arzneimittel fehlen. Die Lage der Unternehmen wurde durch hohe Ausgaben im Bereich der Hochdurchsatzverfahren zusätzlich verschlimmert. Diese werden verwendet, um die mittels kombinatorischer Chemie in großem Maßstab zugänglichen Syntheseprodukte auf ihre Eignung als Leitstrukturen hin zu testen, ${ }^{8}$ wobei auch dieser Ansatz bisher nicht zum erhofften Erfolg führte. Darüber hinaus werden die ohnehin immensen Kosten, welche die Entwicklung und Evaluierung von neuen Arzneimitteln verursacht, durch immer neue gesetzliche Auflagen kontinuierlich in die Höhe 
getrieben. Das führt dazu, dass die forschende Pharmaindustrie derzeitig von trüben Zukunftsaussichten spricht. So werden den Untersuchungen von SERVICE zufolge im Moment 99.9\% der sich im Entwicklungsprozess befindlichen Substanzen in einem frühen Stadium ausselektiert, was einen Großteil der aufgewendeten Ressourcen verschlingt und was für die derzeit geringe Zahl an „Hoffnungsträgern“ in den Wirkstoffpipelines der Pharmakonzerne verantwortlich ist. An dieser Stelle muss die Verringerung oder gar Beendigung der Forschungsaktivitäten auf dem Naturstoffsektor kritisiert werden. Die über die Evolution bereits für biologische Targets validierten Naturstoffe bergen ein viel höheres Wirkpotenzial als die über kominatorische Chemie zugänglichen Strukturen. Ihre Einbeziehung würde daher die hohe Zahl an uninteressanten Stoffen am Beginn der Entwicklungspipelines deutlich verringern.

Dieses Dilemma hat mittlerweile zu einem Umdenken in den verantwortlichen Führungsriegen geführt. So hat das Unternehmen GlaxoSmithKline seine vormals zentral organisierte Abteilung für Forschung und Entwicklung in sechs spezialisierte Teilbereiche aufgeteilt, welche sich nunmehr weitgehend autonom mit bestimmten Schwerpunkten befassen. Der schweizer Pharmakonzern Novartis hat auf ähnliche Weise mit der Gründung eines neuen Forschungszentrums reagiert, welches für geplante zehn Jahre einen Stab von 1000 Wissenschaftlern beschäftigen soll. Die Hoffnung ist hier, dass eine derartige Konzentration an naturwissenschaftlicher Kompetenz neue Ideen zur Entwicklung von Leitstrukturen hervorbringt. So wäre es in einem solchen Rahmen denkbar, dass innerhalb eines breiter angelegten Forschungsansatzes unter konsequenter Nutzung bereits vorhandenen Wissens und etablierter Techniken eine Möglichkeit geschaffen wird, biologische Signalwege und Regelmechanismen, die in die Entstehung von Erkrankungen involviert sind, effizienter aufzuklären. Dieses Wissen könnte dann zur gezielten Ableitung von Schlüsselproteinen als Targets für neue Medikamente genutzt werden. Geeignete Screeningverfahren mit speziell zusammengestellten Substanzbibliotheken ${ }^{9}$ könnten dann zu einem effizienteren Auffinden neuer Leitstrukturen führen. Für den Aufbau derartiger Bibliotheken müssen neben Produkten der kombinatorischen Synthese auch die Naturstoffe genutzt werden, welche aufgrund ihrer einzigartigen Strukturvielfalt nach wie vor eine reichhaltige Quelle an biologisch hochaktiven Substanzen darstellen. ${ }^{10,11}$ 


\section{Mikroorganismen als Quelle hochaktiver Wirkstoffe}

Neben Pflanzen ${ }^{12}$ zählen Mikroorganismen zu den bedeutendsten Produzenten bioaktiver Verbindungen. Sie zeichnen sich durch eine meist kosteneffiziente Kultivierbarkeit im Labor aus, was die Isolierung ausreichender Mengen an benötigten Substanzen in kurzer Zeit ermöglicht. Das ist der entscheidende Vorteil gegenüber oft nur begrenzt verfügbaren, außerhalb des Labors nachwachsenden Rohstoffen wie Schwämmen oder Pflanzen. Der Siegeszug mikrobieller Naturstoffe wurde durch das erstmals 1928 aus dem Pilz Penicillium notatum isolierte $\beta$-Lactam-Antibiotikum Penicillin G (1) eingeläutet, dessen kommerzielle Nutzung der Menschheit beim Kampf gegen bakterielle Infektionskrankheiten zu einem Durchbruch verhalf. Im Lauf der Zeit, besonders während der 50er und 60er Jahre des vorigen Jahrhunderts, führten die intensivierten Bemühungen auf dem mikrobiellen Naturstoffsektor zur Entwicklung zahlreicher weiterer Arzneimittel. So konnten neben zusätzlichen antimikrobiell wirksamen Stoffen wie Erythromycin A (2) und Vancomycin, welche die Behandlung von Infektionen mit penicillinresistenten Stämmen ermöglichten, auch Stoffe mit völlig anderen Einsatzgebieten gefunden werden. Der Pilzmetabolit Lovastatin (Mevacor ${ }^{\circledR}$ (3)) beispielsweise wurde zur Leitstruktur für eine ganze Gruppe von Arzneistoffen, welche zur Senkung von Blutcholesterinwerten eingesetzt werden.

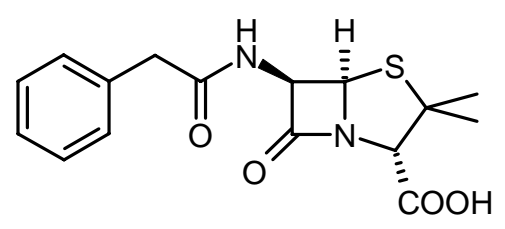

Penicillin G (1)

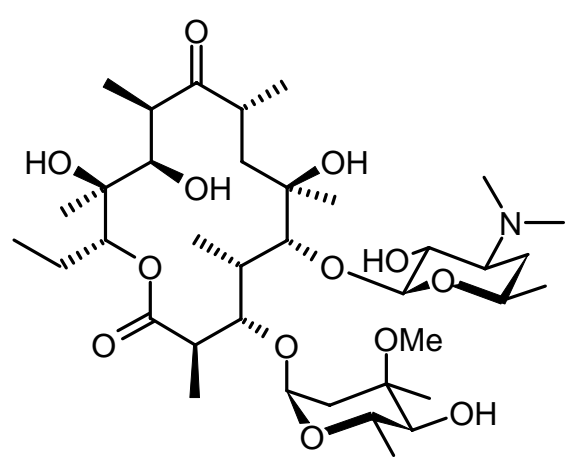

Erythromycin A (2)<smiles>CC[C@H](C)C(=O)O[C@H]1C[C@@H](C)C=C2C=C[C@H](C)[C@H](CC[C@@H]3C[C@@H](O)CC(=O)O3)[C@H]2[C@H]1C</smiles>

Lovastatin (3)

Ein weiterer Meilenstein in der mikrobiellen Naturstoffforschung war die Entdeckung des Oligopeptid-Antibiotikums Cyclosporin A (Sandimmun ${ }^{\circledR}$ (4)) als Sekundärmetabolit von Trichoderma polysporum. Diese Substanz wirkt selektiv cytostatisch auf immunkompetente Zellen, was sie zu einem effizienten Immunsuppressivum mit vergleichsweise geringen Nebenwirkungen macht. Über ein ähnliches Potenzial verfügen die aus Streptomyces sp. isolierten Makrolide Rapamycin (Sirolimus) und FK 506 (Tacrolismus (5)). Ihrer klinischen Anwendung ist es zu verdanken, dass Abstoßungsreaktionen nach Knochenmarks- und 
Organtransplantationen heute weitgehend unterdrückt werden können, ohne dass die Widerstandskraft gegen Krankheitserreger allzu stark beeinträchtigt wird.

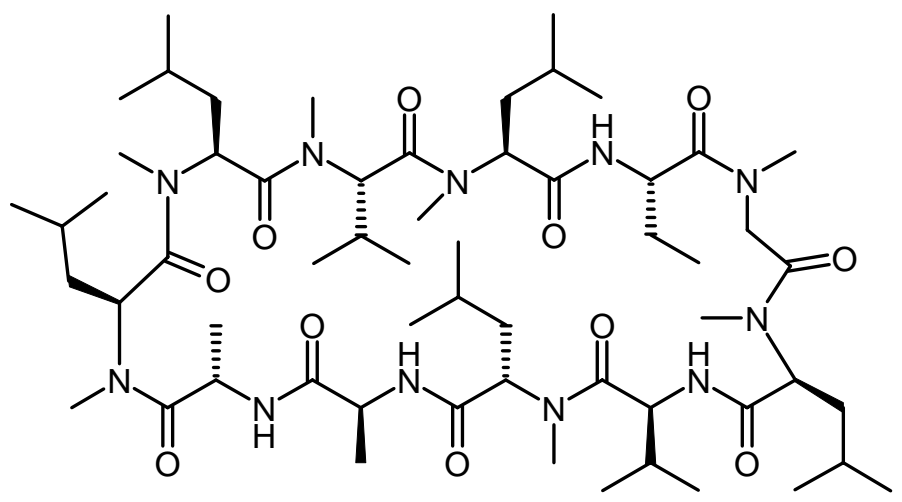

Cyclosporin A (4)

Doxorubicin (Adriamycin $\left.\operatorname{RDF}^{\circledR}(6)\right)$ kann darüber hinaus als Beispiel angeführt werden, dass mikrobielle Sekundärmetaboliten auch als effektive Antitumormittel eingesetzt werden können. ${ }^{13}$ Hier erregten die aus Myxobakterien isolierten Epothilone in jüngster Zeit großes Interesse, da die cytostatische Aktivität dieser Substanz auf einer besonderen, Mikrotubulistabilisierenden Wirkung beruht. ${ }^{14}$

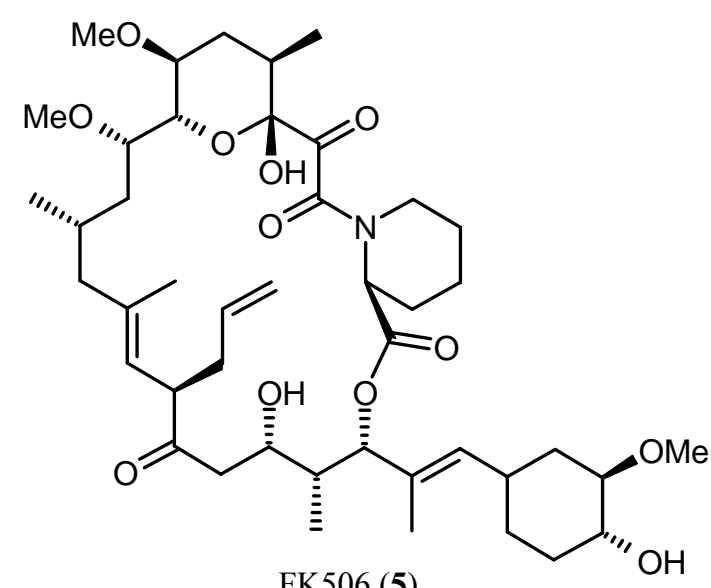

FK506 (5)

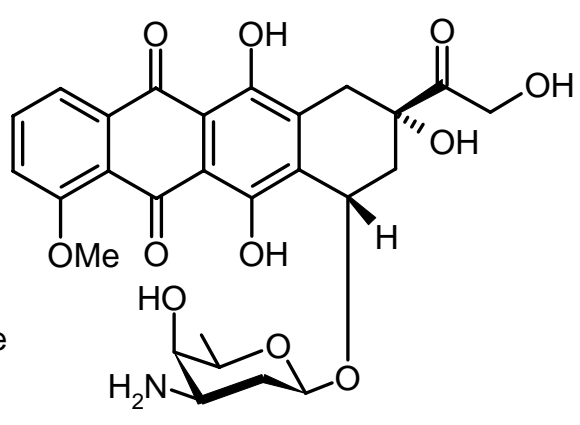

Adriamycin (6)

\section{Biosynthese von Polyketiden}

Naturstoffe können in ihrer ursprünglichen Form meist nicht als Arzneimittel eingesetzt werden, da sie entweder über unbefriedigende pharmakokinetische Eigenschaften verfügen oder anderweitige unerwünschte Nebenwirkungen aufweisen. So geht der klinischen Anwendbarkeit meist eine geeignete Derivatisierung durch im Regelfall klassische chemische Methoden voraus, welche eine Verbesserung des Wirkprofiles zum Ziel hat. Es ist offensichtlich, dass dies aufgrund des sehr komplexen Aufbaus vieler biologisch aktiver 
Sekundärstoffe - wenn überhaupt - nur mit großem Aufwand möglich ist. Es kann angenommen werden, dass zahlreiche vermeintlich vielversprechende Substanzen aufgrund derartiger Beschränkungen nicht weiter bearbeitet wurden. Als Beispiele hierfür können nichtribosomale Peptide sowie Polyketide angeführt werden, wobei insbesondere bei der letztgenannten Gruppe der Prozentsatz an biologisch aktiven Stoffen ungewöhnlich hoch ist. ${ }^{15}$ Um hier Änderungen in die komplexen Molekülstrukturen einzuführen, ist der gezielte Eingriff in die mikrobielle Biosynthese ein erfolgversprechender Ansatz. Die zugrunde liegenden Mechanismen wurden in den letzten 50 Jahren intensiv studiert und man hat heute ein recht detailliertes Bild von der Funktionsweise der am Aufbau von Polyketiden beteiligten Enzyme. ${ }^{16}$ So erfolgt die Biogenese im ersten Schritt durch den Aufbau der linearen Polyketidkette an als Polyketid-Synthasen des Typs I bezeichneten Multienzymkomplexen (siehe Abbildung 2). Diese bestehen aus einer unterschiedlichen Anzahl von Proteinketten, welche iterativ aus einzelnen Modulen aufgebaut sind und über verschiedene funktionelle Einheiten (Domänen) verfügen. Jedes dieser Module katalysiert den Kettenverlängerungsschritt um eine Einheit und beinhaltet mindestens drei Domänen, nämlich eine Ketosynthase (KS), eine Acyltransferase (AT) und ein Acyl-Carrier-Protein (ACP). Ausnahmen bilden sowohl das erste Modul, das meist nur aus AT und ACP besteht und die Kettenstartereinheit als Coenzym-A-Ester bindet, sowie das letzte Modul, das über eine terminale ThioesteraseAktivität (TE) verfügt und für die Abspaltung der vollständig aufgebauten Polyketidkette verantwortlich ist. KS, AT und ACP des zweiten Moduls katalysieren kooperativ die Knüpfung einer Kohlenstoff-Kohlenstoff-Bindung zwischen der Startereinheit und der nächsten Kettenverlängerungseinheit durch eine Claisen-Kondensation unter Abspaltung von Kohlenstoffdioxid (Abbildung 1). Der bei dieser Kopf-Schwanz-Verknüpfung entstehende $\beta$ Ketoester kann anschließend von variabel zwischen AT und ACP positionierten Domänen stufenweise reduziert oder ohne Modifikation an das nächste Modul weitergereicht werden, an dem analoge Schritte stattfinden. So kommt es zum sukzessiven Aufbau der Polyketidkette. Als optional vorkommende reduktive Einheiten findet man Ketoreduktase (KR)-, Dehydratase (DH)- und Enoylreduktase (ER)-Domänen. Befindet sich lediglich eine KR-Aktivität im Modul, kommt es zur Reduktion der $\beta$-Ketogruppe des vorhergehenden Kettenverlängerungsbausteins zur Hydroxyfunktion, während beim Vorliegen von KR und DH zusätzlich die Abspaltung eines Wassermoleküls unter Ausformung einer Doppelbindung zwischen den Biosyntheseeinheiten katalysiert wird. Das simultane Vorliegen aller drei reduktiven Domänen führt schließlich zur Bildung einer 
Methylengruppe. Dieses Prinzip der Reduktion bis auf die Stufe der gesättigten Einheiten wird analog auch bei der Biosynthese von Fettsäuren beschritten.

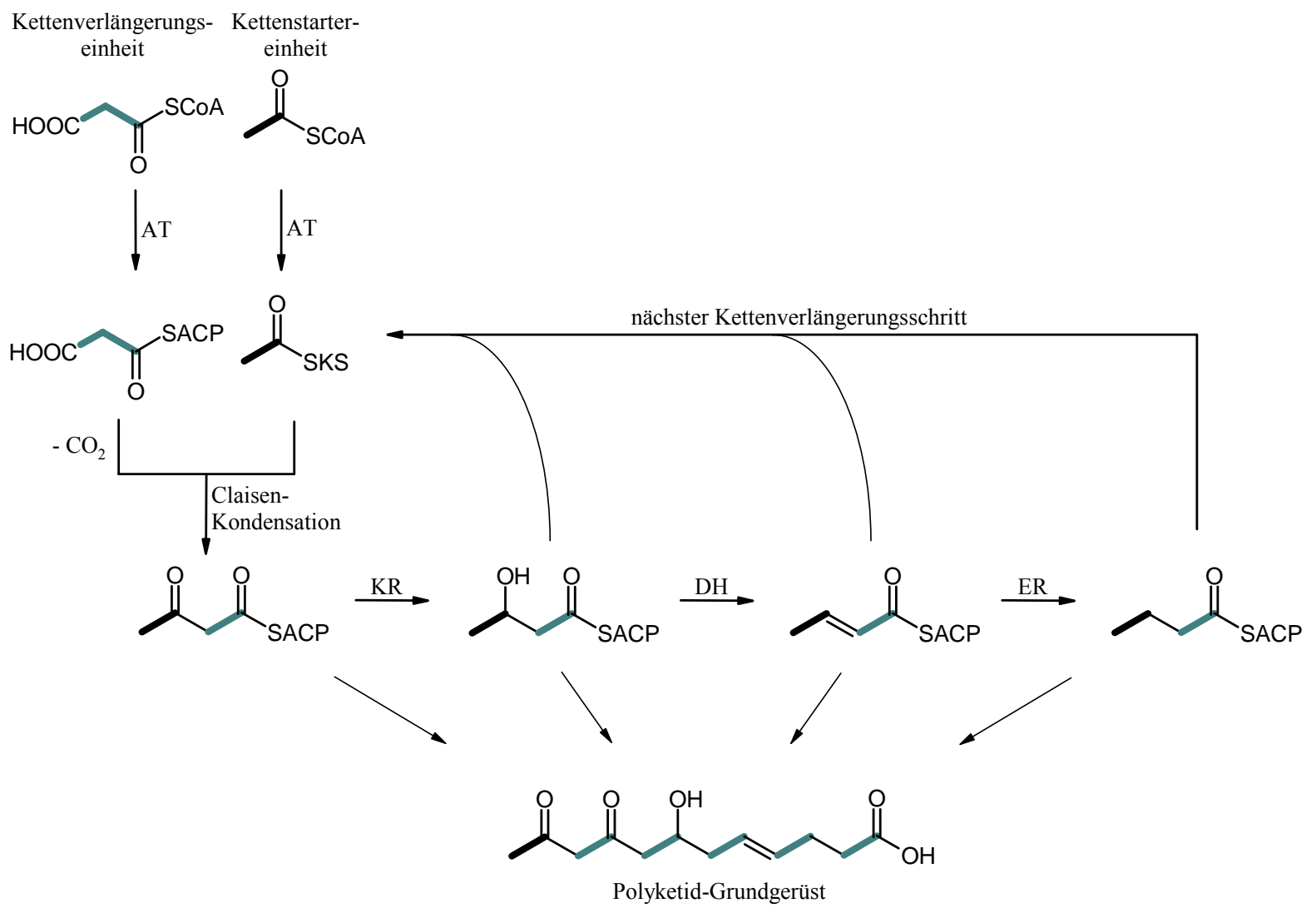

Abbildung 1: Schematischer Ablauf der PKS I-katalysierten Polyketid-Biosynthese (mit AT: Acyltransferase, KR: Ketoreduktase, DH: Dehydratase, ER: Enoylreduktase).

Erst nach komplettiertem Aufbau des Polyketid-Rückgrates erfolgt dessen TE-katalysierte Abspaltung vom PKS-Komplex. In post-PKS-Schritten schließlich wird die Biosynthese mittels weiterer enzymatisch katalysierter Reaktionen wie Oxidationen oder dem Transfer von Zuckereinheiten vervollständigt. Ähnliche Mechanismen liegen dem Aufbau der sich strukturell deutlich von PKS I-Polyketiden unterscheidenden PKS II-, PKS III- und NRPSProdukte zugrunde. ${ }^{17,18}$

Die von der Natur zum Aufbau komplexer Verbindungen genutzte Strategie bietet eine Fülle von Eingriffsmöglichkeiten, die zu einer gezielten Modifikation der natürlichen Polyketide in Frage kommen. So stellt das Konzept des „genetic engineering“, welches 1985 durch Arbeiten von HopwOOD und Mitarbeitern ${ }^{19}$ begründet wurde, einen vielversprechenden Ansatz in dieser Richtung dar. ${ }^{20,21,22}$ 


\section{4. „Genetic engineering“ als zukünftiger Hoffnungsträger}

Neben einem Eingriff in die post-PKS-Modifizierungsschritte ${ }^{23}$ der späten Biosynthese bietet der PKS I-Multienzymkomplex ein interessantes Ziel für eine direkte Einflussnahme in die Biosynthese von Polyketiden. So kann durch einen gezielten Austausch der für die einzelnen Proteindomänen codierenden Gensequenzen eine Variabilität in die Strukturen eingeführt werden. Grundlegende Arbeiten von STAUnTON, LEADLAY und Mitarbeitern ${ }^{24}$ am Erythromycin-PKS-Komplex (DEBS) haben den Grundstein für intensive Studien an diesem Modellsystem gelegt. Der Aufbau des Grundgerüstes von 6-Desoxyerythronolid B (7) am DEBS-Multienzymkomplex und die dabei auftretenden, postulierten Zwischenstufen sind in Abbildung 2 dargestellt.

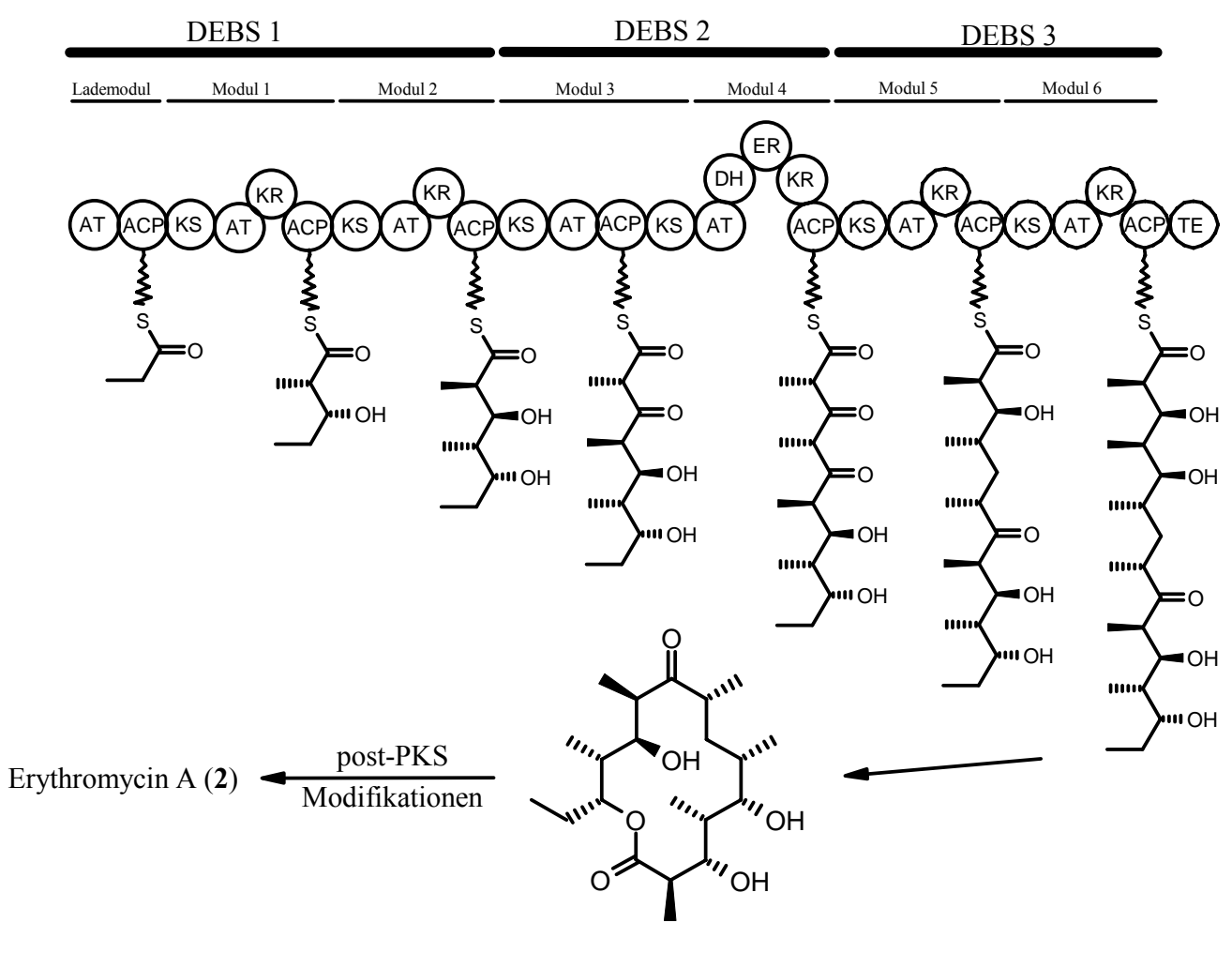

6-Desoxyerythronolid B (7)

Abbildung 2: Aufbau der 6-Desoxyerythronolid B (7) bildenden Polyketidsynthase.

Durch den Austausch der AT-Domänen in DEBS-Modul 1 bzw. 2 gelang es bereits im Jahr 1997, die unnatürlichen Erythromycinderivate 8 und 9 darzustellen (Abbildung 3). Dazu wurden mittels molekularbiologischer Methoden die entsprechenden Abschnitte des Rapamycin-Biosynthese- in den DEBS-Gencluster eingefügt. ${ }^{25}$ Der Austausch von Methylmalonyl-aktivierenden gegen Malonyl-spezifische (mAT) AT-Domänen führte zur Bildung der neuen Erythromycinderivate 8 und 9. 


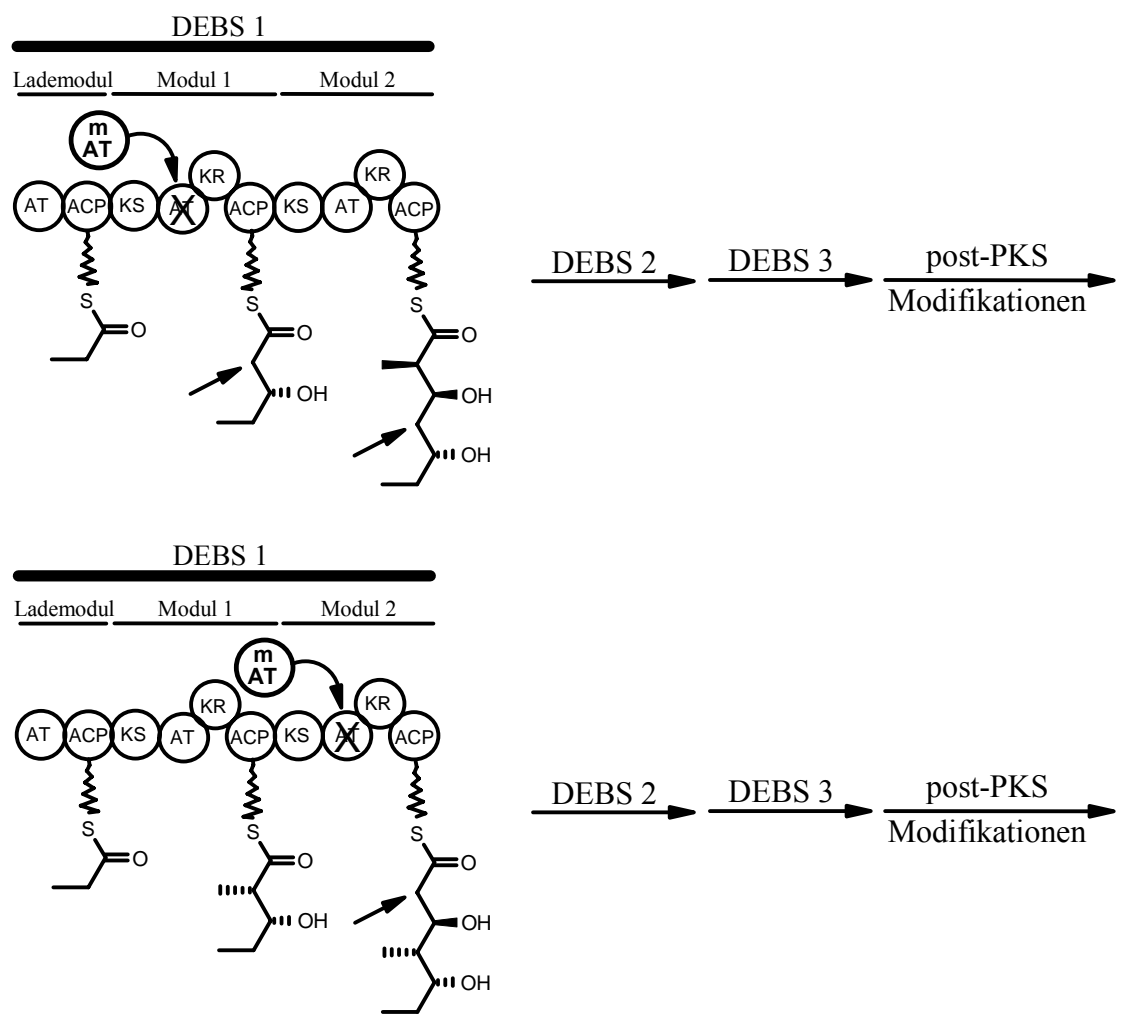

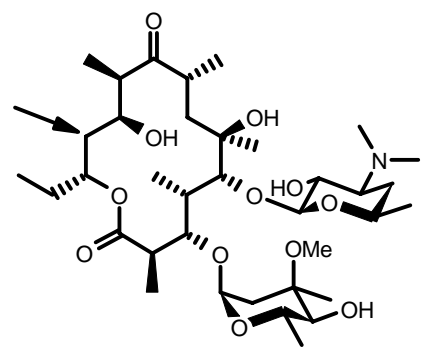

12-Desmethyl-12-desoxyerythromycin (8)

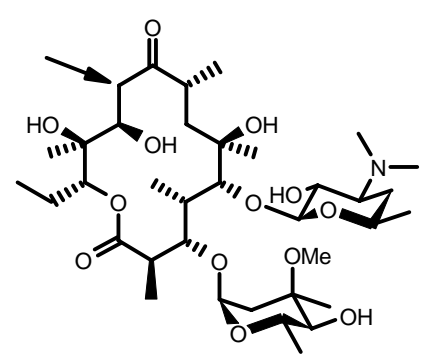

10-Desmethylerythromycin (9)

Abbildung 3: Neue Erythromycinderivate 8 und 9 durch ,genetic engineering“ (nach RUAN et $a .^{25}$ ).

Analoge Versuche führten auch bei den anderen im DEBS-Cluster vorhandenen ATDomänen zum Erfolg. ${ }^{26,27,28,29}$ Ein nächster Schritt war die Einführung kompletter zusätzlicher Module in die PKS-codierenden DNA-Bereiche mit dem Ziel, Einfluss auf die Größe des Erythromycin-Makrolidringes zu nehmen. ${ }^{30,31}$ Doch hier zeigten sich die Grenzen dieses Ansatzes. So konnte man die Bildung der gewünschten Produkte zwar beobachten, deren Ausbeuten lagen jedoch ein Vielfaches unter denen der natürlichen Biosyntheseprodukte, ${ }^{32}$ so dass eine effiziente Isolierung und Testung oft nicht möglich war. Die komplexen Zusammenhänge auf der Ebene der Proteinwechselwirkungen, welche bis heute nur ansatzweise verstanden werden, führen hier offenbar zu unvorhersagbaren Resultaten. So bleibt abzuwarten, ob der methodisch vielversprechende Ansatz der kombinatorischen Biosynthese die in ihn gesetzten Erwartungen dauerhaft erfüllen kann und durch ,genetic engineering“ veränderte Naturstoffe mit optimiertem biologischen Wirkprofil tatsächlich bis zur Marktreife entwickelt werden. Die vorliegende Arbeit ist in das vom BMBF geförderte Projekt „Genomforschung“ eingebunden, welche die praktische Umsetzung dieses Ziels in Kooperation mit Industriepartnern voranbringen soll. 


\section{BMBF-Projekt „Genomforschung““}

Die vorliegende Arbeit wurde im Rahmen des vom BMBF geförderten Kompetenznetzwerkes „Genomforschung an Bakterien für den Umweltschutz, die Landwirtschaft und die Biotechnologie“ (FKZ BEO 01K003092201-031U213D) durchgeführt. Aufgabe dieses Projektes war die Untersuchung multifunktionaler nicht-ribosomaler Peptid-Synthetasen und Polyketid-Synthasen sowie der an der Modifikation der Polypeptid- bzw. PolyketidGrundgerüste beteiligten Enzyme, insbesondere in Hinblick auf ihre Funktion und Organisation. Die gewonnenen Erkenntnisse sollten zur Ableitung allgemeingültiger Regeln für die Biosynthese von Naturstoffen beitragen und so den Weg zur Anwendung von rationaler kombinatorischer Biosynthese ebnen.

Das unsere Arbeitsgruppe betreffende Teilprojekt „Sekundärmetabolit-Biosynthese-Gene aus Streptomyceten: Aufklärung der Funktion und ihre Verwendung zur Synthese modifizierter Polyketide“ hatte die selektiven V-ATPase Inhibitoren Concanamycin (10) und Bafilomycin (11) zum Gegenstand. Anhand grundlegender Biosyntheseuntersuchungen unter Einbeziehung der von U. WeHMEIER (BUGH Wuppertal) in Zusammenarbeit mit der Combinature AG (Berlin) erhaltenen Sequenzdaten von Concanamycin A (10a) sollte die Basis für eine erfolgreiche Derivatisierung dieser cytotoxischen Verbindungen auf molekularbiologischem Weg geschaffen werden.

\section{Aufgabenstellung}

Im Rahmen des BMBF-Projektes sollten Untersuchungen zur Biosynthese der mikrobiellen Sekundärstoffe Bafilomycin $A_{1}$ (11a) und $B_{1}$ (11b) durchgeführt werden. Zu diesem Zweck sollten grundlegende Fütterungsexperimente mit ${ }^{13} \mathrm{C}$-markierten Vorläufern an dem von H. B. BODE während eines Screeningprogramms ${ }^{33}$ gefundenen Bafilomycin (11)-Produzenten Streptomyces griseus Stamm 3822-14F durchgeführt werden. Insbesondere war es von Interesse, die biosynthetische Herkunft zweier in den Molekülen enthaltener ungewöhnlich methoxylierter $\mathrm{C}_{2}$-Einheiten im Detail zu klären. Da solche Einheiten auch Bestandteil des Concanamycin (10)-Gerüstes sind, ${ }^{37}$ sollten hier ebenfalls Fütterungsexperimente mit potenziellen Vorläufern am Produzenten Streptomyces sp. Stamm Gö 22/15 vollzogen werden. 
Um einen tieferen Einblick in die enzymatischen Abläufe der Concanamycin (10)-Bildung zu erhalten und die Möglichkeit einer kombinatorischen Biosynthese zu eröffnen, war es zunächst Ziel, das korrespondierende Gencluster zu sequenzieren. Die Sequenzdaten aus diesen im Rahmen des oben beschriebenen BMBF-Projekts laufenden Arbeiten sollten ausgewertet und eine Funktionszuweisung insbesondere im Bezug auf die für die Biosynthese der „ungewöhnlichen $\mathrm{C}_{2}$-Einheiten" verantwortlichen Gene durchgeführt werden. Dazu mussten Strategien $\mathrm{zu}$ einer rechnergestützten Auswertung etabliert werden. Um die Grundlage für eine experimentelle Bestätigung zu schaffen, dass die sequenzierten Bereiche tatsächlich in vivo exprimiert werden und zur Bildung von Concanamycin A (10a) führen, sollten grundlegende Transformationsversuche am Produzentenstamm vollzogen werden.

Ein weiterer Teil der vorliegenden Arbeit hatte die chemische Derivatisierung des V-ATPaseHemmstoffes Bafilomycin $A_{1}$ (11a) zum Ziel. Während bereits intensive Studien mit photomarkierten Concanamycin (10)-Derivaten betrieben wurden und so dessen V-ATPaseinhibierende Wirkung auf molekularer Ebene erklärt werden konnte, ${ }^{34,35}$ standen analoge Untersuchungen an den Bafilomycinen (11) noch aus. Zusätzliche Motivation für diese Arbeiten resultierte aus Hinweisen auf unterschiedliche Protein-Bindungstaschen, die von Bafilomycin $A_{1}$ (11a) bzw. Concanamycin A (10a) besetzt werden. ${ }^{56,57}$

Die Suche nach neuen Sekundärstoffen ist ein weiterer Aspekt der vorliegenden Arbeit. Neben einigen zur Verfügung gestellten Actinomyceten (Stämme Gö GS31, Gö GS52, Gö GS56 bis Gö GS59) sollten weitere Stämme aus Bodenproben isoliert und einem anschließenden chemischen Screening unterzogen werden. Auffällige Stämme sollten in größerem Maßstab kultiviert und die gebildeten Sekundärmetaboliten mithilfe chromatographischer Methoden isoliert und in ihrer Struktur aufgeklärt werden. Zusätzlich sollte der bereits N. CZEMPINSKI während ihrer Diplomarbeit ${ }^{36}$ aufgefallene Actinomycet JP90 weiter bearbeitet werden. Dieser wurde am Arbeitskreis von J. PIEL (MPI für Chemische Ökologie, Jena) aus dem Inneren des marinen Manteltierchens Aplidium lenticulum isoliert. 


\section{Biosyntheseuntersuchungen an den Plecomakroliden Concanamycin A (10a), Bafilomycin $A_{1}$ (11a) und $B_{1}$ (11b)}

\section{Plecomakrolide - eine Klasse potenter ATPase-Inhibitoren}

Die Plecomakrolide ${ }^{37}$ (von griech.: $\pi \lambda \varepsilon \kappa \omega=$,,ich falte“), eine Gruppe aktiver mikrobieller Sekundärmetaboliten, stellen sowohl strukturell als auch hinsichtlich ihrer biologischen Wirkung eine außerordentlich interessante Stoffklasse dar. Ihnen gemein ist ein Makrolactonring, der über eine $\mathrm{C}_{3}$-Einheit starr mit einem charakteristisch substituierten Tetrahydropyranring verbunden ist. Hinsichtlich der Größe des Makrolactonringes sowie der Molekülsymmetrie können Plecomakrolide in drei Klassen unterteilt werden. Typische Vertreter der Klasse I wären die Concanamycine (10), ${ }^{38,39,40}$ Viranamycin B (12 $)^{41}$ und Virustomycin, ${ }^{42}$ wobei es sich hier um unsymmetrische Verbindungen mit einem 18-gliedrigen Makrolactonring handelt (Abbildung 4). Bei den ebenfalls unsymmetrischen Bafilomycinen (11) $)^{43,44}$ sowie beim Hygrolidin (13) ${ }^{45}$ und Formamicin (14) ${ }^{46}$ handelt es sich um Klasse II-Plecomakrolide, deren Lactonsystem 16-gliedrig ist. Klasse III-Vertreter sind symmetrische, 16-gliedrige Moleküle wie Elaiophylin $(\mathbf{1 5})^{47}$ und die Efomycine. $^{48}$

Von den Plecomakroliden erregten in jüngster Zeit vor allem Concanamycin A (10a) und Bafilomycin $A_{1}$ (11a) große Aufmerksamkeit. Grund dafür war neben ausgeprägter antifungischer, antiparasitärer und antitumoraler Aktivität ${ }^{49}$ vor allem die Eigenschaft, selektiv vakuolare (V-Typ) ATPasen hemmen zu können. ${ }^{50,51,52}$ Hierbei handelt es sich um Enzyme, die bei der Hydrolyse von ATP freiwerdende Energie an den Transport von Protonen über einen an der Zellmembran anliegenden $\mathrm{pH}$-Gradienten koppeln. Sie werden in Endomembranen vieler Eukaryontenzellen exprimiert. 10a und 11a inhibieren V-ATPasen bereits im nanomolaren Bereich $\left(\mathrm{IC}_{50} \sim 10 \mathrm{nM}\right)$. Dagegen werden die strukturell unterschiedlich aufgebauten P-Typ-ATPasen, zu denen die $\mathrm{Na}^{+} / \mathrm{K}^{+}$- sowie die $\mathrm{Ca}^{2+}$-ATPasen gehören, erst in mikromolarer Konzentration gehemmt. Die unter anderem an der ATPSynthese beteiligten ATPasen vom F-Typ werden von Concanamycin A (10a) und Bafilomycin $A_{1}$ (11a) in ihrer Wirkung nicht beeinträchtigt. ${ }^{53}$ 


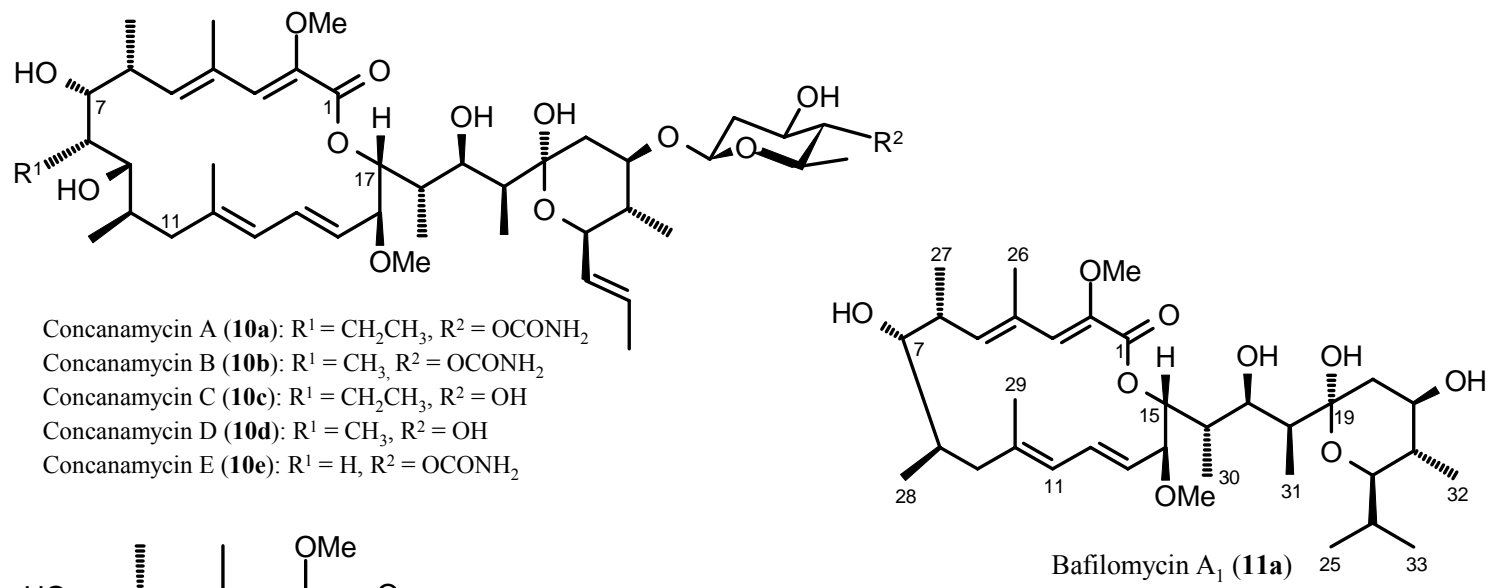

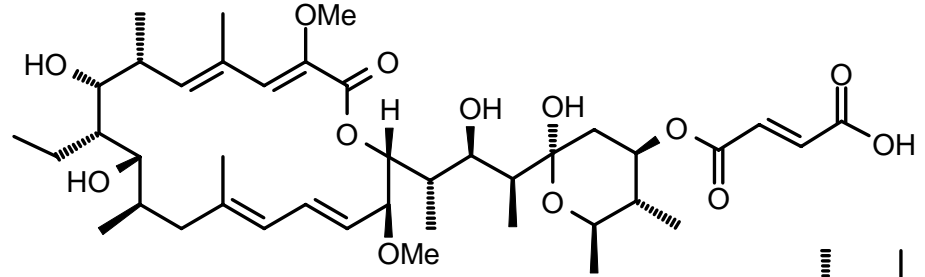

Viranamycin B (12)<smiles>C=CC(=O)O</smiles>

Hygrolidin (13)

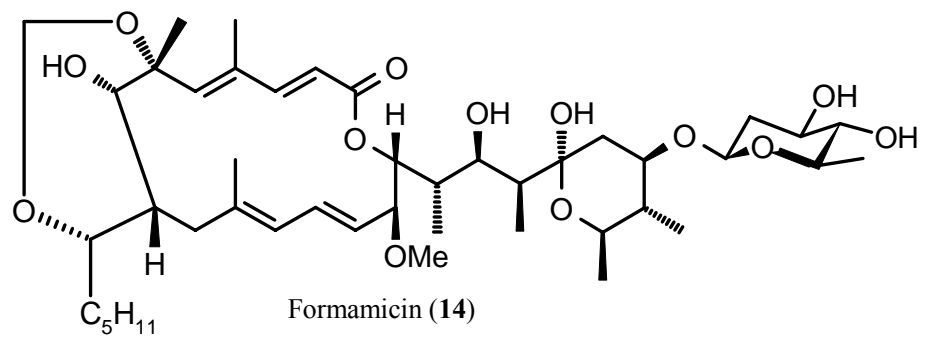

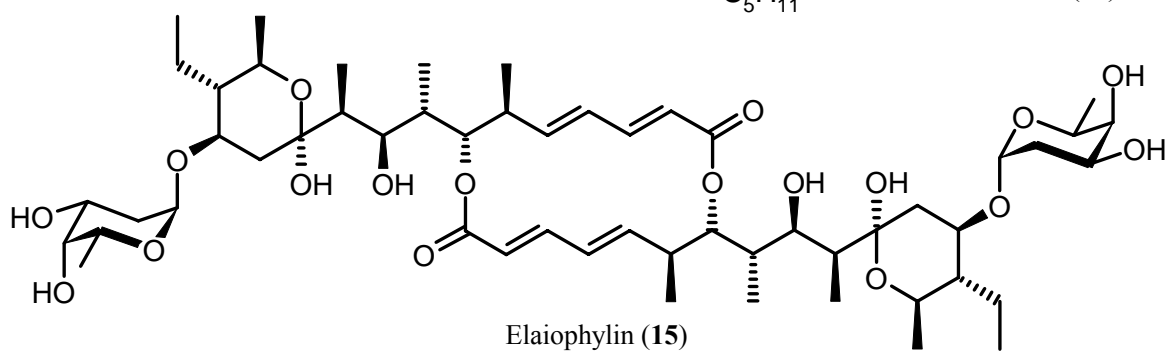

Abbildung 4: Plecomakrolidstrukturen

Anhand von Studien an V-ATPasen aus dem Mitteldarmepithel des Tabakschwärmers Manduca sexta ist es gelungen, die V-ATPase-Bindungstasche von Concanamycin A (10a) mittels eines photoaktivitätsmarkierten Derivates zu lokalisieren. ${ }^{54,55}$ Man fand, dass die Hemmwirkung auf einer Interaktion des Inhibitors mit der c-Untereinheit des 
membranständigen $\mathrm{V}_{0}$-Komplexes beruht (Abbildung 5). Mithilfe von molekularbiologisch orientierten Studien konnte ebenfalls eine konservierte Bindestelle innerhalb der c-Untereinheit der V-ATPase-Gene von Neurospora crassa bzw. Saccharomyces cerevisiae identifiziert werden. ${ }^{56,57}$ Zusätzlich gibt es hier Hinweise darauf, dass Concanamycin A (10a) eine von Bafilomycin $A_{1}$ (11a) verschiedene Bindungstasche besetzt. Dieser Befund konnte durch Untersuchungen untermauert werden, die belegen, dass das Wachstum verschiedener gegen 11a resistenter Zelltypen unter Zusatz von 10a gehemmt wird. ${ }^{58}$

Ihre inhibitorische Aktivität machten 10a und 11a zu einem wertvollen Werkzeug, um die bisher unvollständig geklärte Funktionsweise der weitverbreiteten V-ATPasen eingehend untersuchen zu können. So sind V-ATPasen unter anderem bei der Entstehung von Taubheit ${ }^{59}$ sowie bei Tumoren ${ }^{60}$ von großer Bedeutung. Da sie zusätzlich eine zentrale Rolle bei der Aufrechterhaltung des sensiblen $\mathrm{pH}-$ Gleichgewichts an den Osteoclastenmembranen spielen, ${ }^{61,62}$ nehmen sie regulatorisch Einfluss auf Knochendesorptions- und -resorptionsprozesse. Das macht V-ATPase-Inhibitoren zu vielversprechenden Ausgangsverbindungen für die Entwicklung von Osteoporose-Therapeutika, ${ }^{63}$ da diesem Krankheitsbild eine Fehlfunktion jener Prozesse zugrunde liegt. Einer Anwendung in vivo stand jedoch bislang die hohe Toxizität der Concanamycine (10) und Bafilomycine (11) im Weg, die auf der Hemmung von essentiellen V-ATPasen in anderen Zelltypen, Kompartimenten und Geweben beruht. Um die Selektivität insbesondere von Bafilomycin $A_{1}$ (11a) hinsichtlich OsteoclastenV-ATPasen zu erhöhen, wurden intensive Studien durchgeführt, die in der Anmeldung zahlreicher Patente belegt sind. ${ }^{64,65}$

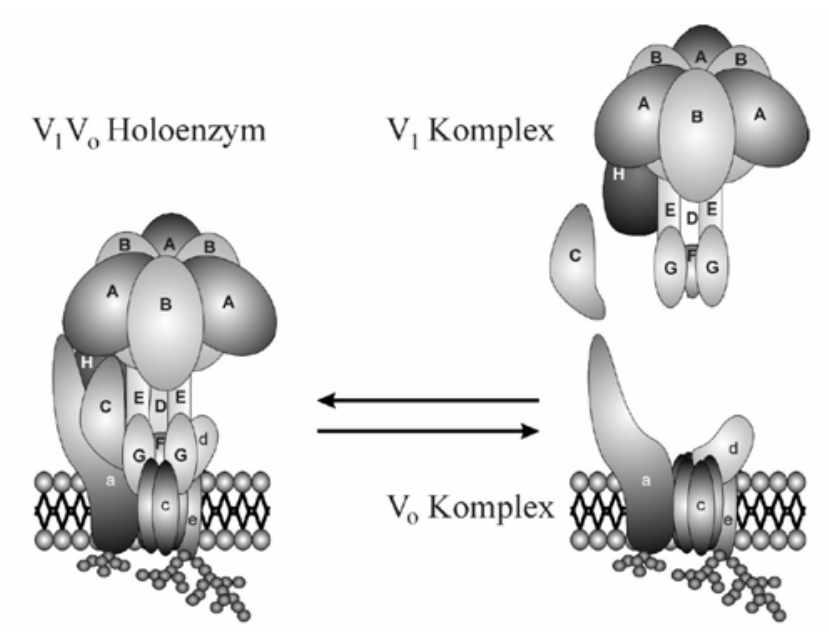

Abbildung 5: V-ATPase von Manduca sexta und reversible Dissoziation in membranständigen $\mathrm{V}_{0}$ - und cytosolischen $\mathrm{V}_{1}$-Komplex. ${ }^{66}$ 
Die außergewöhnlichen biologischen Eigenschaften der Plecomakrolide haben außerdem dazu geführt, dass bereits drei Totalsynthesen von Bafilomycin $A_{1}$ (11a) entwickelt wurden. ${ }^{67,68}$ So erfolgte in einem aktuellen Ansatz von HANESSIAN et al. ${ }^{69}$ ausgehend von D-Mannitol der stereoselektive Aufbau der Einheit C-15 bis C-18, während die stereogenen Zentren an C-6-C-8 über D-Valin eingeführt wurden. Nach getrennter Synthese der Untereinheiten C-1 - C-11 und C-12 - C-24 gelang deren anschließende Verknüpfung durch Anwendung der Stille-Kupplung. Überdies sind zahlreiche effiziente Synthesemethoden von weiteren Teilstrukturen des Bafilomycins $A_{1}$ (11a) ausgearbeitet worden. ${ }^{70,71,72,73}$

\section{Einführende Aspekte zu Biogenesestudien}

Die Natur nutzt zum Aufbau mikrobieller Sekundärstoffe vor allem ubiquitär vorhandene Primärmetaboliten wie Carbonsäuren, Zucker und Aminosäuren. Diese werden in enzymatisch gesteuerten Reaktionen modifiziert und kombiniert, was zur Bildung der unterschiedlichsten Arten von Naturstoffen führt. Die hohe strukturelle Vielfalt basiert dabei im Wesentlichen auf einer großen Variabilität der für die beteiligten Enzyme codierenden Gensequenzen. Die Fortschritte auf den Gebieten der Molekularbiologie und Genetik erlauben es, hier gezielt Einfluss zu nehmen, wodurch Änderungen in die erhaltenen Molekülstrukturen eingeführt werden können (siehe Kapitel A.I.3. und A.I.4.). ${ }^{16,74}$ Zusätzlich beobachtet man für viele Enzyme des Sekundärmetabolismus eine verbreiterte Substratspezifität, so dass es bei der Biosynthese zum Einbau unterschiedlicher Vorläufermoleküle in den Sekundärmetaboliten kommen kann. Dieser Umstand kann innerhalb des Konzeptes der vorläuferdirigierten Biosynthese dazu genutzt werden, strukturell veränderte Sekundärmetaboliten durch die Zufütterung modifizierter Substrate gezielt zu generieren. ${ }^{75}$

Der rationale Eingriff in den Sekundärstoffwechsel mit dem Ziel der Bildung neuer Produkte erfordert somit ein tiefgreifendes Verständnis der zugrunde liegenden Vorgänge und setzt die Aufklärung der Biosynthese voraus. Diese erreicht man durch Fütterung von isotopenmarkierten Vorläufern oder Zwischenprodukten $\mathrm{zu}$ wachsenden Kulturen des betrachteten Mikroorganismus. Während man früher auf die Verwendung von radioaktiven Isotopen angewiesen war, bedient man sich heute im Wesentlichen ${ }^{13} \mathrm{C}-,{ }^{2} \mathrm{H}-,{ }^{15} \mathrm{~N}$ - oder ${ }^{18} \mathrm{O}$-angereicherter Vorläufermoleküle. Durch geeignete NMR- und massenspektroskopischen Untersuchungen am isolierten Reinstoff kann anschließend festgestellt werden, ob und an welcher Position im Molekül ein Einbau stattgefunden hat. Der Einsatz mehrfach markierter 
Vorläufer kann zudem zeigen, ob ein Einbau intakt oder unter vorherigem Bindungsbruch erfolgte.

Zur Auswertung der Fütterungsexperimente werden alle NMR-Signalintensitäten auf die eines nicht angereicherten Kohlenstoffatoms referenziert. Die Berechnung der spezifischen Einbauraten erfolgt anhand der von SCOTT et al. ${ }^{76}$ hergeleiteten Formeln:

$$
\begin{gathered}
\% \text { Anreicherung }=1.1 \% \cdot \frac{\text { Intensität Signal markierte Verbindung }}{\text { Intensität Signal Referenzverbindung }}-1.1 \% \\
\text { spezifischer Einbau }=\frac{\% \text { Anreicherung } \cdot 100}{\% \text { Anreicherung der Vorstufe }}
\end{gathered}
$$

\section{Die ,unusual extender unit“" - Biosynthetische Besonderheit der Plecomakrolide}

Während viele Fragen zur Biosynthese der Concanamycine (10) bereits geklärt werden konnten, ${ }^{37}$ stehen analoge Untersuchungen an den Bafilomycinen noch aus. Beide Substanzklassen zeichnen sich durch enge strukturelle Verwandtschaft aus. Ob diese in einer ähnlichen Biosynthese ihre Entsprechung findet, muss anhand von Fütterungsexperimenten mit ${ }^{13} \mathrm{C}$-markierten Vorläufern geprüft werden.

Die Betrachtung der beiden Grundstrukturen, welche vornehmlich aus Acetat- und Propionateinheiten bestehen, legen die Biosynthese an einer Polyketidsynthase (PKS) vom Typ I nahe. Interessanterweise zeigte sich bei den am Concanamycin A (10a) durchgeführten Einbauversuchen, dass nicht alle Einheiten des Makrolactonrings dem Carbonsäure-Pool entstammen. Vielmehr konnte für C-1/C-2 und C-15/C-16 Glycerin als biosynthetischer Ursprung gefunden werden. Solche ,ungewöhnlichen $\mathrm{C}_{2}$-Einheiten“, die als ,unusual extender units“ oder manchmal auch als „Glycerat-Einheiten“ bezeichnet werden, ${ }^{77}$ wurden ebenfalls im Leucomycin (16), ${ }^{78}$ Geldanamycin (17), ${ }^{79}$ Ansamitocin (18), ${ }^{77}$ FK 506 (5), FK $520(\mathbf{1 9}),{ }^{80}$ Soraphen $(\mathbf{2 0})^{81}$ und weiteren mikrobiellen Sekundärstoffen gefunden. Im Fall von Concanamycin A (10a) und Bafilomycin $\mathrm{A}_{1}$ (11a) konnte anhand intensiver StrukturWirkungsbeziehungen gezeigt werden, dass die methoxylierten $\mathrm{C}_{2}$-Einheiten einen entscheidenden Einfluss auf die richtige Faltung des Makrolactonringes ausüben und sich dadurch für die Entstehung der biologischen Aktivität mitverantwortlich zeichnen. ${ }^{54}$ Das Vorkommen von ungewöhnlichen Bausteinen als PKS I-Substraten ist dabei nicht auf methoxylierte $\mathrm{C}_{2}$-Einheiten beschränkt, vielmehr weist das fungistatische Antibiotikum 
Zwittermicin (21) sowohl einen Hydroxymalonat- als auch einen Aminomalonataustein auf, ${ }^{82}$ wobei auch hier die Biosynthese nicht mit den üblichen Schritten der PKS-Kettenelongation erklärt werden kann (siehe nächster Abschnitt).
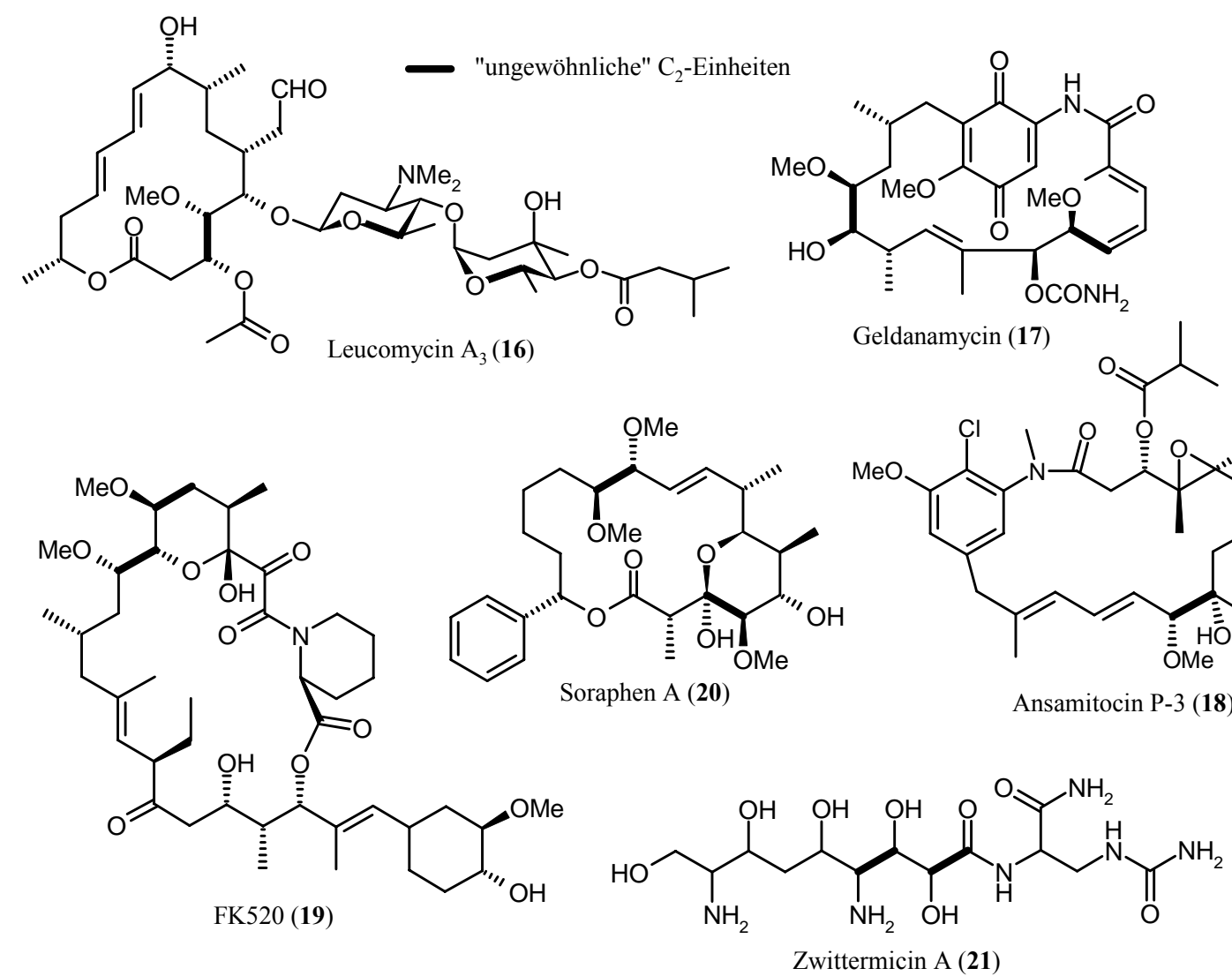

Aufgrund des seltenen, aber immer wieder beobachteten Vorkommens derartiger $\mathrm{C}_{2}$ Einheiten kann für ihre Biosynthese ein relativ weit verbreitetes, allgemeingültiges Prinzip angenommen werden. Das lässt sie im Rahmen des Konzeptes der kombinatorischen Biosynthese zum Aufbau modifizierter Sekundärmetaboliten vom PKS I-Typ sehr attraktiv erscheinen. In diesem Kontext könnten sie genutzt werden, um gezielt $\mathrm{C}_{2}$-Bausteine einzuführen, welche an synthetisch schwer oder nicht zugänglichen Stellen funktionalisiert sind. Eine diesbezügliche Nutzung setzt jedoch die genaue Kenntnis der an der Bildung beteiligten Biosynthese-Schritte unter Einbeziehung der verantwortlichen Gene bzw. Genprodukte voraus (siehe Kapitel A.I.3. und A.I.4.).

Ein Vergleich mit bekannten Kettenverlängerungsschritten legt für die „ungewöhnlichen $\mathrm{C}_{2}$-Einheiten“ Hydroxy- bzw. Methoxymalonyl-CoA als PKS-Substrate nahe. In der Arbeitgruppe von FLoss konnte allerdings kein Einbau entsprechend ${ }^{13} \mathrm{C}$-markierter Vorläufer in das Ansamitocin (18)-Gerüst festgestellt werden. ${ }^{83}$ 
Mit dem Ziel einer Aufklärung der an der Biosynthese der $\mathrm{C}_{2}$-Einheiten beteiligten Vorläufer und Enzyme sind im Rahmen der vorliegenden Arbeit analoge Versuche mit den Bafilomycin (11)- und Concanamycin (10)-Produzenten Streptomyces griseus Stamm 382214F bzw. Streptomyces sp. Stamm Gö 22/15 durchgeführt werden (siehe Kapitel A.II.4.4.5. und A.II.5.3.).

\section{Bafilomycine $A_{1}$ (11a) und $B_{1}$ (11b)}

Die Bafilomycine wurden erstmals 1983 von WERnER, HAGENMAIER et al. aus Kulturen von Streptomyces griseus isoliert. ${ }^{43}$ Nach anfänglicher NMR-basierter Zuordnung der Stereochemie durch COREY et $a l .{ }^{84}$ wurde diese schließlich per Röntgenstrukturanalyse abgesichert. $^{44}$

\section{1. Überlegungen zur Biogenese der Bafilomycine (11)}

Die strukturelle Ähnlichkeit von Bafilomycin $A_{1}$ (11a) und Concanamycin A (10a) lässt eine weitgehend analoge Biosynthese erwarten. So kann für 11 ein hypothetischer Biosyntheseweg ausgehend von sieben Propionat-, zwei Acetat-, zwei Glycerin- sowie einer Isobutyrateinheit formuliert werden (Abbildung 6). Als Methylgruppen-Überträger auf die Hydroxylgruppen der beiden „ungewöhnlichen $\mathrm{C}_{2}$-Einheiten“ $\mathrm{C}-1 / \mathrm{C}-2$ sowie $\mathrm{C}-13 / \mathrm{C}-14$ wird L-Methionin angenommen.
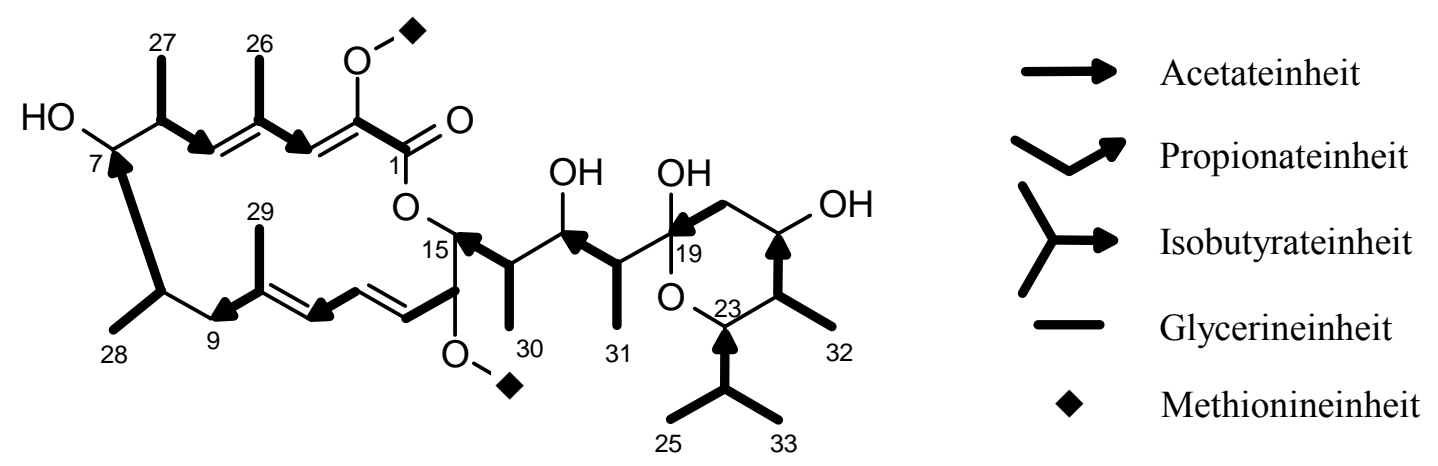

Abbildung 6: Biosynthesehypothese für Bafilomycin $\mathrm{A}_{1}$ (11a).

Bafilomycin $\mathrm{B}_{1}$ (11b) könnte durch nachträgliche Veresterung von 11a an Position 21 entstehen. Die 2-Amino-3-hydroxycyclopent-2-enon-Einheit der übertragenen Seitenkette wird dabei vermutlich - wie für Asukamycin (22) ${ }^{85,86}$ und Reductiomycin (23) ${ }^{87}$ bereits 
gezeigt - aus 5-Aminolävulinsäure aufgebaut. Letztere wird im bakteriellen Stoffwechsel durch Kondensation von Succinyl-CoA und Glutamat unter nachfolgender Decarboxylierung gebildet (siehe Abbildung 12). ${ }^{88}$ Besonderes Augenmerk bei der Überprüfung der Biosynthese-Hypothese galt den ,ungewöhnlichen $\mathrm{C}_{2}$-Einheiten“ C-1/C-2 und C-14/C-15. Sauerstoff-Substituenten befinden sich normalerweise an Position C-1 der eingeführten Acetat-Bausteine, hier jedoch ist das Kohlenstoffatom C-2 einer $\mathrm{C}_{2}$-Einheit in Richtung der wachsenden Polyketidkette methoxyliert.

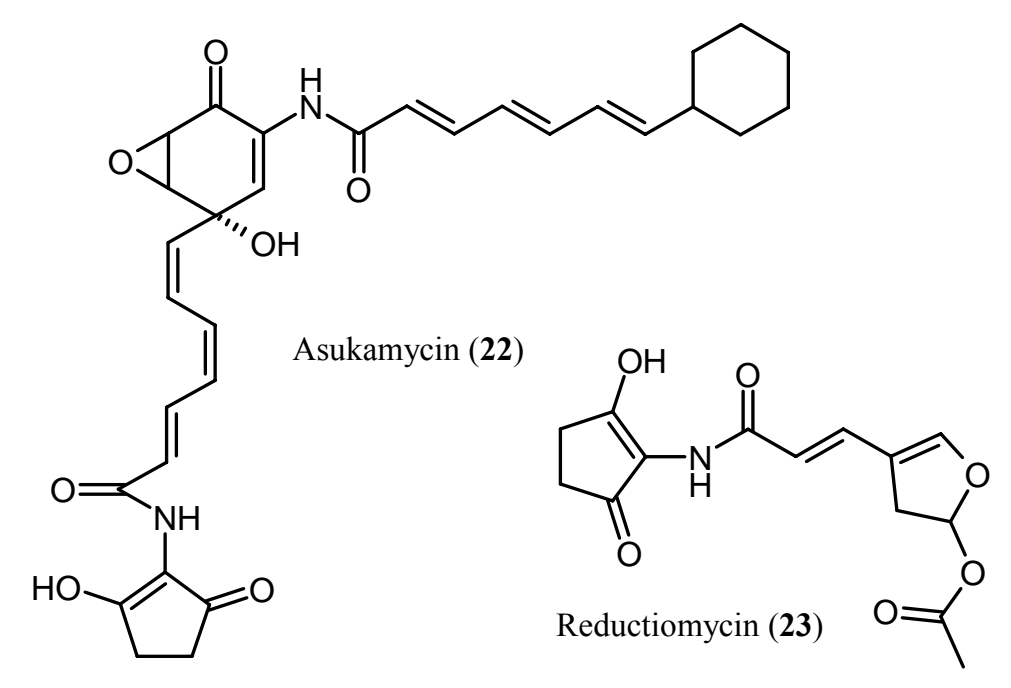

\subsection{Fermentation und Isolierung der Bafilomycine 11a und 11b}

Erste Kultivierungen des Stammes 3822-14F im Rahmen eines chemischen ScreeningAnsatzes wurden von H. B. BoDE durchgeführt. ${ }^{33}$ Er konnte die Bafilomycine $\mathrm{B}_{1}$ (11b) und E (24) sowie Medermycin (25) in Ausbeuten von $30 \mathrm{mg} / \mathrm{L}, 15 \mathrm{mg} / \mathrm{L}$ bzw. $10 \mathrm{mg} / \mathrm{L}$ isolieren.
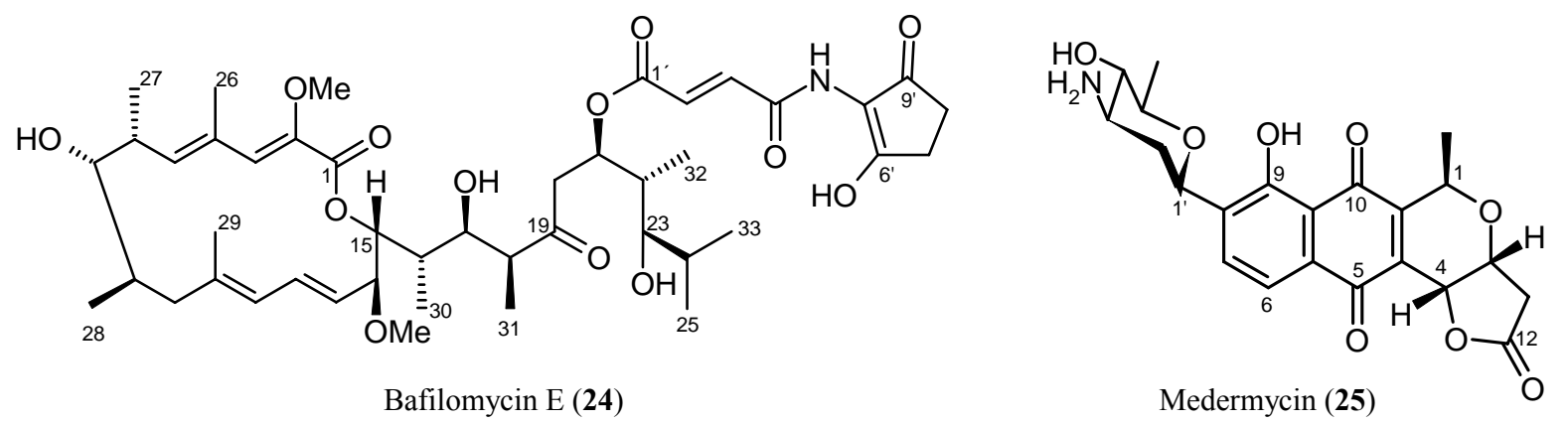

Die relativ hohen Ausbeuten und die Tatsache, dass zwei unterschiedliche Bafilomycine gebildet werden, ließen den Stamm als ideal für die Durchführung von Biosyntheseuntersuchungen erscheinen. 
Allerdings konnte die Produktion von 24 und 25 nicht reproduziert werden. Stattdessen wurde in wiederholten Fermentationsansätzen neben 11b zusätzlich Bafilomycin $A_{1}$ (11a) in Ausbeuten von 20 (11b) bzw. 6 mg/L (11a) aus der Kulturbrühe isoliert. Diese Effekte können auf eine in vielen Fällen beobachtete gewisse Variabilität des Metabolitenspektrums eines Stammes zurückzuführen sein und werden im Rahmen der OSMAC-Methode gezielt untersucht. ${ }^{135}$ Für die geplanten Untersuchungen spielten sie jedoch keine Rolle.

Als nachteilig bei der beschriebenen Art der Fermentation erwies sich die Verwendung des komplexen, fettreichen Soja-Mannit-haltigen (SM)-Mediums. Dies erschwerte die chromatographische Aufarbeitung der Ansätze und somit die Isolierung der Bafilomycine (11a, 11b). Mit dem Ziel, einen einfacheren Zugang zu den Reinstoffen zu gewährleisten, wurde eine Nährmedienvariation durchgeführt. Hier zeigte sich, dass der Gebrauch des stärkehaltigen 1187-Mediums die Produktion der Bafilomycine (11a, 11b) stark hemmte, während die Verwendung des glycerinhaltigen, synthetischen 1358-Mediums im Vergleich zum SM-Medium identische Ausbeuten lieferte. Alle weiteren Kultivierungen wurden folglich im Medium 1358 im 500 mL-Maßstab durchgeführt (Bedingungen siehe Kapitel B.II.1.2.). So konnte eine effiziente Isolierung von für NMR-Untersuchungen ausreichenden Mengen von 1 bis $3 \mathrm{mg} 11 \mathrm{a}$ und 5 bis $10 \mathrm{mg}$ 11b gemäß des Aufarbeitungsschemas in Abbildung 7 sichergestellt werden. Insbesondere 11b zeichnet sich durch hohe Empfindlichkeit gegenüber dem Lösungsmittel Methanol aus, weswegen auf dessen Verwendung während des Aufarbeitungsprozesses verzichtet wurde. Da der Einsatz von deuteriertem Chloroform zu einer nachteiligen Signalüberlappung mit ${ }^{13} \mathrm{C}$-NMR-Resonanzen der Bafilomycine 11a und 11b führte, wurde für NMR-spektroskopische Untersuchungen auf deuteriertes Dichlormethan als Lösungsmittel zurückgegriffen. 


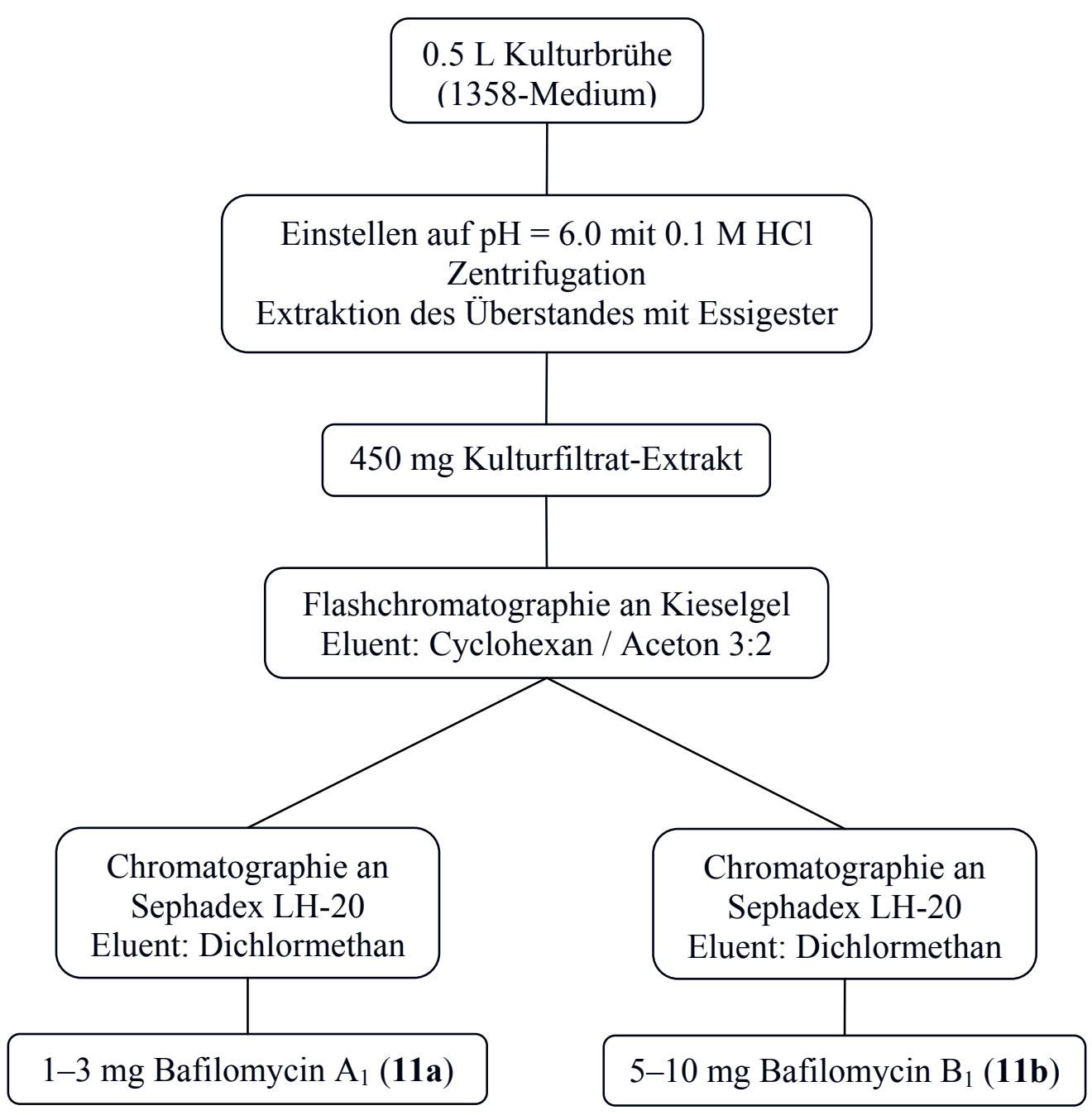

Abbildung 7: Aufarbeitungsschema zur Isolierung der Bafilomycine 11a und 11b aus Fermentationsansätzen von Streptomyces griseus Stamm 3822-14F.

\subsection{Aufnahme der Produktionskurve}

Ziel ist es, die ${ }^{13} \mathrm{C}$-markierten Vorläufer möglichst gezielt und stoffeffizient in die Biogenese der zu untersuchenden Sekundärstoffe einzubringen. Um sowohl den optimalen Zeitpunkt für Fütterungsbeginn und -ende als auch den idealen Erntezeitpunkt zu bestimmen, wurde eine Produktionskurve erstellt. Zu diesem Zweck wurden über einen Zeitraum von 90 Stunden alle vier bis neun Stunden Proben einer wachsenden Kulturlösung von Stamm 3822-14F im Medium 1358 entnommen und diese anschließend mittels HPLC (Bedingungen siehe Kapitel B.II.1.3.) analysiert. Der ermittelte Produktionsverlauf der Bafilomycine 11a und 11b ist in Abbildung 8 dargestellt. 


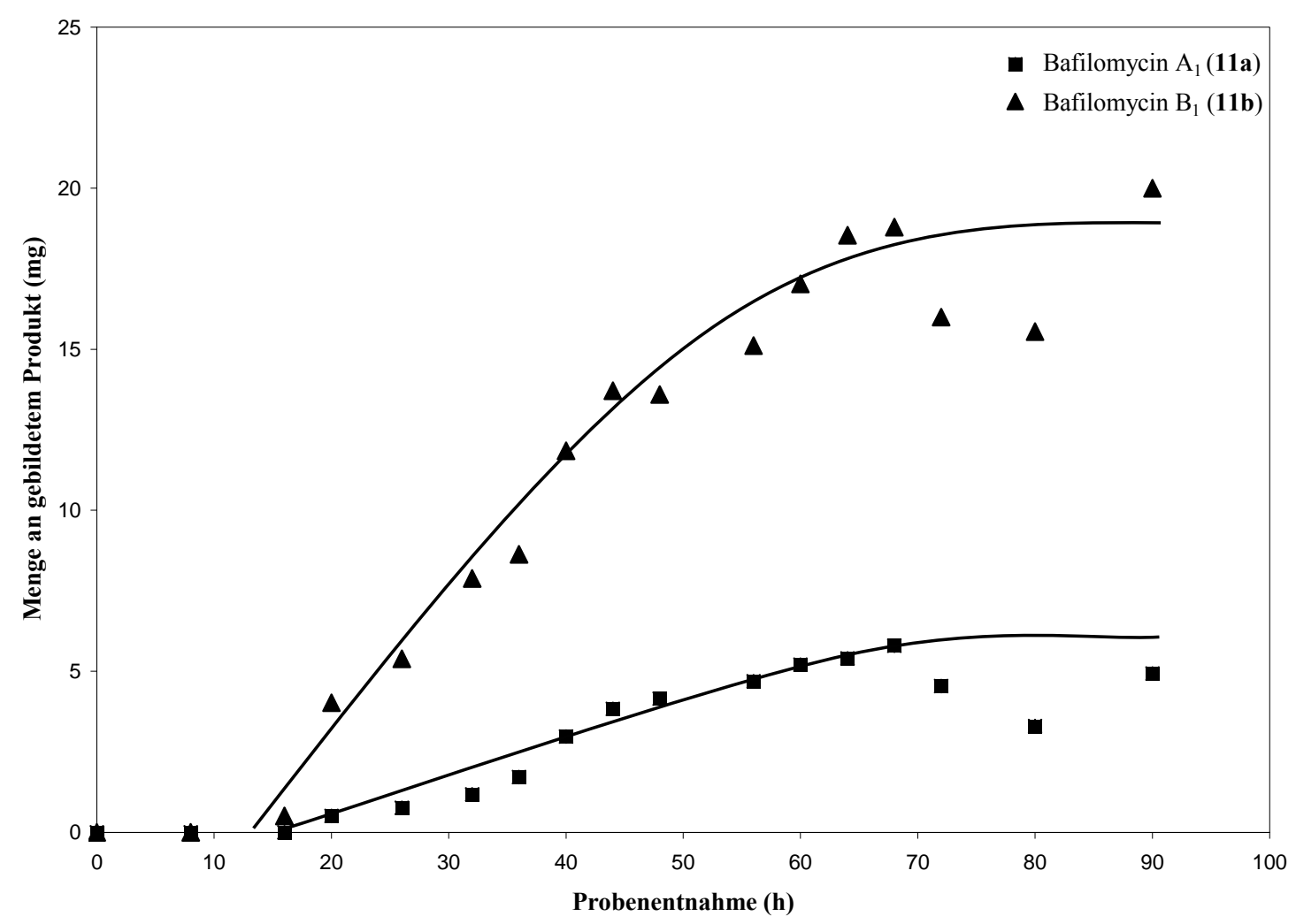

Abbildung 8: Produktionsverlauf von Bafilomycin $A_{1}$ (11a) und $B_{1}(11 b)$ im Medium 1358.

Dem Verlauf ist zu entnehmen, dass die Produktion beider Bafilomycine (11a, 11b) etwa 15 Stunden nach Beimpfen des Mediums einsetzt. Die Konzentration von 11a und 11b steigt danach nahezu linear an und erreicht in der 70. Stunde ihr Maximum. Dies wurde folglich als Erntezeitpunkt gewählt. Um entsprechend dem Kurvenverlauf einen möglichst hohen Einbau der zugefütterten Verbindungen zu gewährleisten, erfolgte das kontinuierliche Zupumpen aller markierter Vorläufer zwischen der 32. und 56. Inkubationsstunde (Bedingungen siehe Kapitel B.II.1.5.).

\subsection{Fütterungsexperimente}

\subsubsection{Fütterung von $\left[1-{ }^{13} \mathrm{C}\right]-$ und $\left[1,2-{ }^{13} \mathrm{C}_{2}\right]$ Acetat}

$\mathrm{Zu}$ Beginn der Biogenese-Untersuchungen an den Bafilomycinen 11a und 11b stand die Fütterung von ${ }^{13} \mathrm{C}$-markiertem Acetat. Dessen aktivierte Form, das Acetyl-Coenzym A, ist im physiologischen Zusammenhang gemeinsames Produkt des Kohlenhydrat-, Fettsäure- und Aminosäureabbaus und stellt damit ein zentrales Intermediat des Primärstoffwechsels dar. Es 
kann durch das Enzym Acetyl-CoA-Carboxylase zu Malonyl-CoA umgebaut werden, wodurch es zum direkten Substrat für die PKS I-Kettenelongationsschritte wird.

Erwartungsgemäß führte die Fütterung einer Endkonzentration von $9.1 \mathrm{mM}\left[1-{ }^{13} \mathrm{C}\right]$ Acetat an Stamm 3822-14F zur Intensitätserhöhung zahlreicher Kohlenstoffatome in den ${ }^{13} \mathrm{C}-\mathrm{NMR}$ Spektren (Abbildung 9) der aufgereinigten Bafilomycine 11a und 11b (Tabelle 1, Abbildung 10). Ein besonders hoher spezifischer Einbau von 8 und 10 bei 11b und jeweils 16 bei 11a konnte für C-11 und C-19 gefunden werden, was auf einen direkten Einbau von Acetat schließen lässt.

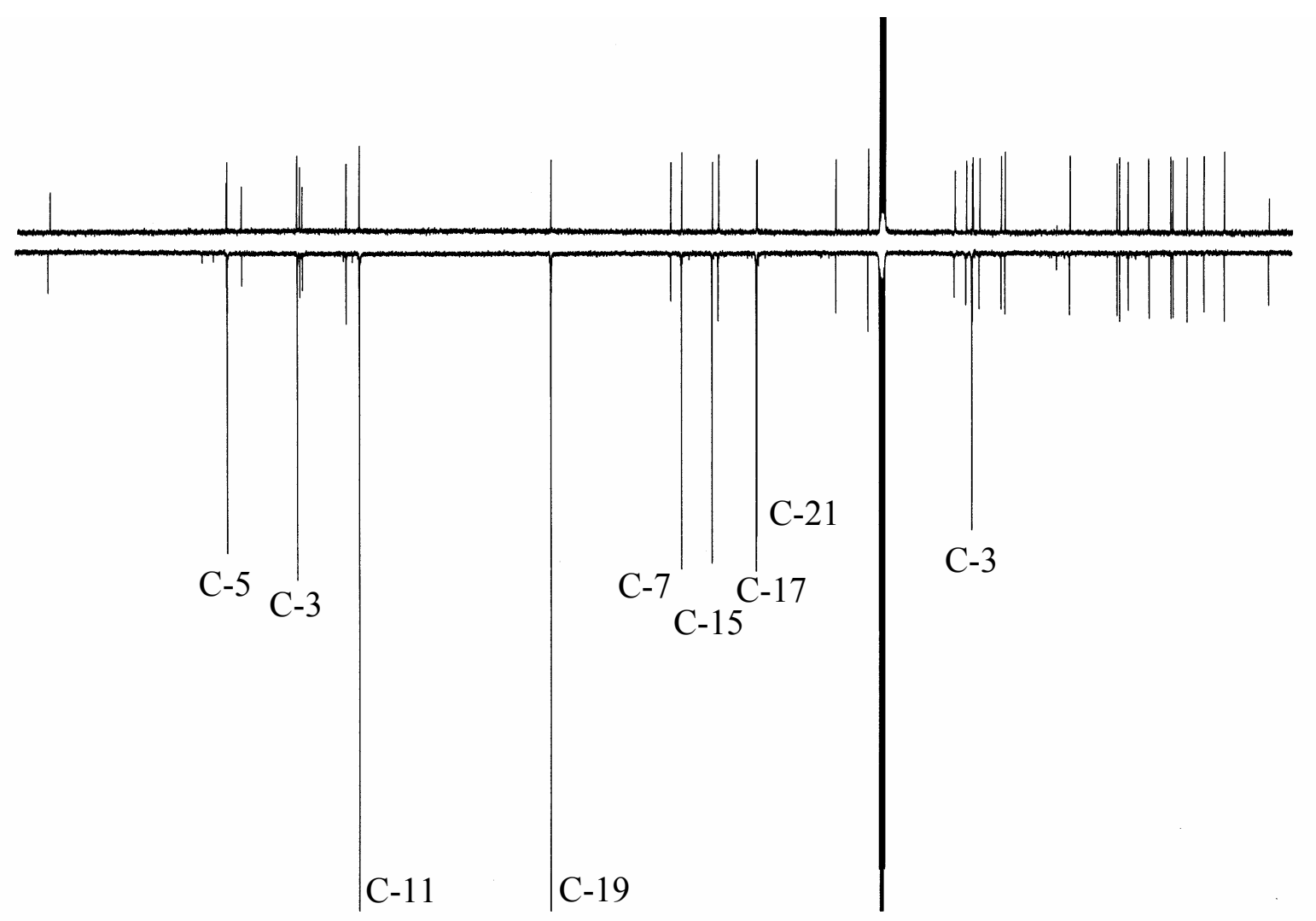

Abbildung 9: ${ }^{13} \mathrm{C}-\mathrm{NMR}-$ Spektrum $\left(150.8 \mathrm{MHz}, \mathrm{CD}_{2} \mathrm{Cl}_{2}\right)$ von $\left[1-{ }^{13} \mathrm{C}\right]$ Acetat angereichertem Bafilomycin $\mathrm{A}_{1}$ (11a, unten) im Vergleich mit dem Referenzspektrum (oben).

Der signifikante spezifische Einbau für C-3, C-5, C-7, C-9, C-15, C-17 und C-21 lässt sich mit einer Beteiligung des Tricarbonsäurecyclus erklären, bei dem intermediär aus Acetyl-CoA Succinyl-CoA gebildet wird. Dieses kann von dem Enzym Methylmalonyl-CoA-Mutase zu Methylmalonyl-CoA umgesetzt werden. ${ }^{88}$ Dabei liegt die nach Fütterung von $\left[1-{ }^{13} \mathrm{C}\right]$ Acetat erhaltene ${ }^{13} \mathrm{C}-$ Markierung an Position $\mathrm{C}-1$ der in die Bafilomycine 11a und 11b eingebauten Propionateinheiten. 


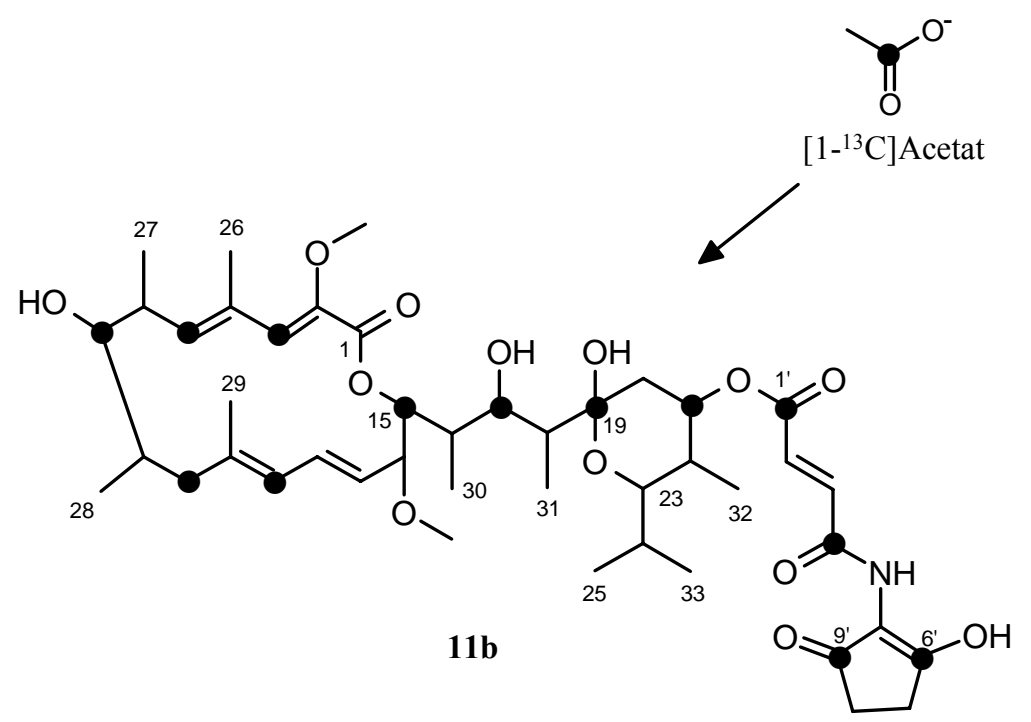

Abbildung 10: Nach Fütterung von $\left[1-{ }^{13} \mathrm{C}\right]$ Acetat erhaltenes Einbaumuster von Bafilomycin $\mathrm{B}_{1}$ (11b).

Die Tatsache, dass bei den Kohlenstoffatomen C-1 und C-15 keine Anreicherung gefunden werden konnte, beweist, dass die ungewöhnlich methoxylierten $\mathrm{C}_{2}$-Einheiten der Bafilomycine nicht dem Acetat-Stoffwechsel entstammen. Ihr Aufbau entspricht somit nicht dem üblichen Polyketidbiosyntheseweg (vgl. Kapitel A.II.3.), sondern es werden hier zwei zusätzliche Vorläufer benötigt. Der Befund deckt sich mit bei Concanamycin A (10a) und anderen Sekundärmetaboliten gemachten Beobachtungen.

Die in den ${ }^{13} \mathrm{C}-\mathrm{NMR}-$ Spektren von Bafilomycin $\mathrm{B}_{1}$ (11b) aufgrund des Vorliegens eines dynamischen Keto-Enol-Tautomerengleichgewichts normalerweise nicht detektierbaren Kohlenstoffatome C-6' und C-9' waren nach Fütterung von markiertem Acetat als breite Signale erkennbar. $\mathrm{Da}$ die zugehörigen Integralhöhen in der Größenordnung des angereicherten, ebenfalls quartären C-19 lagen, konnte hier ebenfalls auf Acetat als direkten Vorläufer geschlossen werden. Dies lässt für die Biogenese der 2-Amino-3hydroxycyclopent-2-enon-Einheit auf einen bereits für Asukamycin (22) ${ }^{85}$ und Reductiomycin (23) ${ }^{87}$ gefundenen Biosyntheseweg schließen (Abbildung 12). Nach einem dort postulierten Mechanismus wird 2-Amino-3-hydroxycyclopent-2-enon (26) aus 5-Aminolävulinsäure (27) unter Einfluss eines pyridoxalphosphathaltigen Enzyms gebildet. 26 entsteht dabei aus Glycin und Succinyl-CoA unter Beteiligung einer 5-AminolävulinatSynthase. Zusätzlich war für 11b ein hoher spezifischer Einbau von C-1' und C-4' erkennbar. Dies deutet darauf hin, dass die verbrückende Fumarsäure-Einheit (C-1' bis C-4') aus Succinat aufgebaut wird, das seinerseits aus Acetyl-CoA über den Citronensäurecyclus entsteht. 
Tabelle 1: Spezifischer Einbau von $\left[1-{ }^{13} \mathrm{C}\right]$ Acetat, $\left[3-{ }^{13} \mathrm{C}\right]$ Propionat, $\left[1-{ }^{13} \mathrm{C}\right]$ Isobutyrat und [Methyl- $\left.{ }^{13} \mathrm{C}\right] \mathrm{L}-\mathrm{methionin}$ für Bafilomycin $\mathrm{A}_{1}$ (11a) und $\mathrm{B}_{1}(\mathbf{1 1 b})$.

\begin{tabular}{|c|c|c|c|c|c|c|c|c|c|c|}
\hline \multirow{3}{*}{ Position } & \multirow{2}{*}{\multicolumn{2}{|c|}{\begin{tabular}{|c|} 
Chemische \\
Verschiebung \\
(ppm)
\end{tabular}}} & \multicolumn{8}{|c|}{ Spezifischer Einbau } \\
\hline & & & \multicolumn{2}{|c|}{$\begin{array}{l}{\left[1-{ }^{13} \mathrm{C}\right]} \\
\text { Acetat }\end{array}$} & \multicolumn{2}{|c|}{$\begin{array}{c}{\left[3-{ }^{13} \mathrm{C}\right]} \\
\text { Propionat }\end{array}$} & \multicolumn{2}{|c|}{$\begin{array}{c}{\left[1-{ }^{13} \mathrm{C}\right] \text { Iso- }} \\
\text { butyrat }\end{array}$} & \multicolumn{2}{|c|}{$\begin{array}{c}{\left[\text { Methyl- }{ }^{13} \mathrm{C}\right]} \\
\text { L-methionin }\end{array}$} \\
\hline & $11 a$ & $11 b$ & $11 \mathrm{a}^{\mathrm{a}}$ & $11 b^{a}$ & $11 a^{b}$ & $11 b^{c}$ & $11 \mathrm{a}^{\mathrm{a}}$ & $11 b^{a}$ & $11 a^{b}$ & $11 b^{c}$ \\
\hline 1 & 167.6 & 167.7 & 0.6 & 0.3 & -0.3 & -0.2 & 0.2 & 0.9 & -0.1 & -0.1 \\
\hline 2 & 141.4 & 141.6 & 0.1 & 0.1 & -0.3 & -0.2 & 0.1 & 0.8 & -0.6 & 0.2 \\
\hline $2-\mathrm{OCH}_{3}$ & 60.1 & 60.3 & 0.2 & 0.1 & -0.2 & -0.1 & 0 & -0.2 & $\underline{57.0}$ & $\underline{51.1}$ \\
\hline 3 & 133.9 & 134.0 & 5.9 & 3.2 & 0.3 & 0.2 & 0.5 & 0.9 & -0.3 & -0.2 \\
\hline 4 & 133.1 & 133.3 & 0.2 & 0.1 & 0.5 & 0.4 & 0.4 & 0.9 & -0.1 & 0.6 \\
\hline 5 & 143.5 & 143.6 & 6.1 & 4.2 & 0.5 & 0.3 & 0.7 & 0.1 & 0.1 & -0.9 \\
\hline 6 & 37.0 & 37.2 & 0.1 & 0.1 & 0.3 & 0.2 & -0.1 & 0.4 & 0 & 0.5 \\
\hline 7 & 81.1 & 81.3 & 5.3 & 3.1 & 0.1 & 0.1 & 0.3 & 0.2 & -0.1 & 0.5 \\
\hline 8 & 41.4 & 40.6 & 0.4 & -0.1 & 0.8 & 0.1 & -0.4 & 0.5 & 0.1 & 0.3 \\
\hline 9 & 41.5 & 41.7 & 5.5 & 3.0 & 0.5 & 0.3 & 0.7 & 1.0 & 0 & 0.8 \\
\hline 10 & 143.6 & 143.7 & 0 & -0.9 & 0.6 & 0.3 & 0.1 & 0.9 & 0.2 & 0.1 \\
\hline 11 & 125.3 & 125.5 & 16.4 & 8.0 & 0 & 0.1 & 0.8 & 0.6 & -0.2 & 0 \\
\hline 12 & 133.5 & 133.6 & 0.1 & -0.2 & 0 & 0 & 0.3 & 0.5 & 0.2 & 0 \\
\hline 13 & 127.1 & 127.3 & 0.6 & 0.2 & 0.3 & -0.2 & 0.2 & -0.2 & -0.1 & -0.1 \\
\hline 14 & 82.6 & 82.8 & 0 & 0 & 0.3 & -0.2 & 0 & 0 & -0.1 & 0.4 \\
\hline $14-\mathrm{OCH}_{3}$ & 55.7 & 55.8 & 0.4 & 0.2 & -0.2 & -0.1 & 0.4 & 0.2 & 57.5 & 40.8 \\
\hline 15 & 77.0 & 77.2 & 6.1 & 3.3 & 0.5 & 0.3 & 0.5 & 0 & -0.4 & 0.3 \\
\hline 16 & 37.5 & 37.7 & 0.1 & 0 & 0.4 & 0.3 & -0.1 & 0.6 & 0 & 0.1 \\
\hline 17 & 71.0 & 71.1 & 6.1 & 2.8 & 0.2 & 0.1 & -0.1 & 0.3 & 0.2 & 0.4 \\
\hline 18 & 42.3 & 42.4 & 0.1 & -0.1 & 0.5 & 0.2 & -0.3 & 0.2 & 0 & 0.3 \\
\hline 19 & 99.3 & 99.3 & $\underline{16.2}$ & $\underline{10.0}$ & 0 & 0.3 & 0.2 & 1.0 & 0 & 0.1 \\
\hline 20 & 43.8 & 40.4 & $\overline{0}$ & $\overline{-0.1}$ & 0 & 0 & -0.5 & 0.7 & 0.2 & 0 \\
\hline 21 & 70.9 & 75.8 & 5.4 & 2.8 & 0.3 & 0.4 & 0.30 & -0.3 & 0.1 & -0.6 \\
\hline 22 & 40.4 & 38.5 & 0.1 & 0.1 & 0.2 & 0.6 & -0.1 & 0.2 & 0.1 & 0 \\
\hline 23 & 76.1 & 76.1 & 0.3 & 0.1 & 0 & 0 & $\underline{62.3}$ & $\underline{35.3}$ & 0 & 0 \\
\hline 24 & 28.2 & 28.4 & 0.2 & 0 & 0 & 0 & -0.6 & 0.2 & 0 & 0.6 \\
\hline 25 & 21.3 & 21.3 & 0.4 & 0.1 & 0.3 & 0.2 & 0.1 & 0.4 & 0.1 & 0.5 \\
\hline 26 & 14.0 & 14.1 & 0.4 & 0.2 & 9.6 & 10.1 & 0.3 & 0.4 & 0.2 & 0.9 \\
\hline 27 & 17.3 & 17.4 & 0.3 & 0.1 & 8.7 & 8.5 & 0.3 & 0.3 & 0.2 & 0.7 \\
\hline 28 & 21.7 & 21.8 & 0.4 & 0.2 & 9.6 & 9.1 & 0.3 & 0.4 & 0.1 & 0.8 \\
\hline 29 & 20.1 & 20.3 & 0.2 & 0.1 & $\underline{10.0}$ & $\underline{8.6}$ & 0.2 & 0.4 & 0.2 & 1.0 \\
\hline 30 & 9.8 & 10.0 & 0.1 & 0.2 & 9.3 & 9.9 & 0.1 & 0.5 & 0.1 & 0.3 \\
\hline 31 & 7.1 & 7.2 & 0.3 & 0.20 & 8.3 & 10.3 & 0 & 0.5 & 0.1 & 0.6 \\
\hline 32 & 12.1 & 12.4 & 0.4 & 0.1 & 10.6 & 9.8 & 0.2 & 0.6 & 0.2 & -0.1 \\
\hline 33 & 14.3 & 14.4 & 0.3 & 0.1 & 0.3 & 0.1 & -0.1 & 0.4 & 0.1 & 0.1 \\
\hline
\end{tabular}




\begin{tabular}{|c|c|c|c|c|c|c|c|c|c|c|}
\hline \multirow{3}{*}{ Position } & \multirow{2}{*}{\multicolumn{2}{|c|}{$\begin{array}{l}\text { Chemische } \\
\text { Verschiebung } \\
\text { (ppm) }\end{array}$}} & \multicolumn{8}{|c|}{ Spezifischer Einbau } \\
\hline & & & \multicolumn{2}{|c|}{$\begin{array}{l}{\left[1-{ }^{13} \mathrm{C}\right]} \\
\text { Acetat }\end{array}$} & \multicolumn{2}{|c|}{$\begin{array}{c}{\left[3-{ }^{13} \mathrm{C}\right]} \\
\text { Propionat }\end{array}$} & \multicolumn{2}{|c|}{$\begin{array}{c}{\left[1-{ }^{13} \mathrm{C}\right] \text { Iso- }} \\
\text { butyrat }\end{array}$} & \multicolumn{2}{|c|}{$\begin{array}{l}\left.\text { [Methyl- }{ }^{13} \mathrm{C}\right] \\
\text { L-methionin }\end{array}$} \\
\hline & $11 \mathrm{a}$ & $11 b$ & $11 \mathrm{a}^{\mathrm{a}}$ & $11 b^{\mathrm{a}}$ & $11 \mathrm{a}^{\mathrm{b}}$ & $11 b^{c}$ & $11 \mathrm{a}^{\mathrm{a}}$ & $11 b^{a}$ & $11 \mathrm{a}^{\mathrm{b}}$ & $11 b^{c}$ \\
\hline $1^{\prime}$ & - & 164.8 & - & 6.6 & - & 0.8 & - & 1.7 & - & -0.5 \\
\hline $2^{\prime}$ & - & 133.4 & - & 0.1 & - & 2.3 & - & 1.1 & - & -0.6 \\
\hline $33^{\prime}$ & - & 133.8 & - & 0.1 & - & 2.4 & - & 0.5 & - & -0.5 \\
\hline $4^{\prime}$ & - & 164.2 & - & 5.8 & - & 0.7 & - & 0.9 & - & -0.7 \\
\hline $55^{\prime}$ & - & 115.2 & - & $\overline{0.1}$ & - & -0.1 & - & 0.8 & - & -0.6 \\
\hline $6^{\prime}$ & - & 175.6 & - & $*$ & - & - & - & - & - & - \\
\hline $77^{\prime}$ & - & 26.2 & - & - & - & - & - & - & - & - \\
\hline $8^{\prime}$ & - & 32.6 & - & - & - & - & - & - & - & - \\
\hline $9^{\prime}$ & - & 198.1 & - & $*$ & - & - & - & - & - & - \\
\hline
\end{tabular}

Fett unterlegte Werte stellen signifikante Einbauraten dar; bei unterstrichenen Angaben wurde aufgrund der hohen Anreicherung vom Einbau direkter Vorläufer ausgegangen.

a Relative Einbauraten wurden auf die Signalintensität von C-14 referenziert.

b Relative Einbauraten wurden auf die Signalintensität von C-24 referenziert.

c Relative Einbauraten wurden auf die Signalintensität von C-20 referenziert.

* die Signale für C-6'-C-9' wiesen aufgund von Keto-Enol-Tautomerie eine starke Linienverbreiterung auf; die ensprechenden Integralhöhen deuteten jedoch klar auf eine Anreicherung für C-6’ und C-9' hin.

Zur Ermittlung der intakt eingebauten Acetat-Einheiten wurde eine Fütterung mit $6 \mathrm{mM}$ $\left[1,2-{ }^{13} \mathrm{C}_{2}\right]$ Acetat durchgeführt (Tabelle 2, Abbildung 12). Das Vorliegen von ${ }^{1} J_{\mathrm{C}, \mathrm{C}^{-}}$ Kopplungen bestätigte für C-11/C-12 und C-19/C-20 einen Einbau ohne vorherigen Bindungsbruch. Zusätzlich konnte für Bafilomycin $B_{1}(\mathbf{1 1 b})$ ein intakter Einbau von C-1'/C-2' sowie C-3'/C-4' gefunden werden. Es handelt sich hier folglich um zwei „Schwanz-Schwanz“-verknüpfte Acetat-Bausteine, was Succinat als biosynthetischen Vorläufer der Fumarsäureeinheit (C-1' bis C-4') bestätigt. Das Vorliegen breiter Singuletts für C-6' und C-9' mit ausgeprägten Integralhöhen ist ebenfalls Indiz für einen Acetateinbau ohne vorherigen Bindungsbruch. Damit kann Succinat auch als Vorläufer für C-6' bis C-9' bestätigt und der beschriebene Biosyntheseweg ausgehend von 5-Aminolävulinsäure (27) bekräftigt werden. 


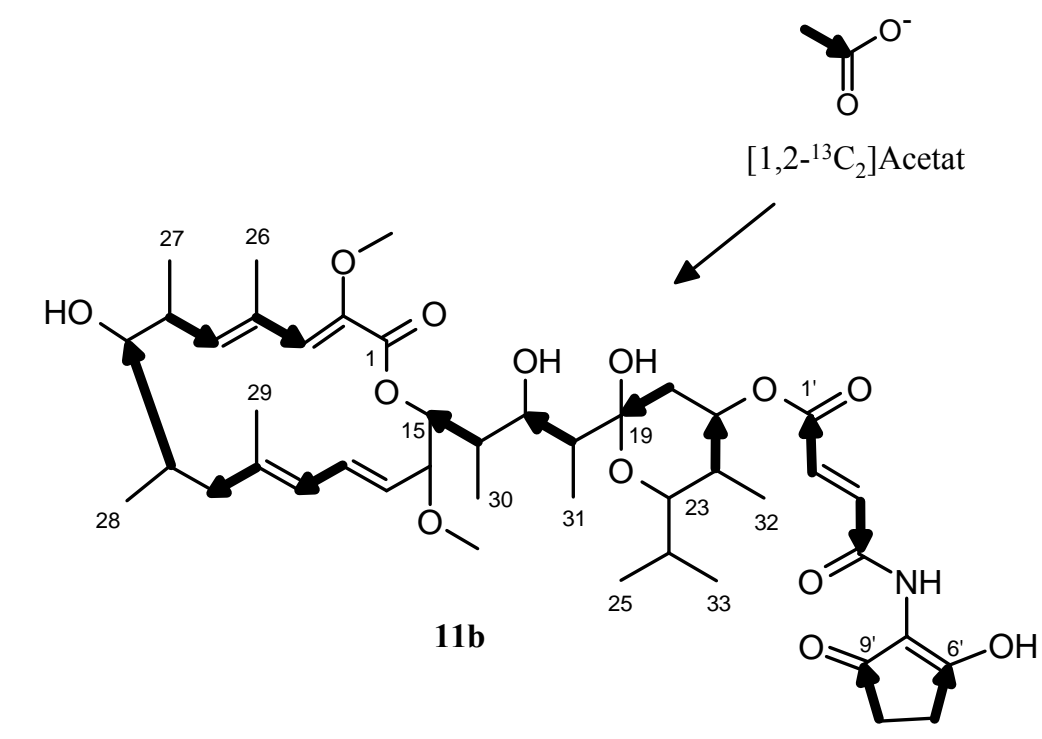

Abbildung 11: Nach Fütterung von $\left[1,2-{ }^{13} \mathrm{C}_{2}\right]$ Acetat erhaltenes Einbaumuster von Bafilomycin $\mathrm{B}_{1}$ (11b).

Die aus der Kombination beider Fütterungsergebnisse ableitbare Einbaurichtung entspricht dem in Kapitel B.II.4.1. postulierten Biosyntheseverlauf.

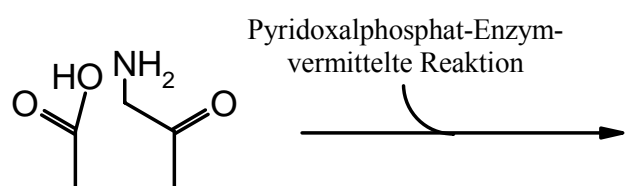

27
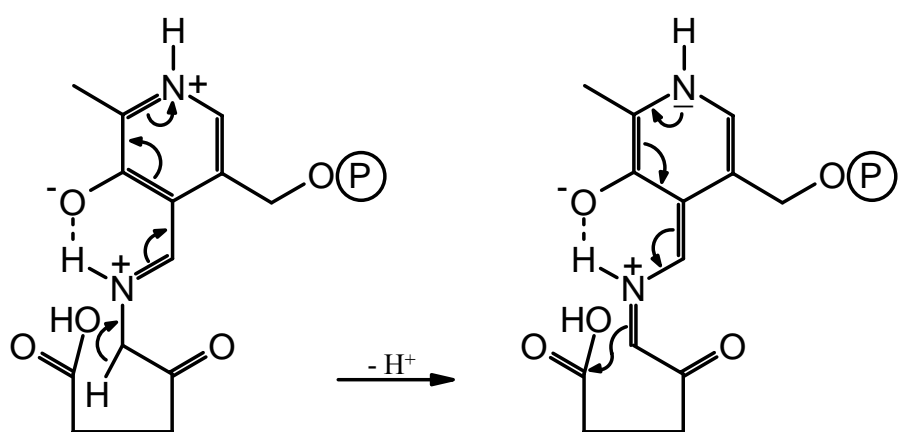

$\downarrow-\mathrm{OH}^{-}$

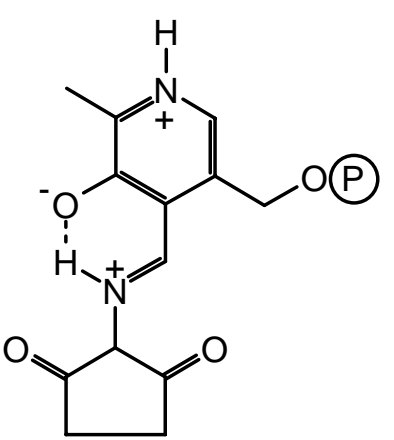

26

Abbildung 12: Biosynthesemechanismus der Entstehung von 2-Amino-3-hydroxy-cyclopent2-enon (26) aus 5-Aminolävulinsäure (27) gemäß FLOSS et al. ${ }^{85}$ 
Tabelle 2: ${ }^{13} \mathrm{C}-{ }^{13} \mathrm{C}-$ Kopplungskonstanten für $\mathbf{1 1 a}$ und $\mathbf{1 1 b}$ nach Fütterung von $\left[1,2-{ }^{13} \mathrm{C}_{2}\right]$ Acetat (n.b: Kopplungskonstanten konnten aufgrund starker Signalüberlappung nicht bestimmt werden, bs: breites Singulett).

\begin{tabular}{|c|c|c|c|c|c|}
\hline Position & $11 a$ & $11 b$ & Position & $11 \mathrm{a}$ & $11 \mathrm{~b}$ \\
\hline 3 & n.b. & n.b. & 21 & n.b. & $\mathrm{d}(37 \mathrm{~Hz})$ \\
\hline 4 & n.b. & n.b. & 22 & $\mathrm{~d}(34 \mathrm{~Hz})$ & $\mathrm{d}(36 \mathrm{~Hz})$ \\
\hline 5 & n.b. & n.b. & 23 & $\mathrm{~d}(36 \mathrm{~Hz})$ & n.b. \\
\hline 6 & $\mathrm{~d}(36 \mathrm{~Hz})$ & $\mathrm{d}(36 \mathrm{~Hz})$ & 26 & $\mathrm{~d}(43 \mathrm{~Hz})$ & $\mathrm{d}(45 \mathrm{~Hz})$ \\
\hline 7 & $\mathrm{~d}(38 \mathrm{~Hz})$ & $\mathrm{d}(38 \mathrm{~Hz})$ & 27 & $\mathrm{~d}(35 \mathrm{~Hz})$ & $\mathrm{d}(35 \mathrm{~Hz})$ \\
\hline 8 & n.b. & n.b. & 28 & $\mathrm{~d}(34 \mathrm{~Hz})$ & $\mathrm{d}(35 \mathrm{~Hz})$ \\
\hline 9 & n.b. & $\mathrm{d}(40 \mathrm{~Hz})$ & 29 & $\mathrm{~d}(43 \mathrm{~Hz})$ & $\mathrm{d}(43 \mathrm{~Hz})$ \\
\hline 10 & n.b. & n.b. & 30 & $\mathrm{~d}(35 \mathrm{~Hz})$ & $\mathrm{d}(35 \mathrm{~Hz})$ \\
\hline 11 & $\mathrm{~d}(57 \mathrm{~Hz})$ & $\mathrm{d}(57 \mathrm{~Hz})$ & 31 & $\mathrm{~d}(36 \mathrm{~Hz})$ & $\mathrm{d}(36 \mathrm{~Hz})$ \\
\hline 12 & $\mathrm{~d}(57 \mathrm{~Hz})$ & $\mathrm{d}(57 \mathrm{~Hz})$ & 32 & $\mathrm{~d}(35 \mathrm{~Hz})$ & $\mathrm{d}(36 \mathrm{~Hz})$ \\
\hline 15 & $\mathrm{~d}(40 \mathrm{~Hz})$ & $\mathrm{d}(40 \mathrm{~Hz})$ & $1^{\prime}$ & & $\mathrm{d}(75 \mathrm{~Hz})$ \\
\hline 16 & $\mathrm{~d}(38 \mathrm{~Hz})$ & $\mathrm{d}(38 \mathrm{~Hz})$ & 2 ' & & $\mathrm{d}(75 \mathrm{~Hz})$ \\
\hline 17 & n.b. & $\mathrm{d}(39 \mathrm{~Hz})$ & $3^{\prime}$ & & $\mathrm{d}(65 \mathrm{~Hz})$ \\
\hline 18 & $\mathrm{~d}(42 \mathrm{~Hz})$ & $\mathrm{d}(43 \mathrm{~Hz})$ & $4 '$ & & $\mathrm{~d}(65 \mathrm{~Hz})$ \\
\hline 19 & $\mathrm{~d}(44 \mathrm{~Hz})$ & $\mathrm{d}(44 \mathrm{~Hz})$ & 6 ' & & bs \\
\hline 20 & $\mathrm{~d}(44 \mathrm{~Hz})$ & $\mathrm{d}(45 \mathrm{~Hz})$ & 9' & & bs \\
\hline
\end{tabular}

Das Vorliegen des für die Propionateinheiten beobachteten Kopplungsmusters kann unter Beteiligung des Citratcyclus erklärt werden. Hier wird Acetyl-CoA in fünf Schritten zu Succinat (28) umgewandelt. Da es sich bei 28 um eine symmetrische Zwischenstufe handelt, kommt es beim erneuten Durchlaufen des Cyclus zu einer Anreicherung der Markierung bei allen im Molekül vorhandenen Kohlenstoffatomen (Abbildung 13). 


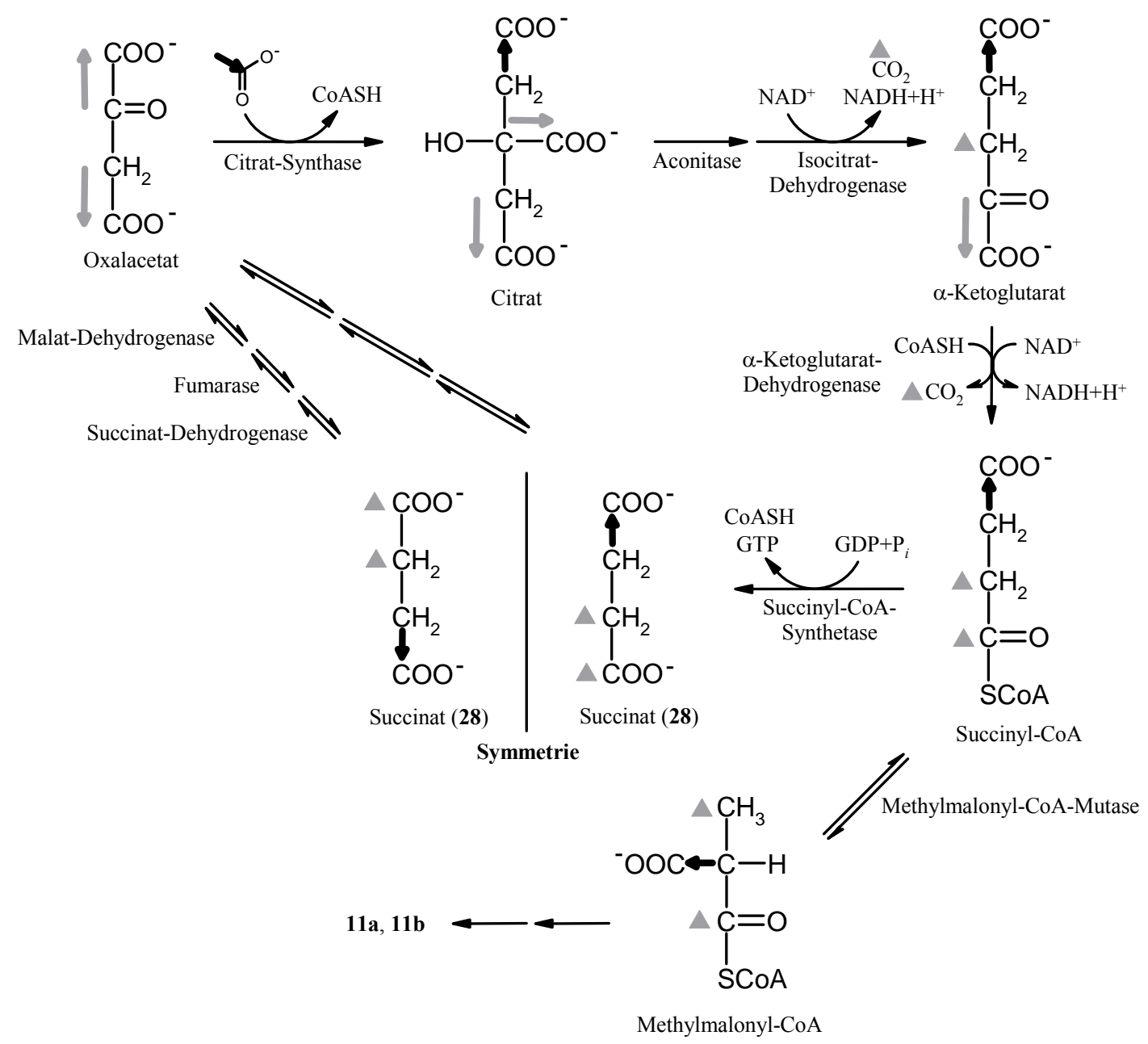

Abbildung 13: Möglicher Biosyntheseweg, der zu einer Markierung der Propionateinheiten nach Fütterung von $\left[1,2-{ }^{13} \mathrm{C}_{2}\right]$ Acetat führt (schwarze Pfeile: Einbaumuster beim ersten Durchlaufen, graue Markierungen: Einbaumuster beim zweiten Durchlaufen des Citratcyclus).

\subsubsection{Fütterung von $\left[3-{ }^{13} \mathrm{C}\right]$ Propionat}

Um den biosynthetischen Ursprung der durch $\left[1-{ }^{13} \mathrm{C}\right]$ Acetat deutlich geringer angereicherten Einheiten zu klären, wurde $3.6 \mathrm{mM}\left[3{ }^{13} \mathrm{C}\right]$ Propionat zugefüttert (siehe Abbildung 14). Der ermittelte spezifische Einbau ist Tabelle $1 \mathrm{zu}$ entnehmen. Starke Anreicherungen fanden sich hier für die Kohlenstoffatome C-26 bis C-32. Dies bestätigt zweifelsfrei Methylmalonyl-CoA als direkten Vorläufer aller sieben Methylverzweigungen in 11a sowie 11b und schließt damit Methionin als Ursprung aus.

Der bei C-2' und C-3' für Bafilomycin $\mathrm{B}_{1}$ (11b) gefundene signifikante Einbau von 2.30 bzw. 2.38 lässt sich durch den katalytischen Einfluss der Methylmalonyl-CoA-Mutase erklären. 
Das enzymatisch gebildete Succinyl-CoA wird durch die Succinyl-CoA-Synthetase im Zuge des Tricarbonsäurecyclus in Succinat überführt. Letzteres wird somit als direkter Vorläufer der Fumarsäure-Einheit C-1' bis C-4' bestätigt (siehe Abbildung 13).

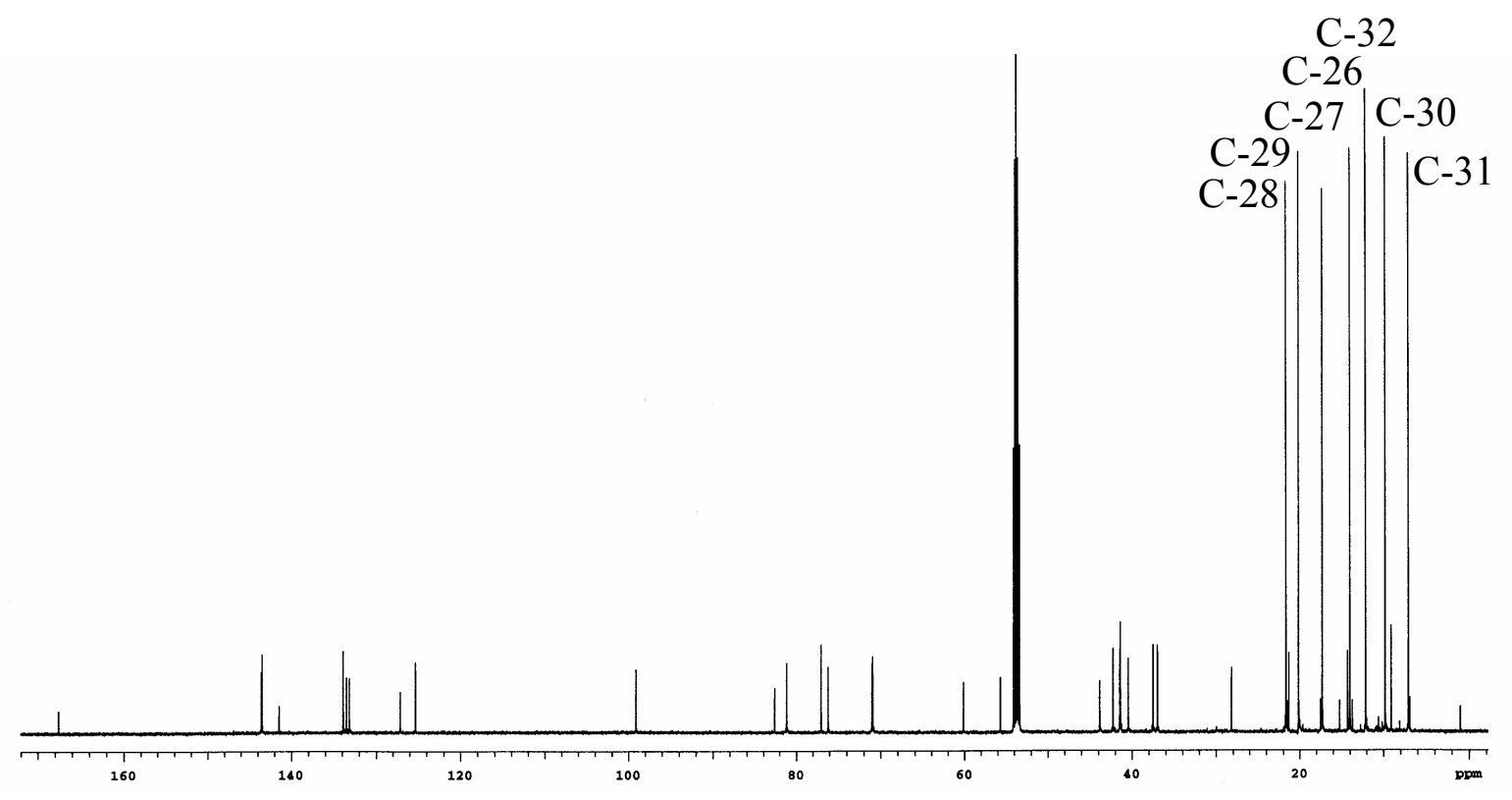

Abbildung 14: ${ }^{13} \mathrm{C}-\mathrm{NMR}-$ Spektrum $\left(150.8 \mathrm{MHz}, \mathrm{CD}_{2} \mathrm{Cl}_{2}\right)$ von 11a nach Fütterung von $\left[3-{ }^{13} \mathrm{C}\right]$ Propionat.

\subsubsection{Fütterung von $\left[1-{ }^{13} \mathrm{C}\right]$ Isobutyrat und $\left[\right.$ Methyl- $\left.{ }^{13} \mathrm{C}\right] \mathrm{L}-\mathrm{Methionin}$}

Die Zufütterung von $3.2 \mathrm{mM}$ Isobutyrat führte zu einem hohen spezifischen Einbau von 62.3 bzw. 35.3 für C-23 von 11a und 11b. Isobutyryl-CoA kann damit als Ausgangspunkt der Bafilomycin (11)-Biosynthese bestätigt werden.

Methionin wird in der Zelle unter ATP-Verbrauch durch die Methionin-Adenosyltransferase zu S-Adenosylmethionin (SAM) umgewandelt. Die Bildung dieses Sulfonium-Ions erhöht die Aktivität der Methyl-Gruppe des Methionins um ein Vielfaches, was SAM zu einem universellen biologischen Methylgruppen-Überträger macht. Fütterung von $1.2 \mathrm{mM}$ [Methyl- ${ }^{13} \mathrm{C}$ ]L-Methionin zur Kulturlösung des Stamms 3822-14F führte zur Anreicherung der Methoxy-Kohlenstoffatome an C-2 und C-14 (Tabelle 1). Damit konnte L-Methionin als Quelle der Methoxy-Gruppen an den ,ungewöhnlichen $\mathrm{C}_{2}$-Einheiten“ C-1/C-2 sowie C13/C-14 nachgewiesen werden.

Im Kulturfiltrat der Methioninfütterung fand sich auf dem Dünnschichtchromatogramm neben den Bafilomycinen 11a und 11b eine weitere, bei $254 \mathrm{~nm}$ UV-löschende Zone, die bei den bisherigen Fermentationen von Stamm 3822-14F nicht aufgetreten war. Nach chromato- 
graphischer Auftrennung konnte 29 in einer Ausbeute von $12.6 \mathrm{mg} / \mathrm{L}$ als farbloser Feststoff erhalten werden, der im EI-Massenspektrum das Ion höchster Masse bei m/z=119 zeigte. Da es sich um eine Kultivierung unter Zusatz einer ${ }^{13} \mathrm{C}$-markierten Verbindung handelte, war zu diesem Zeitpunkt nicht klar, ob dies das tatsächliche Molekulargewicht von 29 widerspiegelte oder - je nach Einbau an [Methyl- $\left.{ }^{13} \mathrm{C}_{3}\right] \mathrm{L}-$ Methionin - von einer geringeren realen Masse des Metaboliten ausgegangen werden musste. Im ${ }^{1} \mathrm{H}-\mathrm{NMR}$-Spektrum waren neben einem mit $\mathrm{D}_{2} \mathrm{O}$ austauschbaren Proton $\left(\delta_{\mathrm{H}}=9.18\right)$ drei weitere Signale sichtbar, von denen eines einer Methylgruppe $\left(\delta_{\mathrm{H}}=2.35\right)$ zugeschrieben werden konnte und die beiden übrigen $\left(\delta_{\mathrm{H}}=5.66\right.$ und 7.85) im Bereich von Doppelbindungsprotonen lagen. Auffällig waren Kopplungskonstanten von $J=141 \mathrm{~Hz}$ für das Signal bei $\delta_{\mathrm{H}}=2.35$ sowie $J=6 \mathrm{~Hz}$ für das Proton bei $\delta_{\mathrm{H}}=7.85$, für die sich im ${ }^{1} \mathrm{H}-\mathrm{NMR}$-Spektrum keine Partner fanden und für die demgemäß eine ${ }^{13} \mathrm{C}$-Anreicherung in der Methylgruppe verantwortlich gemacht wurde. Damit lässt sich die große Signalaufspaltung bei $\delta_{\mathrm{H}}=2.35$ über eine ${ }^{1} J_{\mathrm{CH}}-\mathrm{Kopplung}$ und die deutlich geringere bei $\delta_{\mathrm{H}}=7.85$ über eine ${ }^{3} J_{\mathrm{CH}}$-Kopplung erklären. Im ${ }^{13} \mathrm{C}-\mathrm{NMR}$-Spektrum waren vier Resonanzen erkennbar, wobei das Signal der Methylgruppe $\left(\delta_{\mathrm{C}}=14.6\right)$ eine erwartungsgemäß hohe Intensität aufwies. Neben zwei Kohlenstoffatomen im Doppelbindungsbereich $\left(\delta_{\mathrm{C}}=112.4\right.$ und 150.5) wurde zusätzlich das Vorliegen einer Carboxylgruppe $\left(\delta_{\mathrm{C}}=170.6\right) \mathrm{im}$ Molekül angezeigt. 29 konnte aufgrund dieser Daten als trans-3-Methylthioacrylsäure identifiziert werden.

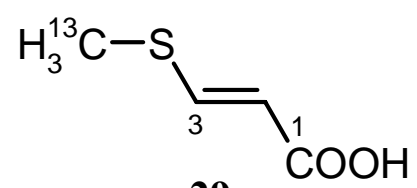

29

Die Bildung des Biotransformationsprodukts 29 nach Zufütterung von L-Methionin konnte schon vorher in der Arbeitsgruppe ZEECK beobachtet werden. ${ }^{89}$ SURETTE und VINING ${ }^{90}$ stellten erstmals 1976 einen Zusammenhang zwischen der Anreicherung von 29 und der Konzentration an L-Methionin im Kulturmedium von Streptomyces lincolnensis fest. Für die Bildung von 29 schlugen sie den in Abbildung 15 dargestellten Mechanismus vor. 


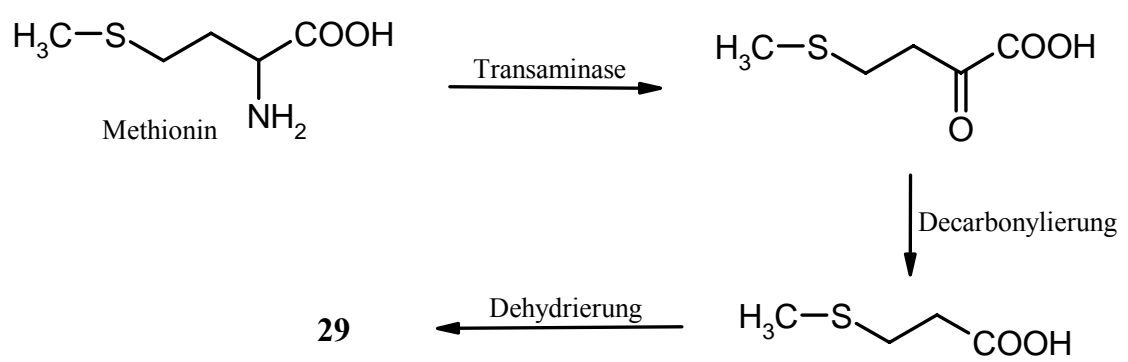

Abbildung 15: Bildung von 29 aus Methionin nach SURETTE und VINING. ${ }^{90}$

\subsubsection{Fütterung von $\left[\mathrm{U}_{-}{ }^{13} \mathrm{C}_{3}\right]$ Glycerin}

Glycerin fällt bei der Hydrolyse von Lipiden sowie als Endprodukt des KohlenhydratStoffwechsels in größeren Mengen an. Es wird über Glycerin-Kinase unter ATP-Verbrauch in Glycerin-3-phosphat überführt und nachfolgend durch Glycerinphosphat-Dehydrogenase zu Dihydroxyacetonphosphat umgesetzt. Als solches kann es in den anabolischen Stoffwechsel eingebunden werden.

$\left[\mathrm{U}-{ }^{13} \mathrm{C}_{3}\right]$ Glycerin wurde dem Bafilomycin(11)-Produzenten $3822-14 \mathrm{~F}$ in einer Endkonzentration von $5.3 \mathrm{mM}$ zugeführt. Die Ergebnisse der Fütterung sind in Tabelle 3 zusammengefasst.

Tabelle 3: ${ }^{13} \mathrm{C}-{ }^{13} \mathrm{C}-$ Kopplungskonstanten für Bafilomycin $\mathrm{A}_{1}$ (11a) und $\mathrm{B}_{1}$ (11b) nach Fütterung von $\left[\mathrm{U}-^{13} \mathrm{C}_{3}\right]$ Glycerin.

\begin{tabular}{|c|c|c|}
\hline Position & 11a & 11b \\
\hline 1 & $\mathrm{~d}(84 \mathrm{~Hz})$ & $\mathrm{d}(83 \mathrm{~Hz})$ \\
\hline 2 & $\mathrm{~d}(84 \mathrm{~Hz})$ & $\mathrm{d}(83 \mathrm{~Hz})$ \\
\hline 11 & $\mathrm{~d}(57 \mathrm{~Hz})$ & $\mathrm{d}(56 \mathrm{~Hz})$ \\
\hline 12 & $\mathrm{~d}(57 \mathrm{~Hz})$ & $\mathrm{d}(56 \mathrm{~Hz})$ \\
\hline 13 & $\mathrm{~d}(50 \mathrm{~Hz})$ & $\mathrm{d}(50 \mathrm{~Hz})$ \\
\hline 14 & $\mathrm{~d}(50 \mathrm{~Hz})$ & $\mathrm{d}(50 \mathrm{~Hz})$ \\
\hline 19 & $\mathrm{~d}(44 \mathrm{~Hz})$ & $\mathrm{d}(44 \mathrm{~Hz})$ \\
\hline 20 & $\mathrm{~d}(44 \mathrm{~Hz})$ & $\mathrm{d}(44 \mathrm{~Hz})$ \\
\hline 24 & $\mathrm{~d}(36 \mathrm{~Hz})$ & $\mathrm{d}(36 \mathrm{~Hz})$ \\
\hline 33 & $\mathrm{~d}(36 \mathrm{~Hz})$ & $\mathrm{d}(36 \mathrm{~Hz})$ \\
\hline
\end{tabular}

Intensive ${ }^{1} J_{\mathrm{C}, \mathrm{C}}$-Kopplungen konnten für C-1/C-2 sowie C-13/C-14 gefunden werden. Dies bestätigt die Hypothese, dass die „ungewöhnlichen $\mathrm{C}_{2}$-Einheiten“ dem KohlenhydratStoffwechsel entstammen. Weiterhin zeigten die Signale für die Einheiten C-11/C-12 sowie 
C-19/C-20, die aus Acetat stammen sollten, ein signifikantes Kopplungsmuster. Dies ist auf die starke Vernetzung der verschiedenen Stoffwechselwege untereinander zurückzuführen. So kann das Endprodukt der Glycolyse, das Pyruvat (30), unter Katalyse des PyruvatDehydrogenase-Multienzymkomplexes wiederum zu Acetyl-CoA umgebaut werden.

Die Anreicherung von C-24/C-33 als Bestandteil der Isobutyryl-Einheit kann ebenfalls über Pyruvat als Zwischenstufe erklärt werden. Das hieraus in Zuge des Valin-Anabolismus gebildete $\alpha$-Ketoisovalerat kann unter dem katalytischen Einfluss der Verzweigtkettigen- $\alpha$ Ketosäure-Dehydrogenase in Isobutyryl-CoA überführt werden (Abbildung 16). ${ }^{88,91}$

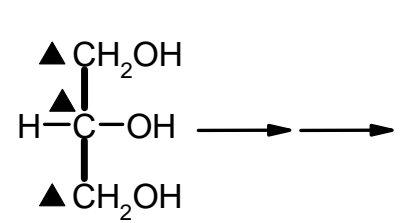

$\left[\mathrm{U}-{ }^{13} \mathrm{C}_{3}\right]$-Glycerin

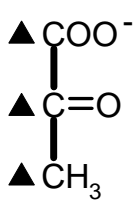

Pyruvat (30)

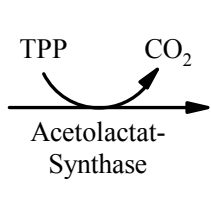

Synthase

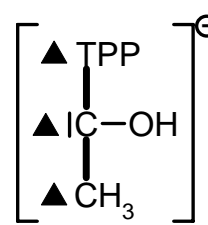

Hydroxyethyl-TPP

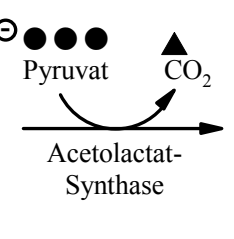

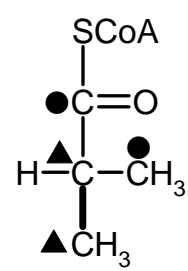

Isobutyryl-CoA

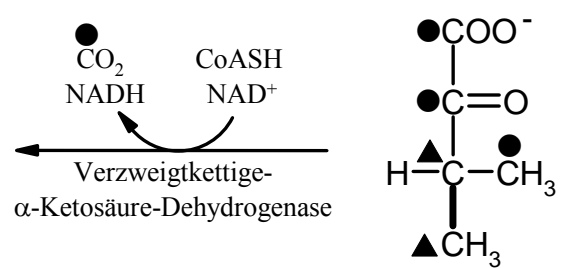

$\alpha$-Ketoisovalerat
$\alpha-(S)$-Acetolactat

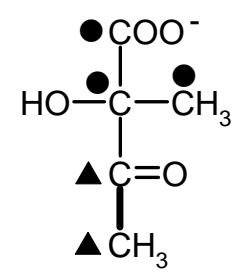
$\underset{\substack{\text { Ketolsäure-Redukto- } \\ \text { Isomerase }}}{\mathrm{NADPH}+\mathrm{H}^{+}}$

Abbildung 16: Biosynthetische Umwandlung von $\left[\mathrm{U}_{-}{ }^{13} \mathrm{C}_{3}\right]$ Glycerin in Isobutyryl-CoA (TPP: Thiaminpyrophosphat). 


\subsubsection{Fütterung von $\left[1-{ }^{13} \mathrm{C}\right]$ Malonyl-SNAC-Estern 31 und 32}

In Analogie zu den bekannten Kettenelongationsschritten kommt für die Biosynthese der ungewöhnlich methoxylierten $\mathrm{C}_{2}$-Einheiten $\mathrm{C}-1 / \mathrm{C}-2$ und $\mathrm{C}-13 / \mathrm{C}-14$ Methoxymalonyl-CoA als PKS-Substrat in Betracht. Ebenso wäre Hydroxymalonyl-CoA und anschließende Methionin-vermittelte Methylierung denkbar. Um diese Hypothesen zu überprüfen, wurden am Arbeitskreis FLOSS die $\left[1-{ }^{13} \mathrm{C}\right]$-markierten Vorläufer 2-Hydroxymalonyl- $N$-acetylcysteamin (31) und 2-Methoxymalonyl- $N$-acetyl-cysteamin (32) gemäß Abbildung 17 synthetisiert. ${ }^{83}$ Ein Teil wurde uns für Fütterungsexperimente zur Verfügung gestellt.

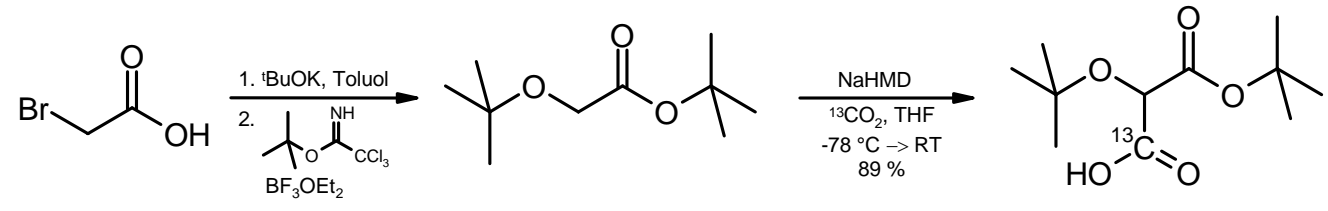

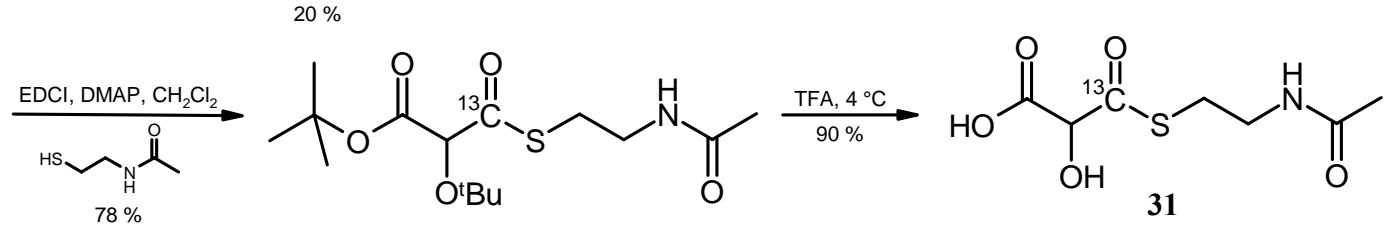

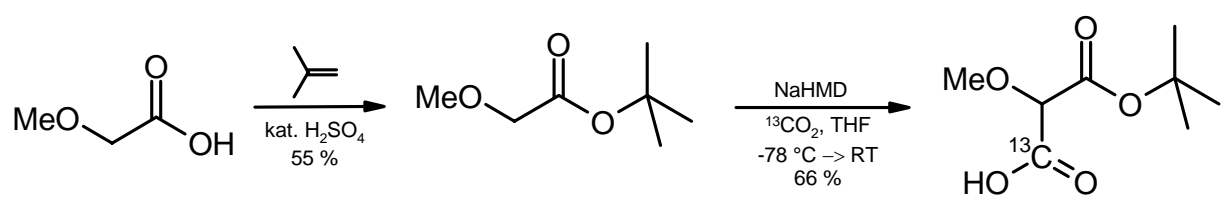<smiles>CO[C@H](C(=O)O)C(=O)SCCNC(=O)CSCCNC(C)=O</smiles>

Abbildung 17: Synthese der $\left[1-{ }^{13} \mathrm{C}\right]$-markierten Hydroxymalonyl- (31) und Methoxymalonyl-SNAC-ester (32) nach FLOSS et al. ${ }^{83}$

$N$-Acetylcysteamin (SNAC)-Ester sind erprobte, vielfach in vitro und in vivo eingesetzte Analoga für Coenzym A-thioester. ${ }^{92}$ Sie werden entweder direkt in die Biosynthese eingebunden oder in einem vorangehenden Umesterungsschritt zunächst durch Übertragung auf Coenzym A aktiviert. Darüber hinaus wird eine verbesserte Membrangängigkeit für die SNAC-Derivate im Vergleich zu den Coenzym A-Estern vermutet.

Fütterungen von $1.9 \mathrm{mM} 31$ sowie $0.9 \mathrm{mM} 32$ führten allerdings weder für Bafilomycin $\mathrm{A}_{1}$ (11a) noch für $B_{1}(\mathbf{1 1 b})$ zu einer signifikanten Anreicherung der Kohlenstoffatome C-1 bzw. 
C-13, was Hydroxy- bzw. Methoxymalonyl-CoA als mögliche Vorläufer der „ungewöhnlichen $\mathrm{C}_{2}$-Einheiten“ unwahrscheinlich erscheinen lässt. Dieser Befund deckt sich mit den bei Fütterungsexperimenten zur Aufklärung der Biosynthese von Ansamitocin P-3 $(\mathbf{1 8})^{83,93}$ und FK520 (19) ${ }^{94}$ erzielten Ergebnissen. Hier wurde die Schlussfolgerung gezogen, dass die untersuchten $\mathrm{C}_{2}$-Einheiten an einem acyl carrier protein (ACP) biosynthetisiert werden und danach auf die ACP-Domäne des PKS-Kettenverlängerungsmoduls übertragen werden (siehe Kapitel A.III.4.2.). Der hohe Grad an Enzymspezifität, der die Voraussetzung für solche Prozesse ist, mag dazu führen, dass extern zugefütterte Hydroxymalonyl- (31) und Methoxymalonyl-SNAC-ester (32) nicht von den entsprechenden Proteinen akzeptiert und folglich auch nicht prozessiert werden können.

\subsection{Diskussion der Biosyntheseexperimente}

Die Ergebnisse der beschriebenen Fütterungsexperimente mit $\left[1-{ }^{13} \mathrm{C}\right]$ Acetat, $\left[1,2-{ }^{13} \mathrm{C}_{2}\right]$ Acetat, $\left[3-{ }^{13} \mathrm{C}\right]$ Propionat, $\left[1-{ }^{13} \mathrm{C}\right]$ Isobutyrat, $\left[\right.$ Methyl- $\left.{ }^{13} \mathrm{C}\right] \mathrm{L}-$ Methionin sowie $\left[\mathrm{U}-{ }^{13} \mathrm{C}_{3}\right]$ Glycerin bestätigen die in Kapitel A.II.4.1. aufgestellte hypothetische Polyketid-Biosynthese von Bafilomycin $A_{1}$ (11a). Ausgehend von Isobutyrat als Startereinheit folgt der weitere Aufbau des Dodekaketid-Grundgerüstes durch zwei Acetat-, sieben Propionat- und zwei Glycerineinheiten sowie zwei weiteren, durch L-Methionin übertragenen Methylgruppen. Die bei den Fütterungsexperimenten mit $\left[1,2-{ }^{13} \mathrm{C}\right]$ Acetat aufgetretenen ${ }^{13} \mathrm{C}-\mathrm{NMR}-K o p p l u n g e n$ in den Propionateinheiten sind auf biosynthetische Umwandlungen im Zuge des Citratcyclus unter Einbeziehung des Enzyms Methylmalonyl-CoA-Mutase zurückzuführen. Der Einbau von intakten $\left[\mathrm{U}^{13} \mathrm{C}\right]$ Glycerin-Bausteinen in die Startereinheit Isobutyryl-CoA kann unter Beteiligung der am Valinstoffwechsel beteiligten Enzyme erklärt werden. Anhand des charakteristischen Einbaumusters konnte die Biogenese der Seitenkette von 11b aus Succinat und 5-Aminolävulinsäure (27) bewiesen werden, wie sie analog auch für Asukamycin $\mathbf{( 2 2}^{85,86}$ und Reductiomycin $(\mathbf{2 3})^{87}$ gefunden wurde. In einem post-PKS-Schritt könnte diese schließlich auf 11a übertragen und so Bafilomycin $B_{1}$ (11b) gebildet werden. Das gesamte Biogeneseschema von 11b ist in Abbildung 18 zusammengefasst. 


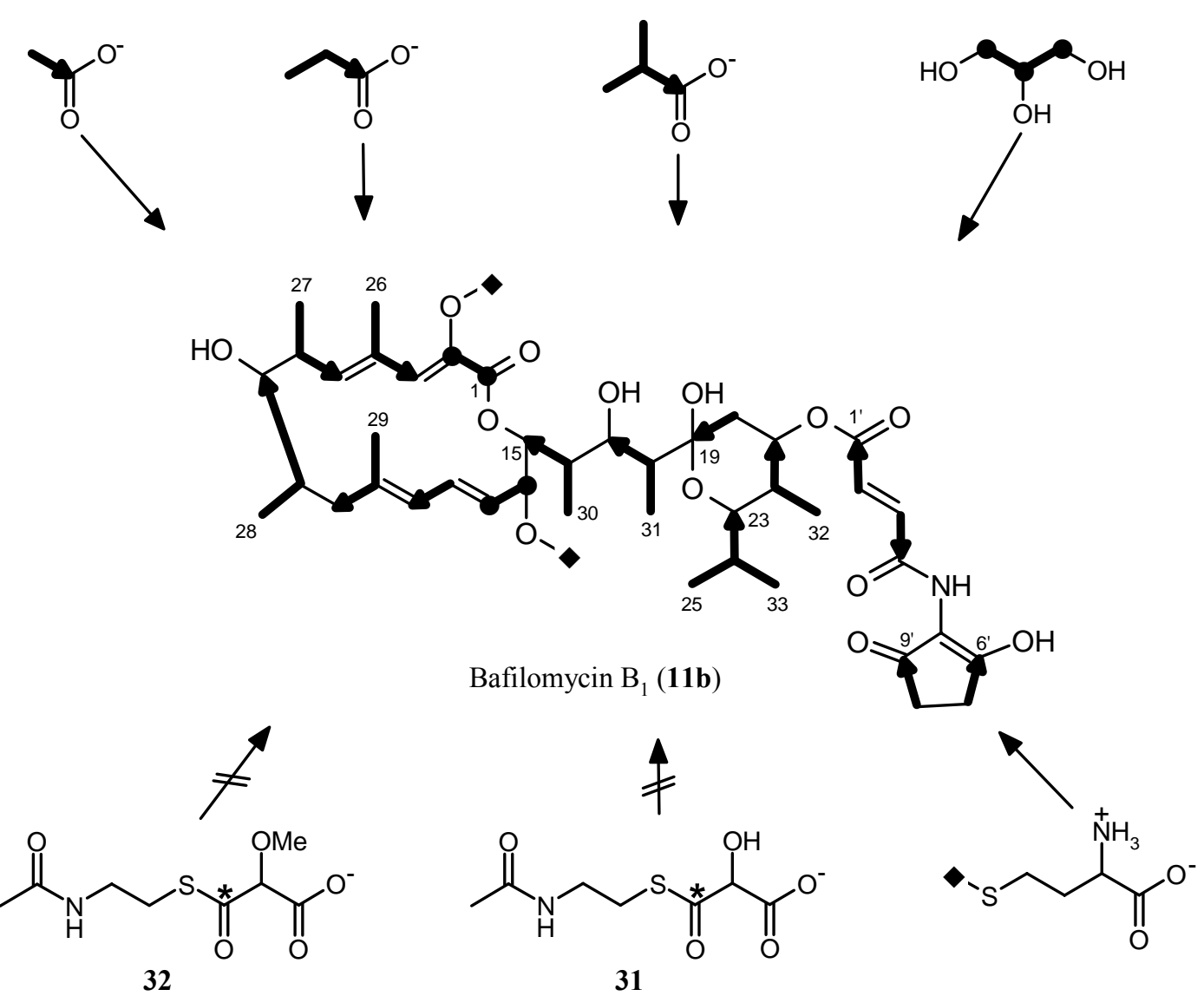

Abbildung 18: Biogeneseschema von Bafilomycin $B_{1}$ (11b).

Als Ursprung der ungewöhnlich methoxylierten $\mathrm{C}_{2}$-Einheiten konnte - wie bereits für Concanamycin A (10a) ${ }^{97}$, FK $520(\mathbf{1 9})^{80}$ und weitere Sekundärstoffe bewiesen - auch für die Bafilomycine (11) der Kohlenhydrat-Stoffwechsel gefunden werden, wobei L-Methionin als Überträger der Methylgruppen fungiert. Die bislang unbekannten direkten Vorläufer dieser $\mathrm{C}_{2}$-Einheiten werden im sechsten und im letzten Kettenelongationsschritt eingebaut.

Die Fütterung der potenziellen Vorläufer 2-Hydroxy- und 2-Methoxy-[1- $\left.{ }^{13} \mathrm{C}\right]$ malonyl-SNACester 31 und 32 führte zu keinem signifikanten Einbau in die ,ungewöhnlichen $\mathrm{C}_{2}$-Einheiten“ von 11a und 11b. Dies deckt sich mit den für Ansamitocin (18) erhaltenen Ergebnissen und macht einen anderen Biosyntheseweg wahrscheinlicher, in dem der Aufbau direkt an einem acyl carrier protein (ACP) abläuft und die vollständig assemblierten Vorläufer anschließend auf die ACP-Domänen der entsprechenden PKS-Kettenverlängerungsmodule übertragen werden. Auf diesen Mechanismus wird detaillierter in Kapitel A.III.4. eingegangen. 


\section{Concanamycin A (10a)}

Die Concanamycine (10) wurden erstmals im Jahr 1981 von KINASHI et al. isoliert und in ihrer Struktur aufgeklärt. ${ }^{38,39}$ Die absolute Stereochemie konnte 1984 auf der Grundlage von röntgenkristallographischen Studien zugeordnet werden. ${ }^{95}$

\subsection{Bisherige Untersuchungen zur Biosynthese}

K. U. Bindseil und C. Boddien konnten die Biogenese der Concanamycine (10) durch Fütterungsexperimente mit ${ }^{13} \mathrm{C}$-markierten Vorläufern nahezu klären (Abbildung 19). ${ }^{37,96,97}$

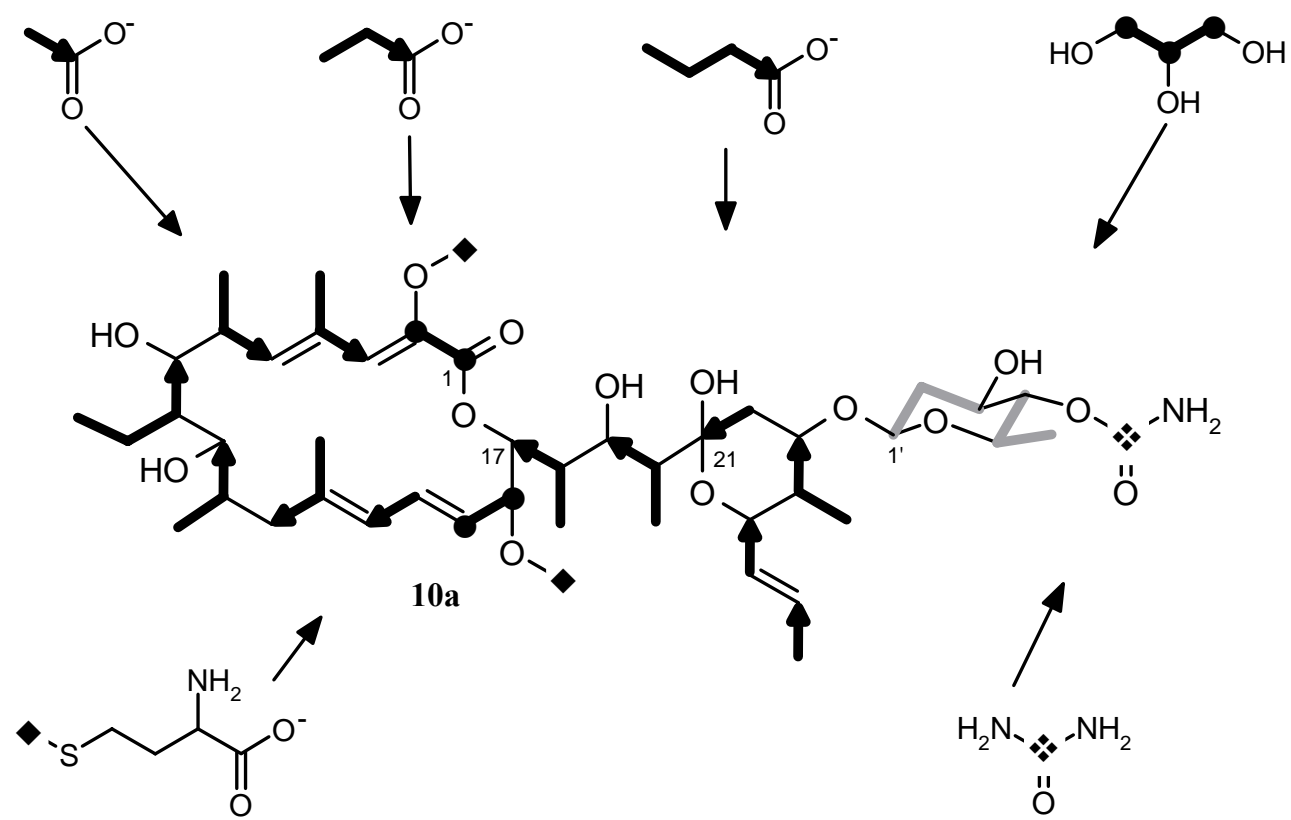

Abbildung 19: Biogeneseschema von Concanamycin A (10a).

Es zeigte sich, dass der Tetradecaketid-Baustein von 10a ausgehend von Acetat als Startereinheit durch den schrittweisen Einbau von drei weiteren Acetat-, sieben Propionat-, zwei Glycerin- sowie einer Butyrateinheit entsteht. Damit konnte auch hier der Ursprung der „ungewöhnlichen $\mathrm{C}_{2}$-Einheiten“ C1-/C-2 und C-15/C-16 aus dem Kohlenhydratstoffwechsel bewiesen werden, wobei - analog zu den Bafilomycinen (11) - L-Methionin Überträger der Methylgruppen ist. Die fraglichen $\mathrm{C}_{2}$-Einheiten werden im siebten und im letzten Kettenverlängerungsschritt durch die PKS I eingebaut. 
Desweiteren konnte gezeigt werden, dass das Kohlenstoffatom der Carbamoylgruppe in Position 4' des $\beta$-2-Desoxy-D-rhamnopyranosid-Bausteins von Concanamycin A (10a) durch $\left[1-{ }^{13} \mathrm{C}\right]$ Harnstoff markiert wird.

\subsection{Fermentationsbedingungen für Streptomyces sp. Stamm Gö 22/15}

K. U. BINDSEIL entdeckte die Concanamycine A (10a), B (10b), C (10c) und D (10d) sowie Prelacton C (33) als Sekundärmetaboliten von Streptomyces sp. Stamm Gö 22/15 mit Hilfe des chemischen Screenings. Durch intensive Nährmedienvariationen ${ }^{96,97}$ wurde gefunden, dass die maximale Produktion von 10a bei Verwendung eines Haferkleie-Mediums gewährleistet ist. Die Isolierung ausreichender Mengen an 10a ist insofern notwendig, als die hohe Beweglichkeit des Makrolactonrings von 10a die Messung von NMR-Spektren bei tiefen Temperaturen erfordert. Es zeigte sich, dass erst ab einer Temperatur von $-20{ }^{\circ} \mathrm{C}$ die raschen Konformationsänderungen des Makrolidsystems soweit eingefroren sind, dass die Detektion aller darin enthaltener Kohlenstoffatome durch scharfe ${ }^{13} \mathrm{C}-\mathrm{NMR}$-Signale gewährleistet ist. Um die erforderliche Messzeit und damit den durch die Notwendigkeit einer externen Stickstoff-Kühlung entstehenden Mehraufwand gering $\mathrm{zu}$ halten, wurde die Isolierung möglichst großer Mengen an Concanamycin A (10a) angestrebt.

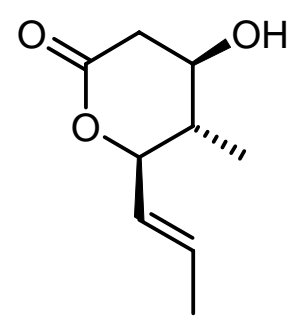

Prelacton C (33)

Gemäß der von C. BoDDIEN erstellten Produktionskurve erfolgte auch in dieser Arbeit die Zufütterung der markierten Vorläufer kontinuierlich von der 34. bis zur 48. Stunde, die Aufarbeitung der Ansätze wurde 72 Stunden nach Inokulation durchgeführt. Bei den Fütterungen der Malonyl-SNAC-Ester wurden bis zu 39 mg Concanamycin A (10a) erhalten, bei den Kultivierungsansätzen mit Glycerin-Zufütterung konnten lediglich zwischen 4 bis $6 \mathrm{mg}$ reines 10a gemäß dem Aufarbeitungsschema in Abbildung 20 isoliert werden. Während der Fermentationen wurde beobachtet, dass etwa sechs Stunden nach Fütterungsbeginn der Sauerstoffsättigungswert auf Null abfiel, was symptomatisch für ein erneutes Einsetzen der Zellteilung ist und damit den Beginn einer erneuten Anwachsphase andeutet. Dies könnte die 
Verminderung der Ausbeute insofern erklären, als es bis zum Erntezeitpunkt nicht zu einer vollständigen Entfaltung des Produktionspotenzials der sich teilenden Zellen kommen konnte.

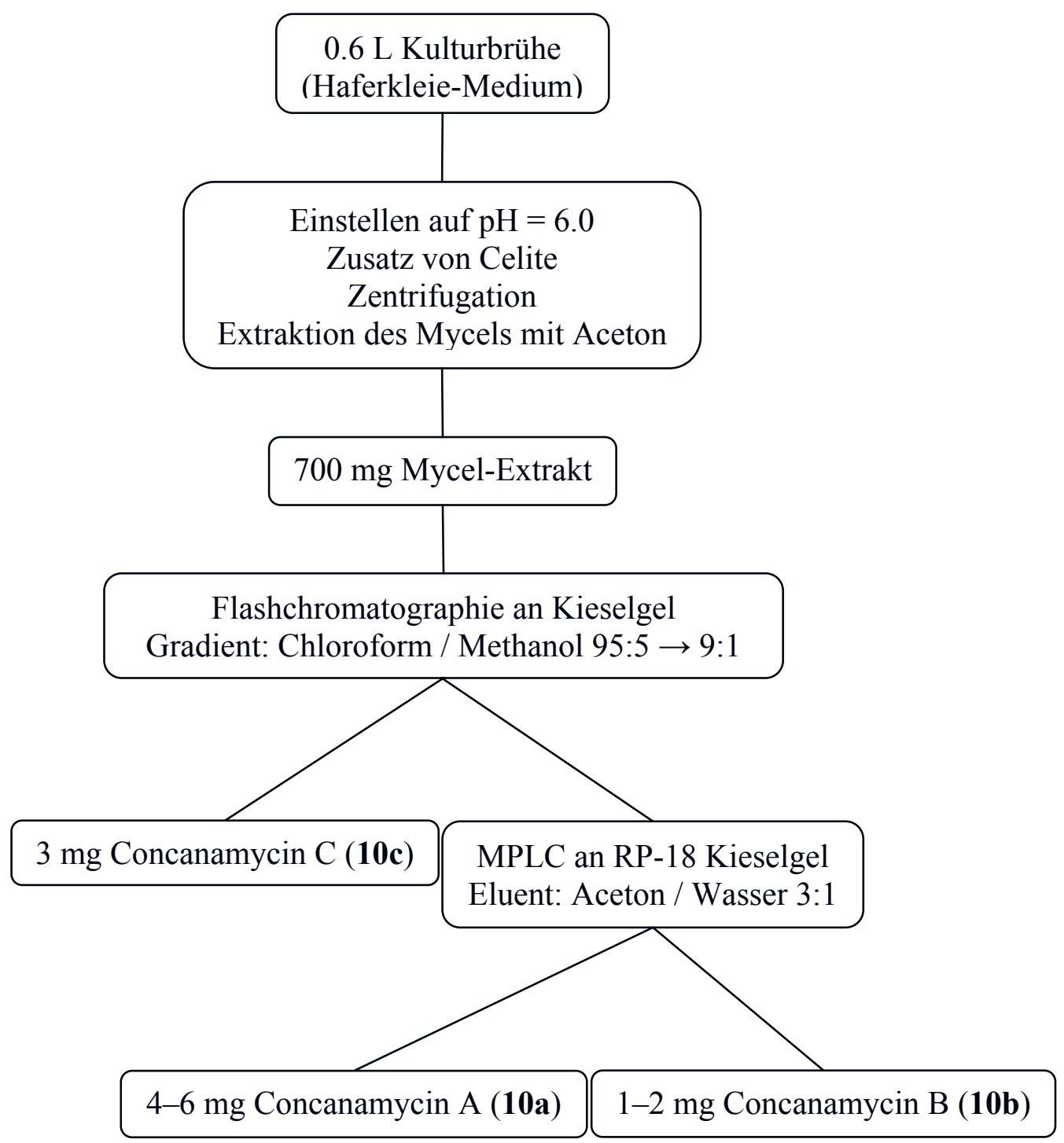

Abbildung 20: Aufarbeitungsschema für Streptomyces sp. Stamm Gö 22/15.

\subsection{Fütterung der $\left[1-{ }^{13}\right.$ C $]$ Malonyl-SNAC-Ester $(31,32)$}

Um die Aussagekraft der für die Bafilomycine $A_{1}(11 a)$ und $B_{1}(11 b)$ erhaltenen Ergebnisse aus Kapitel A.II.4.4.5. zu überprüfen, wurden $1.9 \mathrm{mM}$ 2-Hydroxy-[1- $\left.{ }^{13} \mathrm{C}\right]$ malonyl-SNACester (31) dem Concanamycin-Produzenten Gö 22/15 zugefüttert. Es zeigte sich jedoch kein signifikanter Einbau in den Kohlenstoffatomen C-1 und C-15 der ,ungewöhnlichen $\mathrm{C}_{2}$ Einheiten“"von Concanamycin A (10a). Dasselbe Experiment wurde mit 0.9 mM 2-Methoxy- 
$\left[1-{ }^{13} \mathrm{C}\right]$ malonyl-SNAC-ester $(\mathbf{3 2})$ wiederholt, wobei es auch hier zu keinem relevanten Einbau kam.

Durch die nunmehr doppelte Bestätigung der erstmals für Ansamitocin P-3 (18) ${ }^{83}$ gemachten Beobachtung, dass sich die Markierungen von 31 und 32 nicht in den Zielmolekülen wiederfinden lassen, können Hydroxymalonyl-CoA und Methoxymalonyl-CoA mit hoher Wahrscheinlichkeit als biosynthetische Vorläufer der „ungewöhnlichen $\mathrm{C}_{2}$-Einheiten“ ausgeschlossen werden. Damit bekommen Hypothesen, wonach es sich um ACP-gebundene Vorstufen handelt, weitere Unterstützung.

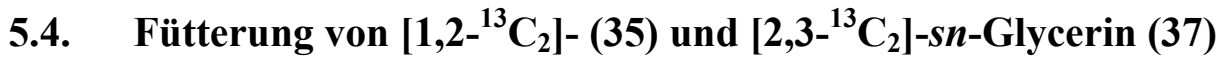

Der starke Einbau von markiertem Glycerin in die ,ungewöhnlichen $\mathrm{C}_{2}$-Einheiten“ der Plecomakrolide 10a, 11a und 11b lässt den Schluss zu, dass es sich hierbei um einen biosynthetisch sehr nahen Vorläufer handelt, es also nicht zu einer vorangehenden Metabolisierung im Sinne komplexer Stoffwechselwege kommt. Unter regulären Bedingungen wird Glycerin zunächst unter ATP-Verbrauch durch die Glycerin-Kinase in L-Glycerin-3-phosphat (34) überführt (Abbildung 21). Dieser Schritt erfolgt vollständig stereospezifisch, aus dem prochiralen Substrat wird ausschließlich das L-konfigurierte Produkt. $^{98}$

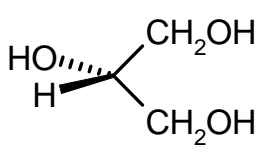

Glycerin

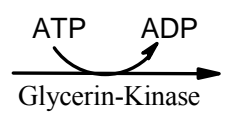

ycerin3-phosphat (34)

Abbildung 21: Stereospezifität der Glycerin-Kinase.

Diese Besonderheit macht es möglich, eine Beteiligung des Enzyms an biosynthetischen Abläufen nachzuweisen. So kann das prochirale Molekül Glycerin durch die Einführung von je zwei benachbarten ${ }^{13} \mathrm{C}$-Markierungen in seine beiden enantiomeren Formen überführt werden. Dabei entspricht die nach IUPAC als $(2 S)-\left[1,2-{ }^{13} \mathrm{C}_{2}\right]$ Glycerin $(35)$ zu bezeichnende Verbindung in der von L-Glycerinaldehyd abgeleiteten Nomenklatur dem $\left[1,2-{ }^{13} \mathrm{C}_{2}\right]-s n$ Glycerin (35), wobei das Präfix sn für stereospecific numbering steht. Durch Glycerin-Kinase wird dieses Enantiomer in $\left[1,2-{ }^{13} \mathrm{C}_{2}\right]-s n$-Glycerin-3-phosphat (36) umgewandelt, während $\left[2,3-{ }^{13} \mathrm{C}_{2}\right]$-sn-Glycerin (37) als Substrat zur Bildung von $\left[2,3-{ }^{13} \mathrm{C}_{2}\right]-$ sn-Glycerin-3-phosphat (38) führt (Abbildung 22). 


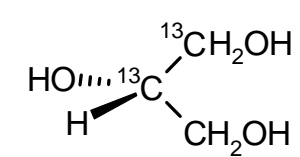

$\left[1,2-{ }^{13} \mathrm{C}_{2}\right]-$ sn-Glycerin

(35)

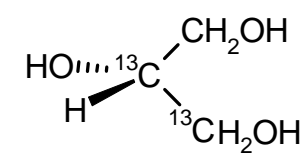

$\left[2,3-{ }^{13} \mathrm{C}_{2}\right]-s n$-Glycerin

(37)

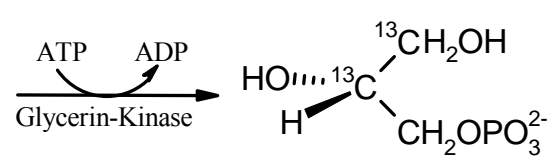

$\left[1,2-{ }^{13} \mathrm{C}_{2}\right]-$ sn-Glycerin3-phosphat (36)

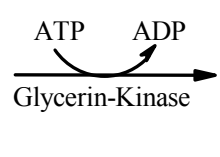<smiles>[14CH3]O[14CH2][C@@H](O)CO</smiles>

$\left[2,3-{ }^{13} \mathrm{C}_{2}\right]-s n$-Glycerin3-phosphat (38)

\begin{abstract}
Abbildung 22: Durch Isotopenmarkierung erzeugte Glycerin-Enantiomere 35 und 37 sowie deren Umwandlungsprodukte.
\end{abstract}

Füttert man Verbindung 35 bzw. 37 an den Concanamycin-Bildner Gö 22/15, so kommt es - eine Beteiligung der Glycerin-Kinase an der Biosynthese des fraglichen $\mathrm{C}_{2}$-Vorläufers vorausgesetzt - nur bei einem der Enantiomere zur Anreicherung beider Kohlenstoffatome. Um entsprechende Experimente durchführen zu können, wurden uns von H. G. Floss ausreichende Mengen an 35 und 37 überlassen. ${ }^{a}$ Um sicherzustellen, dass es auch bei geringerer Konzentration an zugefütterter Substanz zu signikanten Anreicherungen kommt, wurden im Voraus Kontrollversuche mit $\left[\mathrm{U}_{-}{ }^{13} \mathrm{C}_{3}\right]$ Glycerin durchgeführt. Dieses wurde mit der vierfachen Menge an unmarkiertem Glycerin verdünnt, um die Entstehung statistischer Kopplungen, die aus einem möglichen Einbau intakter ${ }^{13} \mathrm{C}_{2}$-Einheiten in benachbarte Positionen resultieren, zu verhindern. Hierbei zeigte sich, dass eine Endkonzentration von $1.1 \mathrm{mM}$ an markierter Verbindung bereits zur deutlichen Anreicherung in allen zu erwartenden Einheiten führte, weswegen für die Fütterung von $\mathbf{3 5}$ und $\mathbf{3 7}$ identische Konzentrationen gewählt wurden. Die erhaltenen Ergebnisse sind in Tabelle 4 und in Abbildung 24 zusammengefasst. Die Zuordnung der ${ }^{13} \mathrm{C}-\mathrm{NMR}$-Signale erfolgte gemäß BINDSEIL et $a .^{37}$, wobei die entsprechenden Spektren bei $-20^{\circ} \mathrm{C}$ in einem $2: 1-$ Gemisch aus deuteriertem Dichlormethan und Methanol aufgenommen wurden.

\footnotetext{
${ }^{\text {a }}$ H. G. Floss danke ich an dieser Stelle für die Bereitstellung von $\left[{ }^{13} \mathrm{C}_{2}\right]$-markiertem Glycerin sowie der in Kapitel A.II.4.4.5. und A.II.5.3. beschriebenen $\left[1-{ }^{13} \mathrm{C}\right]$ Malonyl-SNAC-ester.
} 
Tabelle 4: $\quad{ }^{13} \mathrm{C}-{ }^{13} \mathrm{C}-$ Kopplungskonstanten für Concanamycin A (10a) nach Fütterung von 35 bzw. 37.

\begin{tabular}{|c|c|c|c|c|c|}
\hline Position & $\begin{array}{c}\text { Fütterung } \\
\text { von 35 }\end{array}$ & $\begin{array}{c}\text { Fütterung } \\
\text { von 37 }\end{array}$ & Position & $\begin{array}{c}\text { Fütterung } \\
\text { von 35 }\end{array}$ & $\begin{array}{c}\text { Fütterung } \\
\text { von 37 }\end{array}$ \\
\hline 1 & $\mathrm{~d}(84 \mathrm{~Hz})$ & & 24 & & $\mathrm{~d}(37 \mathrm{~Hz})$ \\
\hline 2 & $\mathrm{~d}(84 \mathrm{~Hz})$ & & 25 & & $\mathrm{~d}(52 \mathrm{~Hz})$ \\
\hline 4 & & $\mathrm{~d}(44 \mathrm{~Hz})$ & 26 & & $\mathrm{~d}(52 \mathrm{~Hz})$ \\
\hline 6 & & $\mathrm{~d}(36 \mathrm{~Hz})$ & 27 & & $\mathrm{~d}(42 \mathrm{~Hz})$ \\
\hline 7 & & $\mathrm{~d}(40 \mathrm{~Hz})$ & 28 & & $\mathrm{~d}(42 \mathrm{~Hz})$ \\
\hline 8 & & $\mathrm{~d}(40 \mathrm{~Hz})$ & 29 & & $\mathrm{~d}(44 \mathrm{~Hz})$ \\
\hline 9 & & $\mathrm{~d}(38 \mathrm{~Hz})$ & 30 & & $\mathrm{~d}(36 \mathrm{~Hz})$ \\
\hline 10 & & $\mathrm{~d}(38 \mathrm{~Hz})$ & 31 & & $\mathrm{~d}(38 \mathrm{~Hz})$ \\
\hline 12 & & $\mathrm{~d}(42 \mathrm{~Hz})$ & 32 & & $\mathrm{~d}(42 \mathrm{~Hz})$ \\
\hline 13 & & $\mathrm{~d}(56 \mathrm{~Hz})$ & 33 & & $\mathrm{~d}(36 \mathrm{~Hz})$ \\
\hline 14 & & $\mathrm{~d}(56 \mathrm{~Hz})$ & 34 & & $\mathrm{~d}(36 \mathrm{~Hz})$ \\
\hline 15 & $\mathrm{~d}(50 \mathrm{~Hz})$ & & 35 & & $\mathrm{~d}(37 \mathrm{~Hz})$ \\
\hline 16 & $\mathrm{~d}(50 \mathrm{~Hz})$ & & 36 & & $\mathrm{~d} \mathrm{(35} \mathrm{Hz)}$ \\
\hline 18 & & $\mathrm{~d}(36 \mathrm{~Hz})$ & 37 & & $\mathrm{~d}(35 \mathrm{~Hz})$ \\
\hline 20 & & $\mathrm{~d}(36 \mathrm{~Hz})$ & 4 & $\mathrm{~d}(42 \mathrm{~Hz})$ & \\
\hline 21 & & $\mathrm{~d}(44 \mathrm{~Hz})$ & 5 & $\mathrm{~d}(42 \mathrm{~Hz})$ & $\mathrm{d}(41 \mathrm{~Hz})$ \\
\hline 22 & & $\mathrm{~d}(44 \mathrm{~Hz})$ & 6 & & $\mathrm{~d}(42 \mathrm{~Hz})$ \\
\hline 23 & & $\mathrm{~d}(37 \mathrm{~Hz})$ & & & \\
\hline & & & & \\
\hline
\end{tabular}

Es zeigte sich nach Fütterung von $\left[1,2-{ }^{13} \mathrm{C}_{2}\right]-s n$-Glycerin (35) ein deutliches Kopplungsmuster für C-1/C-2 und C-15/C-16 (Abbildung 23), während das Enantiomere 37 zu keiner Kopplung an dieser Stelle führte. Dadurch ist ein deutlicher Hinweis erbracht, dass Glycerin-Kinase den ersten Schritt der Biogenese der ,ungewöhnlichen $\mathrm{C}_{2}$-Einheiten“ ausgehend von Glycerin katalysiert.
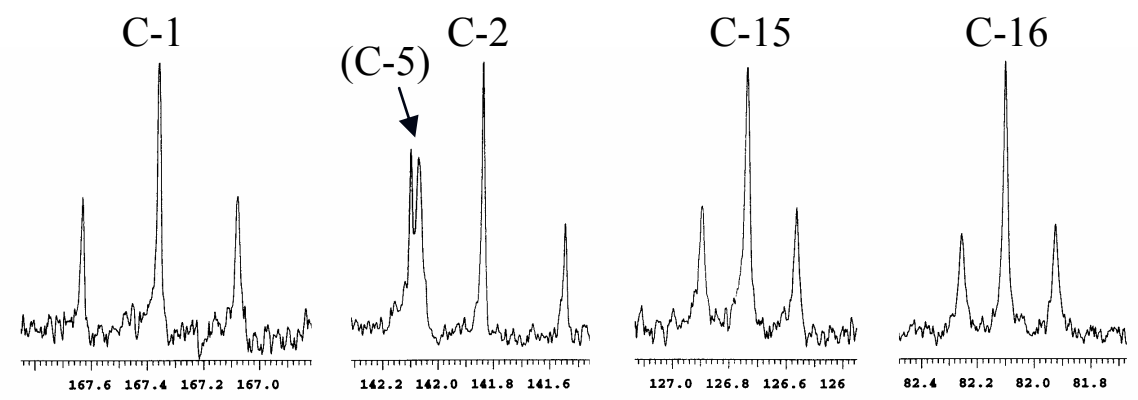

Abbildung 23: ${ }^{13} \mathrm{C}$-NMR-Signale der Kohlenstoffatome der ,ungewöhnlichen $\mathrm{C}_{2}$-Einheit“ von 10a nach Fütterung von $\left[1,2-{ }^{13} \mathrm{C}_{2}\right]-s n$-Glycerin $(150.8 \mathrm{MHz}$, $\left.\mathrm{CD}_{2} \mathrm{Cl}_{2} / \mathrm{CD}_{3} \mathrm{OD} 2: 1,-20^{\circ} \mathrm{C}\right)$. 
Die Kopplung in den Acetateinheiten C-13/C-14, C-21/C-22, C-25/C-26 und C-27/C-28 nach Zufütterung von 37 lässt sich - wie in Kapitel A.II.4.4.4. bereits beschrieben - wiederum über Pyruvat (30) als Zwischenstufe gemäß Abbildung 25a und 25b erklären. ${ }^{88}$ Die Anreicherung in den nicht koppelnden Kohlenstoffatomen C-13, C-21, C-25 und C-27 nach Fütterung von 35 bzw. C-2 sowie C-16 nach Fütterung von 37 konnte durch deutliche Signalerhöhung im ${ }^{13} \mathrm{C}$-NMR-Spektrum festgestellt werden, wurde jedoch nicht quantifiziert.

10a nach Zufütterung von $\left[1,2-{ }^{13} \mathrm{C}_{2}\right]-s n$-Glycerin (35):

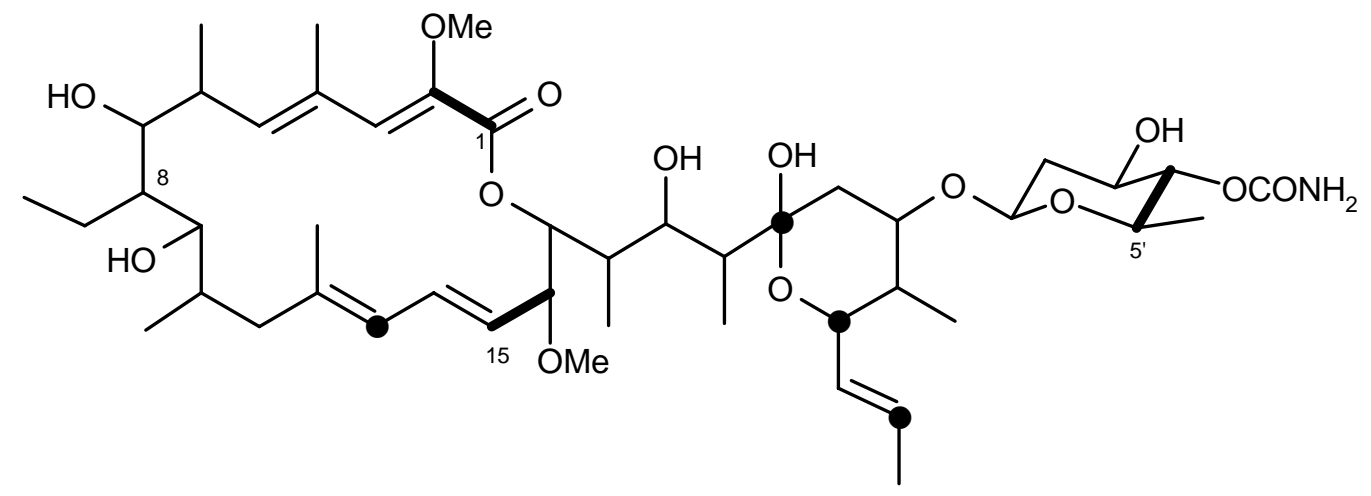

10a nach Zufütterung von $\left[2,3-{ }^{13} \mathrm{C}_{2}\right]-$ sn-Glycerin (37):

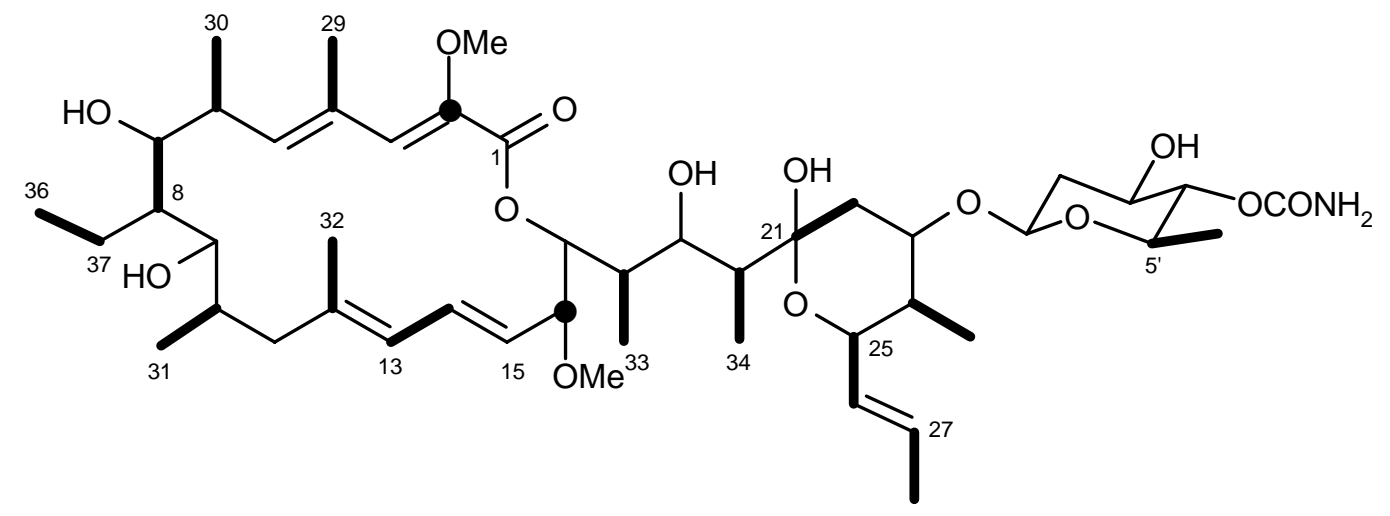

Abbildung 24: Concanamycin A (10a) nach Fütterung der $\left[{ }^{13} \mathrm{C}_{2}\right]$ Glycerin-Enantiomere 35 und 37 (angereicherte, nicht koppelnde Kohlenstoffatome sind durch •, Kopplungen durch - markiert).

Der vergleichsweise geringe Einbau in die Propionat-Einheiten nach Fütterung von $\mathbf{3 7}$ ist über eine Einschleusung des gebildeten Acetyl-CoA in den Citronensäurecyclus und Überführung des gebildeten Succinyl-CoA in Methylmalonyl-CoA erklärbar. Diese Beobachtung deckt sich mit den bei den Bafilomycinen (11) erhaltenen Ergebnissen, wo es zu einer Anreicherung in den Propionateinheiten nach Fütterung von ${ }^{13} \mathrm{C}$-markiertem Acetat kam. Die Anreicherung in der Butyrateinheit kann über den bereits von K. U. BINDSEIL ${ }^{96}$ postulierten Aufbau aus Acetyl-CoA und Malonyl-CoA analog zu den aus dem Lipidstoffwechsel bekannten 
Biosyntheseschritten hergeleitet werden. Das Einbaumuster des 2-Desoxy-D-rhamnoseBausteins hingegen entspricht den gemäß der Gluconeogenese bzw. dem Pentosephosphatweg abzuleitenden Erwartungen, ${ }^{99,100}$ wobei zum Aufbau benötigtes Dihydroxyaceton nicht aus zugefüttertem Glycerin gebildet wird, sondern einem anderem Pool entstammt.

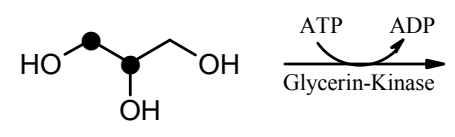

$\left[1,2-{ }^{13} \mathrm{C}_{2}\right]-$ sn-Glycerin

(35)

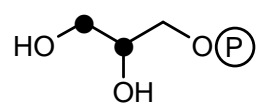

Glycerin-3-phosphat

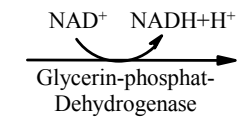

Dehydrogenase

Dihydroxyaceton-

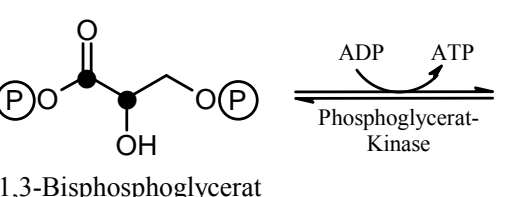

1,3-Bisphosphoglycerat<smiles></smiles>

phosphat

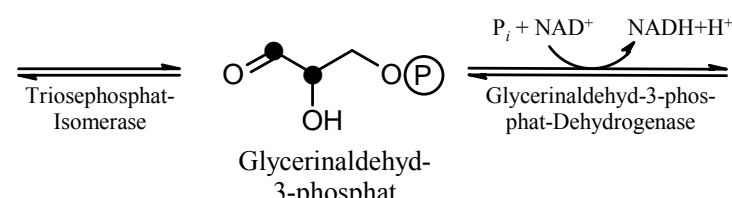

3-phosphat

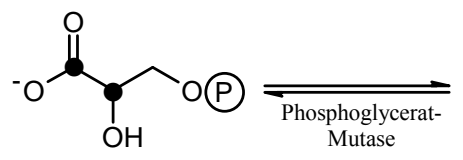

3-Phosphoglycerat<smiles>COC(=O)C(CO)OC</smiles>

2-Phosphoglycerat<smiles>C1=CCC=C1</smiles><smiles>C=C(OC)C(=O)OC</smiles>

Phosphoenolpyruvat

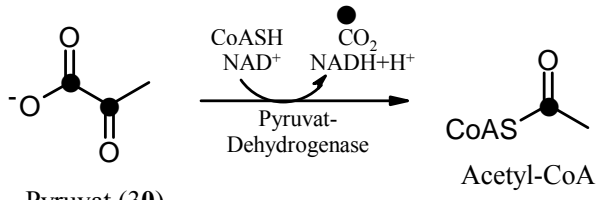

Pyruvat (30)

Abbildung 25a: Biosynthetische Umwandlung des Glycerinenantiomers 35 in Acetyl-CoA.

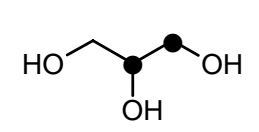

$\left[2,3-{ }^{13} \mathrm{C}_{2}\right]-$ sn-Glycerin

(37)

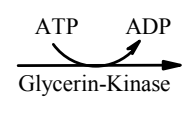

$\overbrace{\mathrm{OH}}^{\mathrm{HO}} \mathrm{OP}$

Glycerin-3-phosphat

Glycerin-3-phosphat

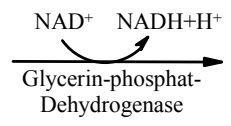

Dehydrogenase
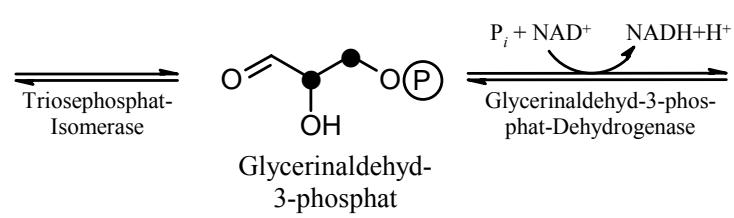

3-phosphat

PO

1,3-Bisphosphoglycerat<smiles>O=C(CO)CO[18O]</smiles>

Dihydroxyacetonphosphat<smiles>COCC(O)C(=O)OC</smiles><smiles>C1C2CC1C2</smiles>

3-Phosphoglycerat Mutase<smiles>COC(=O)[C@@H]([O+])CO</smiles>
2-Phosphoglycerat<smiles>C=C([O-])C(=O)O</smiles>
Phosphoenolpyruvat<smiles>CC(=O)C(C)=O</smiles>

Pyruvat (30)

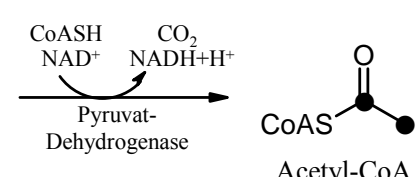

Acetyl-CoA
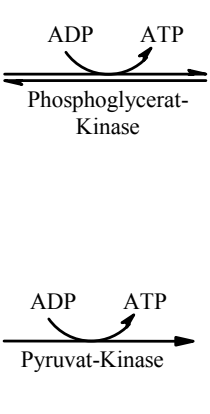


\subsection{Diskussion der Ergebnisse}

Da wie bei den Bafilomycinen (11) auch beim Concanamycin A (10a) ein Einbau der

${ }^{13}$ C-markierten Vorläufer 2-Hydroxy- und 2-Methoxymalonyl-SNAC-ester 31 und 32 in den Makrolactonring ausblieb, kann eine Beteiligung entsprechender freier Malonyl-CoADerivate an der Biosynthese der ungewöhnlich methoxylierten $\mathrm{C}_{2}$-Einheiten nahezu ausgeschlossen werden. Die Tatsache, dass nur die Fütterung von $\left[1,2-{ }^{13} \mathrm{C}_{2}\right]-s n$-Glycerin (35) $\mathrm{zu}$ einer Kopplung in den fraglichen Einheiten führte, ist ein Hinweis, dass die stereospezifische Glycerin-Kinase am Aufbau der Vorläufer beteiligt ist. Im Fall der Biosynthese über ein ACP-gebundenes Malonat scheint Glycerin vor dem Beladen der ACP zunächst phosphoryliert zu werden.

Um mehr über den weiteren Verlauf der Biosynthese zu erfahren, wurde im Rahmen des BMBF-Projektes die Sequenzierung des Concanamycin-Biosynthesegenclusters angestrebt. Alle bisherigen Untersuchungen dazu sind im nächsten Kapitel beschrieben. 


\section{Putatives Biosynthese-Gencluster von Concanamycin A (10a)}

\section{Screening nach Biosynthese-Genclustern}

Während die für die Produktion von Sekundärmetaboliten verantwortlichen Gene bei Pilzen und Pflanzen über das gesamte Genom verteilt sind, liegen sie bei Bakterien in den allermeisten Fällen geclustert vor, d. h. sie befinden sich auf dem Genom in unmittelbarer räumlicher Nachbarschaft. Dieses Phänomen kann ebenso wie das Vorliegen zahlreicher hochkonservierter Domänen innerhalb solcher Gene zu einer effizienten Lokalisierung von kompletten Biosynthese-Genclustern mit bekannter Funktion bei Bakterien genutzt werden. Voraussetzung dafür ist die Vorhersage des für die Bildung eines Sekundärstoffs verantwortlichen Biosyntheseweges und der daran beteiligten Enzyme. Deren Aminosäuresequenz kann herangezogen werden, um gezielt nach Regionen im Genom eines Organismus zu suchen, die für diese Proteine codieren. In der Praxis verwendet man hierfür radioaktiv oder lumineszenz-markierte DNA-Sonden von 30 bis 50 Nucleotiden Länge, deren Sequenz aus der Primärstruktur eines geeigneten Biosynthese-Enzyms abgeleitet wird. Screent man die gesamte DNA eines Organismus mit einer derartigen Sonde, kommt es nur an solchen Stellen zu Hybridisierungen, welche eine hohe Übereinstimmung mit der Basensequenz der eingesetzten Sonde aufweisen. Über die entsprechenden Detektionsverfahren können so die für Biosynthese-Enzyme codierenden DNA-Fragmente rasch identifiziert werden.

Dieses Vorgehen schafft die Grundlage für eine gezielte Sequenzierung nur derjenigen Bereiche im Gesamtgenom, welche an der Biosynthese von Sekundärmetaboliten beteiligt sind und dadurch besonderes Interesse genießen. In den letzten Jahren wurde die Effizienz dieser Methoden kontinuierlich verbessert, was mit dazu geführt hat, dass BiosyntheseGencluster heute nahezu routinemäßig sequenziert werden können.

\section{Arbeiten innerhalb des GenoMik-Projektes}

Im Rahmen des bereits in Kapitel A.I.5. beschriebenen Projekts erfolgt die Identifizierung und Sequenzierung des Biosynthese-Genclusters von Concanamycin A (10a) in Kooperation mit den Arbeitsgruppen von U. WeHMEIER (BUGH Wuppertal) und der Combinature AG (Berlin). Zur Erstellung der Cosmidbank (COMBINATURE AG) wurde der Cosmidvektor 
pOJ436 eingesetzt. Die Lokalisierung des gesuchten Clusters im bakteriellen Genom erfolgte durch Screening der Cosmid-Bibliothek aus genomischer DNA des ConcanamycinProduzenten Streptomyces sp. Stamm Gö 22/15 mit einer Kombination aus zwei DNASonden. Diese zeigten Sequenzhomologien zu Carbamyoltransferasen einerseits sowie PKS IGenen (KS-AT-Sequenz) andererseits und nutzten so die strukturellen Besonderheiten von Concanamycin A (10a) zur Suche der entsprechenden Biosynthesegene gezielt aus. Die Sequenzierung der so gefundenen Cosmide erfolgte bei der Firma GATC (Konstanz) mittels eines Shotgun-Verfahrens, wobei die DNA zunächst durch physikalische Kräfte (Nebulizing) in kleinere Fragmente gespalten wurde und diese anschließend in einen Sequenziervektor ligiert wurden. Die Sequenz der so erhaltenen Konstrukte wurde von beiden Seiten über Standard-Primer in vierfacher Abdeckung ermittelt, wobei die Assemblierung der erhaltenen sich überlappenden Teilsequenzen mit Hilfe des Softwarepakets phred/phrap/consed $^{101,102,103}$ an der Universität Tübingen durch T. WEBER erfolgte.

\section{Annotierung der Sequenzdaten}

Im Rahmen des Projektes wurden bisher drei Cosmide (1F23, 4A22 und 6B08) vollständig sequenziert, wobei sich ein relativ breiter Überlappungsbereich zeigte. Nur ein Teil des Biosynthese-Genclusters konnte so bisher identifiziert werden.

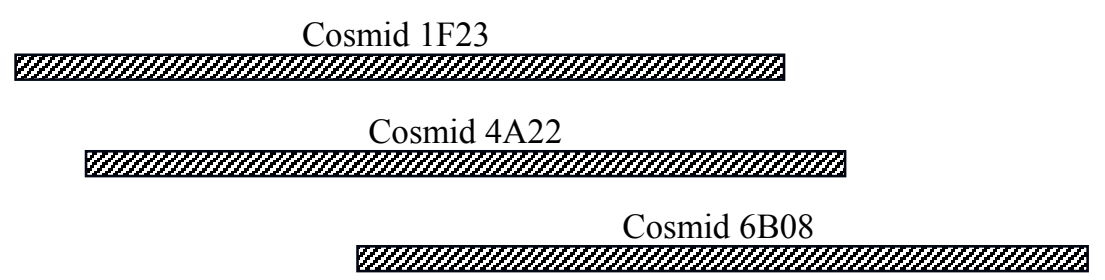

Abbildung 26: Bisher sequenzierte Cosmide mit breitem Überlappungsbereich.

Die Annotierung der assemblierten Daten erfolgte in Zusammenarbeit mit T. WEBER (Universität Tübingen). Der erste Schritt war hierbei die Identifizierung von codierenden Bereichen auf der DNA. Zu diesem Zweck wurden zunächst mit Hilfe des Programmes Critica $^{104}$ offene Leserahmen festgelegt, welche anschließend mit der Software Artemis ${ }^{105}$ manuell editiert wurden. Den so erhaltenen codierenden Abschnitten konnten durch Sequenzvergleiche mit den Software-Paketen Blast ${ }^{106}$ und $\mathrm{HMMer}^{107}$ mögliche Funktionen zugeordnet werden. Zur Identifizierung der Domänenorganisation wurde eine HMM-basierte 
Suche gegen Profile bekannter Domänen durchgeführt. ${ }^{108}$ Mit diesem Ansatz konnten allen Bereichen der Sequenz mögliche Funktionen zugeordnet werden. Hiervon unabhängig wurde eine weitere Annotierung von U. WEHMEIER unter Verwendung unterschiedlicher SoftwarePakete durchgeführt. Beide Ansätze führten zu identischen Ergebnissen. Zur Visualisierung und weiteren Bearbeitung der erhaltenen Daten wurde das Java-basierte Programm Artemis verwendet.

\section{Auswertung}

\subsection{Polyketid-Synthase I-Biosynthesegene}

In den erhaltenen Sequenzdaten konnten bereits die vier letzten der insgesamt 14 PKSModule, die für die Biosynthese von Concanamycin A (10a) zu erwarten sind, zugeordnet werden. Sie stimmen mit dem anhand der Einbaustudien (siehe Kapitel A.II.5.) ableitbaren Aufbau des PKS I-Multienzymkomplexes überein. In Abbildung 27 ist der so abgeleitete gesamte Aufbau des Concanamycin A (10a)-Biosynthese-Genclusters dargestellt. Der markierte Abschnitt stellt den durch die Sequenzdaten bereits abgedeckten Bereich dar. Weiterhin sind die für den Einbau der Vorläufer der ungewöhnlich methoxylierten $\mathrm{C}_{2}$ Einheiten verantwortlichen Module 6 und 13 hervorgehoben, wobei bislang nicht gesichert ist, ob deren Methylierung vor oder nach dem PKS-katalysierten Kettenaufbau erfolgt. Man geht davon aus, dass eine Thioesterase die Abspaltung der multifunktionalisierten Polyketidkette und die Macrolactonisierung vermittelt. Die nachfolgende Pyranringbildung schließt den Aufbau des Concanamycin A (10a)-Aglykons, welches als Concanolid bezeichnet wird, ab.

Unter den bereits sequenzierten Bereichen befindet sich auch das für den Einbau einer „ungewöhnlichen $\mathrm{C}_{2}$-Einheit“" verantwortliche Modul 13. Zur Charakterisierung der darin enthaltenen Acyltransferase (AT) wurde von T. WEBER eine phylogenetische Analyse mit dem Software-Paket Phylip ${ }^{109}$ durchgeführt, deren Ergebnisse in Abbildung 28 dargestellt sind. 


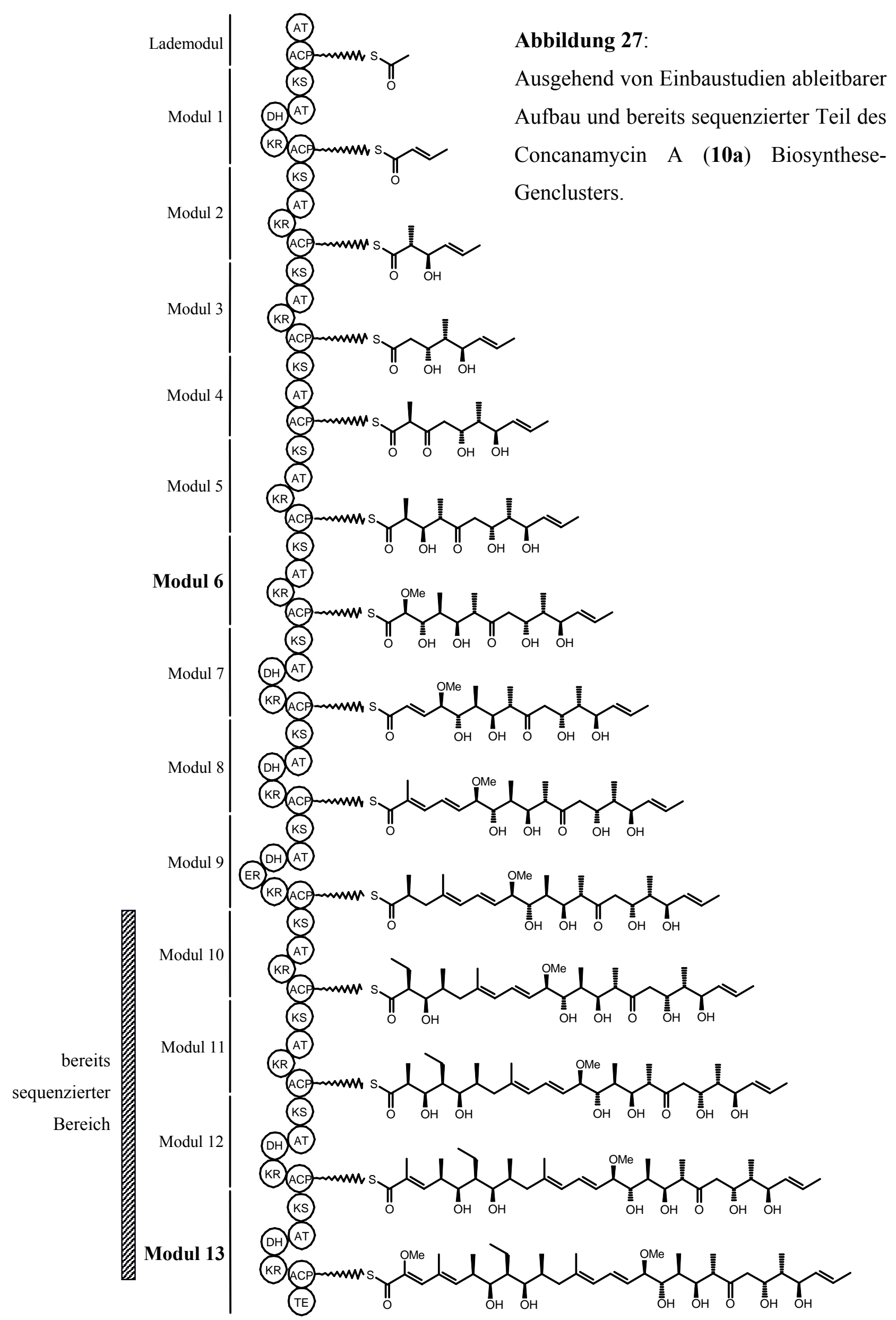




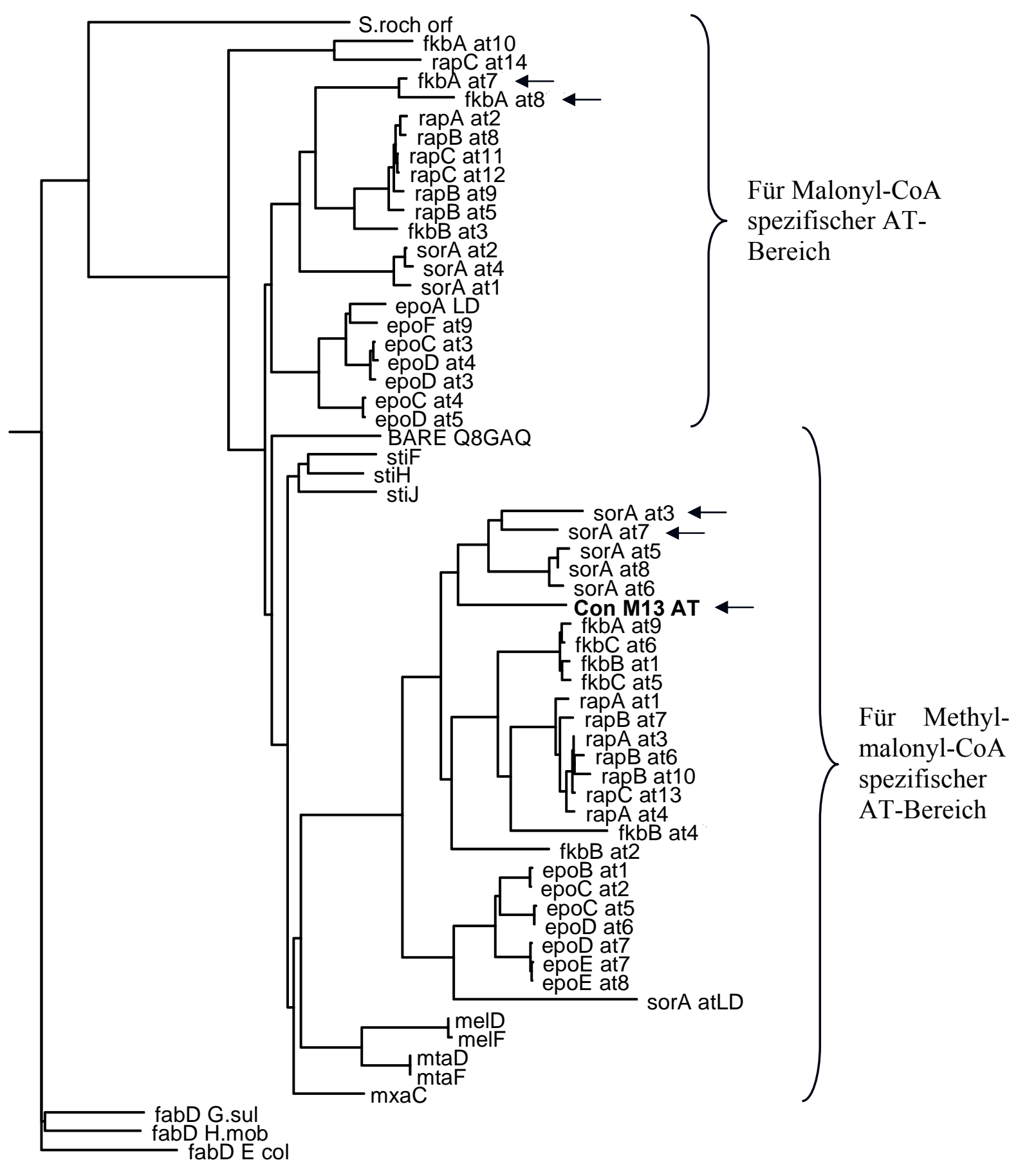

Abbildung 28: Wurzellose Darstellung des phylogenetischen Baumes von AT-Domänen verschiedener Polyketidbiosynthesewege. Mit einem Pfeil markierte Domänen codieren für eine Methoxymalonyl-spezifische AT.

Die phylogenetische Analyse von AT-Domänen erbringt erste Hinweise auf deren Substratspezifität. Sowohl Malonyl-CoA- als auch Methylmalonyl-CoA-aktivierende Domänen bilden jeweils eine eigenständige Gruppe. ${ }^{110}$ Hinsichtlich der Spezifität der Methoxymalonyl-aktivierenden Acyltransferasen ist jedoch keine klare Tendenz erkennbar. Beispielsweise zeichnen sich die Methoxymalonyl-spezifischen Acyltransferasen des 
FK520-Clusters (fkA AT7 und fkA AT8), des Soraphen- (sorA AT3 und sorA AT7) und des Concanamycin-Clusters (ConM13AT) nicht als eine phylogenetische Gruppe aus. Diese Domänen gruppieren sich sowohl in die Klasse der Malonyl-CoA- als auch in die der Methylmalonyl-CoA-aktivierenden Domänen ein. Dies belegt, dass es gegenwärtig nicht möglich ist, Sequenzmotive zuzuordnen, die eine Unterscheidung von Methoxymalonylakzeptierenden ATs von denjenigen anderer Spezifität erlauben. ${ }^{11}$

\subsection{Biosynthesegene der ,ungewöhnlichen $\mathrm{C}_{2}$-Einheit“6}

Die erhaltenen Sequenzdaten decken einen großen Bereich der erwarteten post-PKS-Gene ab. Es konnten fünf Gene (ConG - ConK) zugeordnet werden, die Homologie zum FK520Gencluster zeigen und dort für die Biosynthese des Methoxymalonyl-Bausteins verantwortlich gemacht werden $(\mathrm{FkbG}-\mathrm{FkbK}) .{ }^{111}$ Sie codieren für je eine 3-HydroxyacylCoA-dehydrogenase, ein acyl carrier protein (ACP), eine Acyl-CoA-Dehydrogenase, eine Methyltransferase sowie für ein Protein bislang unbekannter Funktion (Abbildung 29).

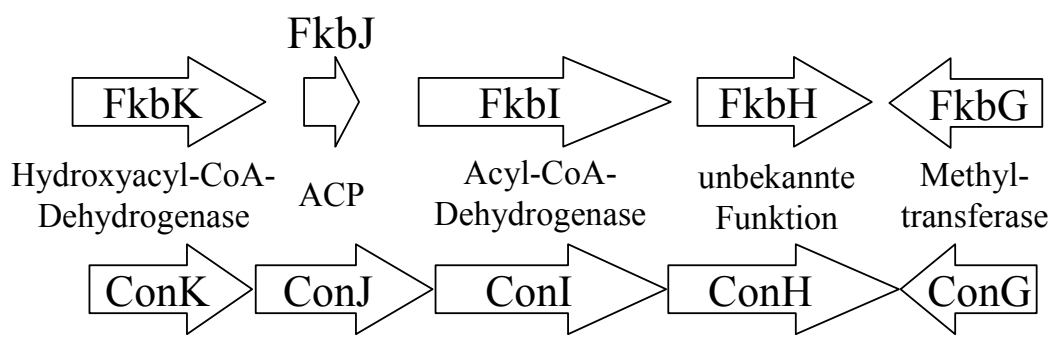

Abbildung 29: Gene, deren Expressionsprodukte putativ an der Biosynthese der
Methoxymalonyl-Einheit beteiligt sind. In den Arbeitsgruppen von REEVES ${ }^{111}$ und FLOSS $^{93}$ wurde bereits ein möglicher Weg für die Bildung des Methoxymalonyl-Bausteins vorgeschlagen, der im Einklang mit den zugeordneten Genfunktionen steht. Demnach erfolgt die Biosynthese über ACP-gebundene Intermediate (Abbildung 30), wobei das Endprodukt der Reaktionsabfolge auf die ACPDomäne des entsprechenden PKS-Moduls übertragen wird. 


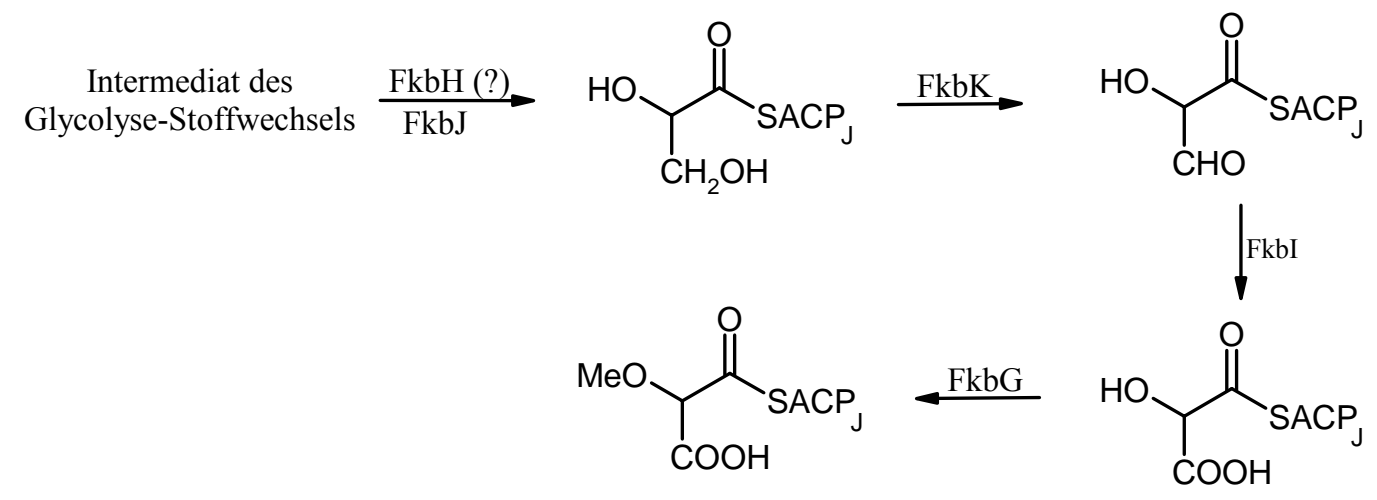

Abbildung 30: Von ReEves et al. ${ }^{111}$ postulierter Biosyntheseweg für den MethoxymalonylVorläufer.

\subsection{Biosynthesehypothese des Methoxymalonyl-Vorläufers}

Die in Kapitel A.II.5.3. beschriebenen Fütterungsexperimente am Concanamycin(10)Produzenten Gö 22/15, bei denen kein Einbau markierter Hydroxymalonyl- bzw. Methoxymalonyl-SNAC-ester (31 bzw. 32) festgestellt werden konnte, unterstützen ein ACPgebundenes Intermediat für die Biosynthese des Vorläufers der ,ungewöhnlichen $\mathrm{C}_{2}$ Einheiten“. Zusätzlich deuten die anhand der Einbaustudien mit $\left[{ }^{13} \mathrm{C}_{2}\right]$ Glycerin-Enantiomeren erhaltenen Ergebnisse (Abschnitt A.II.5.4.) auf die Beteiligung des Enzyms Glycerin-Kinase in der frühen Phase der Biogenese hin. Sie beweisen Glycerin als biosynthetischen Vorläufer der Methoxymalonyl-Einheit und es kann zusammenfassend der in Abbildung 31 dargestellte Ablauf vorgeschlagen werden. Die hervorgehobene Bindung kann nach Fütterung von $\left[1,2-{ }^{13} \mathrm{C}_{2}\right]-s n$-Glycerin (35) im Concanamycin A (10a)-Gerüst detektiert werden (siehe Kapitel A.II.5.4.).

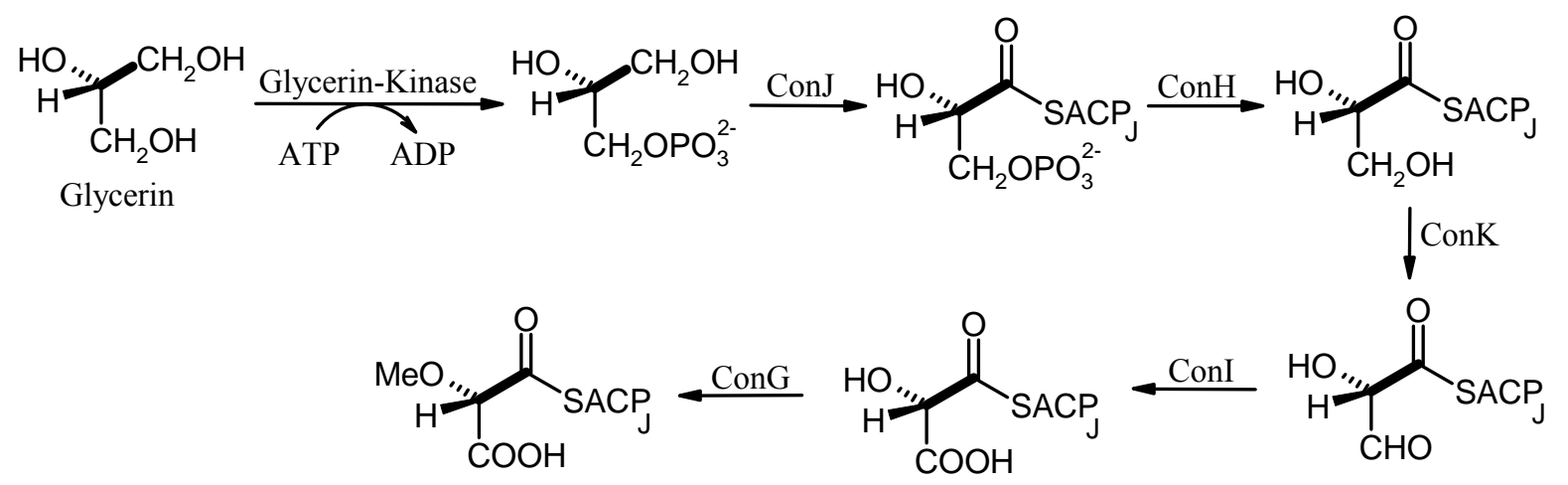

Abbildung 31: Für die Biogenese von Methoxymalonyl-ACP vorgeschlagener Ablauf. 


\subsection{Biosynthesegene des 4-O-Carbamoyl-2-desoxy-D-rhamnosidbausteins}

In den verfügbaren Sequenzdaten konnten bereits alle für die Biosynthese des Zuckerbausteins von Concanamycin A (10a) erwarteten Gene identifiziert werden. So finden sich benachbarte codierende Bereiche für eine Glycosyltransferase, eine 2,3-Dehydratase, eine 3- sowie 4-Ketoreduktase, eine Carbamoyltransferase, eine Thymidyltransferase und eine 4,6-Dehydratase (Abbildung 32).

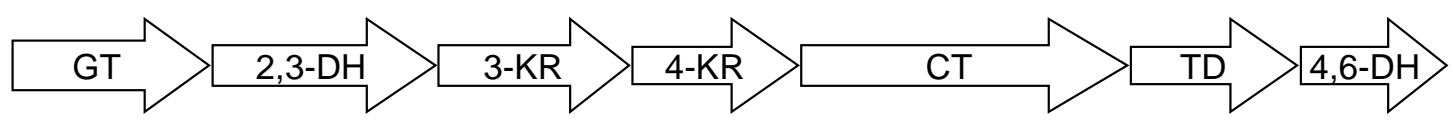

Abbildung 32: Putative, für die Biosynthese des Zuckerbausteins verantwortliche Gene (GT: Glycosyltransferase, DH: Dehydratase, KR: Ketoreduktase, CT: Carbamoyltransferase, TD: Thymidyltransferase).

Während es in der Literatur einige Beispiele für 3-O-carbamoylierte 2-Desoxy-Lrhamnosidbausteine wie im Irumamycin ${ }^{112}$ und im Antibiotikum X-14952B ${ }^{113}$ gibt, ist die entsprechend 4-O-carbamoylierte Zuckereinheit $\mathbf{4 0}$ bislang nur als Bestandteil der Concanamycine (10a, 10e) bekannt. Für die biosynthetische Bildung kann aufgrund der abgeleiteten Genfunktionen der in Abbildung 33 gezeigte Mechanismus ausgehend von D-Glucose-1-phosphat vorgeschlagen werden.
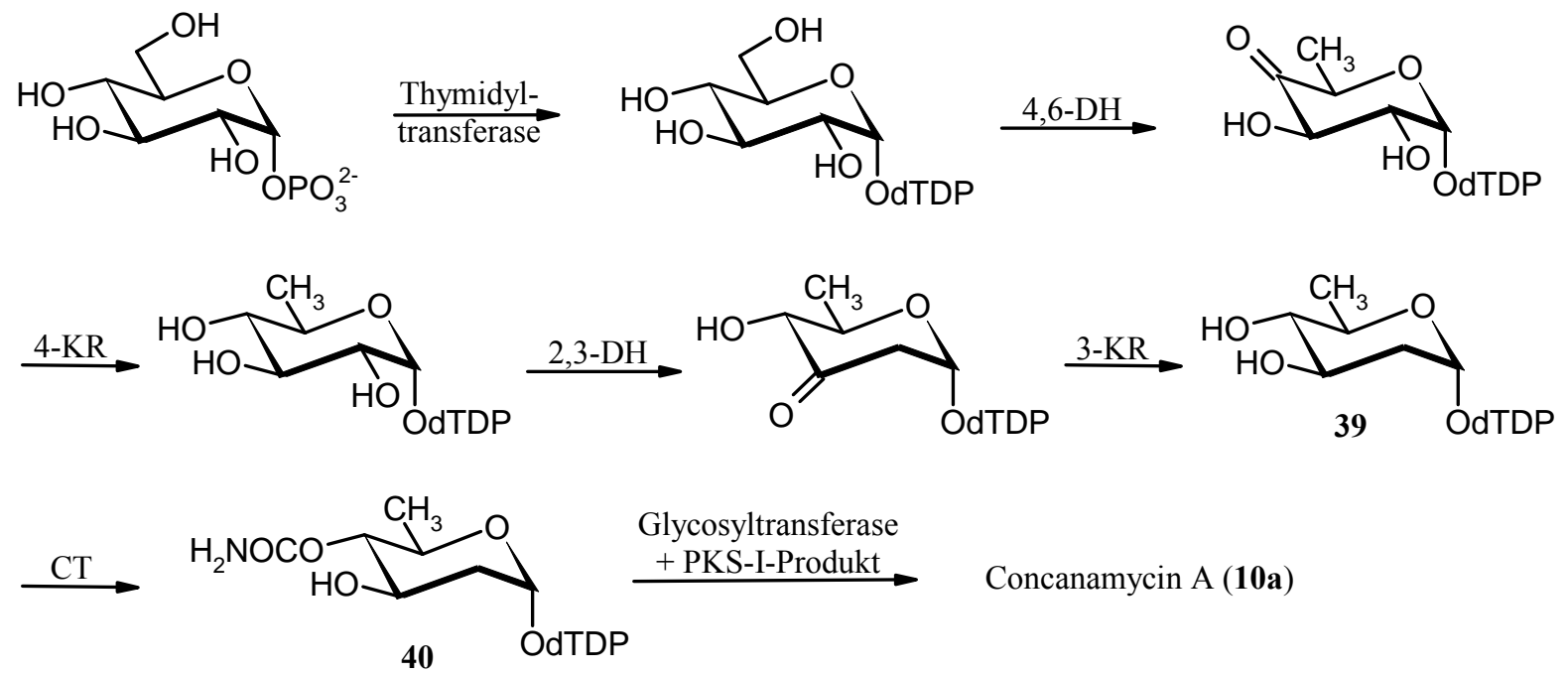

Abbildung 33: Für die Biogenese des 4-Carbamoyl-2-desoxyrhamnosidbausteins von Concanamycin A (10a) vorgeschlagener Ablauf (mit dTDP: Thymidindiphosphat). 
Es scheint plausibel, dass die Einführung der Carbamoylgruppe vor der Übertragung der Glycosyleinheit auf das Concanolid-Gerüst stattfindet, obwohl es hierfür keinen direkten Hinweis gibt. Der Stamm Gö 22/15 bildet neben 10a auch das Concanamycin C (10c), welches das Descarbamoylderivat von 10a darstellt. Das kann über die häufig beobachtete vergleichsweise geringe Substratspezifität von Glycosyltransferasen ${ }^{114,115,116}$ erklärt werden. Es kann angenommen werden, dass diese zu einer teilweisen Übertragung der Vorstufe dTDP-2-Desoxy-D-rhamnose 39 auf das PKS-Produkt führt.

\subsection{Transformationsversuche an Streptomyces sp. Stamm Gö 22/15}

Ein experimenteller Nachweis, dass die sequenzierten Gene auch in vivo exprimiert werden und ihre Transkripte zur Bildung von Concanamycin A (10a) führen, sollte über die Konstruktion von Deletionsmutanten erbracht werden. Voraussetzung hierfür ist die Erarbeitung eines Transformations- bzw. Konjugationsprotokolls, das die Einschleusung geeigneter Genkonstrukte in Stamm Gö 22/15 und auch deren Integration in das BakterienGenom erlaubt. Im Rahmen der vorliegenden Arbeit wurden zu diesem Zweck grundlegende Experimente durchgeführt. Zunächst wurde der Concanamycin (10)-Produzent auf mögliche bestehende Antibiotikaresistenzen hin untersucht. Hierfür wurden Kolonien des Stammes auf apramycin-, thiostrepton-, gentamicin-, kanamycin- und neomycinhaltigem R5-Medium ausplattiert und in Hinblick auf erfolgtes Wachstum überprüft. Bei allen Ansätzen wurde dieses vollständig gehemmt (Beispiel in Abbildung 34). Somit konnte gezeigt werden, dass die getesteten Antibiotika zur Herstellung von Selektionsmedien verwendet werden können.
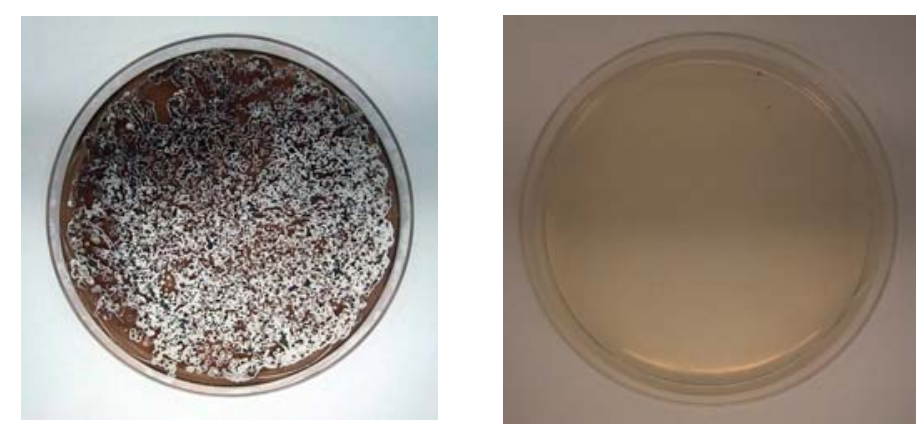

Abbildung 34: Resistenztest (links: Stamm Gö 22/15 auf apramycin-freiem Nährboden nach 48stündiger Inkubationszeit, rechts: identische Wachstumsbedingungen bei Verwendung eines apramycin-haltigen Mediums). 
Im nächsten Schritt wurde der Stammes Gö 22/15 auf seine Transformationsfähigkeit hin untersucht. Zu diesem Zweck fand als Modellvektor das Plasmid pHGF7669 ${ }^{36}$ Verwendung, welches Apramycin-Resistenzgene enthält. Es wurde versucht, dieses Konstrukt mittels eines Polyethylenglykol (PEG)-basierten Transformationsprotokolls ${ }^{117}$ in Protoplasten von Gö 22/15-Zellen einzuschleusen. Die Protoplastierung, welche nötig ist, um die Empfängerzellen für die Aufnahme von Fremd-DNA empfänglich zu machen, erfolgte dabei über Inkubation mit einem Lysozym-Puffer. Für die Transformation wurde neben dem aus Escherichia coli isolierten pHGF7669 auch das in Streptomyceten replizierbare Plasmid pGM9 ${ }^{117}$ verwendet, welches ein Kanamycin-Resistenzgen aufweist. Da jedoch auch nach mehrmaliger Wiederholung beider Transformationsansätze keine in apramycin- bzw. kanamycinhaltigem Nährmedium wachstumsfähigen Zellen erzeugt werden konnten, wurde diese Strategie nicht weiterverfolgt.

Eine weitere Methode, um Fremd-DNA in Streptomyceten-Zellen einzuführen, ist die intergenerische Konjugation mit Escherichia coli. In diesem erstmals von MAZODIER et al. ${ }^{118}$ beschriebenen Ansatz nutzt man die Möglichkeit eines Transfers von Plasmiden zwischen beiden Spezies. Zur experimentellen Durchführung wurde der E. coli Stamm ET12567, welcher über die Plasmide pUB307 und pSET152 verfügte, ${ }^{117}$ zusammen mit Gö 22/15 ausplattiert. Das durch pUB307 für den Vorgang der Konjugation mobilisierte Plasmid pSET152 trägt ein Apramycin-Resistenzgen, welches zur Selektion der erfolgreich konjugierten Streptomyceten-Kolonien herangezogen werden kann. Deshalb erfolgte nach etwa 20stündiger Inkubation die Überschichtung mit einer antibiotikahaltigen Pufferlösung. Diese enthielt sowohl Nalidixinsäure, welche selektiv cytotoxisch gegenüber E. coli Zellen wirkt, als auch Apramycin. So sollte es nach erneuter Inkubation zu einer Selektion ausschließlich derjenigen Zellen gekommen sein, bei welchen eine Integration des pSET152Apramycinresistenzgens ins Bakteriengenom stattgefunden hat. Es konnten jedoch im Fall von Stamm Gö 22/15 trotz mehrmaliger Wiederholung des beschriebenen Ansatzes keine erfolgreich konjugierten Zellen erzeugt werden.

Aus Zeitgründen wurde im Rahmen der vorliegenden Arbeit auf die Anwendung weiterer Methoden zur Einschleusung von Fremd-DNA in den Concanamycin-Produzenten Gö 22/15 verzichtet. 


\subsection{Zusammenfassung und Ausblick}

Den im Rahmen des BMBF-Projekts zur Verfügung gestellten Teilsequenzen aus dem putativen Biosynthese-Gencluster von Concanamycin A (10a) konnten bereits zum größten Teil Funktionen zugeordnet werden. So war es möglich, vier der vierzehn PKS-Module auf genetischer Ebene zu charakterisieren und ihren Aufbau im Hinblick auf die enthaltene Domänestruktur abzuleiten. Darunter befand sich auch Modul 13, welches für den Einbau der Methoxymalonyl-Vorstufe in das Concanolid-Gerüst verantwortlich ist und damit an der Entstehung der ,ungewöhnlichen $\mathrm{C}_{2}$-Einheit“ mitwirkt. Weiterhin konnten bereits alle für den Aufbau des methoxylierten Vorläufers erwarteten Gene in den Sequenzdaten identifiziert werden. In Kombination mit den in Kapitel A.II.5.4. beschriebenen Fütterungsexperimenten konnte hieraus ein plausibler Biosyntheseweg für die Bildung der Methoxymalonyl-Vorstufe vorgeschlagen werden. Ebenso war es möglich, einen Ablauf für die Biogenese des 4-O-Carbamoyl-2-desoxy-D-rhamnosidbausteins (40) basierend auf den erhaltenen Sequenzdaten zu postulieren.

Um eine experimentelle Bestätigung für die Richtigkeit der aufgestellten BiosyntheseHypothesen zu ermöglichen, kann die Erzeugung geeigneter Deletionsmutanten von wertvollem Nutzen sein. Diese könnte damit einhergehend auch den noch ausstehenden, grundsätzlich erforderlichen Nachweis für die in-vivo-Expression der sequenzierten Gene erbringen und damit deren tatsächliche Beteiligung an der Concanamycin (10)-Biosynthese belegen. Weiterhin sind Deletionsmutanten notwendig, um die Möglichkeit der Generierung bislang unbekannter Concanamycin(10)-Derivate innerhalb des Konzeptes der kombinatorischen Biosynthese zu schaffen. Voraussetzung für deren Erzeugung ist die Etablierung eines geeigneten Transformations- bzw. Konjugationsprotokolls für den Produzentenstamm Gö 22/15. Dies war im Rahmen der vorliegenden Arbeit aus Zeitgründen nicht möglich, obwohl bereits grundlegende Experimente diesbezüglich durchgeführt wurden.

Darüber hinaus muss sowohl die Sequenzierung der Bereiche, die für den Beginn der PKS I (upstream) codieren als auch der Abschnitte, die eine zweifelsfreie Identifizierung des Cluster-Endes (downstream) ermöglichen, erfolgen. Diese Arbeiten werden gegenwärtig im Rahmen des GenoMik-Projekts durchgeführt, wobei geeignete Anschluss-Cosmide bereits identifiziert werden konnten. 


\section{Darstellung eines Bafilomycin-Derivates für Bindungsstudien an V-ATPasen}

\section{Prinzip der Photoaffinitätsmarkierung}

Zur Untersuchung von Wechselwirkungen eines Rezeptors mit bestimmten Agonisten bzw. Antagonisten sind Photoaffinitätsmarkierungen in der aktuellen Forschung von hohem Stellenwert. ${ }^{119,120,121}$ Entsprechend derivatisierte Wirkstoffe können nach Erreichen der Bindestelle ihres Zielproteins durch Bestrahlung mit UV-Licht zum Eingehen einer irreversiblen Bindung mit benachbarten Aminosäuren angeregt werden, was zu einer Fixierung des ansonsten labilen Gleichgewichts zwischen Rezeptor und Ligand führt. Durch anschließende denaturierende Gelelektrophorese kann die betroffene Protein-Untereinheit oft direkt anhand einer charakteristischen Bandenverschiebung detektiert werden. Für detailliertere Studien empfiehlt sich das Einbringen einer zusätzlichen Markierung durch radioaktive Isotope oder fluoreszierende Gruppen. Dadurch gelingt meist eine effizientere und exaktere Lokalisierung der für die Aktivität einer Verbindung relevanten Wechselwirkungen.

Häufig eingesetzte Photoaffinitätsreagenzien wie z. B. Azidobenzoesäure enthalten eine Arylazid-Gruppierung, die nach Anregung mit UV-Licht ein reaktives Nitren bildet, welches entweder direkt in C-H-Bindungen insertiert oder nach Umlagerung zum entsprechenden Didehydroazepin mit nucleophilen Thiol- oder Aminogruppen reagiert. Da die gebildeten Intermediate jedoch eine relativ lange Halbwertszeit aufweisen, ${ }^{122}$ kommt es hier vielfach zu unspezifischen Reaktionen. ${ }^{123}$ Die Verwendung des von BRUNNER et al. untersuchten Phenyl(trifluormethyl)diazirin-Systems ${ }^{124}$ erweist sich in dieser Beziehung als deutlich vorteilhafter. Nach Aktivierung entsteht ein äußerst reaktives Carben, das in situ durch Insertion in benachbarte Hydroxyl-, Amino- oder auch C-H-Bindungen reagiert (Abbildung 35). Es kann durch Veresterung mit 4-[3-(Trifluormethyl)-3H-diazirin-3yl]benzoesäure $(\mathbf{4 1})^{125}$ relativ bequem in den $\mathrm{zu}$ untersuchenden Wirkstoff eingebracht werden. $^{126,127,128}$ 


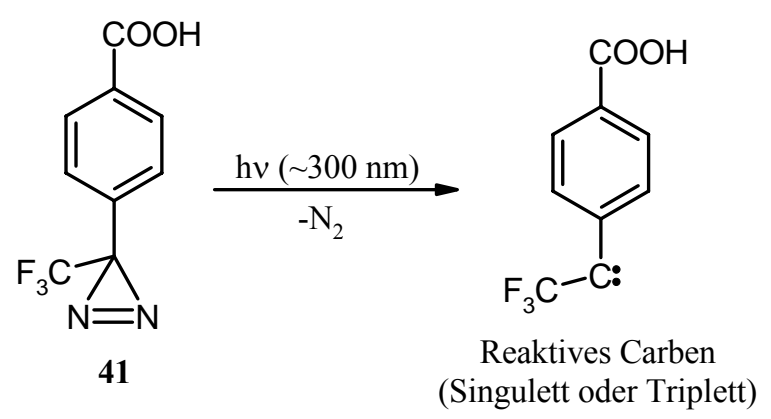

Abbildung 35: Aktivierung des Diazirinylsystems nach Bestrahlung mit UV-Licht.

Mit Hilfe des entsprechend iod- und diazirinylmarkierten Concanolids $\mathbf{4 2}^{35}$, das aus Concanamycin A (10a) über eine sechsstufige chemische Derivatisierung zugänglich ist, gelang es ZEECK, ALTENDORF et al., die für die inhibitorische Aktivität von 10a verantwortliche Bindungsstelle in der c-Untereinheit der V-ATPase zu identifizieren (siehe Kapitel A.II.1.). ${ }^{54,55}$

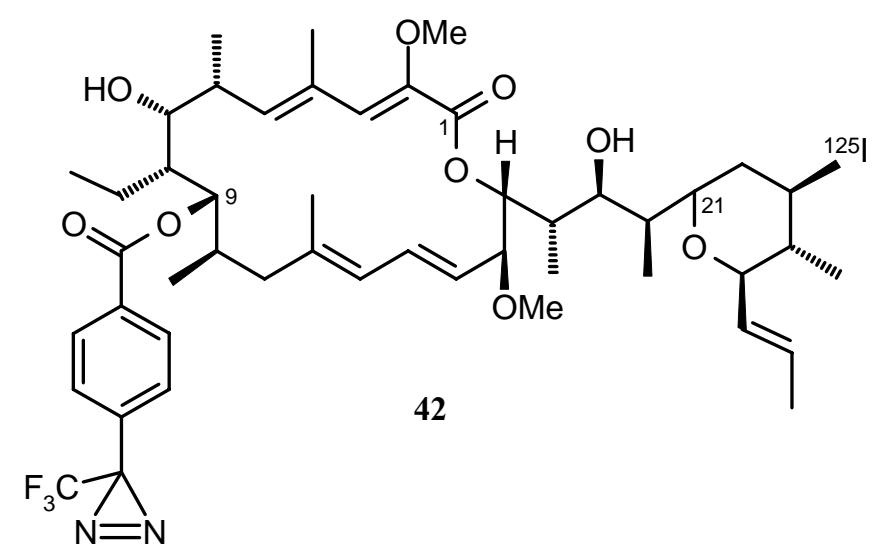

\section{Markierungs- und Synthesestrategie}

Ein Ziel dieser Arbeit war es, diazirinylmarkierte Derivate von Bafilomycin $A_{1}$ (11a) bereitzustellen, die es ermöglichen sollten, die für Concanamycin A (10a) beschriebenen Protein-Bindungsstudien auch an einem Vertreter der Bafilomycin-Gruppe durchzuführen. Um die durch die Verwendung von radioaktiven Isotopen entstehenden Nachteile zu umgehen, sollte eine andere Möglichkeit zur sensitiven und direkten Detektion des entstehenden Inhibitor-Enzym-Komplexes gefunden werden. Das anhand seines charakteristischen Isotopenmusters per Massenspektrometrie gut nachweisbare Element Brom schien für diesen Zweck gut geeignet. Um die Möglichkeit der Abspaltung des leicht polarisierbaren Bromatoms vom Bafilomycin-Gerüst während oder nach der Vernetzung weitgehend zu 
umgehen und gleichzeitig aufwendige Untersuchungen zur Möglichkeit einer Bromierung des Naturstoffs selbst zu vermeiden, sollte $\mathbf{4 1}$ bereits vor der Kondensation mit 11a bromiert werden.

\section{Bromierung von 4-[3-(Trifluormethyl)-3H-diazirin-3-yl]benzoesäure (41)}

Nach einer von DOLBIER et al. beschriebenen Methode gelingt die Monobromierung von desaktivierten Aromaten unter Verwendung von $N$-Bromsuccinimid (NBS) in einer Mischung aus konzentrierter Schwefelsäure und Trifluoressigsäure (TFA) bereits bei Raumtemperatur in guten bis sehr guten Ausbeuten. ${ }^{129}$ In einer Testreaktion wurde die bekanntermaßen säurestabile, kommerziell erhältliche 4-(Trifluormethyldiazirinyl)benzoesäure 41 in einem Schwefelsäure / TFA-Verhältnis von 1:3 gelöst und unter Zusatz von 1.5 Moläquivalenten NBS für 50 Stunden gerührt. Eine HPLC-MS-Analyse des schwer aufzureinigenden Produktgemischs zeigte, dass neben nicht umgesetztem Edukt in etwa gleicher Menge sowohl die monobromierte als auch die dibromierte Form von 41 entstanden war. Zahlreiche Versuche, das Reaktionsgleichgewicht durch Veränderung der Menge an eingesetztem NBS sowie durch Variation des Schwefelsäure/TFA-Mischungsverhältnisse in Richtung des monobromierten Produkts zu drängen, brachten nicht den gewünschten Erfolg. Es zeigte sich jedoch, dass die Verwendung eines Gemisches aus Schwefelsäure und TFA in den Anteilen 2:5 zu einem rascheren Reaktionsumsatz führte.

Um eine aufwendige und zeitintensive HPLC-Trennung des Reaktionsgemisches zu umgehen, wurde versucht, durch einen hohen Überschuss an NBS die Bildung der dibromierten Diazirinylbenzoesäure 43 gemäß Abbildung $36 \mathrm{zu}$ begünstigen. Auf die angestrebten Bindungsstudien und die anschließende Detektion per Massenspektrometrie sollte die Einführung von zwei Bromatomen in das markierte Bafilomycinderivat keinen Einfluss haben.

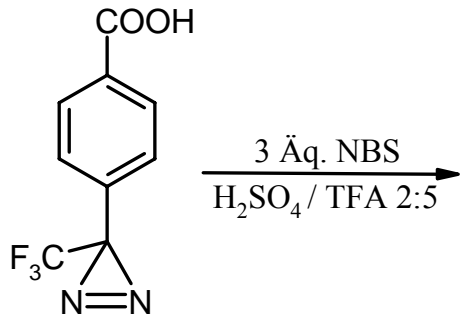

41<smiles>O=C(O)c1cc(Br)c(C2(C(F)(F)F)N=N2)cc1Br</smiles>

43

Abbildung 36: Bromierung unter Überschuss an NBS. 
Kontinuierliche dünnschichtchromatographische Untersuchungen zeigten einen vollständigen

Reaktionsumsatz nach 15 Stunden an. Das ${ }^{1} \mathrm{H}-\mathrm{NMR}-$ Spektrum des aufgearbeiteten Ansatzes zeigte neben den beiden für $\mathbf{4 3}$ zu erwarteten Singulett-Signalen im Tieffeld-Bereich ein weiteres Singulett bei $2.80 \mathrm{ppm}$ an, welches nicht umgesetztem NBS zugeordnet werden konnte. Aus den Signalintegralen ergab sich schließlich das Vorliegen eines Gemisches aus zwei Teilen 2,3-Dibrom-4-[3-(trifluormethyl)-3H-diazirin-3-yl]benzoesäure (43) sowie einem Teil NBS, wobei kein monobromiertes Produkt detektiert werden konnte. Unter Berücksichtigung dieses Verhältnisses konnte somit für $\mathbf{4 3}$ eine Ausbeute von 93 \% bestimmt werden. Da sich aus der Anwesenheit von NBS für die nächste Stufe keine absehbaren Nebenreaktionen ableiten ließen, wurde der komplette Ansatz ohne weitere Aufreinigung eingesetzt.

\section{Veresterung von Bafilomycin $A_{1}$ (11a) zu 44}

Untersuchungen von FARINA et al. zeigten, dass die Hydroxylgruppe an C-21 von Bafilomycin $A_{1}$ (11a) die größte Reaktivität gegenüber elektrophilen Reagenzien aufweist. ${ }^{130}$ Nach Umsetzung von 11a mit Benzoylchlorid in Pyridin unter Zusatz von 4- $N, N$-Dimethylamino-pyridin (DMAP) konnte das 21-O-benzoylierte Produkt in $35 \%$ iger Ausbeute dargestellt werden. Eine Derivatisierung an dieser Position ist von Vorteil, da für die inhibitorische Aktivität von 11a vor allem das Vorliegen eines intakten Makrolactonringes veranwortlich $\mathrm{zu}$ sein scheint. ${ }^{51,54}$ Die biologische Wirkung von 11a sollte durch eine Substitution an C-21 somit nicht allzu stark beeinträchtigt werden.

In einem analogen Vorversuch wurde 11a mit 1.5 Moläquivalenten 2-Brombenzoylchlorid sowie DMAP in Pyridin umgesetzt. Nach Aufarbeitung konnte das 21-O-Brombenzoylderivat in einer Ausbeute von $76 \%$ aus dem Reaktionsgemisch isoliert werden. Um die Möglichkeit einer Veresterung mit freien Säuren zu prüfen, wurde 11a in einem weiteren Ansatz mit 1.5 Moläquivalenten 2-Brombenzoesäure sowie $N^{\prime}$-(3-Dimethylaminopropyl)- $N$-ethylcarbodiimid-Hydrochlorid (EDCI) als Kupplungsreagens und katalytischen Mengen DMAP versetzt. Hier konnte das 21-O-Derivat in $69 \%$ iger Ausbeute gewonnen werden, was in Anbetracht der komplexen Struktur von 11a und der daraus ableitbaren potenziellen Neigung zu Nebenreaktionen ein überraschend hoher Wert war. 
<smiles>O=C(O)c1ccc(C2(C(F)(F)F)N=N2)cc1</smiles>

41<smiles>O=C(O)c1cc(Br)c(C2(C(F)(F)F)N=N2)cc1Br</smiles>

43
11

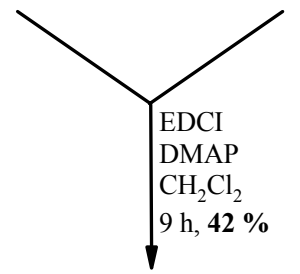

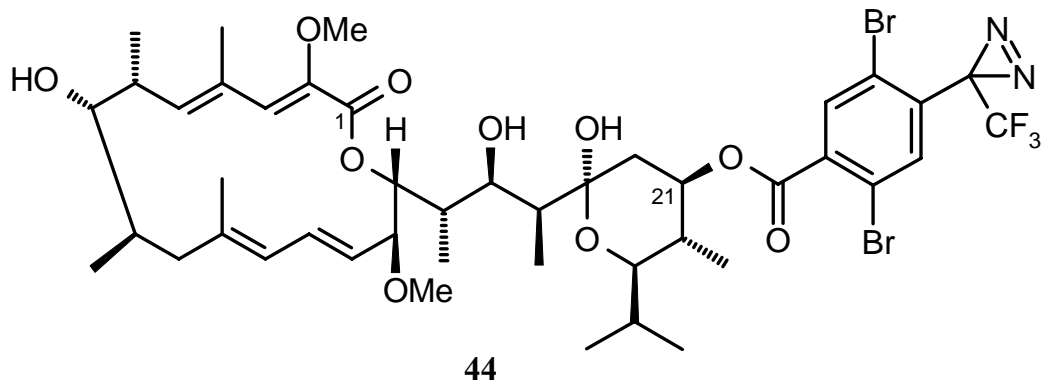

Abbildung 37: Synthese des markierten Bafilomycin $A_{1}$-Derivates 44 für V-ATPaseBindungsstudien.

Identische Bedingungen wurden folglich für die Umsetzung von $35 \mathrm{mg}$ 11a mit der dibromierten Diazirinylbenzoesäure 43 gewählt. In $42 \%$ iger (23 mg) Ausbeute ergab sich hier das für die Proteinbindungsstudien mit V-ATPasen benötigte Endprodukt 44. Abbildung 37 zeigt eine zusammenfassende Darstellung des zur Synthese von $\mathbf{4 4}$ beschrittenen Ansatzes. Das aus der Einführung von zwei Bromatomen resultierende Isotopomerenmuster ist in Abbildung 38 dargestellt.

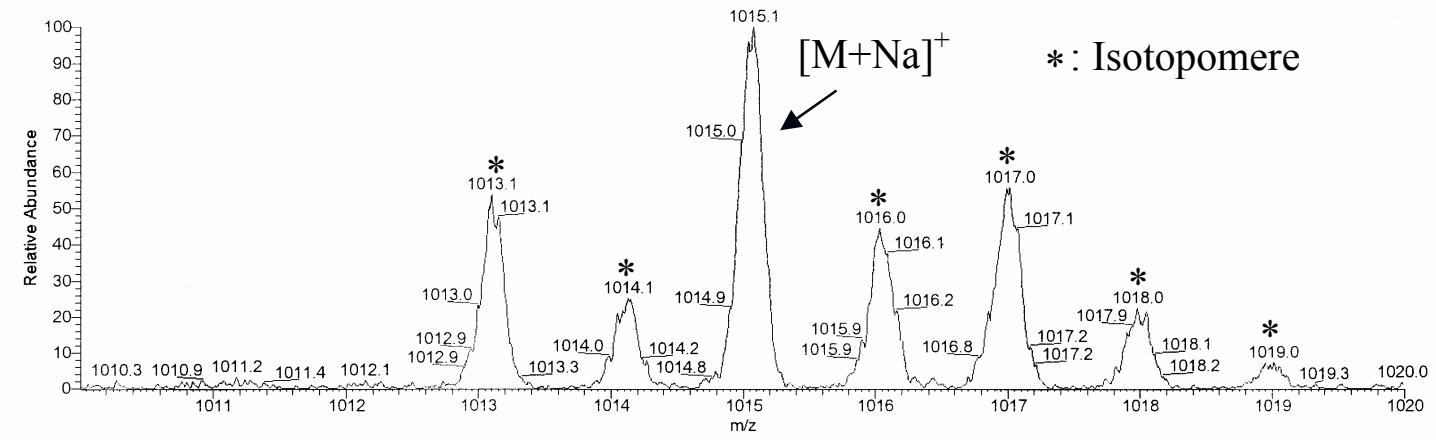

Abbildung 38: ESI-Massenspektrum von 44. 


\section{Ergebnisse der biologischen Untersuchungen}

Erste V-ATPase-Bindungsstudien mit 44 wurden am gereinigten $\mathrm{V}_{1} \mathrm{~V}_{0}$-Holoenzym des Mitteldarmepithels aus der Raupe des Tabakschwärmers Manduca sexta von M. Huss und Mitarbeitern durchgeführt. Es ergab sich der in Abbildung 39 dargestellte Inhibitionsverlauf, ${ }^{131}$ aus dem ein $\mathrm{IC}_{50}$-Wert von $0.1 \mu \mathrm{M}$ für das Derivat 44 abgeleitet werden kann. Dieses hemmt somit erst ab einer zehnfach höheren Konzentration als der Naturstoff 11a selbst. Als Gründe hierfür können einerseits verschlechterte kinetische Eigenschaften angegeben werden, die die Diffusion an das Enzym erschweren. Weiterhin kann ein Einfluss der Substitution an C-21 des Tetrahydropyranrings auf die Inhibition nicht gänzlich ausgeschlossen werden.

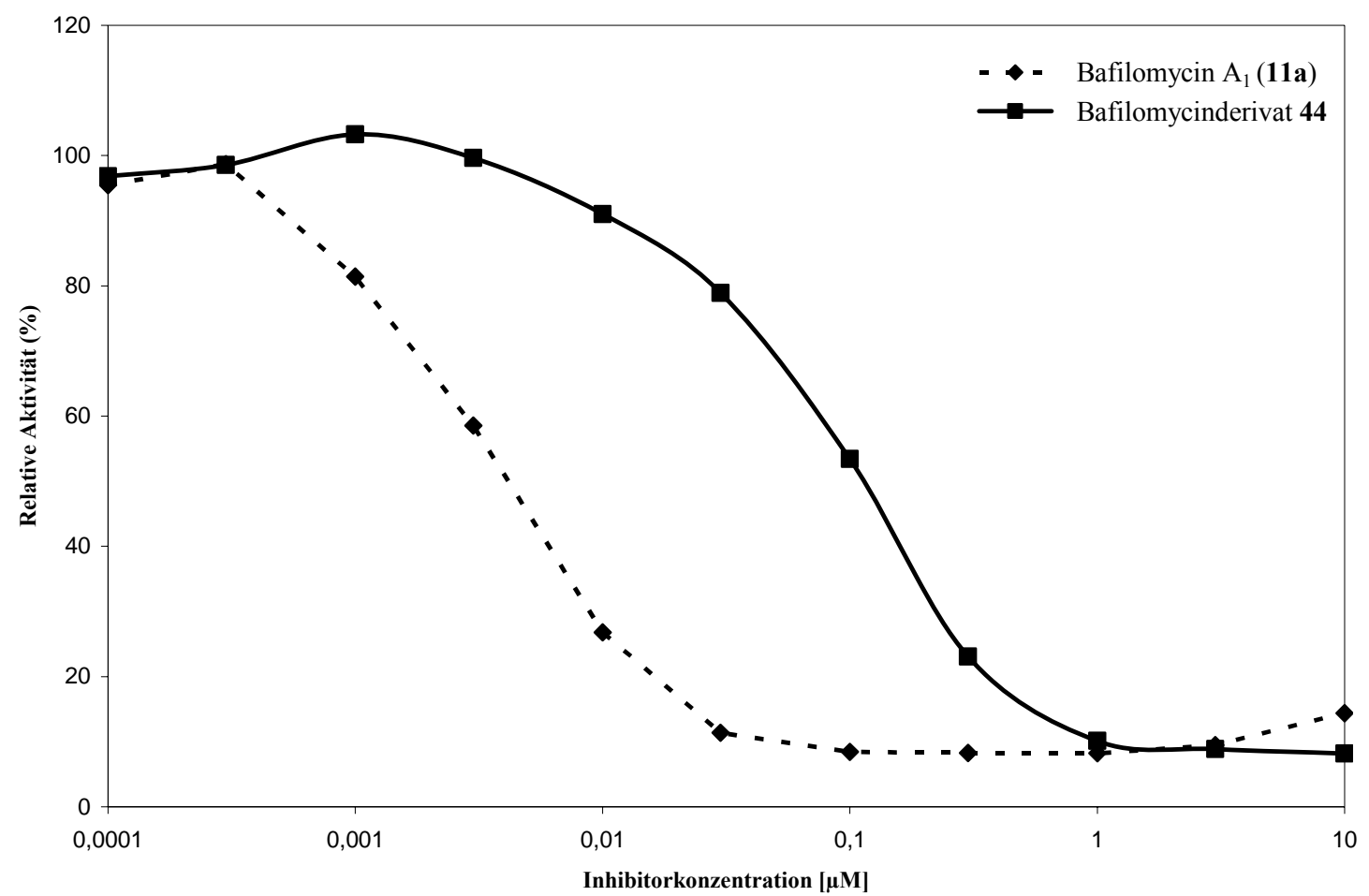

Abbildung 39: Hemmung der V-ATPase aus Manduca sexta durch Bafilomycin $A_{1}$ (11a) und das Dibromdiazirinylderivat $\mathbf{4 4}^{131}$

Für das markierte Concanolid 42 ergab sich in vergleichbaren Studien ein $\mathrm{IC}_{50}$-Wert von 10-20 $\mu \mathrm{M}$, während der Wert für den Naturstoff selbst (10a) bei $10 \mathrm{nM}$ lag. ${ }^{66}$ Der wesentlich geringere Aktivitätsverlust des Bafilomycin-Derivats $44 \mathrm{im}$ Vergleich zu 11a bestätigt daher den drastischen Einfluss einer Substitution am Makrolactonring auf die V-ATPaseinhibitorische Aktivität. 
Die geplanten Quervernetzungsexperimente von $\mathbf{4 4}$ mit dem aktiven Zentrum der aufgereinigten V-ATPase aus M. sexta wurden von M. Huss und Mitarbeitern (Universität Osnabrück) bereits durchgeführt. Dabei konnte keine Bindung an das bei Verwendung des analogen Concanamycin-Derivates $\mathbf{4 2}$ markierte Proteinfragment gefunden werden, was ein Hinweis auf einen unterschiedlicher Inhibitionsmechanismus hindeutet. Die Suche nach den durch 44 markierten Fragmenten ist Gegenstand aktueller Arbeiten. Hier erweist sich das Fehlen einer einfachen, direkten Detektiermöglichkeit für das Element Brom als Nachteil, welches eine aufwendige massenspektrometrische Untersuchung aller Proteinfragmente erforderlich macht. 


\section{Isolierung von Sekundärmetaboliten aus Actinomyceten}

\section{Isolierung und chemisches Screening der untersuchten Stämme}

Die im Rahmen dieser Arbeit untersuchten Actinomyceten-Stämme entstammen Erdproben aus einem Göttinger Waldgebiet (Gö GS31, Gö GS52, Gö GS56 bis Gö GS59) ${ }^{\mathrm{a}}$ sowie aus dem Stadtgebiet von Bayreuth (Gö TS11 bis Gö TS19, Gö TS110 und Gö TS111) und wurden taxonomisch nicht charakterisiert. Bei den letztgenannten Stämmen handelt es sich um eine Auswahl aus insgesamt etwa 30 Kolonien, die mittels des in B.IV.1. beschriebenen Verfahrens isoliert und aufgrund einer interessanten Morphologie selektiert wurden.

Um eine Auswahl zu treffen, welche der Stämme über ein interessantes Metabolitenspektrum verfügen und infolgedessen weiterbearbeiten werden sollten, wurde ein chemisches Screening durchgeführt. Bei dieser von UMEZAWA ${ }^{132}$ et al. eingeführten und in den Arbeitsgruppen von ZÄHNER $^{133}$ und ZEECK ${ }^{134}$ weiterentwickelten Methode versucht man, das komplette Biosynthesepotenzial eines Stammes durch Variation der Kultivierungsparameter im Sinne des OSMAC-Ansatzes (One Strain - Many Compounds) ${ }^{135}$ abzuschätzen. Um die gebildeten Sekundärmetaboliten nachzuweisen, bedient man sich unterschiedlicher chromatographischer Methoden wie DC, HPLC oder HPLC-MS. Primäres Ziel dieses Ansatzes ist die Identifikation neuer, interessanter chemischer Strukturen, wobei deren biologische Wirksamkeit zunächst unbetrachtet bleibt und erst nach erfolgter Isolierung und Charakterisierung getestet wird.

Für das Screening der zu untersuchenden Stämme wurden diese in vier unterschiedlichen Nährmedien (Hafer, M2, SM und SGG) im 50 mL-Maßstab in Schüttelkolben kultiviert und die Ansätze nach 84 Stunden standardisiert aufgearbeitet. Anschließend wurden sowohl Kulturfiltrat als auch Mycel extrahiert und die erhaltenen Rohprodukte dünnschichtchromatographisch analysiert. Dabei fanden zwei verschiedene Laufmittelsysteme (Chloroform/Methanol 9:1 und Butanol/Essigsäure/Wasser 4:1:5) sowie drei unterschiedliche Ansprühreagenzien (Anisaldehyd, Orcin und Ehrlich) Verwendung. Von den 14 getesteten Stämmen waren fünf (Gö GS56, Gö TS15, Gö TS17, Gö TS18 und Gö TS19) aufgrund ihres Metabolitenmusters auffällig und wurden infolgedessen weiterbearbeitet.

\footnotetext{
${ }^{a}$ S. Grond danke ich für die Bereitstellung der Stämme Gö GS31, Gö GS52 sowie Gö GS56 bis Gö GS59.
} 


\section{Actinomyces sp. Stamm Gö GS56}

Der Stamm Gö GS56 war im chemischen Screening durch eine bei $254 \mathrm{~nm}$ UV-löschende, mit Anisaldehyd in der Wärme intensiv grün anfärbende Zone bei $\mathrm{R}_{\mathrm{f}}=0.3 \mathrm{im}$ Dünnschichtchromatogramm (Chloroform/Methanol 9:1) des Kulturfiltrat-Extraktes aufgefallen. Aus einem Kultivierungsansatz in $2 \mathrm{~L}$ M2-Medium konnten allerdings keine für die Charakterisierung dieser Substanz ausreichenden Mengen isoliert werden. Stattdessen konnten die bisher nicht beschriebenen Verbindungen (Cyanomethyldihydroxymethylbutyl)indol 45 und Dimethyluridin (46) sowie die bekannte Verbindung Thioaurin (47) isoliert werden.

\section{1. (Cyanomethyldihydroxymethylbutyl)indol (45)}

45 fiel im Dünnschichtchromatogramm durch UV-Löschung bei $254 \mathrm{~nm}$ sowie durch hellblaue Fluoreszenz bei $366 \mathrm{~nm}$ auf und färbt mit Anisaldehyd in der Wärme braun an. Die Verbindung konnte in einer Ausbeute von $1.8 \mathrm{mg} / \mathrm{L}$ in Form eines braunen Öls isoliert werden.

Im EI-Massenspektrum zeigte 45 bei $\mathrm{m} / \mathrm{z}=258$ das Ion höchster Masse, aus dem sich durch Hochauflösung die Summenformel $\mathrm{C}_{15} \mathrm{H}_{18} \mathrm{~N}_{2} \mathrm{O}_{2}$ ermitteln ließ. Aus den typischen chemischen Verschiebungen der Kohlenstoffatome im ${ }^{13} \mathrm{C}-\mathrm{NMR}$-Spektrum $\left(\delta_{\mathrm{C}}=104.9,112.8,118.1\right.$, 121.9, 123.5, 125.3, 135.4 und 137.7) konnte auf Indol als Grundstruktur geschlossen werden. Im Aromatenbereich des ${ }^{1} \mathrm{H}-\mathrm{NMR}-$ Spektrums zeigten sich charakteristische Signale für zwei benachbarte Protonen $\left(\delta_{\mathrm{H}}=7.03\right.$ und 7.52, $\left.{ }^{3} J_{\mathrm{HH}}=8.0 \mathrm{~Hz}\right)$ sowie zwei weitere Methingruppen $\left(\delta_{\mathrm{H}}=7.31\right.$ und 7.34) ohne vicinalen Kopplungspartner. Es musste folglich ein disubstituiertes Indolderivat vorliegen. Im ${ }^{1} \mathrm{H}-\mathrm{NMR}-$ Spektrum fanden sich zusätzliche Signale für zwei Methylgruppen $\left(\delta_{\mathrm{H}}=1.23\right.$ und 1.26), eine homotope $\left(\delta_{\mathrm{H}}=3.98\right)$ sowie eine diastereotope $\left(\delta_{\mathrm{H}}=2.59\right.$ und 3.07) Methylengruppe und eine Methingruppe $\left(\delta_{\mathrm{H}}=3.58\right)$. Letztere mussten aufgrund der charakteristischen chemischen Verschiebungen an ein Heteroatom gebunden sein. 


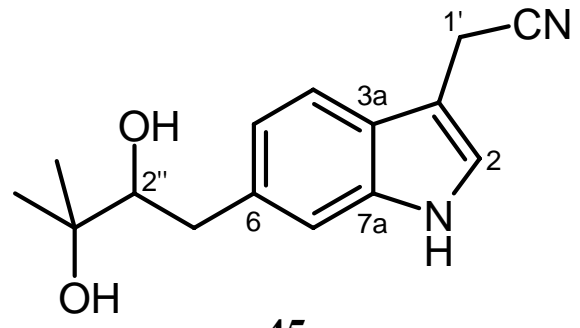

45

Mit Hilfe von 2D-NMR-Spektroskopie $\left({ }^{1} \mathrm{H},{ }^{1} \mathrm{H}-\mathrm{COSY}\right.$, HSQC und HMBC) gelang die Zuordnung der einzelnen Signale (Abbildung 40) und es konnte ein Strukturvorschlag für 45 abgeleitet werden. Unter Berücksichtigung der vorgegebenen Summenformel und 2D-Korrelationen wurde auf eine Hydroxyl-Substitution der bereits erwähnten Kohlenstoffatome C-2', und C-3', geschlossen. Als ungewöhnlich erwies sich das Vorliegen einer Methylengruppe, deren Kohlenstoffatom eine chemische Verschiebung von $\delta_{\mathrm{C}}=13.8$ aufwies, während die zugehörigen Protonen bei $\delta_{\mathrm{H}}=3.98$ lagen. Literaturstudien ergaben, dass sich derartige Effekte auf den anisotropen Einfluss einer benachbarten Cyanogruppe zurückführen lassen können. ${ }^{136}$ Eine Bande im IR-Spektrum bei $2251 \mathrm{~cm}^{-1}$ bestätigte die Anwesenheit einer derartigen Einheit im Molekül. ${ }^{192}$
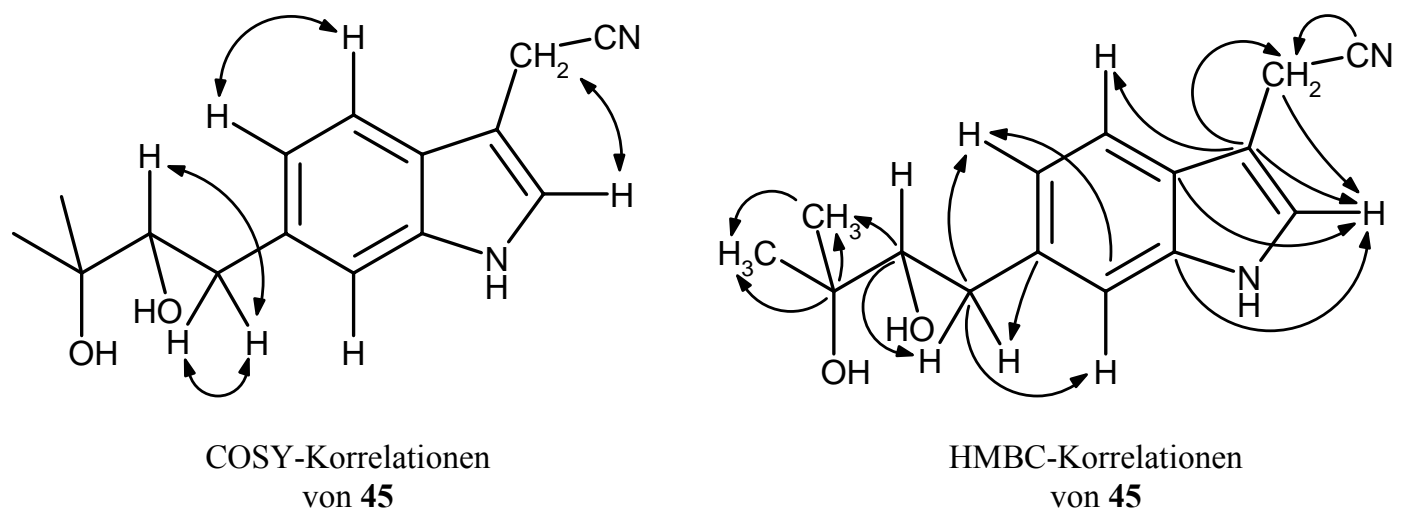

Abbildung 40: Für die Strukturaufklärung entscheidende ${ }^{1} \mathrm{H},{ }^{1} \mathrm{H}-\mathrm{COSY}$ - und $\mathrm{HMBC}$ Korrelationen von 45.

Während 45 bislang nicht literaturbekannt ist, konnte 3-Cyanomethylindol 48 bereits als Metabolit des Myxobakteriums Archangium gephyra gefunden werden. ${ }^{137}$ Dort wurde zusätzlich das entsprechende Acetaldoxim 49 isoliert, was einen potenziellen biosynthetischen Vorläufer von 48 darstellt und durch Zufütterung von L-[1'- $\left.{ }^{14} \mathrm{C}\right]$ Tryptophan markiert wurde. Der für die Bildung von 48 postulierte Biosyntheseweg ist in Abbildung 41 dargestellt und könnte entsprechend auch im Metabolismus von Actinomyceten ablaufen. 
Während 49 moderate fungizide Aktivität aufwies, konnte für 48 keine biologische Wirkung gefunden werden.

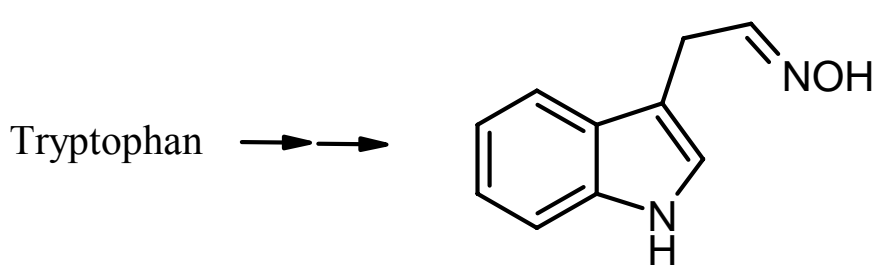

49

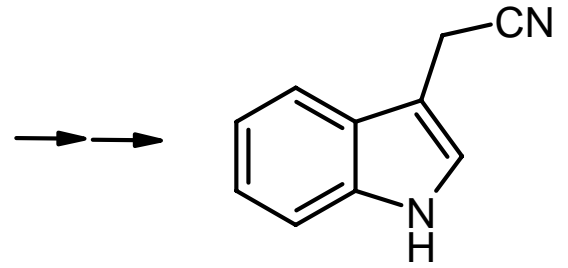

48

Abbildung 41: Nach HöFLE et al. ${ }^{137}$ postulierte Biosynthese von 3-(Cyanomethyl)indol (48).

Eine Literaturrecherche nach der an C-6 von 45 befindlichen Seitenkette ergab, dass C-3substituierte (Dihydroxymethylbutyl)indole als Pflanzenmetabolite bekannt sind. So konnten ACHENBACH et al. aus der Rinde des afrikanischen Baums Hexalobus crispiflorus die Hexalobuline $\mathbf{5 0}$ und $\mathbf{5 1}$ isolieren, wobei deren absolute Stereochemie mittels CDSpektroskopie aufgeklärt werden konnte. ${ }^{138}$ Interessanterweise zeigte $\mathbf{5 0}$ gute bis sehr gute Aktivität gegen verschiedene Pilzarten, während $\mathbf{5 1}$ nahezu keine fungizide Wirkung aufwies.

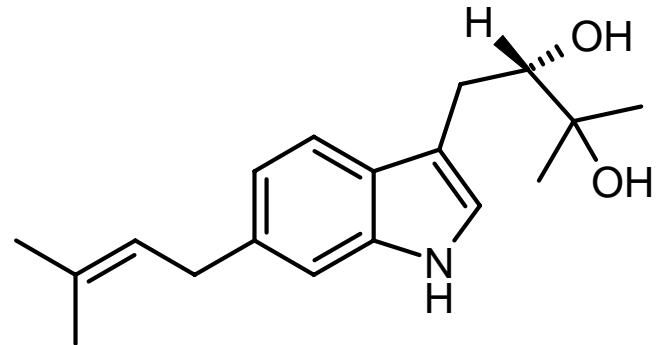

50

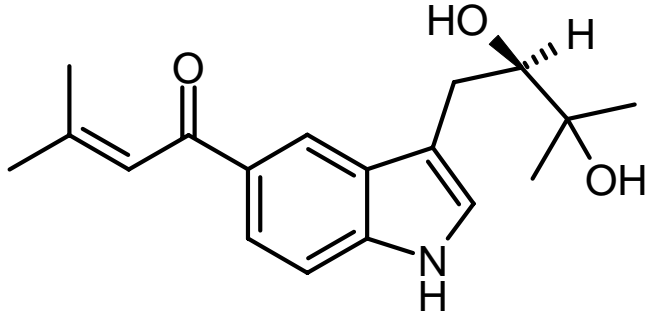

51

Abbildung 42: Aus Hexalobus crispiflorus isolierte Hexalobuline 50 und 51.

Bei den in der gleichen Studie erhaltenen 1',2'-epoxidierten Strukturen von $\mathbf{5 0}$ und $\mathbf{5 1}$ könnte es sich um biosynthetische Vorläufer handeln. Für die monoterpenoide Seitenkette der Verbindung 45 kann der Mevalonatweg ${ }^{88}$ als Ursprung vermutet werden, wobei ein Aufbau über den von ROHMER et al. postulierten Nicht-Mevalonatweg, ${ }^{139}$ bei dem Isoprenoide aus Kohlenhydraten hervorgehen, ebenso in Frage käme.

Zur Klärung der absoluten Stereochemie von $\mathbf{4 5}$ wurde beschlossen, Kristallisationsversuche durchzuführen, mit dem Ziel, 45 röntgenographischen Untersuchungen zugänglich zu machen. Um für diesen Zweck ausreichende Substanzmengen zu erhalten und zugleich die Isolierung der im Screening auffälligen Substanz zu ermöglichen, wurde beschlossen, Stamm 
Gö GS56 im 10 L-Maßstab zu kultivieren. Zur Ausbeuteoptimierung von 45 wurde vorher eine Nährmedienvariation durchgeführt, wobei Gö GS56 in vier Ansätzen im Medium M2 unter Zusatz von je $0.5 \mathrm{~g} / \mathrm{L}$ Tryptophan, Glutamin, Tryptophan zusammen mit Glutamin sowie Glycerin kultiviert wurde. Durch die Veränderung des Aminosäureangebots sowie durch das Bereitstellen einer zusätzlichen Kohlenstoffquelle sollte die Biosyntheseleistung des Stammes hinsichtlich der Produktion von $\mathbf{4 5}$ gesteigert werden. Es zeigte sich jedoch, dass 45 lediglich in reinem sowie glycerinhaltigem M2-Medium gebildet wurde. Da die Verwendung des letzteren leicht gesteigerte Ausbeuten zu versprechen schien, wurde die Kultivierung in $10 \mathrm{~L}$ M2-Medium mit $0.5 \mathrm{~g} / \mathrm{L}$ Glycerin in einem Rührblattfermenter durchgeführt. Aus diesem Ansatz konnte 45 in einer Ausbeute von $1.1 \mathrm{mg} / \mathrm{L}$ isoliert werden. Bisherige Kristallisationsversuche verliefen allerdings nicht erfolgreich. Neben $\mathbf{4 5}$ konnten in diesem Zusammenhang jedoch zwei weitere Sekundärmetaboliten isoliert werden, die in den folgenden Abschnitten beschrieben werden.

\subsection{Dimethyluridin (46)}

46 fiel im Dünnschichtchromatogramm durch UV-Löschung bei $254 \mathrm{~nm}$ sowie durch Violettfärbung beim Besprühen mit Orcin auf. Die Substanz konnte als farbloser Feststoff in einer Ausbeute von $0.1 \mathrm{mg} / \mathrm{L}$ isoliert werden. 46 zeigte im ESI-Massenspektrum ein Ion bei $\mathrm{m} / \mathrm{z}=271\left([\mathrm{M}-\mathrm{H}]^{-}\right)$, aus dem per Hochauflösung die Summenformel $\mathrm{C}_{11} \mathrm{H}_{16} \mathrm{~N}_{2} \mathrm{O}_{6}$ ermittelt werden konnte. Dem ${ }^{1} \mathrm{H}-\mathrm{NMR}$-Spektrum waren zwei Signale bei $\delta_{\mathrm{H}}=5.77$ und $8.12 \mathrm{zu}$ entnehmen, die für je ein Proton integrierten und eine Kopplungskonstante von ${ }^{3} J_{\mathrm{HH}}=8.1 \mathrm{~Hz}$ aufwiesen. Zusätzlich waren vier weitere Methingruppen $\left(\delta_{\mathrm{H}}=3.82,4.11,4.17\right.$ und 5.92) vorhanden, die aufgrund ihrer chemischen Verschiebungen und anhand des charakteristischen Kopplungsmusters einer Pentose-Zuckereinheit zugeordnet wurden. Ein Vergleich der ${ }^{1} \mathrm{H}$ und ${ }^{13} \mathrm{C}$-NMR-Daten mit Literaturwerten ${ }^{140}$ ließ auf das Vorliegen eines Uridin-Derivats schließen. Allerdings fehlten die für die Hydroxymethylengruppe an C-5' der Riboseeinheit typischen Signale. Stattdessen fanden sich zusätzliche ${ }^{1} \mathrm{H}-\mathrm{NMR}$-Signale für eine Methylgruppe $\left(\delta_{\mathrm{H}}=1.27\right)$ sowie eine $N$-Methylgruppe $\left(\delta_{\mathrm{H}}=3.28\right)$. Mit Hilfe von 2D-NMRSpektroskopie ( ${ }^{1} \mathrm{H},{ }^{1} \mathrm{H}-\mathrm{COSY}$, HSQC und HMBC) gelang schließlich die Zuordnung der Signale und es konnte ein Strukturvorschlag für $\mathbf{4 6}$ abgeleitet werden. 
<smiles></smiles>

46<smiles></smiles>

52

46 wurde in der Literatur bislang nicht beschrieben. Während das 3-N-Methylderivat von Uridin lediglich als Syntheseprodukt bekannt ist, ${ }^{141,142,143}$ gibt es einige Beispiele für 5'substituierte Uridine als biologisch hochaktive Naturstoffe. So zeigt das erstmals 1973 aus Streptomyces griseolus NRRL 3739 isolierte Sinefungin (52) ${ }^{144}$ neben antifungischer, antiviraler und antiparasitärer Wirkung auch eine selektive inhibitorische Aktivität gegenüber der Methylierung von RNA in Viren und eukaryotischen Organismen, nicht jedoch bei Bakterien. $^{145}$

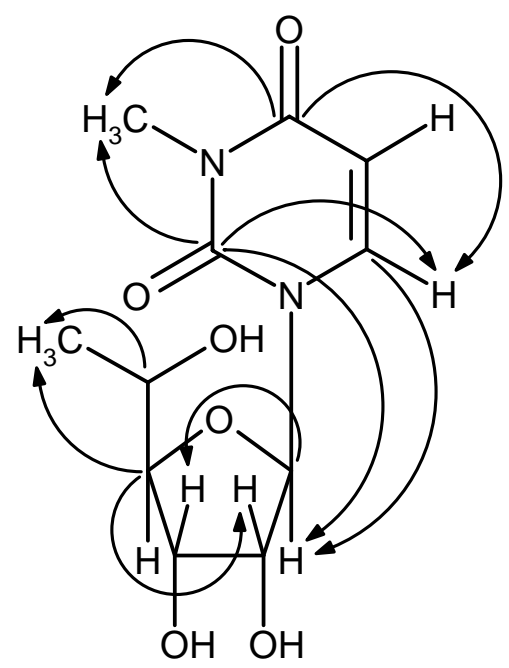

Abbildung 43: Ausgewählte HMBC-Kopplungen von 46.

Die strukturell komplexer aufgebauten Tunicamycine (53), die als Sekundärmetaboliten von Streptomyces lysosuperificus sp. gefunden wurden, ${ }^{146}$ sind reversible Hemmstoffe von Polyprenolphosphat- $N$-Acetylhexosamin-1-phosphat-Translokasen und werden zur Unter- 
drückung der $N$-Glykosylierung im Zuge posttranslationaler Modifikationen bei der Biosynthese von Proteinen eingesetzt. ${ }^{147}$

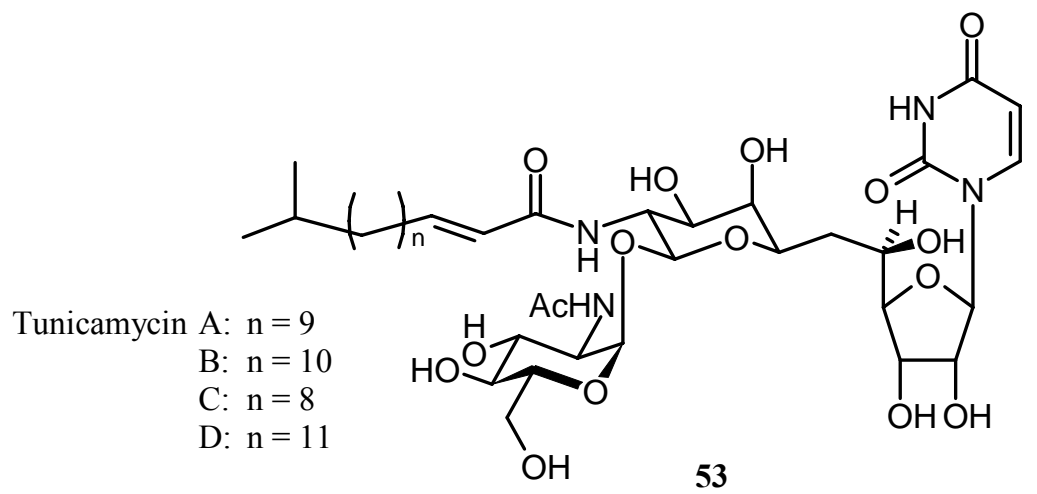

\subsection{Thioaurin (47)}

47 färbt mit Anisaldehyd intensiv dunkelgrün an und führte dazu, dass der Stamm Gö GS56 im chemischen Screening zur Weiterbearbeitung selektiert wurde. Aus dem Kulturfiltrat eines 10 L-Ansatzes konnte 47 in einer Ausbeute von $0.7 \mathrm{mg} / \mathrm{L}$ als gelber Feststoff isoliert werden. Die Substanz zeigte im ESI-Massenspektrum ein Ion bei $\left.\mathrm{m} / \mathrm{z}=213([\mathrm{M}-\mathrm{H}]]^{-}\right)$. Das ${ }^{1} \mathrm{H}-\mathrm{NMR}-$ Spektrum wies einen doppelten Signalsatz auf, wobei die zugehörigen Integralhöhen im Verhältnis 4:3 zueinander standen. Ebenso zeigte das ${ }^{13} \mathrm{C}-\mathrm{NMR}-$ Spektrum (Abbildung 45) das Vorliegen eines Substanzgemisches an. Aus den erhaltenen Daten konnte auf das Vorhandensein einer $N$-Methylgruppe $\left(\delta_{\mathrm{H}}=3.46 \mathrm{bzw}\right.$. 3.17) sowie zweier Methingruppen $\left(\delta_{\mathrm{H}}=8.13\right.$ bzw. 8.40 und $\delta_{\mathrm{H}}=7.26$ bzw. 7.30) geschlossen werden. Letztere sollten aufgrund ihrer chemischen Verschiebungen an $\mathrm{sp}^{2}$-hybridisierten Kohlenstoffatomen gebunden vorliegen. Eine Suche in Antibase ${ }^{148}$ mit der ermittelten Molmasse sowie den aus der NMRSpektroskopie erhaltenen Strukturelementen ergab, dass es sich bei 47 um Thioaurin (47) handeln musste.

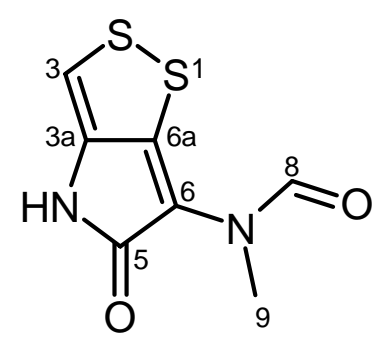

47

47 wurde als Reinsubstanz bereits 1953 beschrieben, ${ }^{149}$ eine exakte Strukturzuordnung gelang jedoch erst im Jahre 1969. ${ }^{150,151}$ Im Zuge der letztgenannten Arbeiten war 47 als Metabolit 
eines Streptomyceten-Stammes isoliert worden, welcher in einem biologischen Screening durch starke Hemmwirkung gegenüber Neisseria-Stämmen sowie anderen gram-negativen Mikroorganismen auffiel. Untersuchungen an reinem Thioaurin (47) ergaben neben starker antibiotischer Wirkung gegen $N$. gonorrhoeae, $N$. meningitidis sowie $N$. catarrhalis zusätzlich ausgeprägte Aktivität gegen die pathogenen Bakterien Staphylococcus aureus, Haemophilus influenzae und Bordetella pertussis.

Das Auftreten doppelter Signalsätze in den NMR-Spektren ist auf das Vorliegen zweier Rotationsisomere von 47 zurückzuführen. Aufgrund des partiellen Doppelbindungscharakters und der damit einhergehenden hohen Rotationsbarriere für die C-N-Bindung bestehen beide in Abbildung 44 dargestellte Isomere hinreichend lange, um auf der NMR-Zeitskala aufgelöst zu werden. ${ }^{152,153,154}$
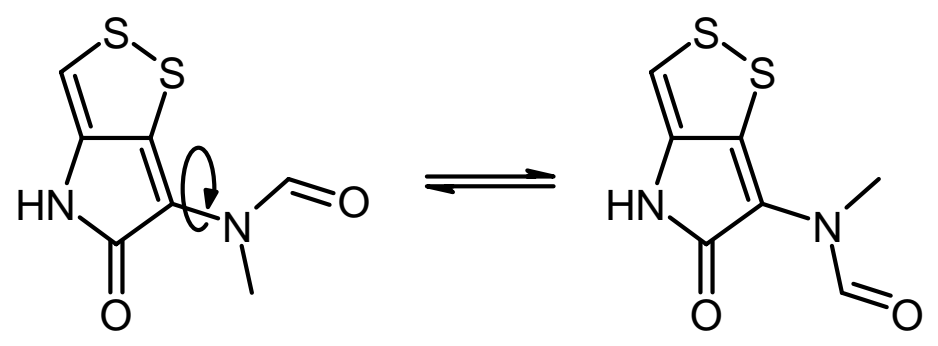

Abbildung 44: Rotationsisomere von 47, die zu einem doppelten NMR-Signalsatz führen.

Die Relevanz dieses Effektes wird dadurch bestätigt, dass die Differenz der NMRResonanzen für die beiden Isomere mit zunehmendem Abstand von der C-N-Bindung abnimmt (Tabelle 5).

Tabelle 5: Differenz von $\delta_{\mathrm{C}}$ der Rotationsisomere von 47 in Abhängigkeit des Abstands von der C-N-Bindung.

\begin{tabular}{|c|c|}
\hline Position & $\Delta \delta_{\mathrm{C}}[\mathrm{ppm}]$ \\
\hline C-9 & 4.1 \\
\hline C-6 & 2.5 \\
\hline C-8 & 1.1 \\
\hline C-6a & 0.3 \\
\hline C-3 & 0.3 \\
\hline C-5 & 0.2 \\
\hline C-3a & 0.2 \\
\hline
\end{tabular}


Untersuchungen zur Biosynthese von 47 wurden bislang nicht durchgeführt, es kann aber vermutet werden, dass ein Aufbau über die Kondensation zweier Cysteineinheiten unter Umlagerung und anschließender $N$-Methylierung bzw. $N$-Acetylierung erfolgt. Eine Zufütterung von ${ }^{13} \mathrm{C}$-markiertem Cystein könnte hier weitere Einblicke liefern.

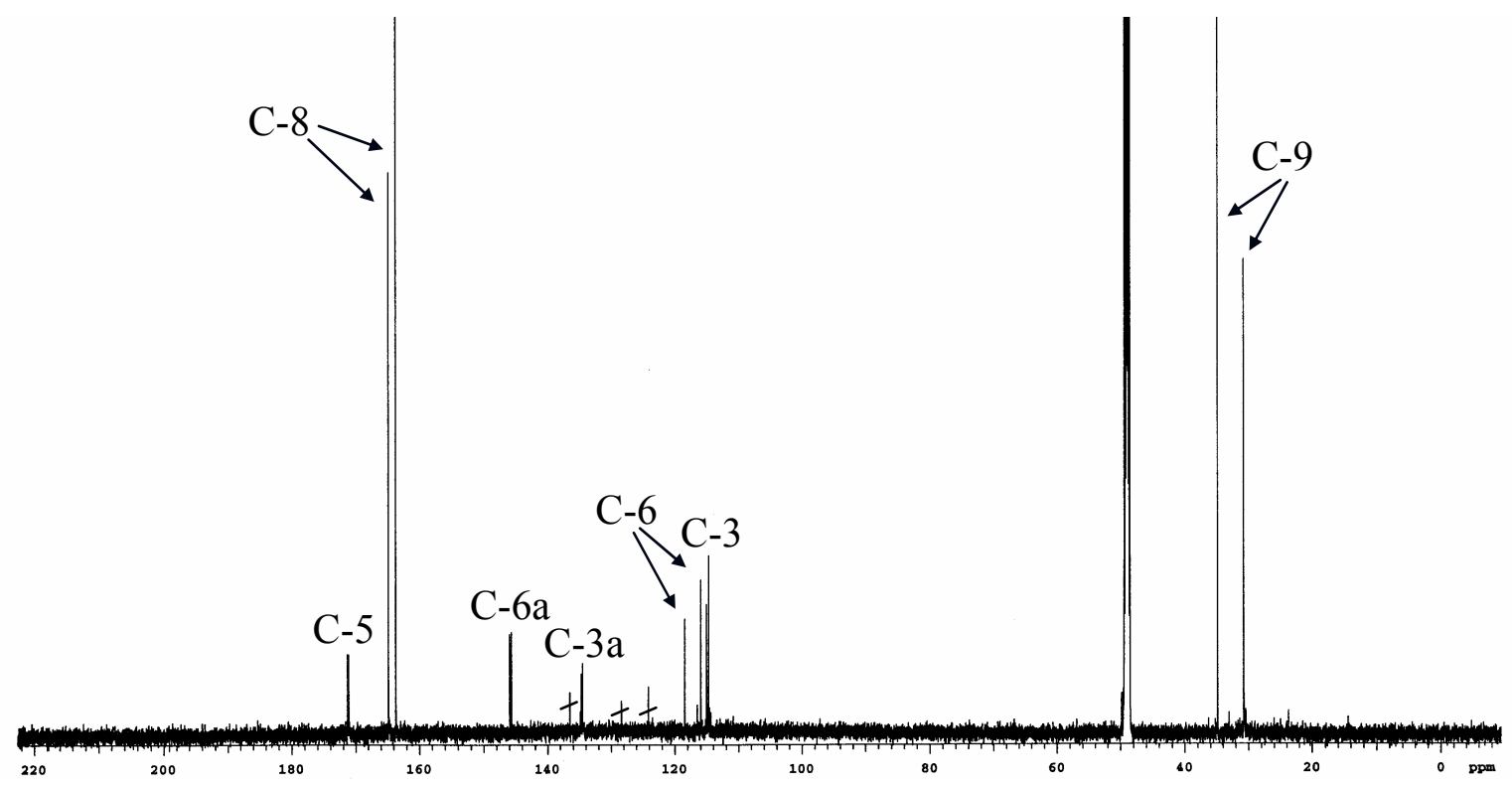

Abbildung 45: ${ }^{13} \mathrm{C}-\mathrm{NMR}-$ Spektrum von 47 (150.8 MHz, $\left.\mathrm{CD}_{3} \mathrm{OD}\right)$.

\subsection{Biologische Aktivität der Metaboliten}

Alle aus Stamm Gö GS56 isolierten Substanzen wurden auf antimikrobielle Aktivität gegenüber Escherichia coli, Bacillus subtilis, Staphylococcus aureus und Candida albicans untersucht. Dabei führte lediglich Thioaurin (47) zur Ausbildung eines Hemmhofs bei Staphylococcus aureus $(\varnothing=23 \mathrm{~mm})$, die übrigen Tests fielen negativ aus. 


\section{Actinomyces sp. Stamm Gö TS15}

Der Stamm Gö TS15 fiel im Screening durch eine bei $254 \mathrm{~nm}$ UV-löschende und bei $366 \mathrm{~nm}$ hellblau fluoreszierende Zone auf, die mit Anisaldehyd in der Wärme intensiv dunkelbraun und mit Ehrlich violett anfärbte. Aus einem 4 L-Kultivierungsansatz konnten $11.8 \mathrm{mg} / \mathrm{L} 54$ in Form farbloser Kristalle isoliert werden. Die Verbindung wies im ${ }^{1}$ H-NMR-Spektrum zwei Singuletts auf, die anhand ihrer Intensitäten als Methylengruppe $\left(\delta_{\mathrm{H}}=4.48\right)$ und Methingruppe $\left(\delta_{\mathrm{H}}=6.23\right)$ identifiziert werden konnten. Zusammen mit der durch EIMassenspektrometrie ermittelten Molmasse von $\mathrm{m} / \mathrm{z}=128$ konnte 54 per Datenbanksuche in Antibase $^{148}$ als 2,5-Bis(hydroxymethyl)furan (54) identifiziert werden. Ein Vergleich mit Literaturdaten bestätigte die Zuordnung. ${ }^{155}$

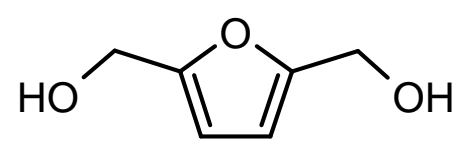

54

Da 54 sowohl im Rahmen dieser Arbeit als auch bei anderen im Medium M2 durchgeführten Fermentationen $^{156,157,158}$ sehr häufig isoliert werden konnte, kann nicht ausgeschlossen werden, dass es sich hierbei um einen Nährmedienbestandteil oder ein Biotransformationsprodukt eines solchen handelt. Aus dem Stamm Gö TS15 konnten weiterhin die bekannten Metaboliten 2,3-Dihydroxybenzoesäure (55), Hydroxymethylmaltol (56) und 2-Aminobenzamid (57) isoliert werden.

\subsection{2,3-Dihydroxybenzoesäure (55)}

Der gelbbraune Feststoff 55 fiel im Dünnschichtchromatogramm durch Absorption bei $254 \mathrm{~nm}$ sowie hellblaue Fluoreszenz bei $366 \mathrm{~nm}$ auf. Er zeichnete sich durch hohe Polarität aus, was sich in einem $\mathrm{R}_{\mathrm{f}}$-Wert von 0.4 bei Verwendung des Laufmittelgemischs Dichlormethan / Methanol 2:1 widerspiegelt. 55 konnte in einer Ausbeute von $2 \mathrm{mg} / \mathrm{L}$ isoliert werden und zeigte im EI-Massenspektrum das Ion höchster Masse bei $\mathrm{m} / \mathrm{z}=154$. Im ${ }^{1} \mathrm{H}$ NMR-Spektrum fanden sich charakteristische Signale für drei benachbarte aromatische Protonen $\left(\delta_{\mathrm{H}}=6.60,6.85\right.$ und 7.35). Das ${ }^{13} \mathrm{C}$-NMR-Spektrum zeigte die Existenz einer Carboxylgruppe $\left(\delta_{\mathrm{C}}=167.6\right)$ sowie zweier $O$-substituierter quartärer aromatischer Kohlen- 
stoffatome $\left(\delta_{\mathrm{C}}=146.4\right.$ und 151.3) an. Durch Literaturvergleiche der erhaltenen Daten konnte 55 als 2,3-Dihydroxybenzoesäure (55) identifiziert werden.<smiles>O=C(O)c1cccc(O)c1O</smiles>

55

Bei 55 handelt es sich um einen weit verbreiteten Metaboliten, der bereits als Stoffwechselprodukt der filamentösen Pilze Aspergillus niger ${ }^{159}$ und Claviceps paspali ${ }^{160}$ identifiziert werden konnte. Anhand von Fütterungsversuchen mit radioaktiv markierten Vorläufern konnte in beiden Fällen Tryptophan als biosynthetischer Ursprung gefunden werden. ${ }^{161,162}$ Als Metabolit von Streptomyces griseus, ${ }^{163}$ Aerobacter aerogenes ${ }^{164}$, Bacillus subtilis sowie dem stickstofffixierenden Bakterium Azotobacter vinelandii ${ }^{165}$ war 55 bisher interessanterweise nur bei Fermentationen unter Eisenmangelbedingungen aufgetreten. Im Fall von Aerobacteraerogenes sowie Escherichiacoli konnte zudem Chorismat als biosynthetischer Vorläufer von 55 bestätigt werden. ${ }^{166,167}$ Im Jahr 1995 schließlich wurde 55 als antioxidativ wirksame Substanz von Penicillium roquefortii gefunden. ${ }^{168}$

\subsection{Weitere Metaboliten}

Aus dem Kulturfiltrat von Stamm Gö TS15 konnte die bei $254 \mathrm{~nm}$ löschende, mit Orcin in der Wärme intensiv rot anfärbende Verbindung 56 in einer Ausbeute von $2.3 \mathrm{mg} / \mathrm{L}$ isoliert werden. Im EI-Massenspektrum zeigte 56 ein Ion höchster Masse bei $\mathrm{m} / \mathrm{z}=142$, während dem ${ }^{1} \mathrm{H}-\mathrm{NMR}$-Spektrum Signale zweier miteinander koppelnder Methingruppen $\left(\delta_{\mathrm{H}}=6.40\right.$ und 8.00) sowie ein für zwei Protonen integrierendes Singulett $\left(\delta_{\mathrm{H}}=4.60\right) \mathrm{zu}$ entnehmen waren. Mittels eines ${ }^{13} \mathrm{C}-\mathrm{NMR}-S p e k t r u m s$ konnte zusätzlich auf die Existenz einer Ketogruppe $\left(\delta_{\mathrm{H}}=176.1\right)$ im Molekül geschlossen werden. Eine Suche mit der Datenbank Antibase $^{148}$ ergab, dass es sich bei 56 um Hydroxymethylmaltol (56) handeln musste. Diese Verbindung ist in der Literatur bereits als Metabolit des filamentösen Pilzes Talaromyces flavus bekannt. ${ }^{169}$ 
<smiles>O=c1ccoc(CO)c1O</smiles>

56<smiles>NC(=O)c1ccccc1N</smiles>

57

Weiterhin konnte aus Gö TS15 die im Dünnschichtchromatogramm UV-löschende (254 nm) sowie fluoreszierende $(366 \mathrm{~nm})$ und mit Ehrlich charakteristisch gelb anfärbende Verbindung 57 in einer Ausbeute von $1.1 \mathrm{mg} / \mathrm{L}$ isoliert werden. Im ${ }^{1} \mathrm{H}-\mathrm{NMR}-$ Spektrum waren für einen ortho-disubstituierten Aromaten typische Signale zu erkennen. In Kombination mit dem durch EI-Massenspektrometrie bestimmten Molekulargewicht von $136 \mathrm{~g} / \mathrm{mol}$ konnte 57 als 2-Aminobenzamid (57) identifiziert werden. Diese Substanz konnte schon mehrmals aus Streptomyces-Stämmen isoliert werden, ${ }^{156,170}$ wobei jedoch nicht ausgeschlossen werden kann, dass es sich um eine Nährmedienkomponente handelt. 


\section{Actinomyces sp. Stamm Gö TS17}

Im chemischen Screening fiel der Stamm Gö TS17 auf dem Dünnschichtchromatogramm durch eine bei Kultivierung in Hafermedium auftretende, UV-Licht der Wellenlänge $254 \mathrm{~nm}$ löschende sowie bei $366 \mathrm{~nm}$ fluoreszierende Zone auf, die mit Anisaldehyd in der Wärme orange anfärbte. Diese Substanz wurde allerdings bei einer Fermentation im 4 L-Maßstab nicht reproduziert. Stattdessen konnten $0.8 \mathrm{mg} / \mathrm{L}$ Maltol (58) isoliert werden, welches anhand des charakteristischen Fragmentmusters im EI-Massenspektrum identifiziert werden konnte. Ein Vergleich der erhaltenen NMR-Daten mit Literaturwerten bestätigte die Annahme. ${ }^{156}$ Hier handelt es sich höchstwahrscheinlich um einen Bestandteil des verwendeten Nährmediums. Im Mycelextrakt von Stamm Gö TS17 wurden weiterhin der Metabolit Grincamycin (59) gefunden.

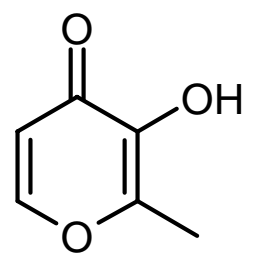

58

\subsection{Grincamycin (59)}

Auf dem Dünnschichtchromatogramm des Mycelextrakts waren zusätzlich mehrere gelbe Zonen zu erkennen, die UV-Licht bei $254 \mathrm{~nm}$ absorbierten und mit Anisaldehyd in der Wärme bräunlich anfärbten. Mittels Chromatographie an Kieselgel, RP-18 und Sephadex ${ }^{\circledR}$ LH-20 gelang zwar eine weitgehende Trennung dieser Substanzen, eine Isolierung bis auf die Stufe der Reinstoffe war jedoch nicht möglich. Erst die wiederholte Anwendung semipräparativer HPLC brachte hier Fortschritte. Da die einzelnen Fraktionen durchgehend in sehr geringen Mengen vorlagen, war allerdings nur die vollständige Isolierung und Charakterisierung der Hauptkomponente 59 erfolgreich, die als gelber Feststoff in einer Ausbeute von $0.2 \mathrm{mg} / \mathrm{L}$ anfiel. Aufgrund der großen Ähnlichkeit in den ${ }^{1} \mathrm{H}-\mathrm{NMR}-\mathrm{Spektren}$ aller Substanzen kann jedoch davon ausgegangen werden, dass es sich um strukturell nah verwandte Verbindungen handelt.

59 wies im ESI-Massenspektrum ein Ion bei $\mathrm{m} / \mathrm{z}=961\left([\mathrm{M}+\mathrm{Na}]^{+}\right)$auf, aus dem per Hochauflösung die Summenformel $\mathrm{C}_{49} \mathrm{H}_{62} \mathrm{O}_{18}$ bestimmt werden konnte. Diese führte bei einer

Datenbanksuche zusammen mit den im ${ }^{1} \mathrm{H}-\mathrm{NMR}-$ Spektrum vorhandenen für Benz[a]anthra- 
chinon-Derivate typischen Signalen bei $\delta_{\mathrm{H}}=6.40,6.87,7.59$ und 7.87 zur Identifikation von

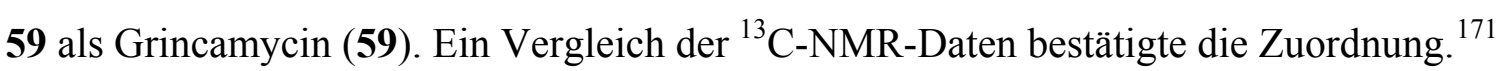

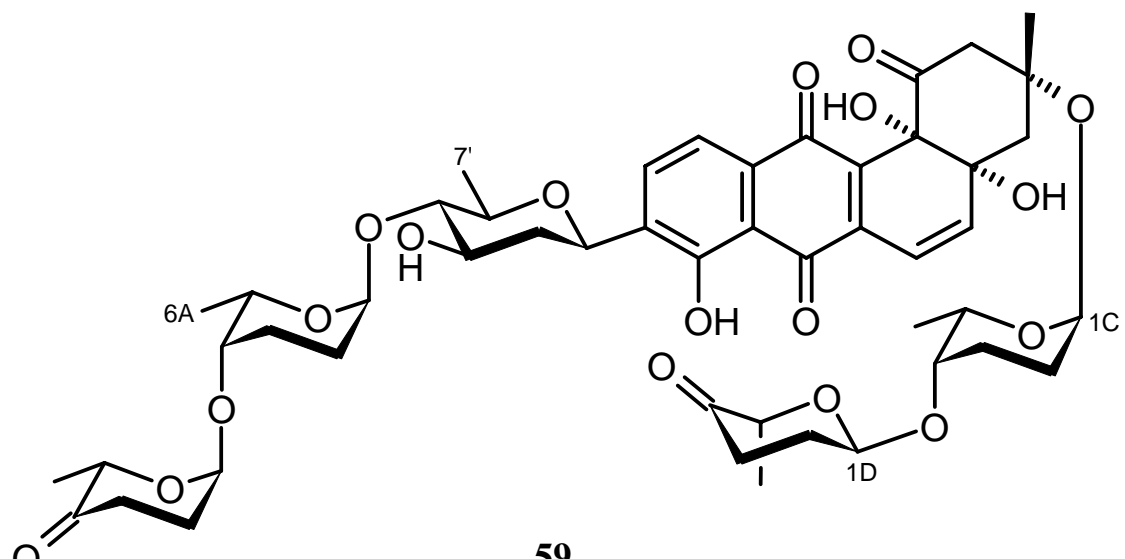

59 wurde erstmals 1987 als Sekundärmetabolit von Streptomyces griseoincarnatus beschrieben und zeichnet sich durch antibiotische Aktivität gegen gram-positive Bakterien wie Staphylococcus aureus, Micrococcus luteus und Bacillus cereus aus. Zusätzlich konnte eine ausgeprägte cytostatische Wirkung gegenüber P388-Leukämiezellen aus Mäusen gefunden werden $\left(\mathrm{IC}_{50}=13 \mathrm{ng} / \mathrm{mL}\right)$. Nach der von ZEECK et al. vorgeschlagenen Klassifizierung ${ }^{172}$ ist $\mathbf{5 9}$ als Angucyclin zu bezeichnen, da es im Gegensatz zu den Angucyclinonen über $O$-glykosidische Bindungen verfügt. Zu dieser Gruppe zählen bis heute mehr als 100 Verbindungen, ${ }^{173,174}$ die ausschließlich mikrobiellen Ursprungs sind und von denen kürzlich in der Arbeitsgruppe ZEECK einige bislang unbekannte Vertreter gefunden werden konnten. ${ }^{175,176,177}$ Neben antibiotischer und antitumoraler Aktivität findet man unter den Angucyclinen auch Substanzen mit enzyminhibitorischer (z.B. Aquayamycin (60)), thrombozytenaggregationshemmender (vor allem Antibiotika aus der PI-080-Serie ${ }^{178}$ ) sowie antiviraler (z.B. Saquayamycin ${ }^{179}$ ) Wirkung. Die Biosynthese von 59 verläuft vermutlich ausgehend von der Startereinheit Acetyl-CoA und neunmaliger Kettenverlängerung durch Malonyl-CoA zunächst analog der von Urdamycin G (61), wobei es durch unterschiedliche Regio- und Substratspezifitäten der beteiligten Glycosyltransferasen $\mathrm{zu}$ verschiedenen Endprodukten kommt (Abbildung 46). 


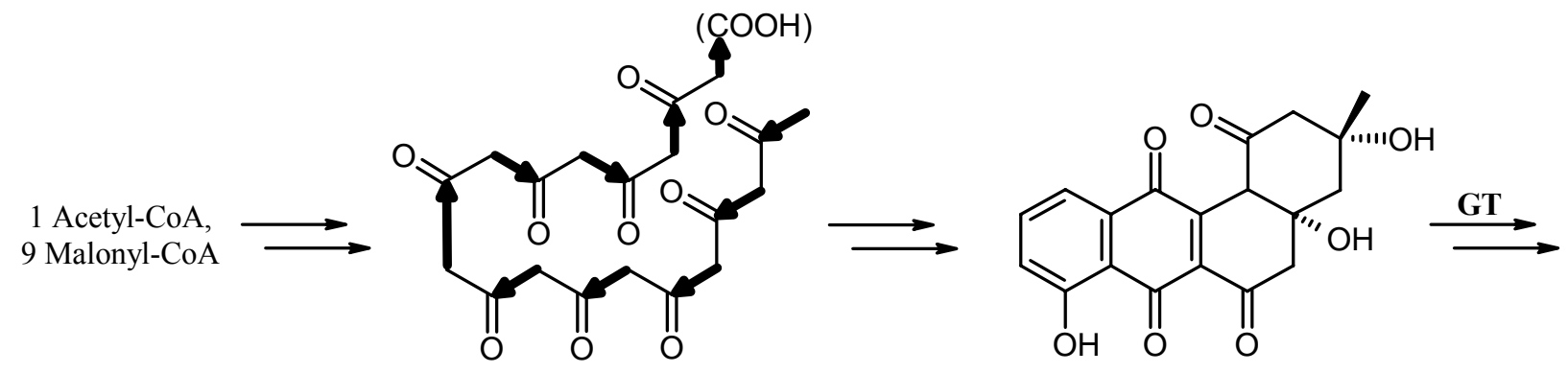

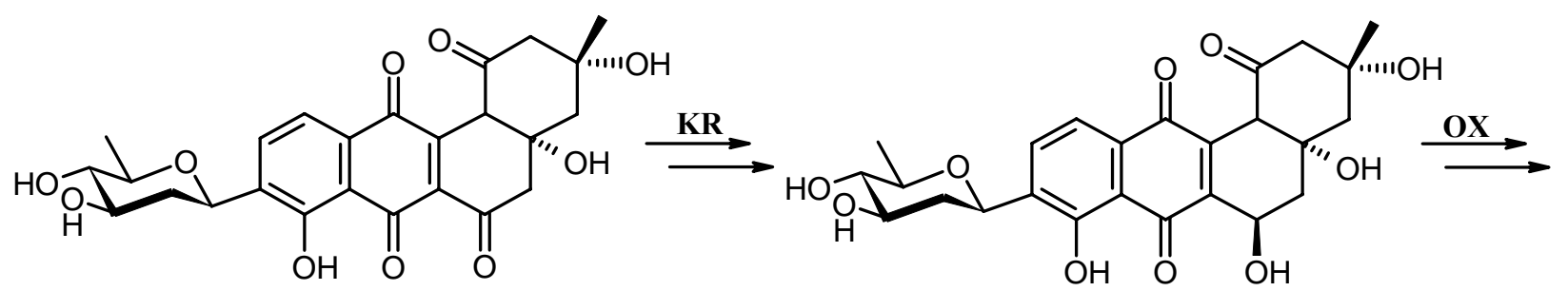

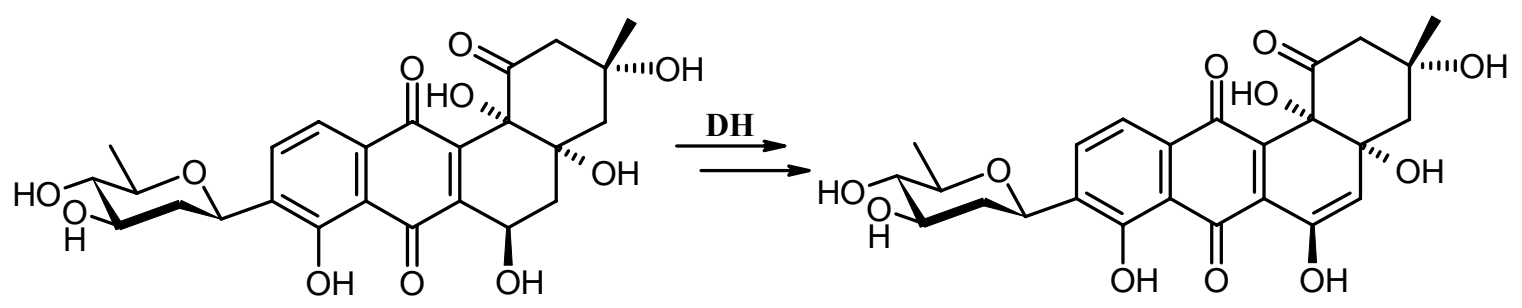

60

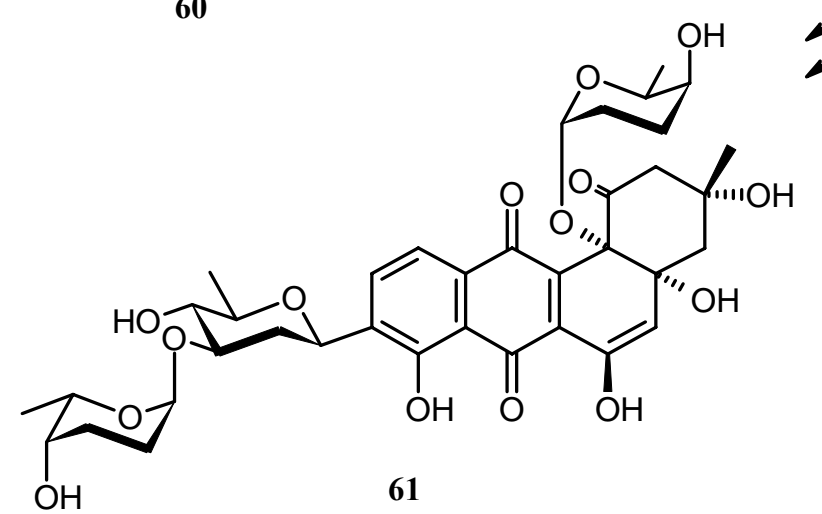

Abbildung 46: Hypothetischer Biosyntheseweg von Angucyclinen (mit GT= Glycosyltransferase, $\mathrm{KR}=$ Ketoreduktase, $\mathrm{DH}=$ Dehydrase, $\mathrm{OX}=$ Oxygenase). 


\section{Actinomyces sp. Stamm Gö TS18}

Der Stamm Gö TS18 fiel im chemischen Screening durch eine bei $254 \mathrm{~nm}$ UV-löschende, mit Anisaldehyd in der Wärme blaugrün anfärbende Zone auf. Aus einem 10 L-Fermentationsansatz im Medium M2 konnte das bekannte Antibiotikum Virginiamycin $M_{1}$ (62) isoliert werden. Weiterhin wurden die bislang als Naturstoffe nicht beschriebenen Metaboliten 16Dihydro-Virginiamycin $\mathrm{M}_{1}$ (63) und Dimethylaminophenylhydroxy-propionsäureamid (64) sowie die bereits bekannten Verbindungen Phenylacetamid (65), 2'-O-Methyluridin (66), 2- und 4-Aminobenzamid (57 bzw. 67) gefunden.

\subsection{Virginiamycin $M_{1}(62)$}

Die in einer Ausbeute von $1.5 \mathrm{mg} / \mathrm{L}$ als kristalliner Feststoff erhaltene Substanz 62 zeigte im ESI-Massenspektrum ein Ion bei $\mathrm{m} / \mathrm{z}=524\left([\mathrm{M}-\mathrm{H}]^{-}\right)$. Im ${ }^{1} \mathrm{H}-\mathrm{NMR}-$ Spektrum waren vier Methylgruppen $\left(\delta_{\mathrm{H}}=0.94,0.97,1.09\right.$ und 1.55), fünf Methylengruppen $\left(\delta_{\mathrm{H}}=2.69-4.31\right)$, elf Methingruppen $\left(\delta_{\mathrm{H}}=2.01,4.78-7.78\right)$ sowie zwei durch $\mathrm{D}_{2} \mathrm{O}$ austauschbare Protonen $\mathrm{zu}$ erkennen. Auffällig war ein isoliertes Singulett bei $\delta_{\mathrm{H}}=7.78$, das einem Heterocyclus zugeordnet wurde. Das ${ }^{13} \mathrm{C}$-NMR-Spektrum zeigte die Existenz von 28 Kohlenstoffatomen an, wobei anhand der typischen chemischen Verschiebungen eine Ketogruppe $\left(\delta_{C}=200.9\right)$ sowie drei Ester-/Amidgruppen $\left(\delta_{\mathrm{C}}=160.2,160.8\right.$ und 167.0) zuzuordnen waren. Eine Datenbanksuche mit Antibase ${ }^{148}$ ergab, dass es sich bei 62 um das Macrolacton-Antibiotikum Virginiamycin $M_{1}$ (62) handelte. Ein Vergleich der NMR-Daten mit Literaturwerten bestätigte die Zuordnung. ${ }^{180,181}$

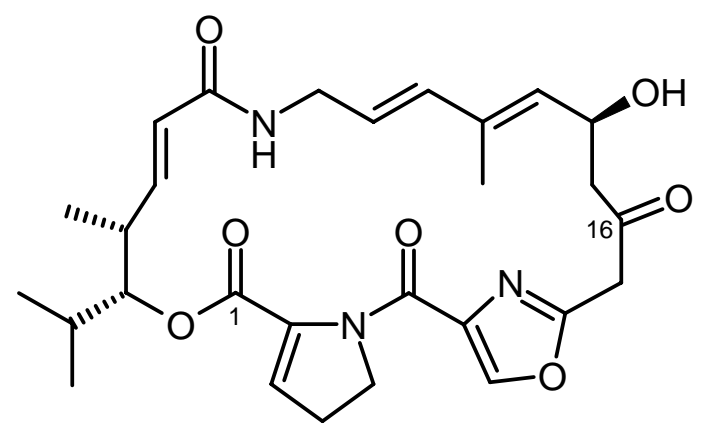

62

62 ist in der Literatur auch unter den Namen Mikamycin A, Ostreogrycin A, Pristinamycin IIA, Streptogramin A, PA 114 A1 und Vernamycin A bekannt, doch konnte 
sich im Lauf der Zeit vor allem die Bezeichnung Virginiamycin $\mathrm{M}_{1}$ durchsetzen. Die Verbindung hemmt die für die bakterielle Proteinbiosynthese wichtige Konformationsänderung des $24 \mathrm{~S}$ ribosomalen Proteins ${ }^{182}$ und wird daher als Antibiotikum in Form einer Mischung mit anderen Vertretern aus der Gruppe der Virginiamycine dem Futter von Wiederkäuern zur Leistungsförderung zugesetzt. In der Humanmedizin wird es als Synercid ${ }^{\circledR}$ zur Behandlung von Infektionen mit gram-positiven Keimen verwendet. ${ }^{183}$ Da Virginiamycine außerdem Antagonisten von Cholecystokinin und Gastrin sind, können sie bei Verdauungs- und Appetitstörungen sowie Magen-Darm-Erkrankungen eingesetzt werden. ${ }^{184}$

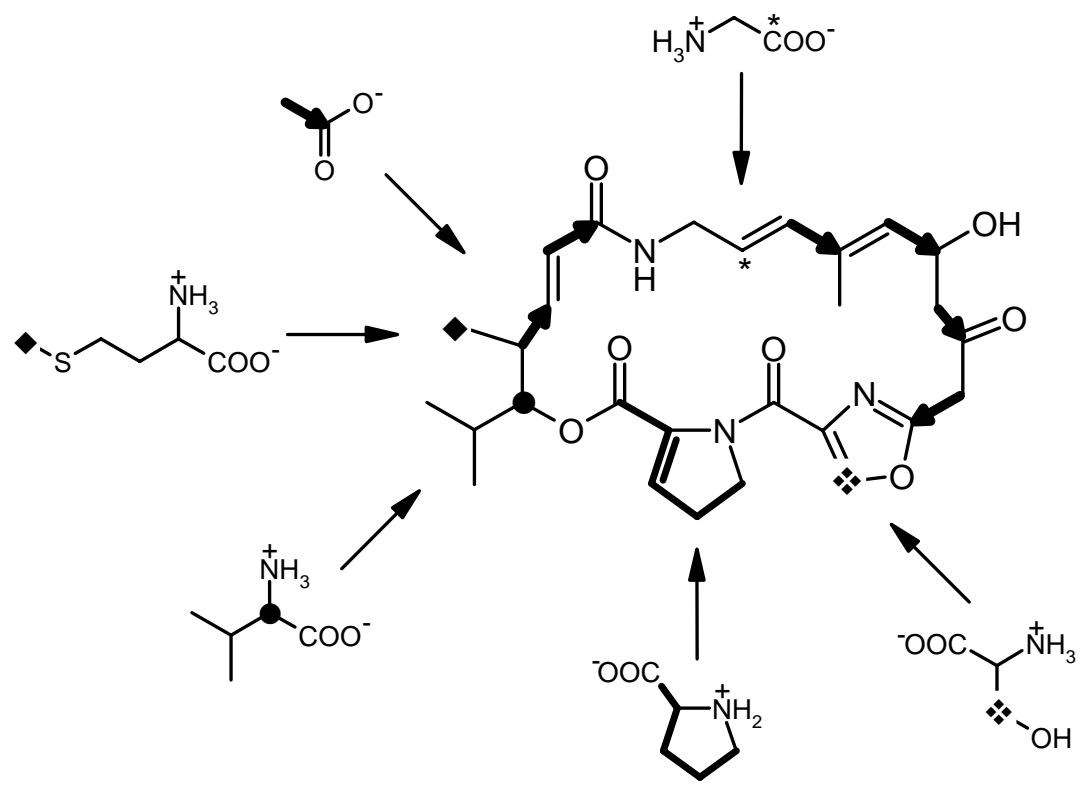

Abbildung 47: Biogeneseschema von 62 nach KINGSTON et al.

Anhand von Fütterungsexperimenten mit markierten Vorläufern konnte gezeigt werden, dass die Biogenese von 62 sowohl aus Bausteinen des Carbonsäure- wie des Aminosäure-Pools erfolgt (Abbildung 47). ${ }^{185,186}$ Dies lässt den Aufbau an einem gemischten NRPS/PKS-Multienzymkomplex vermuten. ${ }^{187}$

\subsection{6-Dihydro-Virginiamycin $M_{1}(63)$}

Die Substanz 63 war auf dem Dünnschichtchromatogramm hinsichtlich UV-Löschung und Anfärbeverhalten identisch mit 62, zeichnete sich aber durch eine höhere Polarität aus. 63 konnte in einer Ausbeute von $0.2 \mathrm{mg} / \mathrm{L}$ isoliert werden und zeigte im ESI-Massenspektrum ein Ion bei $\mathrm{m} / \mathrm{z}=550\left([\mathrm{M}+\mathrm{Na}]^{+}\right)$. Im ${ }^{1} \mathrm{H}-\mathrm{NMR}-$ Spektrum war im Vergleich $\mathrm{zu} 62$ ein zusätzliches Proton bei $\delta_{\mathrm{H}}=3.92$ vorhanden, während dem ${ }^{13} \mathrm{C}-\mathrm{NMR}-\mathrm{Spektrum}$ das Signal 
für die Ketogruppe an Position C-16 fehlte. Anhand von 2D-NMR-Experimenten $\left({ }^{1} \mathrm{H},{ }^{1} \mathrm{H}-\right.$ COSY, HMBC und HSQC) konnte ein Strukturvorschlag für $\mathbf{6 3}$ abgeleitet werden, demzufolge es sich um das 15,16-Dihydroderivat von Virginiamycin $\mathrm{M}_{1}$ (62) handelt. Ein Vergleich der NMR-Daten mit den für synthetisch dargestelltes 63 publizierten bestätigte die Zuordnung. ${ }^{188}$

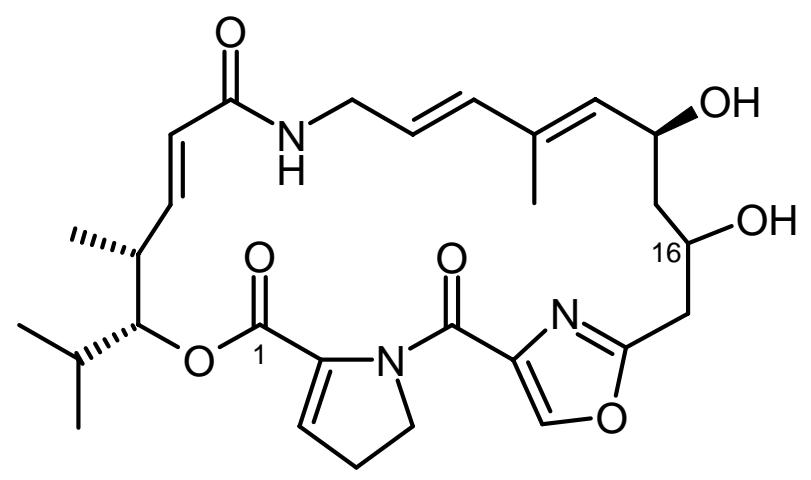

63

63 ist in der Literatur bisher nur als Produkt der Reduktion von 62 mit Natriumborhydrid beschrieben. Es wurde dort mit dem Ziel dargestellt, die biologischen Aktivitäten gegenüber 62 mittels struktureller Modifikationen zu verbessern. 63 zeigte jedoch im Bezug auf antimikrobielle und cholecystokinin-antagonistische Wirkung ein zur Leitsubstanz Virginiamycin $M_{1}$ (62) ähnliches Profil. ${ }^{188}$ Biosynthetisch ist die Entstehung von 63 vermutlich auf die zusätzliche Aktivität einer Ketoreduktase-Domäne im für die Bildung der Einheit C-15/C-16 verantwortlichen Modul zurückzuführen. Ob dies auf die Existenz zweier verschiedener Biosynthese-Gencluster im Produzentenstamm oder auf eine durch sterische Effekte in der Enzymstruktur begründete eingeschränkte Domänen-Aktivität zurückzuführen ist, bleibt derzeitig ungewiss.

Auf dem Dünnschichtchromatogramm des Kulturfiltrats von Gö TS18 fand sich eine Reihe weiterer Zonen, die ein ähnliches UV- und Anfärbeverhalten zeigten wie 62 bzw. 63. Da die entsprechenden Sustanzen sich mit Hilfe herkömmlicher chromatographischer Methoden (Kieselgel, RP-18 sowie Sephadex ${ }^{\circledR}$ LH-20) nicht bis zum Reinstoff auftrennen ließen, wurde dies mittels semipräparativer HPLC versucht. Es war hier jedoch nicht möglich, für eine vollständige Charakterisierung der Naturstoffe ausreichende Mengen zu isolieren. Anhand ${ }^{1}$ H-NMR- und massenspektrometrischer Daten kann allerdings auf hohe strukturelle Ähnlichkeit zu Virginiamycin $\mathrm{M}_{1}(\mathbf{6 2})$ geschlossen werden. 


\subsection{Dimethylaminophenylhydroxypropionsäureamid (64)}

64 konnte in einer Ausbeute von $0.6 \mathrm{mg} / \mathrm{L}$ als farbloser Feststoff isoliert werden und zeigte im ESI-Massenspektrum ein Ion bei $\mathrm{m} / \mathrm{z}=209\left([\mathrm{M}+\mathrm{H}]^{\dagger}\right)$, das per Hochauflösung zur Summenformel $\mathrm{C}_{11} \mathrm{H}_{16} \mathrm{~N}_{2} \mathrm{O}_{2}$ führte. Dem ${ }^{1} \mathrm{H}-\mathrm{NMR}$-Spektrum waren zwei magnetisch äquivalente Methylgruppen $\left(\delta_{\mathrm{H}}=2.85\right)$, eine diastereotope Methylengruppe $\left(\delta_{\mathrm{H}}=2.72\right.$ und 2.99), eine Methingruppe $\left(\delta_{\mathrm{H}}=4.14\right)$ sowie charakteristische Signale für zwei benachbarte aromatische Protonen $\left(\delta_{\mathrm{H}}=6.72\right.$ und 7.11) zu entnehmen. Aufgrund dieser Daten wurde vermutet, dass es sich um einen para-disubstituierten Aromaten handeln musste. $\mathrm{Im}{ }^{13} \mathrm{C}$-NMR-Spektrum zeigte 64 erwartungsgemäß 10 Signale, wobei eines $\left(\delta_{C}=179.9\right)$ einer Säure- bzw. Amidgruppe zugeordnet werden konnte. Datenbankrecherchen auf dieser Basis führten jedoch zu keinem Treffer, weswegen auf 2D-NMR-Spektren zurückgegriffen wurde. Anhand der in Abbildung 48 dargestellten COSY - und HMBC-Korrelationen konnte für 64 schließlich der folgende Strukturvorschlag abgeleitet werden.

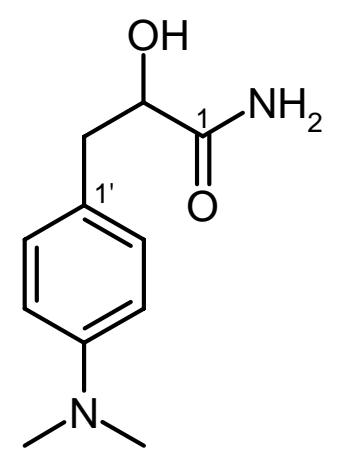

64

64 wurde in der Literatur bisher nicht beschrieben. Das Vorliegen eines biosynthetisch naheliegenderen para-substituierten Phenylalanin-Derivats kann jedoch insofern ausgeschlossen werden, als die für C-2 ermittelte chemische Verschiebung von $\delta_{\mathrm{C}}=74.2 \mathrm{sehr}$ deutlich auf eine Hydroxylsubstitution an dieser Position hinweist und somit die Anordnung von Amino- und Hydroxylgruppe gesichert ist. Als Literaturwert für die chemische Verschiebung von C-2 bei Phenylalanin ist $\delta_{\mathrm{C}}=57.3$ angegeben. ${ }^{192}$

Biosyntheseuntersuchungen von 64 wurden im Rahmen dieser Arbeit nicht durchgeführt, es kann jedoch vermutet werden, dass der Aufbau auf dem Shikimisäureweg stattfindet. Wie und auf welcher Stufe es zur Bildung der ungewöhnlichen $\alpha$-Hydroxyamideinheit kommt, ist jedoch unklar und müsste anhand von Fütterungsexperimenten geklärt werden. 


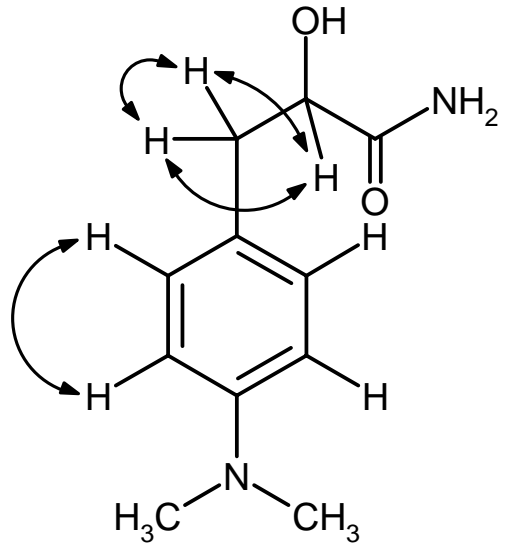

COSY-Korrelationen von 64

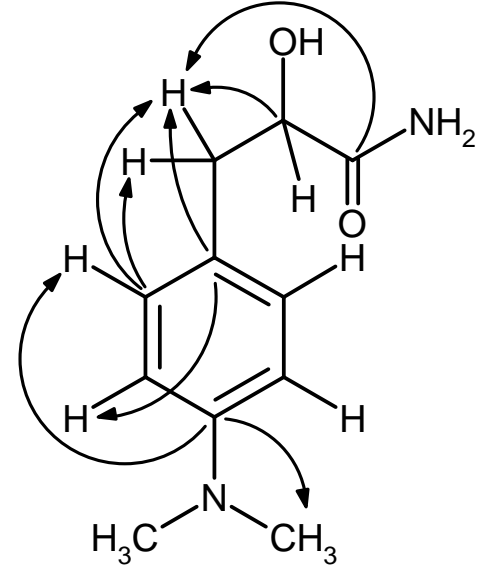

HMBC-Korrelationen von 64

Abbildung 48: Ausgewählte ${ }^{1} \mathrm{H},{ }^{1} \mathrm{H}-\mathrm{COSY}$ - und HMBC-Korrelationen, die zur Strukturaufklärung von 64 herangezogen wurden.

\subsection{Sonstige Metaboliten}

\section{Phenylacetamid (65)}

65 wurde als bei $254 \mathrm{~nm}$ löschender farbloser Feststoff in einer Ausbeute von $1.4 \mathrm{mg} / \mathrm{L}$ erhalten. Die Verbindung zeigte im EI-Massenspektrum das Ion höchster Masse bei $\mathrm{m} / \mathrm{z}=135$ und wies hinsichtlich ihres Fragmentierungsmusters eine große Ähnlichkeit zu Phenylacetamid (65) auf. Dieser Verdacht wurde durch einen Vergleich der NMR-Daten bestätigt. $\mathbf{6 5}$ konnte bereits häufiger aus Mikroorganismen isoliert werden. ${ }^{156,170,189,190}$<smiles>NC(=O)Cc1ccccc1</smiles>

65<smiles>COC1C(O)C2OC1C(n1ccc(=O)[nH]c1=O)C2O</smiles>

66<smiles>NC(=O)c1ccc(N)cc1</smiles>

67 


\section{2'-O-Methyluridin (66)}

Im Kulturfiltrat von Gö TS18 konnte die mit Orcin nach Erhitzen grün anfärbende, bei $254 \mathrm{~nm}$ UV-löschende Verbindung 66 in einer Ausbeute von $1 \mathrm{mg} / \mathrm{L}$ isoliert werden. Sie zeigte im ESI-Massenspektrum ein Ion bei $\mathrm{m} / \mathrm{z}=259\left([\mathrm{M}+\mathrm{H}]^{+}\right)$und im ${ }^{1} \mathrm{H}-\mathrm{NMR}-$ Spektrum das bereits bei 3,5'-Dimethyluridin (46) beschriebene, für Nucleoside typische Signalmuster. Somit konnte 66 als Uridinderivat identifiziert werden, wobei eine zusätzliche $O$-Methylgruppe bei $\delta_{\mathrm{H}}=3.51 \mathrm{im}{ }^{1} \mathrm{H}-\mathrm{NMR}-$ Spektrum vorhanden war. Eine Datenbanksuche mit Antibase $^{148}$ ergab, dass 2'-O-Methyluridin (66) vorlag. Ein Vergleich der NMR-Daten mit Literaturwerten bestätigte die Zuordnung. ${ }^{191}$ 2'-O-methylierte Ribonucleoside spielen im Primärmetabolismus beim Aufbau ribosomaler RNA eine wichtige Rolle. Hier dienen sie vermutlich dazu, benachbarte Phosphodiesterbindungen vor dem Abbau durch intrazelluläre RNasen zu schützen. Ob derartige Verbindungen eine darüber hinausgehende Funktion haben, ist ungewiss.

\section{4-Aminobenzamid (67)}

Weiterhin konnten $0.7 \mathrm{mg} / \mathrm{L}$ der UV-löschenden $(254 \mathrm{~nm})$, mit Ehrlich in der Wärme gelb anfärbenden Substanz 67 isoliert werden. Im ESI-Massenspektrum lag das Ion höchster Masse bei $\mathrm{m} / \mathrm{z}=159\left([\mathrm{M}+\mathrm{H}]^{+}\right)$. Anhand der Abspaltung eines charakteristischen Fragments mit 16 Masseeinheiten konnte auf die Anwesenheit einer Aminogruppe im Molekül geschlossen werden. Im ${ }^{1} \mathrm{H}-\mathrm{NMR}$-Spektrum waren lediglich zwei Signale erkennbar, die das Vorliegen eines para-disubstituierten Aromaten vermuten ließen. Mittels Inkrementrechnungen ${ }^{192}$ wurde 67 als 4-Aminobenzamid (67) identifiziert. Ebenso konnten $1 \mathrm{mg} / \mathrm{L}$ des bereits bei der Fermentation von Gö TS15 erhaltenen Isomeren 2-Aminobenzamid (57) isoliert werden.

\subsection{Biologische Aktivität der Metaboliten}

Bei einer Untersuchung der bislang nicht literaturbekannten Substanzen aus Stamm Gö TS18 hinsichtlich ihrer antimikrobiellen Aktivität gegen Escherichiacoli, Bacillus subtilis, Staphylococcus aureus und Candida albicans war lediglich 16-Dihydro-Virginiamycin $\mathrm{M}_{1}$ (63) auffällig. Die Verbindung verursachte einen Hemmhof bei Staphylococcus aureus $(\varnothing=13 \mathrm{~mm})$. 


\section{Actinomyces sp. Stamm Gö TS19}

Der Stamm Gö TS19 fiel im chemischen Screening durch eine Zone bei $R_{\mathrm{f}}=0.45 \mathrm{im}$ Dünnschichtchromatogramm auf, welche mit Anisaldehyd in der Wärme braun und mit Orcin intensiv gelbgrün anfärbte. Diese Färbung wird durch die neuartige Verbindung Okaspirodiol (68) hervorgerufen, die aus einem $4 \mathrm{~L}$ Fermentationsansatz isoliert werden konnte. Eine Kultivierung im $50 \mathrm{~L}$ Maßstab führte $\mathrm{zu}$ als Naturstoff bislang nicht beschriebenem 3-Amino-4-chlorbenzamid (69) sowie zu $N_{\beta}$-Acetyltryptamin (70).

\subsection{Okaspirodiol (68)}

68 fiel im Dünnschichtchromatogramm durch eine intensive gelbgrüne Färbung mit Orcin auf. Die Verbindung konnte in einer Ausbeute von $61 \mathrm{mg} / \mathrm{L}$ als farbloser, kristalliner Feststoff isoliert werden und zeigte im ESI-Massenspektrum ein Ion bei $\mathrm{m} / \mathrm{z}=225\left([\mathrm{M}+\mathrm{Na}]^{+}\right)$. Aus diesem ließ sich durch Hochauflösung die Summenformel $\mathrm{C}_{10} \mathrm{H}_{18} \mathrm{O}_{4}$ ableiten, welche das Vorliegen von zwei Doppelbindungsäquivalenten im Molekül anzeigte. Im ${ }^{1} \mathrm{H}-\mathrm{NMR}-$ Spektrum waren neben einer Methylgruppe $\left(\delta_{\mathrm{H}}=1.14\right)$ und drei Methingruppen $\left(\delta_{\mathrm{H}}=2.49\right.$, 3.84 und 3.93) fünf diastereotope Methylengruppen sichtbar, von denen zwei aufgrund ihrer charakteristischen chemischen Verschiebung an ein Sauerstoffatom gebunden sein sollten $\left(\delta_{\mathrm{H}}=3.76\right.$ und 3.98, 3.74 und 3.69). Im ${ }^{13} \mathrm{C}-\mathrm{NMR}$-Spektrum fiel das Signal für ein quartäres Kohlenstoffatom bei $\delta_{\mathrm{H}}=103.9$ auf, welches auf die Existenz einer vollacetalischen Bindung im Molekül schließen ließ. Aufgrund starker Signalüberlappung im ${ }^{1}$ H-NMR-Spektrum musste zur Ableitung der in Abbildung 51 dargestellten Strukturfragmente vorwiegend auf ${ }^{1} \mathrm{H}-{ }^{1} \mathrm{H}-\mathrm{COSY}-$ Spektroskopie (Abbildung 49) zurückgegriffen werden. Die Verknüpfung der erhaltenen Fragmente erfolgte schließlich unter Zuhilfenahme eines HMBC-Experiments (Abbildung 50). Als Struktur ergab sich eine Spiroverbindung mit einem Fünf- und einem Sechsringsystem.

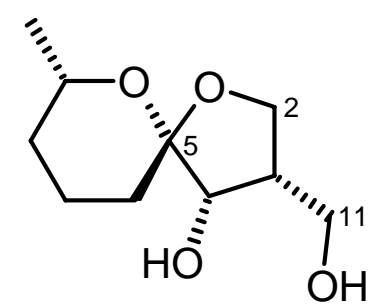

68 


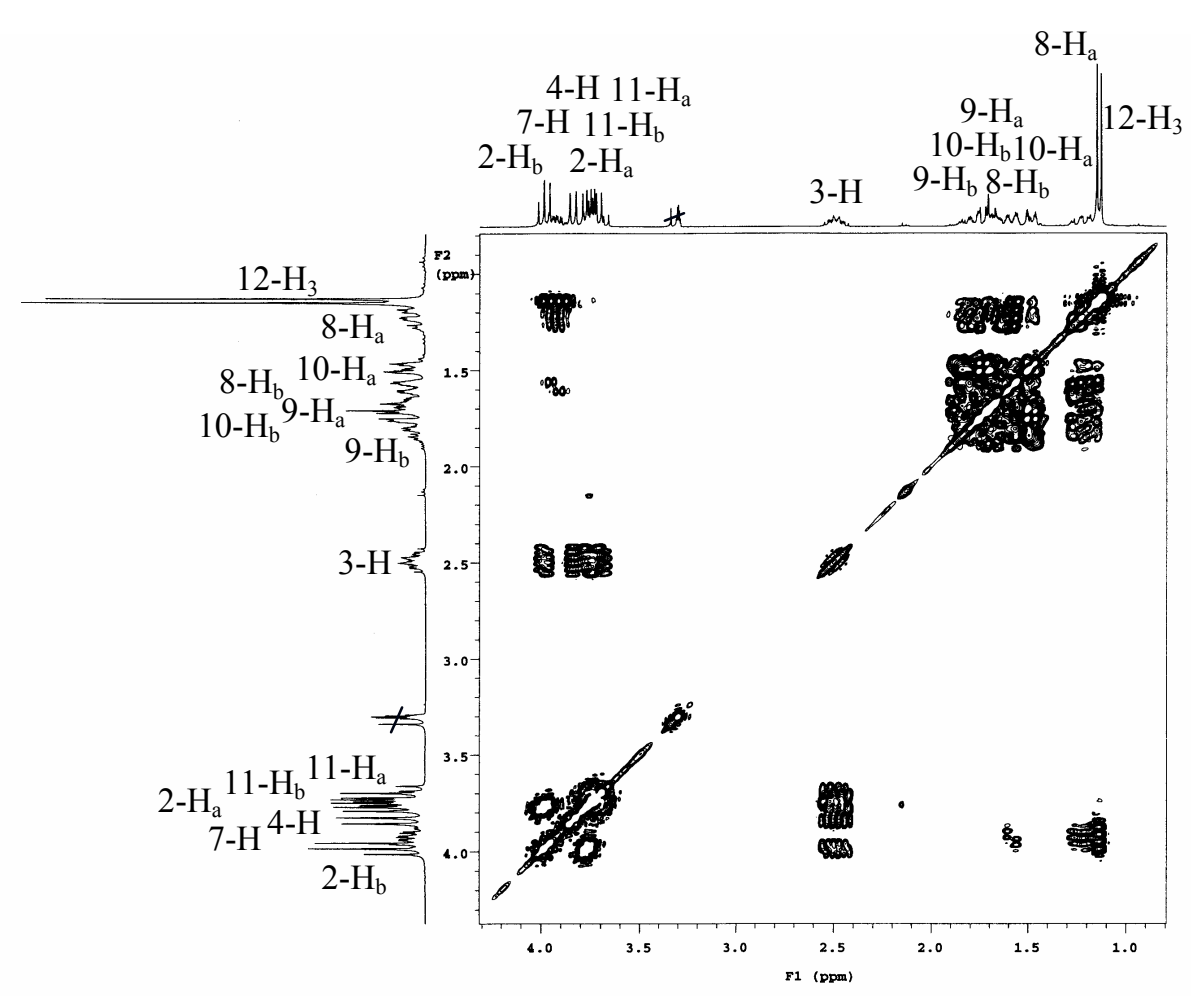

Abbildung 49: ${ }^{1} \mathrm{H},{ }^{1} \mathrm{H}-\mathrm{COSY}-S p e k t r u m$ von 68 (300 MHz, $\left.\mathrm{CD}_{3} \mathrm{OD}\right)$.

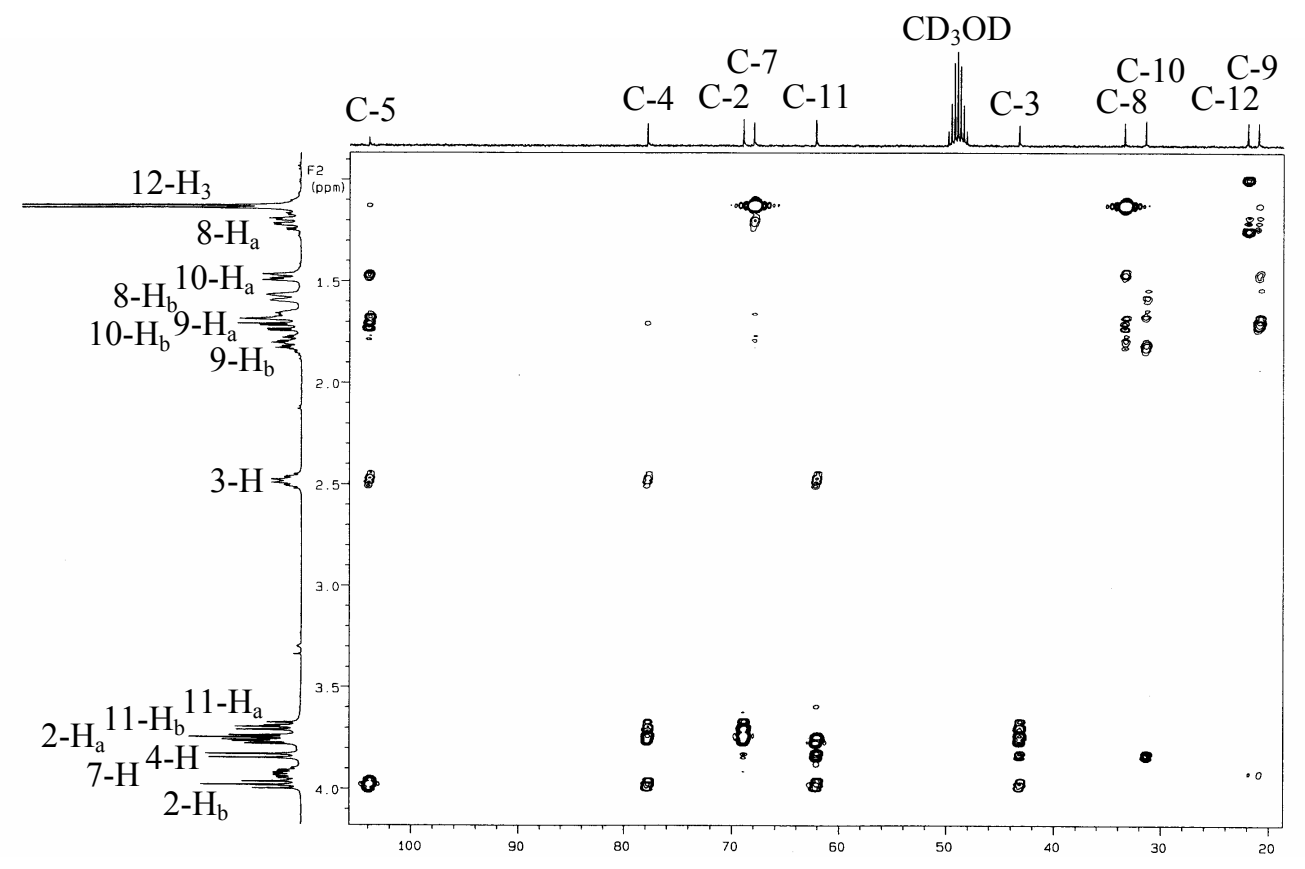

Abbildung 50: HMBC-Spektrum von 68 (500 MHz, $\left.\mathrm{CD}_{3} \mathrm{OD}\right)$. 


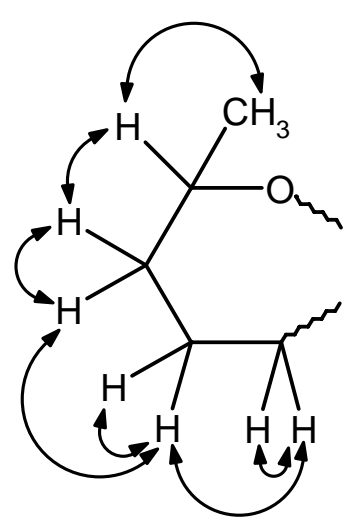

anhand der COSY-Korrelationen ermittelte Strukturfragmente

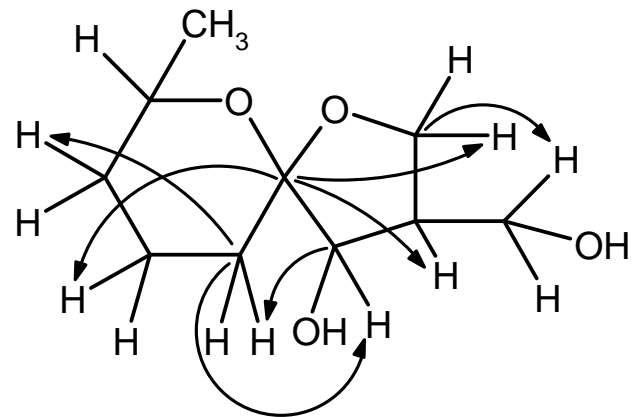

aus HMBC-Kopplungen abgeleitete Verknüpfung der Fragmente

Abbildung 51: Zur Strukturaufklärung von 68 wichtige ${ }^{1} \mathrm{H},{ }^{1} \mathrm{H}-\mathrm{COSY}-$ und $\mathrm{HMBC}-$ Kopplungen.

68 ist in der Literatur bisher nicht bekannt und wurde Okaspirodiol (68) genannt. Trotz einer hohen Neigung zur Kristallbildung gelang es nicht, hinreichend große Einkristalle von $\mathbf{6 8}$ zu züchten, wie sie zur Bestimmung der Stereochemie mittels Röntgenstrukturanalyse Voraussetzung sind. Erst nach Einführung eines 4-Brombenzoylsubstituenten an der primären Hydroxylgruppe gelang es T. BENDER im Rahmen seiner Diplomarbeit, ${ }^{193}$ Kristalle zu erzeugen, deren röntgenographische Untersuchung den Strukturvorschlag bestätigte und die absolute Konfiguration der vier Stereozentren an C-3, C-4, C-5 und C-7 bestimmen ließ (Abbildung 52). Es zeigte sich, dass sämtliche asymmetrischen Kohlenstoffatome im Molekül $(S)$-konfiguriert vorliegen.

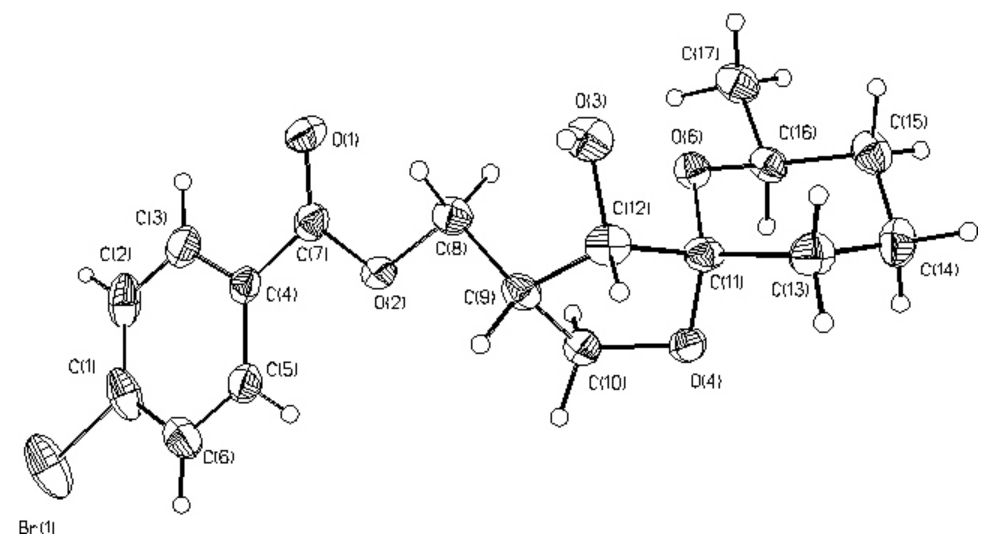

Abbildung 52: Kristallstruktur des 11-O-( $p$-Brombenzoyl)-Derivates von Okaspirodiol (68).

68 zeichnet sich durch eine für Vollacetale typische hohe Säurelabilität aus. So führte bereits das kurzzeitige Lösen der Substanz in deuteriertem Chloroform, welches stets Spuren von Säure enthält, zu Umlagerungen im Molekül. Es konnte im Dünnschichtchromatogramm die Bildung von drei neuen Substanzen festgestellt werden, die sich deutlich hinsichtlich ihrer 
Polarität unterschieden, wodurch eine Trennung an Kieselgel möglich war. Die NMRspektroskopische Untersuchung der aufgereinigten Verbindungen zeigte, dass sich zwei der gebildeten Isomere durch eine deutliche Tieffeldverschiebung $\left(\Delta \delta_{\mathrm{C}}=7 \mathrm{~Hz}\right)$ des SpiroKohlenstoffatoms gegenüber dem Naturstoff auszeichneten. Dies wurde als Hinweis auf eine Konfigurationsänderung an diesem Stereozentrum gewertet. T. BENDER gelang es mittels Derivatisierungen am Molekül und intensiven 2D-NMR-Studien, Vorschläge für die isomeren Strukturen und deren Bildung abzuleiten. Demnach kommt es zur säurekatalysierten Öffnung des Fünfringes, wobei die Stereospezifität der anschließenden Rekondensation nach thermodynamischen Gesichtspunkten verläuft. Es kommt so zur Bildung der Verbindungen 71,72 und 73.

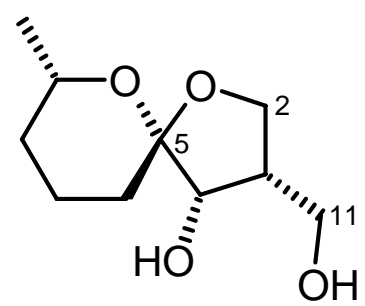

68<smiles>C[C@@H]1CCC[C@]2(OC[C@@H](CO)[C@@H]2O)O1</smiles>

72

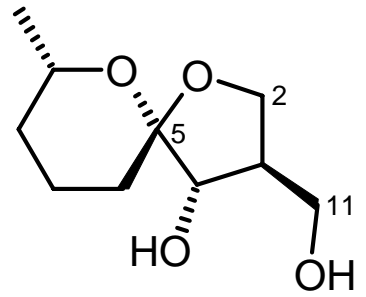

71

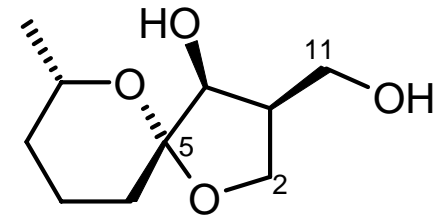

73

Das 68 zugrundeliegende Strukturelement, nämlich ein Bicyclus aus einem jeweils gesättigten Pyran- und Furanring, tritt bei Naturstoffen nicht sehr häufig auf. Zu den Ausnahmen zählen die Griseorhodine (z.B. Griseorhodin C (74)) ${ }^{194}$ und die Rubromycine (z.B. $\gamma$-Rubromycin (75)). ${ }^{195}$ Die Telomerase-inhibierende Wirkung dieser Verbindungen wird hier auf das Vorliegen des Spiroketalsystems zurückgeführt. ${ }^{196,197}$

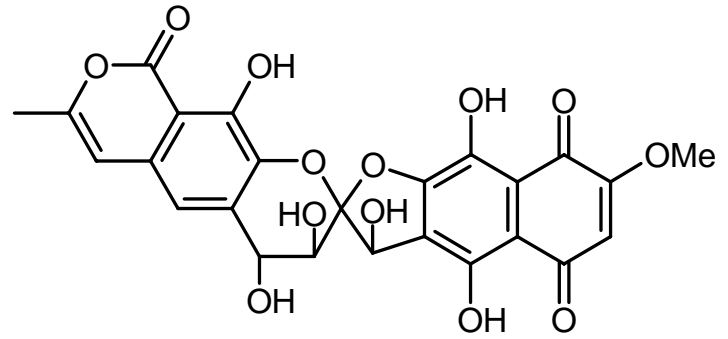

Griseorhodin C (74)<smiles>COC(=O)c1cc2cc3c(c(O)c2c(=O)o1)OC1(CC3)Cc2c(O)c3c(c(O)c2O1)C(=O)C(OC)=CC3=O</smiles>

$\gamma$-Rubromycin (75) 
Während seiner Diplomarbeit gelang T. BENDER neben der Etablierung einer Totalsynthese zusätzlich die weitgehende Aufklärung der Biogenese von 68. Anhand von Fütterungsexperimenten mit ${ }^{13} \mathrm{C}$-markierten Vorläufern konnte er zeigen, dass der Aufbau ausgehend von vier Acetat- und einer Glycerineinheit erfolgt (Abbildung 53).

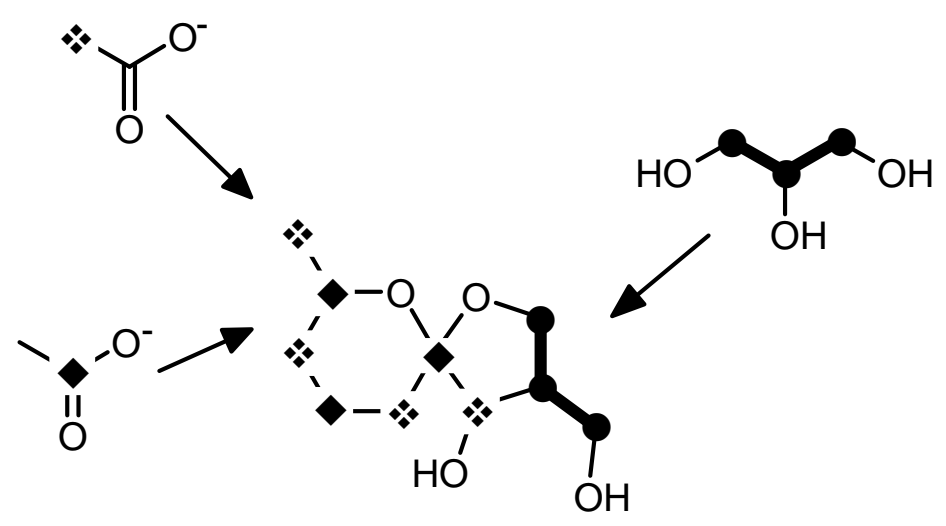

Abbildung 53: Durch Fütterungsexperimente erhaltenes Biogeneseschema von 68.

Während das sechsgliedrige Ringsystem vermutlich auf dem Polyketidweg aufgebaut wird, findet man für den fünfgliedrigen Cyclus Glycerin und ein von Acetat stammendes C-2Kohlenstoffatom als biosynthetischen Ursprung. In Analogie zu bekannten Biogenesewegen wie beispielsweise dem des Virginiaebutanolids $\mathrm{A}^{198}$, welcher $\mathrm{zu}$ einem identischen Einbaumuster führt, konnten zwei hypothetische Biosynthesewege abgeleitet werden (Abbildung 54). In beiden Fällen erfolgt zunächst die Addition von Dihydroxyaceton an ein Tetraketid unter Bildung von 76. Hiervon ausgehend kann in einer ersten möglichen Reaktionsabfolge zunächst das Sechsringsystem über eine intramolekulare Acetalbildung entstehen und in einem nächsten Schritt analog der Fünfring gebildet werden. Eliminierung von Wasser und Decarboxylierung ergäben schließlich 68.

In einem alternativen Weg fände im ersten Schritt eine Cyclisierung zum Fünfring statt. Nach der Abspaltung von Wasser würde die Ausbildung des Bicyclus erfolgen, aus dem nach Decarboxylierung 68 hervorginge. 


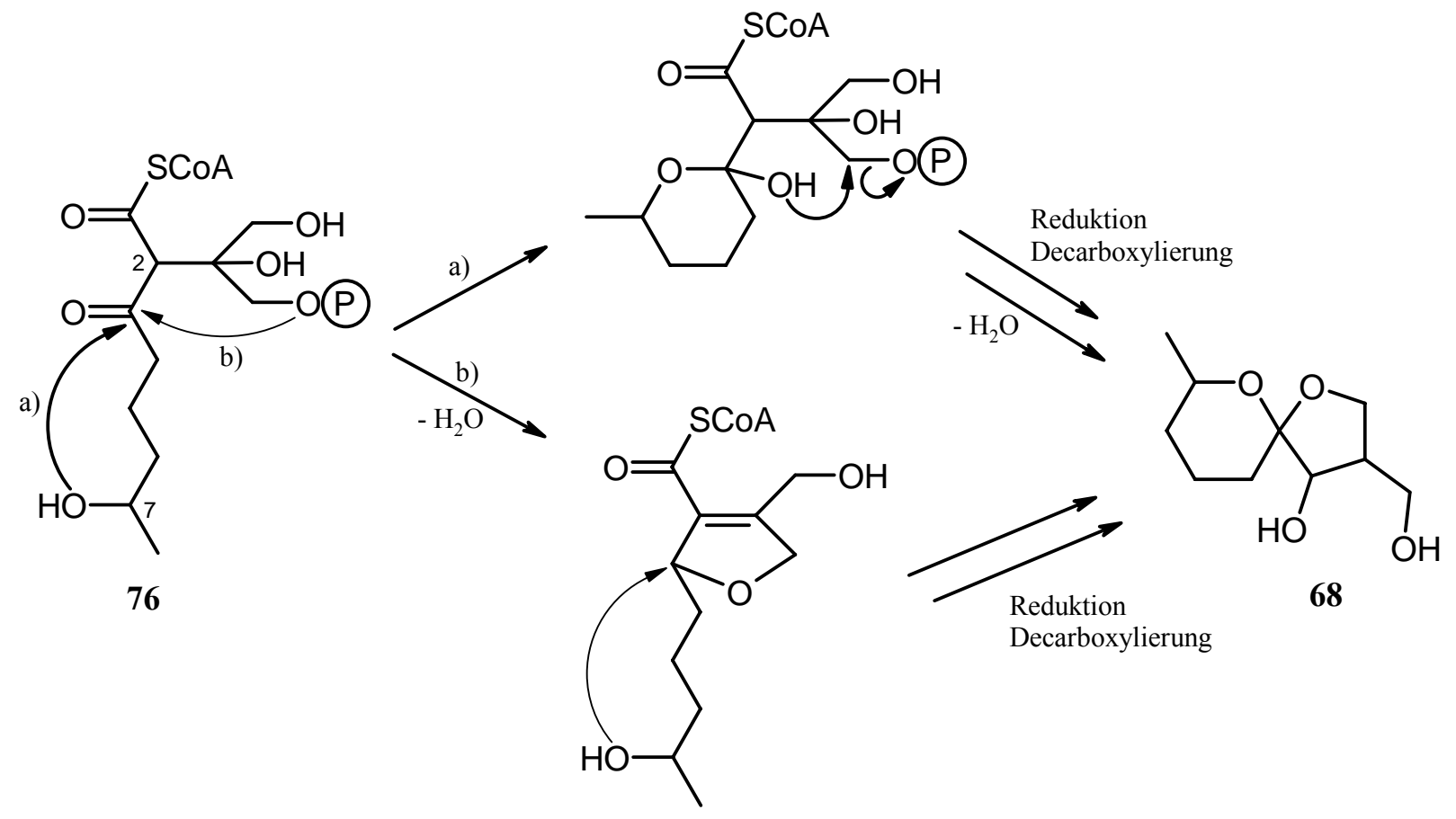

Abbildung 54: Zwei hypothetische Biosynthesewege, die zur Bildung von 68 führen.

\subsection{3-Amino-4-chlorbenzamid (69)}

Im Kulturfiltrat wurden neben $0.4 \mathrm{mg} / \mathrm{L}$ des Primärmetaboliten Adenosin (77), der durch Vergleich der NMR-spektroskopischen Daten mit Literaturwerten ${ }^{158}$ identifiziert werden konnte, auch geringe Mengen einer Substanz gefunden, deren Molekulargewicht mittels ESIMassenspektrometrie zu $528 \mathrm{~g} / \mathrm{mol}$ bestimmt wurde. In Kombination mit den aus dem ${ }^{1}$ H-NMR-Spektrum erhaltenen Daten wurde auf das Vorliegen einer bislang nicht beschriebenen, den Virginiamycinen strukturell verwandten Verbindung geschlossen. Um für eine vollständige Charakterisierung ausreichende Substanzmengen zu erhalten, wurde eine 50 L-Fermentation des Stammes Gö TS19 im Medium M2 durchgeführt. Aufgrund eines technischen Defekts kam es bei dem verwendeten Fermenter jedoch zu einem kontinuierlichen Abfall der Temperatur, was ein vollständig verändertes Metabolitenspektrum des kultivierten Actinomyceten zur Folge hatte und folglich einem OSMAC-Ansatz entspricht. Obwohl sich weder die gesuchte Substanz noch 68 gebildet hatte, konnten aus dem Kulturfiltrat dieses Ansatzes dennoch neben Verbindung 70 auch $0.1 \mathrm{mg} / \mathrm{L}$ des farblosen Feststoffs 69 isoliert werden, der sich auf dem Dünnschichtchromatogramm durch UVLöschung (254 nm) und hellblaue Fluoreszenz $(366 \mathrm{~nm}) \mathrm{zu}$ erkennen gab und mit Ehrlich in der Wärme schwach gelb anfärbte. 
<smiles>Nc1ncnc2c1ncn2C1OC2C(O)C1C(O)C2CO</smiles>

77<smiles>NC(=O)c1ccc(Cl)c(N)c1</smiles>

69

69 zeigte im EI-Massenspektrum das Ion höchster Masse bei $\mathrm{m} / \mathrm{z}=170$, über dessen charakteristisches Isotopenmuster auf das Vorhandensein eines Chloratoms im Molekül geschlossen werden konnte. Anhand der Abspaltung eines Fragmentes mit der typischen Masse von $\mathrm{m} / \mathrm{z}=17$ konnte zusätzlich auf das Vorliegen von Aminofunktionen in der Verbindung geschlossen werden. Im ${ }^{1}$ H-NMR-Spektrum wurden sechs Signale angezeigt, von denen drei mit $\mathrm{D}_{2} \mathrm{O}$ austauschbar waren. Die übrigen befanden sich im Bereich der chemischen Verschiebung von aromatischen Protonen $\left(\delta_{\mathrm{H}}=7.12,7.25\right.$ und 7.41) und zeigten ein für meta, para-trisubstituierte Benzole typisches Kopplungsmuster. Im ${ }^{13} \mathrm{C}-\mathrm{NMR}$ Spektrum waren acht Kohlenstoffatome detektierbar, von denen vier aufgrund der Signalintensitäten als quartär eingestuft werden konnten und eines im Bereich einer Carboxylbzw. Säureamidgruppe $\left(\delta_{C}=172.1\right)$ lag. Aufgrund dieser Daten kamen als mögliche Strukturen 3-Amino-4-chlorbenzamid (69) bzw. das Isomere 4-Amino-3-chlorbenzamid (78) in Frage.

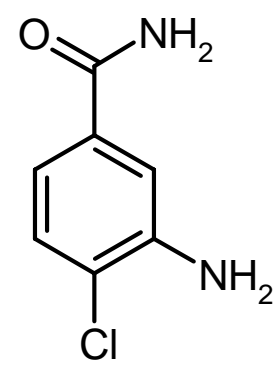

69<smiles>NC(=O)c1ccc(N)c(Cl)c1</smiles>

78

Durch die völlige Übereinstimmung der spektroskopischen Daten von 69 mit denen von kommerziell erhältlichem 3-Amino-4-chlorbenzamid (69) konnte die strukturelle Zuordnung gesichert werden. Das Vorliegen von drei im ${ }^{1} \mathrm{H}-\mathrm{NMR}-$ Spektrum unterscheidbaren, mit $\mathrm{D}_{2} \mathrm{O}$ austauschbaren Signalen, welche für insgesamt vier Protonen integrieren, lässt sich auf die 
eingeschränkte Rotation um die C-N-Achse der Amidbindung zurückführen ${ }^{199}$ (siehe auch Kapitel B.V.2.3.). Diese verursacht den beobachteten Unterschied von $0.76 \mathrm{ppm}$ in der chemischen Verschiebung der Amidprotonen.

Es handelt sich bei 69 um eine bisher als Naturstoff nicht bekannte Verbindung, die als Indiz für die Existenz einer Halogenase bzw. Haloperoxidase im Stamm Gö TS19 angeführt werden kann.

\section{3. $\quad N_{\beta}$-Acetyltryptamin (70)}

70 wurde in einer Ausbeute von $0.1 \mathrm{mg} / \mathrm{L}$ aus dem Mycelextrakt einer 50 L-Fermentation von Gö TS19 isoliert. Die Verbindung fiel durch UV-Löschung bei $254 \mathrm{~nm}$, hellblaue Fluoreszenz bei $366 \mathrm{~nm}$ und intensive Rotfärbung beim Besprühen mit Anisaldehyd auf dem Dünnschichtchromatogramm auf. 70 zeigte im ESI-Massenspektrum ein Ion bei $\mathrm{m} / \mathrm{z}=203\left([\mathrm{M}+\mathrm{Na}]^{+}\right)$. Dem ${ }^{1}$ H-NMR-Spektrum konnte das Vorkommen einer Methylgruppe, die aufgrund ihrer chemischen Verschiebung $\left(\delta_{\mathrm{H}}=1.90\right)$ einer Acetyleinheit zugeordnet wurde, zweier benachbarter Methylengruppen $\left(\delta_{\mathrm{H}}=2.92\right.$ und $\left.3.45,{ }^{3} J_{\mathrm{HH}}=7.0 \mathrm{~Hz}\right)$ sowie fünf aromatischer Protonen $\left(\delta_{\mathrm{H}}=7.03,7.31\right.$ und 7.54) entnommen werden. Das ${ }^{13} \mathrm{C}-\mathrm{NMR}-$ Spektrum zeigte zwölf Kohlenstoffatome. Aufgrund der charakteristischen Signallage im aromatischen Bereich $\left(\delta_{\mathrm{C}}=112.2,113.2,119.2,119.6,122.3,123.3,128.8\right.$ und 138.2) wurde das Vorliegen eines Indol-Grundgerüsts vermutet. Eine Resonanz bei $\delta_{\mathrm{C}}=173.3$ wies auf die Existenz einer Ester-/Amidgruppe im Molekül hin. Eine Datenbanksuche mit diesen Strukturelementen in Antibase $^{148}$ ergab, dass $N_{\beta}$-Acetyltryptamin (70) isoliert wurde. Ein Vergleich der NMRDaten mit Literaturwerten bestätigte die Zuordnung.

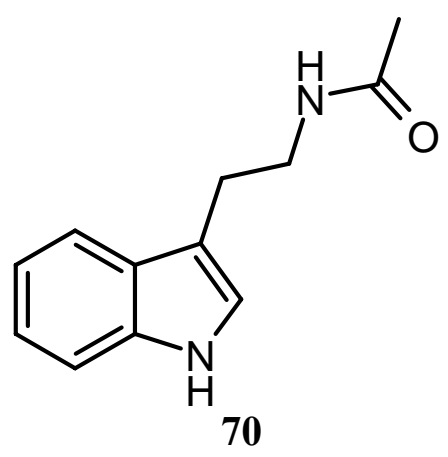

70 konnte kürzlich auch von S. MEYER im Rahmen seiner Doktorarbeit ${ }^{200}$ als Metabolit des Hexacyclinsäure-Produzenten Streptomyces cellulosae subsp. griseorubiginosus S 1013 gefunden werden und ist außerdem aus Myxobakterien ${ }^{137}$ und marinen Mikroorganismen ${ }^{201}$ bekannt. 


\subsection{Biologische Aktivität der Metaboliten}

Bei einem Test der Verbindungen Okaspirodiol (68) und 3-Amino-4-chlorbenzamid (69) auf antimikrobielle Aktivität gegen Escherichia coli, Bacillus subtilis, Staphylococcus aureus und Candida albicans konnte keine hemmende Wirkung beobachtet werden. 68 wurde zusätzlich von der BASF AG auf Aktivität gegen phytopathogene Pilze hin untersucht, es zeigte sich jedoch auch in diesem Fall kein antibiotischer Effekt. 


\section{Endosymbionten aus Aplidium lenticulum}

\section{Projektbeschreibung}

Bei vielen aus marinen Weichtieren (z.B. Schwämmen oder Manteltierchen) isolierten Naturstoffen handelt es sich um komplexe Polyketide. Da diese Substanzklasse auch unter Mikroorganismen weit verbreitet ist, liegt die Vermutung nahe, dass die wahren Produzenten nicht die Invertebraten selbst, sondern mit ihnen assoziiert auftretende Bakterien sind. Um der Hypothese, für die es bereits zahlreiche Evidenzen gibt, ${ }^{202}$ weiter nachzugehen, wurden in der Arbeitsgruppe von J. PIEL ${ }^{\text {a }}$ Bakterienstämme aus dem Inneren der marinen Tunikate (Manteltierchen) Aplidium lenticulum isoliert, von denen Exemplare dem Great Barrier Reef vor Heron Island (Australien) entnommen wurden. In einem chemischen Screening der

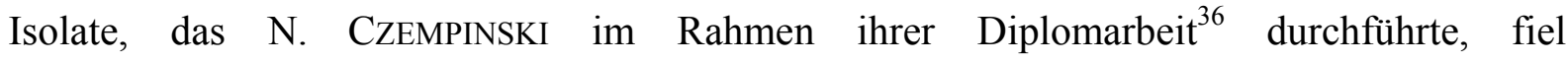
Actinomyces sp. Stamm JP90 durch ein interessantes Metabolitenmuster auf. Die aus der weiteren Bearbeitung des Stammes erhaltenen Ergebnisse werden in diesem Kapitel beschrieben.

\section{Actinomyces sp. Stamm JP90}

Bei Stamm JP90 handelt es sich um eine phylogenetisch Streptomyces rimosus am nähesten verwandte Spezies. Er fiel im chemischen Screening auf dem Dünnschichtchromatogramm durch eine Reihe unterschiedlicher UV-aktiver sowie anfärbbarer Zonen besonders im Medium SGG auf. Aus einer Fermentation im 4 L-Maßstab konnten die Verbindungen Desferrioxamin E (79), Phosphoryloxyphenylester (80), 6-Hydroxy-6-methylheptansäure (81), Rosiridol (82), Cyclo(tyrosylprolyl) (83), N-Acetyltyramin (84), sowie Indol-3carbonsäure (85) isoliert werden.

\footnotetext{
a J. Piel (MPI Jena) danke ich für die Isolierung und Bereitstellung der Mikroorganismen.
} 


\subsection{Desferrioxamin E (79)}

Verbindung 79 fiel insbesondere durch ihre Schwerlöslichkeit in allen gängigen organischen Lösungsmitteln auf und zeigte neben UV-Löschung bei $254 \mathrm{~nm}$ eine schwache gelbbraune Färbung nach Besprühen mit Anisaldehyd in der Wärme. Da eine Trennung der Substanz mit herkömmlichen chromatographischen Methoden aufgrund ihrer geringen Löslichkeit nicht möglich war, wurde diese durch wiederholtes Auswaschen mit Methanol gereinigt. Dadurch konnte 79 als Reinstoff in Form farbloser Kristalle in einer Ausbeute von $12 \mathrm{mg} / \mathrm{L}$ erhalten werden. Mittels ESI-Massenspektrometrie wurde das Molekulargewicht $\mathrm{zu} 600 \mathrm{~g} / \mathrm{mol}$ bestimmt. Im ${ }^{1}$ H-NMR-Spektrum waren lediglich neun Signale erkennbar, von denen sechs Methylengruppen $\left(\delta_{\mathrm{H}}=1.20,1.37,1.49,2.28,2.58,3.00\right.$ und 3.45$)$ waren und zwei $\left(\delta_{\mathrm{H}}=7.69\right.$ und 9.62) aufgrund der hohen Linienbreite und chemischen Verschiebung Amino- oder Hydroxylgruppen zugeordnet wurden. Anhand des Kopplungsmusters konnte das Vorliegen sowohl von Ethylen- als auch Pentylengruppen im Molekül abgeleitet werden. $\operatorname{Im}{ }^{13} \mathrm{C}-\mathrm{NMR}$ Spektrum wurden neun Kohlenstoffatome angezeigt, wobei zwei $\left(\delta_{C}=171.7\right.$ und 172.2) im Bereich von Ester-/Amidgruppen lagen. Um die hohe Molmasse von 79 zu erklären, wurde das Vorliegen einer symmetrischen Verbindung vermutet. Eine Datenbanksuche führte zum Desferrioxamin E (79), das in allen spektralen Daten mit 79 übereinstimmt.

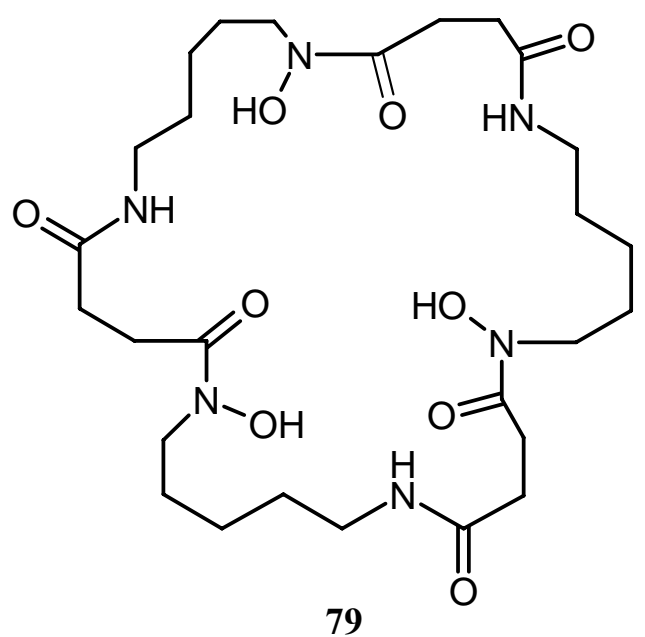

79 ist ein weit verbreiteter Naturstoff, der bereits aus verschiedenen Mikroorganismen wie Streptomyceten, ${ }^{203,204}$ Pseudomonas-, Nocardia- und Micromonospora-Arten ${ }^{205}$ isoliert wurde und auch unter dem Namen Nocardamin bekannt ist. ${ }^{206}$ Es handelt sich dabei um ein cyclisches Hydroxamat, das in der Lage ist, Eisen(III)-Ionen zu chelatisieren. Im mikrobiellen Stoffwechsel dienen derartige als Siderophore bezeichnete Stoffe dazu, Eisen über ein aktives 
Transportsystem in die Zelle zu befördern. Darüber hinaus können auch andere Metallionen wie Plutonium(IV) und Aluminium(III) gebunden werden, wobei die resultierenden Komplexe sich hinsichtlich ihrer Geometrie deutlich von Eisen(III)-Siderophoren unterscheiden. Gegenwärtig wird diskutiert, ob dieses Phänomen für die Erkennung der verschiedenen Metallkomplexe durch Mikroorganismen und den anschließenden Transport in die Zelle wichtig ist. ${ }^{207}$ Siderophore finden auch in der Humanmedizin Anwendung, vor allem zur Behandlung von Eisen- und Aluminiumüberdosen bei Transfusionen.

\subsection{Phosphoryloxyphenyl-acrylsäuremethylester (80a) bzw. \\ Phosphoryloxyphenyl-acrylimidsäuremethylester (80b)}

80 war im Dünnschichtchromatogramm durch UV-Löschung bei $254 \mathrm{~nm}$ detektierbar, färbte jedoch mit keinem der gängigen Sprühreagenzien an. Die Verbindung konnte in einer Ausbeute von $1.2 \mathrm{mg} / \mathrm{L}$ als farbloses Öl isoliert werden. Im ESI-Massenspektrum von 80 war ein Ion bei $\mathrm{m} / \mathrm{z}=294\left([\mathrm{M}+\mathrm{Na}]^{+}\right)$sichtbar, aus dessen Hochauflösung ließ sich die Summenformel $\mathrm{C}_{11} \mathrm{H}_{14} \mathrm{NO}_{5} \mathrm{P}$ ableiten. Das Vorliegen des für Sekundärmetabolite eher ungewöhnlichen Elements Phosphor konnte durch ein Signal bei $\delta_{\mathrm{P}}=6.1 \mathrm{im}{ }^{31} \mathrm{P}-\mathrm{NMR}-$ Spektrum (Abbildung 55) bestätigt werden. Im ${ }^{1} \mathrm{H}-\mathrm{NMR}-$ Spektrum waren sechs Signale detektierbar, von denen zwei auf Methoxygruppen $\left(\delta_{\mathrm{H}}=3.76\right.$ sowie 3.79$)$ und jeweils zwei auf Methingruppen im Doppelbindungs- $\left(\delta_{\mathrm{H}}=6.37\right.$ und 7.23) und im Aromatenbereich $\left(\delta_{\mathrm{H}}=7.50\right.$ sowie 7.62) entfielen. Letztere ließen anhand ihres Kopplungsmusters auf das Vorliegen eines paradisubstituierten Aromaten schließen. Das ${ }^{13} \mathrm{C}-\mathrm{NMR}-$ Spektrum (Abbildung 56) zeigte neun Resonanzen, wobei die Dublettaufspaltung der Signale bei $\delta_{\mathrm{C}}=53.9\left(\mathrm{~d},{ }^{2} J_{\mathrm{C}-\mathrm{P}}=5.8 \mathrm{~Hz}\right), 121.0$ $\left(\mathrm{d},{ }^{3} J_{\mathrm{C}-\mathrm{P}}=4.5 \mathrm{~Hz}\right)$ und $152.7\left(\mathrm{~d},{ }^{2} J_{\mathrm{C}-\mathrm{P}}=11.3 \mathrm{~Hz}\right)$ auffällig war. Diese wurden auf das Vorliegen von ${ }^{13} \mathrm{C}_{-}{ }^{31} \mathrm{P}-$ Kopplungen zurückgeführt. Weiterhin war eine Resonanz bei $\delta_{\mathrm{C}}=167.4$ sichtbar, die Rückschlüsse auf eine ester- bzw. amidartige Bindung im Molekül zuließ. Mittels 2D-NMR-Experimenten ( ${ }^{1} \mathrm{H},{ }^{1} \mathrm{H}-\mathrm{COSY}$, HSQC und HMBC) gelang schließlich die Zuordnung der in Abbildung 57 dargestellten Strukturfragmente. 


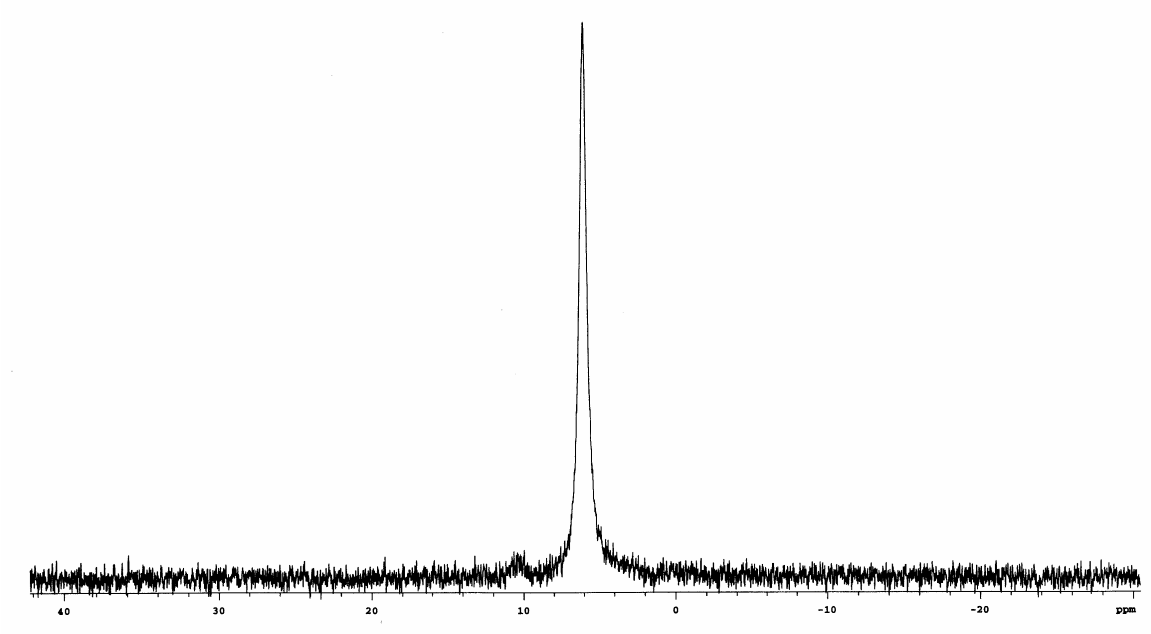

Abbildung 55: ${ }^{31} \mathrm{P}-\mathrm{NMR}-\mathrm{Spektrum}$ von 80 (121.5 MHz, $\left.\mathrm{CD}_{2} \mathrm{Cl}_{2}\right)$.

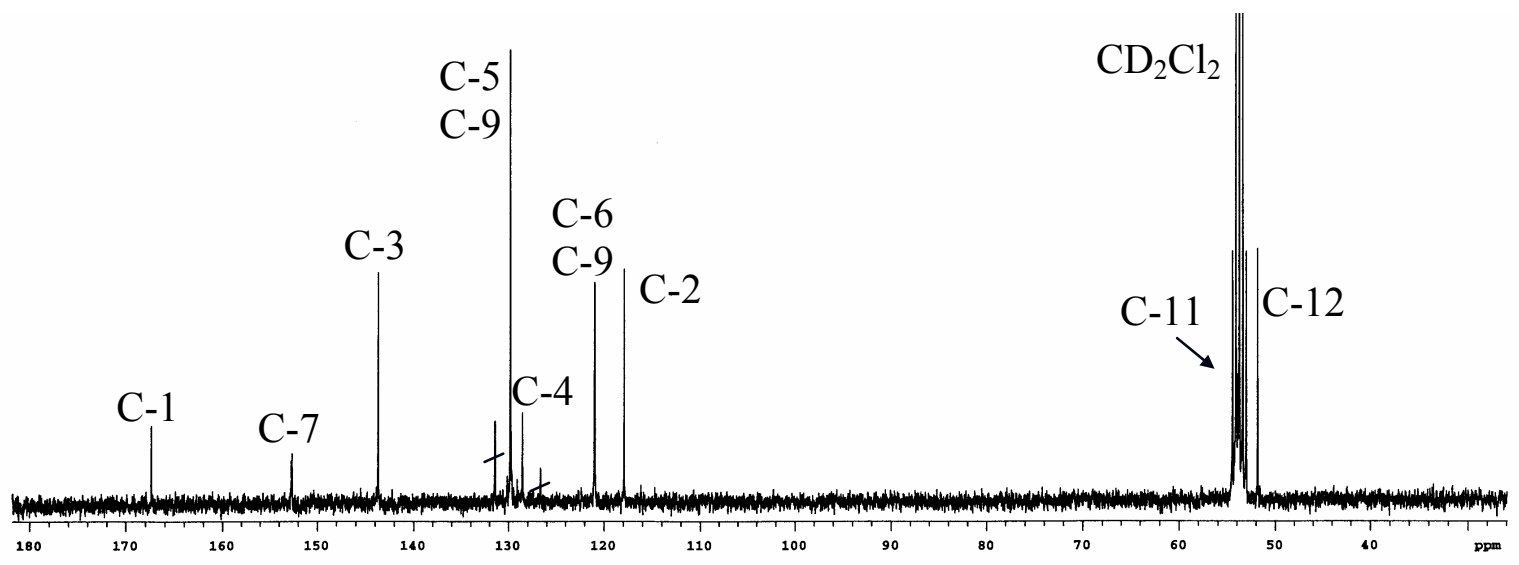

Abbildung 56: ${ }^{13} \mathrm{C}-\mathrm{NMR}-\mathrm{Spektrum}$ von $80\left(600 \mathrm{MHz}, \mathrm{CD}_{2} \mathrm{Cl}_{2}\right)$.

Die hohe vicinale Kopplungskonstante von ${ }^{3} J_{\mathrm{HH}}=16 \mathrm{~Hz}$ beweist die trans-ständige Anordnung der Vinylen-Protonen. $\mathrm{Ob}$ es sich bei 80 um einen Carbonsäure (a)- oder Imidsäureester (b) handelt, kann aufgrund der NMR-Daten nicht zweifelsfrei festgestellt werden. Um die sich aus der Summenformel ergebenden Anforderungen für beide Fälle zu erfüllen, verblieb ein Substituent mit der Summenformel $\mathrm{CH}_{5} \mathrm{NO}_{2} \mathrm{P}$ (für a) bzw. $\mathrm{CH}_{4} \mathrm{O}_{3} \mathrm{P}$ (für b). Für diesen ergab sich als Strukturvorschlag eine Aminomethoxyphosphoryl- (a) bzw. eine Hydroxymethoxyphosphoryl-Gruppierung (b). Davon ausgehend konnten die Strukturvorschläge 80a und 80b abgeleitet werden. Eine exakte Strukturzuordnung würde geeignete chemische Derivatisierungen größerer Mengen an $\mathbf{8 0}$ erfordern. Die beobachtete Abnahme der ${ }^{13} \mathrm{C}-{ }^{31} \mathrm{P}-$ Kopplungskonstante in der Reihenfolge C-7/C-11/C-6 lässt sich anhand der für 80 ermittelten Strukturen über den zunehmenden Abstand vom NMR-aktiven Phosphorkern erklären. 


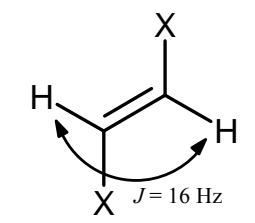

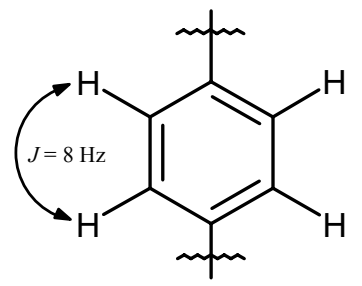

anhand der COSY-Korrelationen ermittelte Strukturfragmente

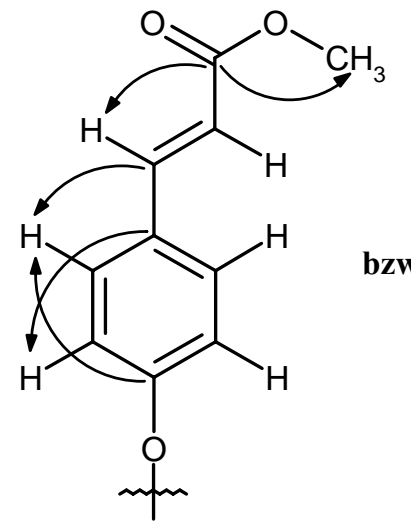

a

durch HMBC-Kopplungen abgeleitete Verknüpfung der Fragmente

Abbildung 57: Aus COSY- und HMBC-Korrelationen abgeleitete Strukturfragmente von 80.

Weder bei 80a noch bei 80b handelt es sich um als Naturstoffe bzw. Syntheseprodukte beschriebene Verbindungen. Sowohl der ungewöhnliche Phosphor-Substituent beim Strukturvorschlag 80a als auch das Vorliegen einer Imidsäureester-Gruppierung bei 80b erschweren für beide Strukturen eine Vorhersage des biosynthetischen Ursprungs.

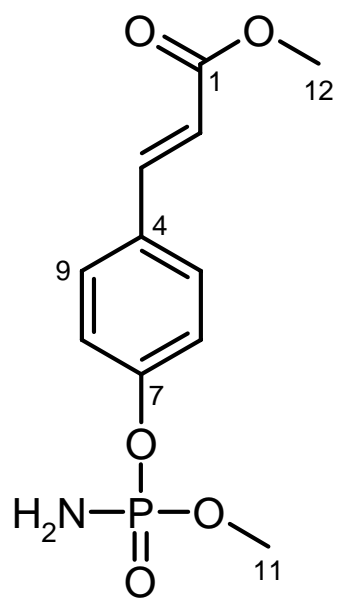

80a<smiles>CCOC(=N)/C=C/c1ccc(OP(=O)(O)OC)cc1</smiles>

80b 


\subsection{6-Hydroxy-6-methylheptansäure (81)}

81 zeichnete sich durch UV-Löschung bei $254 \mathrm{~nm}$ und eine blaue Farbreaktion beim Besprühen mit Anisaldehyd aus. Die Verbindung konnte als farbloser Feststoff in einer Ausbeute von $1.2 \mathrm{mg} / \mathrm{L}$ aus dem Kulturfiltrat des Stammes JP90 isoliert werden und zeigte im ESI-Massenspektrum ein Ion bei $\mathrm{m} / \mathrm{z}=183\left([\mathrm{M}+\mathrm{Na}]^{+}\right)$. Durch ESI-Hochauflösung ergab sich die Summenformel $\mathrm{C}_{8} \mathrm{H}_{16} \mathrm{O}_{3}$. Im ${ }^{1} \mathrm{H}-\mathrm{NMR}$-Spektrum waren fünf Signale sichtbar, von denen eines $\left(\delta_{\mathrm{H}}=1.16\right)$ auf eine Methylgruppe sowie vier $\left(\delta_{\mathrm{H}}=1.40-2.29\right)$ auf Methylengruppen entfielen. Das ${ }^{13} \mathrm{C}$-NMR-Spektrum zeigte darüber hinaus die Existenz einer Carboxylgruppe $\left(\delta_{\mathrm{C}}=178.0\right)$ sowie eines quartären Kohlenstoffatoms bei $\delta_{\mathrm{C}}=71.3$ an, welches aufgrund seiner Tieffeld-Verschiebung an ein Sauerstoffatom gebunden vorliegen sollte. Mit Hilfe von 2D-NMR-Experimenten konnte ein Strukturvorschlag für 81 abgeleitet werden, wonach es sich um 6-Hydroxy-6-methylheptansäure (81) handelt.

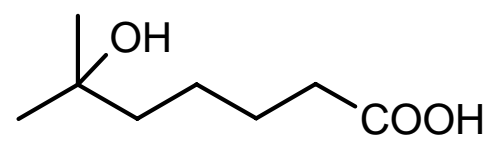

81

81 ist in der Literatur weder als Naturstoff noch als Syntheseprodukt bekannt. Für die Biogenese ist ein Aufbau über den Fettsäurestoffwechsel mit ungerader Kohlenstoffanzahl möglich, außerdem könnte eine Bildung auf dem Polyketid- oder Mevalonatweg vermutet werden. Für letzteres spricht das Auftreten des Monoterpens Rosiridol (82) als Metabolit von Stamm JP90 (siehe nächster Abschnitt). Dies kann als Hinweis auf einen aktiven Isoprenstoffwechsel in dem bearbeiteten Endosymbionten gewertet werden.

\subsection{Rosiridol (82)}

Im Dünnschichtchromatogramm fiel 82 durch Braunfärbung beim Besprühen mit Anisaldehyd und anschließendem Erhitzen auf. Die Verbindung wurde in einer Ausbeute von $2 \mathrm{mg} / \mathrm{L}$ isoliert und zeigte im DCI-Massenspektrum ein Ion bei $\mathrm{m} / \mathrm{z}=188\left(\left[\mathrm{M}+\mathrm{NH}_{4}\right]^{+}\right)$. Im ${ }^{1}$ H-NMR-Spektrum waren acht Signale sichtbar, von denen drei auf Methylgruppen $\left(\delta_{\mathrm{H}}=1.62,1.63\right.$ und 1.69), zwei auf Methylengruppen $\left(\delta_{\mathrm{H}}=2.22\right.$ sowie 4.12$)$ und drei auf Methingruppen $\left(\delta_{\mathrm{H}}=3.92,5.10\right.$ und 5.52) entfielen. Das ${ }^{13} \mathrm{C}-\mathrm{NMR}$-Spektrum zeigte die Anwesenheit von zehn Kohlenstoffatomen im Molekül an, wobei vier davon $\left(\delta_{C}=121.7-140.6\right)$ im Bereich von Doppelbindungen lagen. Mittels eines ${ }^{1} \mathrm{H}-{ }^{1} \mathrm{H}-\mathrm{COSY}$ - 
Experimentes konnten die in Abbildung 58 gezeigten Strukturfragmente abgeleitet werden, die anhand von HMBC-Korrelationen miteinander verknüpft wurden.

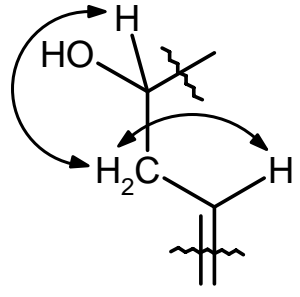

anhand von COSY-Korrelationen ermittelte Strukturfragmente

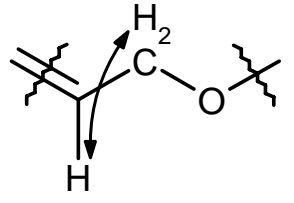

durch HMBC-Kopplungen abgeleitete Verknüpfung der Fragmente

Abbildung 58: Für die Ableitung der Struktur von 82 wichtige 2D-NMR-Korrelationen.

In einer Literaturrecherche wurde gefunden, dass es sich bei 82 um das Monoterpen Rosiridol (82) handelt. Diese Verbindung war bisher lediglich als Metabolit des Rosenwurzes Rhodiola rosea bekannt. ${ }^{208}$ Als Strukturelement ist $\mathbf{8 2}$ ferner in Xestovanin A $(\mathbf{8 6})^{209}$, einem aus marinen Schwämmen isolierten Metaboliten, enthalten.<smiles>CC(C)=CCC(O)C(C)=CCO</smiles>

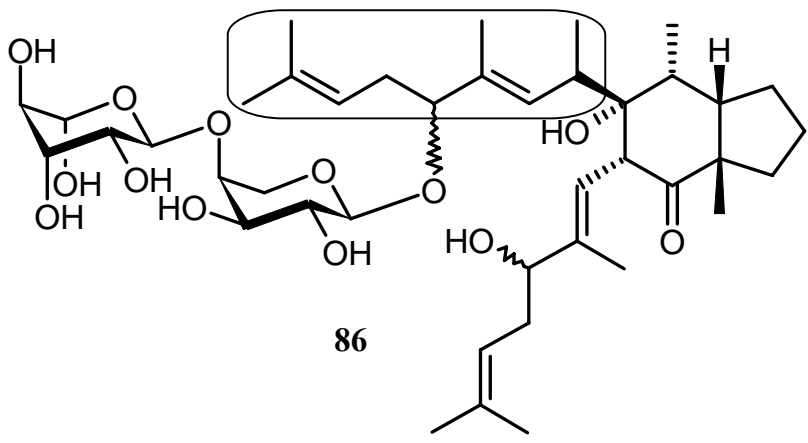

Für die bislang nicht untersuchte Biosynthese von 82 kommen zum Aufbau der Isopreneinheiten sowohl der Mevalonatweg als auch der Kohlenhydrat-Stoffwechsel (Nicht-Mevalonatweg) in Betracht (Abbildung 59). ${ }^{88,139}$ 


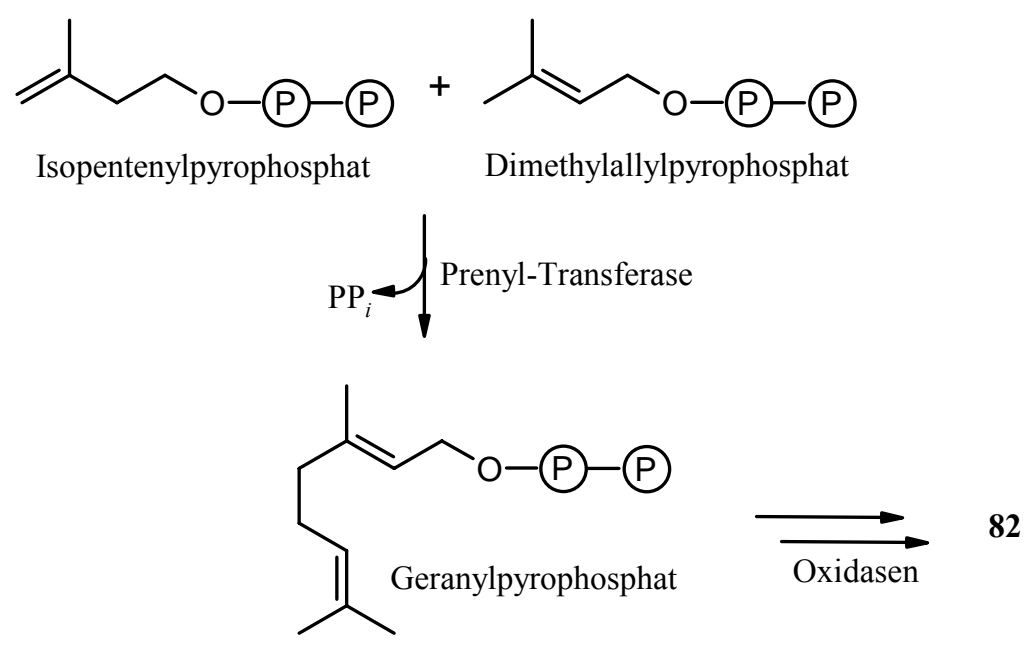

Abbildung 59: Möglicher Biosyntheseweg von 82.

\subsection{Cyclo(tyrosylprolyl) (83)}

Die mit Anisaldehyd gelbbraun anfärbende und UV-Licht bei $254 \mathrm{~nm}$ absorbierende Substanz 83 konnte in einer Ausbeute von $2.5 \mathrm{mg} / \mathrm{L}$ als farbloser Feststoff isoliert werden. Im ESIMassenspektrum zeigte sie ein Ion bei $\mathrm{m} / \mathrm{z}=261\left([\mathrm{M}+\mathrm{H}]^{+}\right)$. Das ${ }^{13} \mathrm{C}-\mathrm{NMR}-$ Spektrum beinhaltete zwölf Signale, von denen vier $\left(\delta_{C}=116.2-157.7\right)$ im Bereich aromatischer Kohlenstoffatome lagen und zwei $\left(\delta_{\mathrm{C}}=166.9\right.$ und 170.8) eine für Ester-/Amidbindungen charakteristische chemische Verschiebung aufwiesen. Des Weiteren fanden sich Signale für vier Methylengruppen $\left(\delta_{\mathrm{C}}=22.7-45.9\right)$ sowie zwei Methingruppen $\left(\delta_{\mathrm{C}}=57.9\right.$ und 60.0$)$. Im ${ }^{1}$ H-NMR-Spektrum waren elf Signale erkennbar, wobei im Aromatenbereich zwei DublettSignale $\left(\delta_{\mathrm{H}}=6.69\right.$ und 7.03) auftraten, die für jeweils zwei Protonen integrierten und somit auf das Vorliegen eines para-disubstituierten Aromaten schließen ließen. Eine Datenbanksuche mit diesen Vorgaben ergab, dass das Diketopiperazin Cyclo(tyrosylprolyl) (83) vorlag. Ein Vergleich der NMR-Daten bestätigte zwar die Zuordnung, ${ }^{210}$ eine eindeutige Ableitung der Stereochemie an den Positionen C-11 und C-2 konnte jedoch nicht erfolgen.<smiles>O=C1N[C@@H](Cc2ccc(O)cc2)C(=O)N2CCC[C@H]12</smiles> 
Bei Diketopiperazinen handelt es sich um eine unter Mikroorganismen weit verbreitete Substanzklasse. So wurde $\mathbf{8 3}$ unter anderem aus Myxobakterien, ${ }^{137}$ Pilzen $^{211}$ sowie aus Pseudomonaden $^{210}$ und Streptomyceten ${ }^{212,213}$ isoliert. Die Verbindung ist als Wachstumsregulator bei Pflanzen sowie als Chitinase-Hemmstoff beschrieben worden. ${ }^{214}$

\section{6. $\quad N$-Acetyltyramin (84)}

Im Kulturfiltrat von JP90 fand sich weiterhin eine auf dem Dünnschichtchromatogramm bei $254 \mathrm{~nm}$ löschende, mit Anisaldehyd in der Wärme intensiv rot-orange anfärbende Verbindung. Nach Auftrennung wurden $4.2 \mathrm{mg} / \mathrm{L}$ des farblosen Feststoffs 84 erhalten, dessen Molekulargewicht durch ein ESI-Massenspektrum zu $260 \mathrm{~g} / \mathrm{mol}$ bestimmt wurde. Das ${ }^{1}$ H-NMR-Spektrum zeigte neben Methylprotonen einer Acetylgruppe $\left(\delta_{\mathrm{H}}=1.83\right)$ zwei benachbarte Methylengruppen $\left(\delta_{\mathrm{H}}=2.60\right.$ und 3.25) sowie zwei Signale im Tieffeld-Bereich $\left(\delta_{\mathrm{H}}=6.65\right.$ und 6.95), die für je zwei Protonen integrierten und aufgrund ihres charakteristischen Kopplungsmusters das Vorliegen eines para-disubstituierten Aromaten anzeigten. Dem ${ }^{13} \mathrm{C}$-NMR-Spektrum waren acht Resonanzen $\mathrm{zu}$ entnehmen, wobei die Tieffeld-Verschiebung des quartären, aromatischen Kohlenstoffatoms bei $\delta_{\mathrm{C}}=156.9$ auf die Anwesenheit einer Hydroxylgruppe schließen ließ. Durch eine Datenbanksuche mit Antibase $^{148}$ konnte 84 als $N$-Acetyltyramin (84) identifiziert werden.

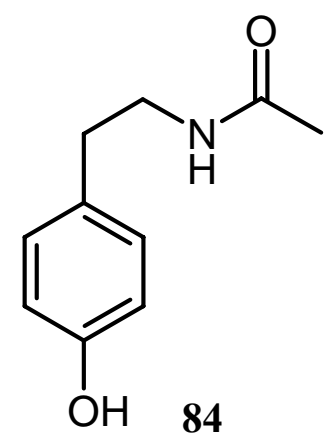

84 wurde erstmals 1959 aus Streptomyces griseus isoliert. ${ }^{215}$ Im Jahr 1987 wurde es im Rahmen eines Screening-Ansatzes wiederentdeckt, bei dem gezielt nach Substanzen gesucht wurde, die einer Desensibilisierung von Leukämie-P388/ADR-Zellen gegenüber Doxorubicin entgegenwirken. 84 konnte in diesem Zusammenhang eine teilweise Aufhebung der Resistenz gegen diesen gebräuchlichen Antitumor-Wirkstoff herbeiführen. ${ }^{216}$ Desweiteren sind Derivate von 84 wie das aus Corynebakterien isolierte $N$-2-Methylbutyryl-tryptamin potente Inhibi- 
toren von Aldose-Reduktasen. Diese Enzyme stehen im Verdacht, an der Entstehung von Diabetes-bedingten Folgeerkrankungen beteiligt zu sein. ${ }^{217,218}$

\section{7. Übrige Metaboliten}

Neben $1 \mathrm{mg} / \mathrm{L} N_{\beta}$-Acetyltryptamin (70), das bereits als Metabolit von Stamm Gö TS19 gefunden wurde (siehe Kapitel B.6.3.), konnten $0.7 \mathrm{mg} / \mathrm{L}$ einer weiteren Substanz isoliert werden. Der farblose Feststoff $\mathbf{8 5}$ färbt mit Anisaldehyd in der Wärme gelb an, löscht UVLicht bei $254 \mathrm{~nm}$ und fluoresziert hellblau bei $366 \mathrm{~nm}$. 85 zeigte im EI-Massenspektrum das Ion höchster Masse bei $\mathrm{m} / \mathrm{z}=161$ sowie ein Fragment-Ion bei einer für Carbonsäuren charakteristischen Abspaltung von $\Delta \mathrm{m} / \mathrm{z}=45$ Masseneinheiten. Im ${ }^{1} \mathrm{H}-\mathrm{NMR}$-Spektrum waren fünf Protonen im aromatischen Bereich $\left(\delta_{\mathrm{H}}=7.14-8.10\right)$ detektierbar, wobei ein SingulettSignal bei 7.88 das Vorliegen eines 3-substituierten Indolderivates vermuten ließ. Im ${ }^{13}$ C-NMR-Spektrum waren neun Resonanzen sichtbar, wobei ein Signal bei $\delta_{\mathrm{C}}=170.3$ die Existenz der im Molekül bereits vermuteten Carboxylgruppe bestätigte. Durch eine Datenbanksuche in Antibase konnte 85 als 3-Indolcarbonsäure (85) identifiziert werden. Ein Vergleich der NMR-Daten mit Literaturwerten bestätigte die Zuordnung. ${ }^{140}$

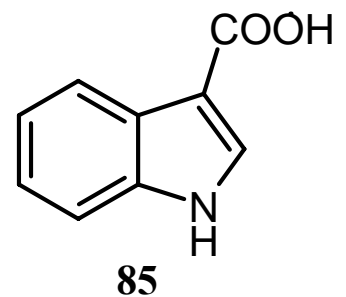

85 ist auch unter den Namen Heteroauxin sowie Rhizopin bekannt und spielt als Wuchsstoff im Metabolismus von Pflanzen eine Rolle. ${ }^{219}$ Ebenso ist die Verbindung als Metabolit mariner Mikroorganismen sowie halophiler Bakterien ${ }^{220}$ bekannt.

\subsection{Biologische Aktivität der Metaboliten}

Bei einem Test auf antimikrobielle Aktivität gegen Escherichia coli, Bacillus subtilis, Staphylococcus aureus und Candidaalbicans zeigten weder der Phosphoryloxyphenylacrylester 80 noch die Verbindungen 6-Hydroxy-6-methylheptansäure $\mathbf{8 1}$ und Rosiridol 82 eine hemmende Wirkung. Die übrigen Metaboliten aus JP90 wurden bisher noch nicht auf ihr biologisches Wirkpotenzial hin untersucht. 


\section{Zusammenfassung der Ergebnisse}

\section{Biosyntheseuntersuchungen}

1. Die Kultivierung des Bafilomycin-Produzenten Streptomyces griseus Stamm 3822-14F und die zur Isolierung der Reinsubstanzen verwendete Chromatographie-Sequenz wurden auf die Erfordernisse von Biosyntheseuntersuchungen hin optimiert.

2. Durch Fütterungsexperimente mit $\left[1-{ }^{13} \mathrm{C}\right]-$ und $\left[1,2-{ }^{13} \mathrm{C}_{2}\right]$ Acetat sowie $\left[3-{ }^{13} \mathrm{C}\right]$ Propionat und $\left[1-{ }^{13} \mathrm{C}\right]$ Isobutyrat konnte die Herkunft von 29 der 33 Kohlenstoffatome des Bafilomycin (11)-Grundgerüsts bewiesen werden. Zusätzlich konnten für die Biosynthese der Seitenkette von Bafilomycin $B_{1}(\mathbf{1 1 b})$ eindeutige Beweise für einen Aufbau aus Succinat (28) und 5-Aminolävulinsäure (27) gefunden werden. ${ }^{221}$

3. Durch Fütterung von $\left[\mathrm{U}_{-}{ }^{13} \mathrm{C}_{3}\right]$ Glycerin konnte gezeigt werden, dass die auf zwei „ungewöhnlich methoxylierte“ $\mathrm{C}_{2}$-Einheiten verteilten restlichen vier Kohlenstoffatome dem Kohlenhydrat-Stoffwechsel entstammen.

4. Einbauversuche mit [Methyl- $\left.{ }^{13} \mathrm{C}\right] \mathrm{L}-$ Methionin ergaben, dass diese Aminosäure der Überträger der beiden Methoxygruppen an C-2 und C-14 ist.

5. Zufütterung der 2-Hydroxy- und 2-Methoxy-[1- $\left.{ }^{13} \mathrm{C}\right]$ malonyl-SNAC-ester 31 und 32 führte zu keiner Anreicherung in den methoxylierten $\mathrm{C}_{2}$-Einheiten. Dieses Experiment gibt wertvolle Hinweise darauf, dass 2-Hydroxymalonyl- bzw. 2-Methoxymalonyl-CoA keine Vorläufer für die untersuchten Bausteine sind.

6. 31 und 32 führten bei analogen Fütterungsexperimenten mit dem Concanamycin (10)Bildner Streptomyces sp. Stamm Gö 22/15 nicht zu einer Anreicherung in den entsprechenden $\mathrm{C}_{2}$-Einheiten des Concanamycin $\mathrm{A}$ (10a), was die bei den Bafilomycinen (11) erhaltenen Ergebnisse stützt.

7. Durch die aus Einbauversuchen mit $\left[1,2-{ }^{13} \mathrm{C}_{2}\right]-s n$ - (35) und $\left[2,3-{ }^{13} \mathrm{C}_{2}\right]-s n$-Glycerin (37) an Stamm Gö 22/15 erhaltenen Ergebnisse konnte eine Beteiligung des Enzyms Glycerin-Kinase an der Biosynthese der methoxylierten $\mathrm{C}_{2}$-Einheiten nahegelegt werden. Vergleichende Fütterungsexperimente am Bafilomycin(11)-Bildner Streptomyces griseus Stamm 3822-14F stehen noch aus. 


\section{Gencluster von Concanamycin A (10a)}

In einem von BMBF geförderten Projekt wird derzeit der Biosynthese-Gencluster von Concanamycin A (10a) sequenziert. Erste verfügbare Daten (39.2 kb von erwarteten etwa $79.2 \mathrm{~kb}$ ) wurden im Rahmen der vorliegenden Arbeit ausgewertet.

1. In den Sequenzdaten konnten die für die vier letzten PKS-Module codierenden Bereiche zugeordnet werden, darunter auch das für den Einbau der methoxylierten Einheit verantwortliche Modul 13.

2. In einer phylogenetischen Analyse der Acyltransferase-Domäne des Moduls 13 konnte festgestellt werden, dass diese sich nicht mit anderen Methoxymalonyl-spezifischen Domänen gruppiert.

3. Die für die Biosynthese des Methoxymalonyl-Vorläufers putativ verantwortlichen Gene konnten identifiziert und eine Funktionszuweisung durchgeführt werden. Unter Einbeziehung der aus Fütterungsexperimenten erhaltenen Ergebnisse konnte ein Biosyntheseweg postuliert werden.

4. Die putativen Biosynthesegene des 2-Desoxy-D-rhamnosidbausteins (39) konnten identifiziert und ein auf deren Funktionen basierender Biosyntheseablauf vorgeschlagen werden.

5. Erste Transformations- und Konjugationsversuche am Concanamycin (10)-Produzenten Streptomyces sp. Stamm Gö 22/15 wurden vollzogen, führten jedoch nicht zum Erfolg.

\section{Darstellung eines photomarkierten Bafilomycin-Derivates}

Für Bindungsstudien des V-ATPase-Inhibitors Bafilomycin $A_{1}$ (11a) am Enzym sollte ein geeignet markiertes Derivat hergestellt werden.

1. Eine auf den Anforderungen des verwendeten biologischen Testsystems basierende Markierungsstrategie wurde abgeleitet und ein Syntheseplan für das entsprechende Bafilomycin $\mathrm{A}_{1}$-Derivat $\mathbf{4 4}$ aufgestellt. 
2. Ausgehend von 4-[3-(Trifluormethyl)-3H-diazirin-3-yl)benzoesäure (41) und dem Naturstoff Bafilomycin $A_{1}$ (11a) konnte in einer zweistufigen Derivatisierung 21-O$\left\{2^{\prime}, 5^{\prime}\right.$-Dibrom-4'-[3-(trifluormethyl)-3H-diazirin-3-yl]benzoyl $\}$ bafilomycin $\mathrm{A}_{1}$ (44) in einer Gesamtausbeute von 39 \% dargestellt werden.

3. Eine vorliegende Hemmkurve für das Bafilomycinderivat $\mathbf{4 4}$ zeigte gegenüber dem Naturstoff 11a eine Abnahme der inhibitorischen Aktivität um den Faktor zehn. Gründe für diese Beobachtung wurden diskutiert. Bisherige Untersuchungen zeigen, dass der Wirkort am V-ATPase-Proteinkomplex verschieden von dem des Concanamycin A (10a) ist.

\section{Isolierung von Sekundärmetaboliten aus Actinomyceten}

1. Von über 30 aus Erdproben isolierten Actinomyceten-Stämmen wurden vierzehn Stämme einem chemischen Screening unterzogen. Fünf hinsichtlich ihres Metabolitenmusters auffällige Actinomyceten wurden zur Weiterbearbeitung selektiert. Dabei wurden sechs neue, bisher nicht in der Literatur beschriebene Naturstoffe gefunden, elf bereits bekannte wurden mittels Datenbankrecherchen identifiziert.

2. Aus dem Kulturfiltrat des Stammes Gö GS56 konnten die bislang nicht bekannten Verbindungen (Cyanomethyldihydroxymethylbutyl)indol 45 sowie das Dimethyluridin 46 isoliert werden. Weiterhin wurde das bereits in der Literatur beschriebene Thioaurin (47) erhalten.

3. Die literaturbekannten Verbindungen 2,3-Dihydroxybenzoesäure (55) und 2-Aminobenzamid (57) wurden im Extrakt des Kulturfiltrates von Stamm Gö TS15 gefunden.

4. Der Stamm Gö TS17 erwies sich als Angucyclin-Produzent. Neben dem bekannten Grincamycin (59) wurde auf die Existenz weiterer Vertreter dieser Stoffklasse im Kulturfiltrat von Gö TS17 geschlossen, welche aufgrund der zu geringen Ausbeuten nicht näher charakterisiert werden konnten. 
5. Im Kulturfiltratextrakt des Stammes Gö TS18 wurde neben dem bekannten Antibiotikum Virginiamycin $M_{1}$ (62) auch 16-Dihydro-Virginiamycin $M_{1}$ (63) gefunden, welches bislang nur als Syntheseprodukt bekannt war. Neben weiteren strukturanalogen Verbindungen von 62, welche aufgrund zu geringer Substanzmengen nicht näher charakterisiert werden konnten, wurde die bisher in der Literatur nicht beschriebene Verbindung Dimethylaminophenylhydroxy-propionsäureamid (64) isoliert und in ihrer Struktur aufgeklärt. Als bekannte Verbindungen konnten Phenylacetamid (65), 2'-O-Methyluridin (66) sowie 2- und 4-Aminobenzamid (57 bzw. 67) im Extrakt von Gö TS18 gefunden werden.

6. Als Sekundärmetabolit des Stammes Gö TS19 konnte die neue Verbindung Okaspirodiol (68) gefunden werden. Im Rahmen der Diplomarbeit von T. BENDER ${ }^{193}$ wurde deren absolute Stereochemie per Kristallstruktur bestimmt sowie eine Totalsynthese und ein Biogeneseschema basierend auf Fütterungsexperimenten ausgearbeitet. Im Kulturfiltrat einer 50 L-Fermentation von Gö TS19 wurde neben der bekannten Verbindung $N_{\beta}$-Acetyltryptamin (70) auch das als Naturstoff bislang nicht beschriebene 3-Amino-4-chlorbenzamid (69) gefunden.

7. Die als Metaboliten der untersuchten Actinomyceten erhaltenen nicht literaturbekannten Verbindungen wurden in Plattendiffusionstests auf ihre antibakterielle Aktivität hin untersucht. 63 zeigte einen deutlichen Hemmeffekt auf das Wachstum von Staphylococcus aureus, während sich die übrigen Substanzen als inaktiv erwiesen.

\section{Endosymbionten aus Aplidium lenticulum}

In einer Zusammenarbeit mit J. PIEL (MPI für chemische Ökologie, Jena) wurde der aus dem Inneren des marinen Manteltierchens Aplidium lenticulum isolierte Actinomycet Streptomyces rimosus Stamm JP90 auf die Produktion von Sekundärmetaboliten hin untersucht. Dabei wurden zwei neue, bisher nicht literaturbekannte und fünf bereits beschriebene Verbindungen isoliert und identifiziert. 
1. Aus dem Kulturfiltrat einer 4 L-Fermentation des Stammes JP90 konnten die bislang nicht bekannten Verbindungen Phosphoroxyphenyl-acrylsäureester 80a bzw. Phosphoryloxyphenyl-acrylimidsäuremethylester 80b und 6-Hydroxy-6-methylheptansäure (81) isoliert und in ihrer Struktur aufgeklärt werden. 80 enthält das für Sekundärstoffe ungewöhnliche Element Phosphor.

2. Im Extrakt von JP90 konnte weiterhin das bisher nur als Pflanzenmetabolit beschriebene Rosiridol (82) sowie die bereits aus Mikroorganismen isolierten Verbindungen Desferrioxamin E (79), Cyclo(tyrosylprolyl) (83), $N$-Acetyltyramin (84), und Indol-3-carbonsäure (85) gefunden werden.

3. Die aus dem Stamm isolierten Metaboliten 80, 81 und 82 wurden in Plattendiffusionstests auf ihre antibakterielle Aktivität gegenüber Escherichia coli, Bacillus subtilis, Staphylococcus aureus und Candida albicans hin untersucht. Die getesteten Substanzen zeigten keinen wachstumshemmenden Effekt. 


\section{B. Experimenteller Teil}

\section{Allgemeines}

\section{Instrumentelle Analytik}

Massenspektren: EI-MS: Finnigan MAT 95, $70 \mathrm{eV}$, Hochauflösungen mit Perfluorkerosin als Vergleichssubstanz, die relativen Intensitäten beziehen sich auf den Basispeak $(I=100 \%)$ und sind in Klammern angegeben. DCI-MS: Finnigan MAT 95, $200 \mathrm{eV}$, Reaktandgas $\mathrm{NH}_{3}$. ESI-MS: Finnigan LC-Q. HR-ESI-MS: Bruker Apex-Q III, 7 Tesla.

Infrarotspektren (IR): Alle IR-Spektren wurden mit einem FT-IR-Spektrometer der Firma Perkin-Elmer (Modell 1600) aufgenommen, wobei die Substanzen in Form von $\mathrm{KBr}$ Presslingen vermessen wurden, $\mathrm{sh}=$ Schulter.

Elektronenspektren (UV): Alle Elektronenspektren wurden mit einem Spektrometer der Firma Varian (Modell Cary 3E) gemessen. Der molare Extinktionskoeffizient $\varepsilon$ ist in der Dimension $\left[1000 \mathrm{~cm}^{2} \mathrm{~mol}^{-1}\right]$ angegeben, $\mathrm{sh}=$ Schulter;

Methanol / HCl bzw. Methanol / NaOH: Zu 2 mL methanolischer Lösung wurde jeweils ein Tropfen $1 \mathrm{M} \mathrm{HCl}$ bzw. $1 \mathrm{M} \mathrm{NaOH}$ gegeben. $\varepsilon$ wurde nach folgender Formel berechnet:

$$
\varepsilon=\frac{\text { Absorption } \cdot \text { Molmasse } \cdot 10}{\text { Einwaage in } \mathrm{mg}}
$$

Drehwerte: Alle Drehwerte $[\alpha]_{\mathrm{D}}^{20}$ wurden mit einem Polarimeter der Firma Perkin-Elmer

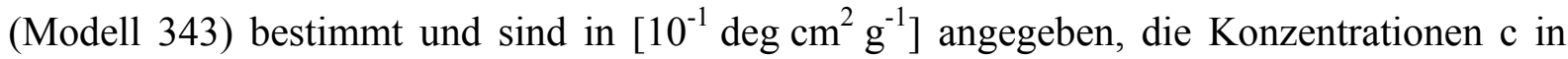
$\left[10^{-2} \mathrm{~g} \mathrm{ml}^{-1}\right]$.

${ }^{1}$ H-NMR-Spektren: Varian Inova-600 (600 MHz), Varian Inova-500 (500 MHz), Varian Mercury-300 (300 MHz), Varian Unity-300 (300 MHz), Bruker AMX 300 (300 MHz). Chemische Verschiebungen in $\delta$-Werten ( $\mathrm{ppm}$ ) relativ zum jeweiligen Lösungsmittel als internem Standard; Kopplungskonstanten $(J)$ in Hertz $(\mathrm{Hz})$. 
Abkürzungen: $\mathrm{s}=$ Singulett, $\mathrm{d}=$ Dublett, $\mathrm{dd}=$ Dublett vom Dublett, $\mathrm{ddd}=$ Dublett vom Dublett vom Dublett, ddt $=$ Dublett vom Dublett vom Triplett, $\mathrm{dt}=$ Dublett vom Triplett, $\mathrm{t}=$ Triplett, $\mathrm{td}=$ Triplett vom Dublett, $\mathrm{q}=$ Quartett, $\mathrm{qd}=$ Quartett vom Dublett, quint $=$ Quintett, thept $=$ Triplett vom Heptett, $\mathrm{m}=$ Multiplett, $\mathrm{br}=$ breit.

Alle ${ }^{1}$ H-NMR-Spektren wurden näherungsweise als Spektren erster Ordnung interpretiert.

${ }^{13}$ C-NMR-Spektren: Varian Inova-600 (150.8 MHz), Varian Inova-500 (125.7 MHz), Varian Mercury-300 (75.5 MHz), Varian Unity-300 (75.5 MHz), Bruker AMX-300 (75.5 MHz). Chemische Verschiebungen in $\delta$-Werten (ppm) relativ zum jeweiligen Lösungsmittel als internem Standard.

APT (Attached Proton Test): $\mathrm{CH}$ und $\mathrm{CH}_{3}$ stehen nach oben, $\mathrm{C}$ und $\mathrm{CH}_{2}$ stehen nach unten.

${ }^{13} \mathrm{C}-{ }^{1} \mathrm{H}-$ Multiplizitäten sind aus HSQC-Experimenten in Verbindung mit APT-Experimenten ableitbar. Abkürzungen: $\mathrm{s}=$ Singulett, $\mathrm{d}=$ Dublett, $\mathrm{t}=$ Triplett, $\mathrm{q}=$ Quartett.

2D-NMR-Spektren: ${ }^{1} \mathrm{H},{ }^{1} \mathrm{H}-\mathrm{COSY}\left({ }^{1} \mathrm{H},{ }^{\mathbf{1}} \mathrm{H}\right.$-Correlated Spectroscopy), HSQC (Heteronuclear Singular Quantum Coherence), HMBC (Heteronuclear Multiple Bond Connectivity).

\section{Chromatographische Methoden}

Dünnschichtchromatographie (DC): Merck HPTLC-Fertigplatten Kieselgel 60 F $\mathrm{F}_{254}$ : 10 x $10 \mathrm{~cm}$, Schichtdicke $0.2 \mathrm{~mm}$; Merck DC-Alufolien Kieselgel $60 \mathrm{~F}_{254}: 20 \times 20 \mathrm{~cm}$, Schichtdicke $0.2 \mathrm{~mm}$; Merck DC-Alufolien RP-18 $\mathrm{F}_{254 \mathrm{~s}}: 20$ x $20 \mathrm{~cm}$, Schichtdicke $0.2 \mathrm{~mm}$. Angegeben sind $\mathrm{R}_{\mathrm{f}}$-Werte (Laufhöhe relativ zur Laufmittelfront).

Säulen- und Gelchromatographie: ICN Kieselgel 60 (KG), $32-63 \mu \mathrm{m}$, Flash-Kieselgel: MN KG 60, $<0.063$ mm, Flashchromatographie nach W. C. Still, ${ }^{222}$ Fluka Sephadex ${ }^{\circledR}$ LH-20, Merck Lobar C-8.

Sprühreagenzien: Nach Merck, Anfärbereagenzien für die Dünnschichtchromatographie. ${ }^{223}$ Die DC-Platten wurden nach dem Ansprühen auf ca. $120^{\circ} \mathrm{C}$ erwärmt.

Anisaldehyd (Anis, Nr. 21): $1.0 \mathrm{~mL}$ Anisaldehyd in einer Lösung aus $85 \mathrm{~mL}$ Methanol, $10 \mathrm{~mL}$ Eisessig und $5 \mathrm{~mL}$ konz. Schwefelsäure. 
Ehrlichs Reagenz (Ehrlich, Nr. 91): 1 g 4-Dimethylaminobenzaldehyd in einer Mischung aus $25 \mathrm{~mL}$ Salzsäure (36\%) und $75 \mathrm{~mL}$ Methanol.

Orcin-Sprühreagenz (Orcin, Nr. 120-122): Mischung aus gleichen Teilen von $1 \mathrm{~g}$ Eisen(III)-chlorid in $100 \mathrm{~mL}$ Schwefelsäure und 6 \%iger ethanolischer Orcinlösung.

Analytische HPLC: Pumpe: Kontron Modell 322; Autosampler: Kontron 360; Detektor: Kontron Diode Array Detector 440; Mischkammer: Kontron HPLC 360, Datensystem: Kontron Kromasystem 2000 Version 1.60; analytische Aufgabenschleife; Säule: Knauer Nucleosil-100 C18, $5 \mu \mathrm{m}, 250 \times 3$ mm; Lösungsmittelsystem: Lösung A: $0.1 \%$ Trifluoressigsäure in Wasser, Lösung B: 0.1 \% Trifluoressigsäure in Acetonitril; Gradient: von 30 \% B zu $100 \%$ B in 10 Minuten, 10 Minuten $100 \%$ B; Flussrate: 0.5 mL/min.

Semipräparative HPLC: Pumpe: Jasco Modell PU-2080 Plus ( $1 \mu \mathrm{L} / \mathrm{min}-10 \mathrm{~mL} / \mathrm{min})$; Autosampler: Jasco AS-2055; Detektor: Jasco MD-2010 Plus; Datensystem: Jasco Borwin PDA; Mischkammer: Jasco LG-2080-02; Entgaser: Jasco DG-2080-53 In-line degasser; Säulenofen: Jasco CO-2065; semipräparative $500 \mu \mathrm{L}$ Aufgabeschleife; Säule: MachereyNagel Nucleodur-100 C18 ec, $5 \mu \mathrm{m}, 250$ x 8 mm, Lösungsmittelsystem: Lösung A: Wasser, Lösung B: Acetonitril, Gradient: von 20 \% B zu 100 \% B in 30 Minuten, 5 Minuten 100 \% B; Flussrate: $2.5 \mathrm{~mL} / \mathrm{min}$.

HPLC-MS: Pumpe: Flux Instruments Rheos 4000; Autosampler: Jasco AS-851 (0 - $100 \mu \mathrm{L}$ variable Aufgabeschleife); UV-Detektor: Linear UVIS-205; Massendetektor: Finnigan LC-Q; Entgaser: Flux Instruments ERC-3415a; Steuersoftware HPLC: Flux Instruments Janeiro; Datensystem: Finnigan Xcalibur; Vorsäule: Grom Supersphere 100 RP-18 endcapped, $4 \mu \mathrm{m}$, 10 x 2 mm; Säule: Grom Supersphere 100 RP-18 endcapped, $4 \mu \mathrm{m}, 100$ x 2 mm.

Programm: von $20 \%$ Methanol auf $100 \%$ Methanol in $20 \mathrm{~min}, 5 \mathrm{~min} 100 \%$ Methanol, Flussrate: $300 \mu \mathrm{L} / \mathrm{min}$; UV-Detektion: $254 \mathrm{~nm}$, Massendetektion: positive und negative Ionen.

Lösungsmittel: Für die Säulenchromatographie verwendete Lösungsmittel wurden zuvor destilliert. Für die HPLC kamen analysenreine Lösungsmittel und bidestilliertes Wasser zum Einsatz. Lösungsmittel für die analytische HPLC wurden im Ultraschallbad (10 min) und anschließend durch Durchleiten von Helium (10 min) entgast. 


\section{Mikrobiologische Methoden}

Nährmedienbestandteile: Malzextrakt, D-Glucose, Stärke und Caseinpepton stammten von der Fa. Merck. Hefeextrakt wurde von der Fa. Oxoid, Cornsteep Powder von der Fa. Marcor, D(-)-Mannit von der Fa. Riedel-deHaën, Haferkleie mit Keim (Quickvital) sowie Hafermehl (Holo Hafergold) von der Fa. Neuform, Sojamehl fettarm von der Fa. Henselwerk GmbH und BiTek Agar, Bactopepton sowie Trypton-Pepton von der Fa. Difco bezogen. Casaminoacids und Bactotrypton stammten von der Fa. Becton, Dickinson and Co.

Nährmedien: Für alle komplexen Nährmedien wurde Leitungswasser, für synthetische Medien demineralisiertes Wasser verwendet. Die pH-Werte wurden vor dem Autoklavieren mit $0.5 \mathrm{~N} \mathrm{NaOH}$ bzw. $0.5 \mathrm{~N} \mathrm{HCl}$ korrigiert. Die Nährmedien wurden durch Autoklavieren (feuchte Hitze, $121^{\circ} \mathrm{C}, 1$ bar Überdruck, $30 \mathrm{~min}$ ) sterilisiert.

Hafer-Medium: Hafermehl 20 g/L, Spurenelementlösung 11: 2.5 mL/L, pH = 6.5.

M2-Medium: Malzextrakt $10 \mathrm{~g} / \mathrm{L}$, Hefeextrakt $4 \mathrm{~g} / \mathrm{L}$, Glucose $4 \mathrm{~g} / \mathrm{L}, \mathrm{pH}=7.0$.

Für die Stammhaltung Zusatz von $\mathrm{CaCO}_{3} 0.3 \mathrm{~g} / \mathrm{L}$, Agar $20 \mathrm{~g} / \mathrm{L}$.

SM-Medium: entfettetes Sojamehl $20 \mathrm{~g} / \mathrm{L}$, Mannit $20 \mathrm{~g} / \mathrm{L}, \mathrm{pH}=7.0$.

Für die Stammhaltung Zusatz von Agar $20 \mathrm{~g} / \mathrm{L}$.

Haferkleie-Medium: Haferkleie $20 \mathrm{~g} / \mathrm{L}, \mathrm{pH}=7.8$.

SGG: Glucose $10 \mathrm{~g} / \mathrm{L}$, Glycerin $10 \mathrm{~g} / \mathrm{L}$, Stärke $10 \mathrm{~g} / \mathrm{L}$, Cornsteep Powder $2.5 \mathrm{~g} / \mathrm{L}$, Caseinpepton $5 \mathrm{~g} / \mathrm{L}$, Hefeextrakt $2 \mathrm{~g} / \mathrm{L}, \mathrm{NaCl} 1 \mathrm{~g} / \mathrm{L}, \mathrm{CaCO}_{3} 3 \mathrm{~g} / \mathrm{L}, \mathrm{pH}=7.3$

NL 1187: Stärke $10 \mathrm{~g} / \mathrm{L},\left(\mathrm{NH}_{4}\right)_{2} \mathrm{SO}_{4} 2 \mathrm{~g} / \mathrm{L}, \mathrm{K}_{2} \mathrm{HPO}_{4} 1 \mathrm{~g} / \mathrm{L}, \mathrm{MgSO}_{4}$ × $7 \mathrm{H}_{2} \mathrm{O} 1 \mathrm{~g} / \mathrm{L}, \mathrm{NaCl}$ $1 \mathrm{~g} / \mathrm{L}, \mathrm{CaCO}_{3} 2 \mathrm{~g} / \mathrm{L}$, Spurenelementlösung 11: $5 \mathrm{~mL} / \mathrm{L}$, pH unkorrigiert.

NL 1358: Glycerin $30 \mathrm{~g} / \mathrm{L}$, Caseinpepton $2 \mathrm{~g} / \mathrm{L}, \mathrm{K}_{2} \mathrm{HPO}_{4} 1 \mathrm{~g} / \mathrm{L}, \mathrm{NaCl} 1 \mathrm{~g} / \mathrm{L}, \mathrm{MgSO}_{4} \times{ }_{7} \mathrm{H}_{2} \mathrm{O}$ $0.5 \mathrm{~g} / \mathrm{L}$, Spurenelementlösung 11: $5 \mathrm{~mL} / \mathrm{L}, \mathrm{pH}=7.0$.

R5: Sucrose $103 \mathrm{~g} / \mathrm{L}, \quad \mathrm{K}_{2} \mathrm{SO}_{4} \quad 0.25 \mathrm{~g} / \mathrm{L}, \quad \mathrm{MgCl}_{2} \times 6 \mathrm{H}_{2} \mathrm{O} \quad 10.12 \mathrm{~g} / \mathrm{L}$, Glucose $10 \mathrm{~g} / \mathrm{L}$, Casaminoacids $0.1 \mathrm{~g} / \mathrm{L}$, Spurenelementlösung A $1 \mathrm{~mL}$, Hefeextrakt $5 \mathrm{~g} / \mathrm{L}$, TES Puffer $5.73 \mathrm{~g} / \mathrm{L}, \mathrm{pH}=6.5$, für die Stammhaltung Zusatz von Agar $24 \mathrm{~g} / \mathrm{L}$; nach Autoklavieren hinzufügen: $\mathrm{KH}_{2} \mathrm{PO}_{4}(0.5 \%) 5 \mathrm{~mL}, \mathrm{CaCl}_{2} \times 2 \mathrm{H}_{2} \mathrm{O}(5 \mathrm{M}) 2 \mathrm{~mL}$, L-Prolin (20\%) $7.5 \mathrm{~mL}, \mathrm{NaOH}(1 \mathrm{~N}) 3.5 \mathrm{~mL}$. 
YEME: Hefeextrakt $3 \mathrm{~g} / \mathrm{L}$, Bactopepton $5 \mathrm{~g} / \mathrm{L}$, Malzextrakt $3 \mathrm{~g} / \mathrm{L}$, Glucose $10 \mathrm{~g} / \mathrm{L}$, Sucrose $340 \mathrm{~g} / \mathrm{L}$, nach Autoklavieren hinzufügen: $\mathrm{MgCl}_{2}$ × $6 \mathrm{H}_{2} \mathrm{O}(2.5 \mathrm{M}) 2 \mathrm{~mL} / \mathrm{L}$, Glycin (20\%) $25 \mathrm{~mL} / \mathrm{L}$.

LB: Trypton-Pepton $10 \mathrm{~g} / \mathrm{L}$, Hefeextrakt $5 \mathrm{~g} / \mathrm{L}, \mathrm{NaCl} 5 \mathrm{~g} / \mathrm{L}, \mathrm{pH}=7.0$ - 7.2.

Für die Stammhaltung Zusatz von $\mathrm{CaCO}_{3} 0.3 \mathrm{~g} / \mathrm{L}$, Agar $20 \mathrm{~g} / \mathrm{L}$.

2 x YT: Bactotrypton 16 g/L, Hefeextrakt 10 g/L, NaCl 5 g/L.

Spurenelementlösung 11: $\mathrm{CaCl}_{2}$ × $2 \mathrm{H}_{2} \mathrm{O} 3 \mathrm{~g} / \mathrm{L}, \mathrm{Fe}(\mathrm{III})$-citrat $1 \mathrm{~g} / \mathrm{L}, \mathrm{MnSO}_{4} 0.2 \mathrm{~g} / \mathrm{L}, \mathrm{ZnCl}_{2}$ $0.1 \mathrm{~g} / \mathrm{L}, \quad \mathrm{CuSO}_{4} \times 5 \mathrm{H}_{2} \mathrm{O} \quad 0.025 \mathrm{~g} / \mathrm{L}, \quad \mathrm{Na}_{2} \mathrm{~B}_{4} \mathrm{O}_{7} \times 10 \mathrm{H}_{2} \mathrm{O} \quad 0.02 \mathrm{~g} / \mathrm{L}, \quad \mathrm{CoCl}_{2} \quad 0.004 \mathrm{~g} / \mathrm{L}$, $\mathrm{Na}_{2} \mathrm{MoO}_{4} \times 2 \mathrm{H}_{2} \mathrm{O} 0.01 \mathrm{~g} / \mathrm{L}$.

Spurenelementlösung A: $\mathrm{ZnCl}_{2} 0.04 \mathrm{~g} / \mathrm{L}, \mathrm{FeCl}_{3} \times 6 \mathrm{H}_{2} \mathrm{O} 0.2 \mathrm{~g} / \mathrm{L}, \mathrm{CuCl}_{2} \times 2 \mathrm{H}_{2} \mathrm{O} 0.01 \mathrm{~g} / \mathrm{L}$, $\mathrm{MnCl}_{2}$ × $4 \mathrm{H}_{2} \mathrm{O} 0.01 \mathrm{~g} / \mathrm{L}, \mathrm{Na}_{2} \mathrm{~B}_{4} \mathrm{O}_{7}$ × $10 \mathrm{H}_{2} \mathrm{O} 0.01 \mathrm{~g} / \mathrm{L},\left(\mathrm{NH}_{4}\right)_{2} \mathrm{MoO}_{4} \times 4 \mathrm{H}_{2} \mathrm{O} 0.01 \mathrm{~g} / \mathrm{L}$.

TES-Puffer: 20 mM TRIS ( $\mathrm{pH}=8.0), 10 \mathrm{mM}$ EDTA $(\mathrm{pH}=8.0), 25 \%$ Saccharose.

Für Transformations- und Konjugationsversuche verwendete Puffer / Lösungen:

P1: $\quad$ Tris- $\mathrm{HCl}(\mathrm{pH}=8.0) 7.9 \mathrm{~g} / \mathrm{L}$, EDTA $(\mathrm{pH}=8.0) 3.7 \mathrm{~g} / \mathrm{L}$.

P2: Natriumdodecylsulfat (SDS, $10 \%) 100 \mathrm{~mL}, \mathrm{NaOH}(1 \mathrm{M}) 200 \mathrm{~mL}, \mathrm{ddH}_{2} \mathrm{O} 700 \mathrm{~mL}$.

P3: $5 \mathrm{M}$ Kaliumacetat $600 \mathrm{~mL}$, Eisessig $115 \mathrm{~mL}, \mathrm{ddH}_{2} \mathrm{O} 285 \mathrm{~mL}$.

P-Puffer: Sucrose $103 \mathrm{~g}, \mathrm{~K}_{2} \mathrm{SO}_{4} 0.25 \mathrm{~g}, \mathrm{MgCl}_{2}$ x $6 \mathrm{H}_{2} \mathrm{O} 2.02 \mathrm{~g}$, Spurenelementlösung A $2 \mathrm{~mL}$, mit $\mathrm{ddH}_{2} \mathrm{O}$ auf $800 \mathrm{~mL}$ auffüllen; nach Autoklavieren hinzufügen: $\mathrm{KH}_{2} \mathrm{PO}_{4}(0.5 \%) 1 \mathrm{~mL}, \mathrm{CaCl}_{2} \times 2 \mathrm{H}_{2} \mathrm{O}(3.68 \%) 10 \mathrm{~mL}$, TES-Puffer $(5.73 \%$, $\mathrm{pH}=7.2) 10 \mathrm{~mL}$.

TESLR: $\quad 25 \mathrm{mM}$ Tris-HCl $(\mathrm{pH}=8.0), 25 \mathrm{mM} \quad$ EDTA $\quad(\mathrm{pH}=8.0), \quad 0.3 \mathrm{M}$ Sucrose, $0.2 \mathrm{mg} / \mathrm{mL}$ Lysozym (Sigma).

TE: $\quad$ Tris- $\mathrm{HCl}(2 \mathrm{M}, \mathrm{pH}=8.0) 5 \mathrm{~mL}$, EDTA $(0.25 \mathrm{M}, \mathrm{pH}=8.0) 4 \mathrm{~mL}, \mathrm{ddH}_{2} \mathrm{O} 991 \mathrm{~mL}$.

NaOH / SDS: $0.3 \mathrm{M} \mathrm{NaOH,} \%$ SDS.

Isotopenmarkierte Verbindungen: $\left[1-{ }^{13} \mathrm{C}\right]$ Acetat wurde von der Firma Campro Scientific Inc., $\left[3-{ }^{13} \mathrm{C}\right]$ Propionate von Isotec Inc. bezogen. $\left[1,2-{ }^{13} \mathrm{C}_{2}\right]$ Acetat, $\left[\mathrm{U}-{ }^{13} \mathrm{C}_{3}\right]$ Glycerin und $\left[1-{ }^{13} \mathrm{C}\right]$ Isobutyrat stammten von Cambridge Isotope Lab. (CIL).

Schüttler und Fermenter: Braun Inkubationsschüttelschrank BS4, Braun Certomat RM, Braun Biostat B (2 L und 5 L), Braun Biostat E (10 L), Braun Biostat U (50 L), Ingold $\mathrm{O}_{2}$ Elektrode. 
Plattendiffusionstest: Auf die mit den verschiedenen Testkeimen beimpfte Agarplatte wurden Filterplättchen (Durchmesser: $6 \mathrm{~mm}$, Dicke: $0.5 \mathrm{~mm}$ ) gelegt, die mit $15 \mu \mathrm{L}$ Substanzlösung (in Methanol gelöst, $\mathrm{c}=1 \mathrm{mg} / \mathrm{mL}$ ) getränkt und vor dem Auflegen unter sterilen Bedingungen getrocknet worden waren. Als Testkeime dienten Bacillus subtilis, Escherichia coli, Staphylococcus aureus und Candida albicans. Die Agarplatten wurden $24 \mathrm{~h}$ bei $25^{\circ} \mathrm{C}$ (C. albicans) bzw. $37^{\circ} \mathrm{C}$ (B. subtilis, E. coli und S. aureus) inkubiert.

\section{Zusammensetzung der Nährböden für die Plattendiffusionstests:}

B. subtilis und E. coli: Glucose $5 \mathrm{~g} / \mathrm{L}$, Trinatriumcitrat $\times 2 \mathrm{H}_{2} \mathrm{O} 0.5 \mathrm{~g} / \mathrm{L}, \mathrm{KH}_{2} \mathrm{PO}_{4} 3 \mathrm{~g} / \mathrm{L}$, $\mathrm{K}_{2} \mathrm{HPO}_{4} 7 \mathrm{~g} / \mathrm{L}, \mathrm{MgSO}_{4} \times 7 \mathrm{H}_{2} \mathrm{O} 0.1 \mathrm{~g} / \mathrm{L},\left(\mathrm{NH}_{4}\right)_{2} \mathrm{SO}_{4} 1 \mathrm{~g} / \mathrm{L}$ und Agar $15 \mathrm{~g} / \mathrm{L}$, keine pHEinstellung.

S. aureus: Bacto Nutrient Broth $8 \mathrm{~g} / \mathrm{L}, \mathrm{NaCl} 5 \mathrm{~g} / \mathrm{L}$ und Agar $15 \mathrm{~g} / \mathrm{L}$, keine pH-Einstellung.

C. albicans: Hefeextrakt 4 g/L, Malzextrakt $10 \mathrm{~g} / \mathrm{L}$, Glucose $4 \mathrm{~g} / \mathrm{L}$ und Agar $15 \mathrm{~g} / \mathrm{L}, \mathrm{pH}=5.5$.

Zum Ansetzen der Testplatten-Medien wurde demineralisiertes Wasser verwendet. Die Glucose wurde erst nach der 30minütigen Sterilisation hinzugegeben. 


\section{Biosyntheseuntersuchungen an Plecomakroliden}

\section{Fütterungsexperimente am Bafilomycin-Produzenten}

\subsection{Stammhaltung von Streptomyces griseus Stamm 3822-14F}

Die für die Stammhaltung eingesetzten SM-Agarplatten wurden nach Beimpfung für drei Tage bei $28^{\circ} \mathrm{C}$ inkubiert und anschließend bei $4{ }^{\circ} \mathrm{C}$ maximal drei Monate aufbewahrt. Stamm 3822-14F färbte nach Anwachsen den Agar braun und bildete ein graues Luftmycel aus. Die Langzeitkonservierung erfolgte durch Einlagerung eingeschweißter, gut bewachsener Agarstückchen in flüssigem Stickstoff.

\subsection{Fermentation und Aufarbeitung}

Alle Fermentationen für Biosyntheseuntersuchungen wurden im $500 \mathrm{~mL}-\mathrm{Maßstab}$ im Medium NL 1358 auf einem Längsschüttler bei $120 \mathrm{rpm}$ und $28^{\circ} \mathrm{C}$ durchgeführt. Zum Animpfen der mit je $250 \mathrm{~mL}$ befüllten 1 L-Erlenmeyerkolben diente $1 / 8$ einer gut bewachsenen Agarplatte. Die Aufarbeitung der Kulturen erfolgte nach 70 h durch Korrektur des pH-Wertes auf 6.0 und anschließender 20minütiger Zentrifugation bei $3200 \mathrm{rpm}$. Das Kulturfiltrat wurde zweimal mit je $1 \mathrm{~L}$ Essigester extrahiert und das Lösungsmittel im Vakuum entfernt. Fermentationsvariationen wurden unter Verwendung der Medien SM und NL 1187 durchgeführt.

\subsection{Erstellen der Fermentationskurve}

Zur Erstellung der Fermentationskurve wurden aus wachsenden Kulturen von Stamm 3822$14 \mathrm{~F}$ ab der achten Inkubationsstunde alle vier bis sechs Stunden Proben von je $10 \mathrm{~mL}$ Volumen entnommen. Diese wurden mit $15 \mathrm{~mL}$ Essigester extrahiert, wobei $10 \mathrm{~mL}$ der organischen Phase abgetrennt wurden. Nach Entfernung des Lösungsmittels im Vakuum wurden die erhaltenen Extrakte in $10 \mathrm{~mL}$ Acetonitril aufgenommen und mittels HPLC (Programm 1) analysiert. Die erhaltenen Bafilomycin (11a, 11b)-Konzentrationen wurden mittels einer Eichkurve bestimmt. 


\subsection{Isolierung der Bafilomycine 11a und 11b}

Die Isolierung der Bafilomycine (11a, 11b) erfolgte gemäß Abbildung 7 (Kapitel A.II.4.2.) durch Säulenchromatographie an Kieselgel (Eluent: Cyclohexan / Aceton 3:2) und Sephadex ${ }^{\circledR}$ LH-20 (Eluent: Dichlormethan).

\subsection{Durchführung der Fütterungsexperimente}

Alle zugefütterten markierten Vorläufer wurden zunächst in $80 \mathrm{~mL}$ sterilem Wasser gelöst und der pH-Wert gegebenenfalls durch Zugabe von 2 M Salzsäure bzw. Natronlauge auf 7.0 korrigiert. Die Lösungen wurden den Ansätzen zu gleichen Teilen kontinuierlich von der 32. bis zur 56. Inkubationsstunde zugepumpt. Die Endkonzentrationen der gefütterten Substanzen betrugen: $9.1 \mathrm{mM}$ Natrium- $\left[1-{ }^{13} \mathrm{C}\right]$ acetat, $6.0 \mathrm{mM}$ Natrium- $\left[1,2-{ }^{13} \mathrm{C}_{2}\right]$ acetat, $3.6 \mathrm{mM}$ Natrium$\left[3-{ }^{13} \mathrm{C}\right]$ propionat, $3.2 \mathrm{mM}$ Natrium- $\left[1-{ }^{13} \mathrm{C}\right]$ isobutyrat, $5.3 \mathrm{mM}\left[\mathrm{U}-{ }^{13} \mathrm{C}_{3}\right]$ Glycerin, $1.9 \mathrm{mM}$ 2-Hydroxy- $\left[1-{ }^{13} \mathrm{C}\right]$ malonyl- $N$-acetylcysteamin (31) und $0.9 \mathrm{mM}$ 2-Methoxy- $\left[1-{ }^{13} \mathrm{C}\right]$ malonyl$N$-acetylcysteamin (32).

\subsection{Charakterisierung der Metaboliten}

\section{Bafilomycin $A_{1}$ (11a)}

$\mathbf{C}_{35} \mathbf{H}_{58} \mathbf{O}_{9}(622.85)$

weißer Feststoff

UV-löschend (254 nm)

Smp.: $102{ }^{\circ} \mathrm{C}$

$\mathbf{R}_{\mathbf{f}}=0.82\left(\mathrm{KG}, \mathrm{CHCl}_{3} / \mathrm{MeOH} 9: 1\right)$.

Anfärbeverhalten: dunkelviolett (Anis).

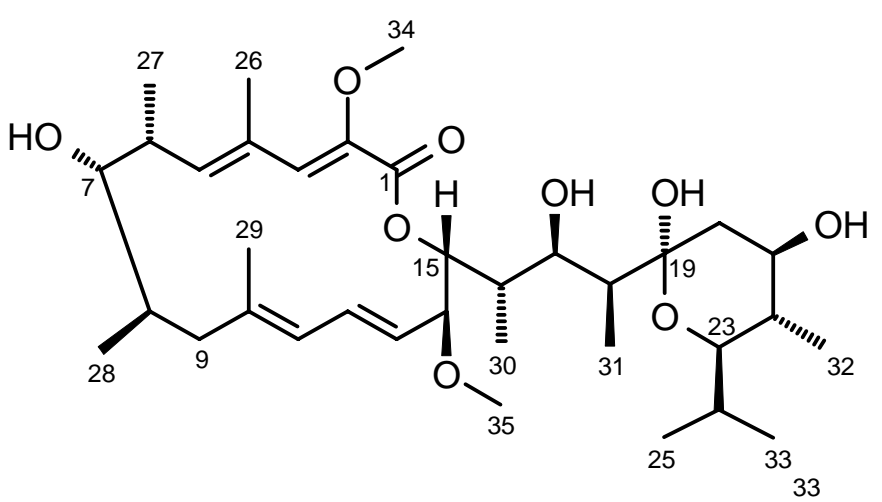
$[\boldsymbol{\alpha}]_{\mathbf{D}}^{\mathbf{2 0}}=-29^{\circ}(\mathrm{c}=0.03, \mathrm{MeOH})$.

UV (MeOH): $\lambda_{\max }(\lg \varepsilon)=207(5.17), 242(5.16), 286(4.76) \mathrm{nm}$;

(MeOH, HCl): $\lambda_{\max }(\lg \varepsilon)=207$ (5.08), 243 (5.12), 287 (4.68) nm.

$(\mathrm{MeOH}, \mathrm{NaOH}): \lambda_{\max }(\lg \varepsilon)=241$ (5.19), $285(4.76) \mathrm{nm}$.

IR (KBr): $\widetilde{v}=3421,2967,2931(\mathrm{sh}), 2874(\mathrm{sh}), 1735,1718,1687,1646,1662,1246$, $1195,1163,1100,974 \mathrm{~cm}^{-1}$. 
${ }^{1}$ H-NMR $\left(500 \mathrm{MHz}, \mathrm{CD}_{2} \mathrm{Cl}_{2}\right): \delta=0.76\left(\mathrm{~d}, J=7.0 \mathrm{~Hz}, 3 \mathrm{H}, 33-\mathrm{H}_{3}\right), 0.81(\mathrm{~d}, J=7.0 \mathrm{~Hz}, 3 \mathrm{H}$, $\left.30-\mathrm{H}_{3}\right), 0.89$ (d, $\left.J=7.0 \mathrm{~Hz}, 3 \mathrm{H}, 32-\mathrm{H}_{3}\right), 0.91$ (d, $\left.J=6.5 \mathrm{~Hz}, 3 \mathrm{H}, 28-\mathrm{H}_{3}\right), 0.92(\mathrm{~d}, J=7.0 \mathrm{~Hz}$, $\left.3 \mathrm{H}, 25-\mathrm{H}_{3}\right), 1.00\left(\mathrm{~d}, J=7.0 \mathrm{~Hz}, 3 \mathrm{H}, 31-\mathrm{H}_{3}\right), 1.04$ (d, $\left.J=7.0 \mathrm{~Hz}, 3 \mathrm{H}, 27-\mathrm{H}_{3}\right), 1.11$ (td, $\left.J=11.5,2.0 \mathrm{~Hz}, 1 \mathrm{H}, 20-\mathrm{H}_{\mathrm{a}}\right), 1.76(\mathrm{dq}, J=7.0 \mathrm{~Hz}, 1.0 \mathrm{~Hz}, 1 \mathrm{H}, 18-\mathrm{H}), 1.85-1.92(\mathrm{~m}, 3 \mathrm{H}$, H-24, H-22, H-8), 1.93 (s, 3H, 29-H $), 1.93-1.97$ (m, 1H, 9- $\left.\mathrm{H}_{\mathrm{a}}\right), 1.98$ (d, J=1.0 Hz, 3H, 26- $\left.\mathrm{H}_{3}\right), 2.08(\mathrm{~m}, 1 \mathrm{H}, 16-\mathrm{H}), 2.12\left(\mathrm{~m}, 1 \mathrm{H}, 9-\mathrm{H}_{\mathrm{b}}\right), 2.23\left(\mathrm{dd}, J=12.0,5.0 \mathrm{~Hz}, 1 \mathrm{H}, 20-\mathrm{H}_{\mathrm{b}}\right), 2.53$ (m, 1H, 6-H), 3.23 (s, 3H, 35- $\left.\mathrm{H}_{3}\right), 3.28(\mathrm{~m}, 1 \mathrm{H}, 7-\mathrm{H}), 3.46$ (dd, $\left.J=10.0,2.1 \mathrm{~Hz}, 1 \mathrm{H}, 23-\mathrm{H}\right)$, $3.60\left(\mathrm{~s}, 3 \mathrm{H}, 34-\mathrm{H}_{3}\right), 3.61(\mathrm{~m}, 1 \mathrm{H}, 21-\mathrm{H}), 3.89$ (t, $\left.J=9.0 \mathrm{~Hz}, 14-\mathrm{H}\right), 4.12$ (ddd, $J=19.0,4.2$, $2.0 \mathrm{~Hz}, 1 \mathrm{H}, 17-\mathrm{H}), 4.59(\mathrm{dd}, J=4.2,1.0 \mathrm{~Hz}, 1 \mathrm{H}, 17-\mathrm{OH}), 4.88(\mathrm{dd}, J=8.5,1.0 \mathrm{~Hz}, 1 \mathrm{H}$, $15-\mathrm{H}), 5.13(\mathrm{dd}, J=15.0,9.5 \mathrm{~Hz}, 1 \mathrm{H}, 13-\mathrm{H}), 5.31$ (d, $J=2.0 \mathrm{~Hz}, 19-\mathrm{OH}), 5.78$ (d, $J=9.0 \mathrm{~Hz}$, $1 \mathrm{H}, 5-\mathrm{H}), 5.81(\mathrm{~d}, J=11.0 \mathrm{~Hz}, 1 \mathrm{H}, 11-\mathrm{H}), 6.53$ (dd, $J=15.0,11.0 \mathrm{~Hz}, 1 \mathrm{H}, 12-\mathrm{H}), 6.68(\mathrm{~s}, 1 \mathrm{H}$, 3-H) ppm.

${ }^{13}$ C-NMR (125.7 MHz, $\left.\mathrm{CD}_{2} \mathrm{Cl}_{2}\right): \delta=7.1$ (q, C-31), 9.8 (q, C-30), 12.1 (q, C-32), 14.0 (q, C-26), 14.3 (q, C-33), 17.3 (q, C-27), 20.1 (q, C-29), 21.3 (q, C-25), 21.7 (q, C-28), 28.2 (d, C-24), 37.0 (d, C-6), 37.5 (d, C-16), 40.4 (d, C-22), 43.8 (t, C-20), 41.4 (d, C-8), 41.5 (t, C-9), 42.3 (d, C-18), 55.7 (q, C-35), 60.1 (q, C-34), 71.0 (d, C-17), 70.9 (d, C-21), 76.1 (d, C-23), 77.0 (d, C-15), 81.1 (d, C-7), 82.6 (d, C-14), 99.3 (s, C-19), 125.3 (d, C-11), 127.1 (d, C-13), 133.1 (s, C-4), 133.5 (d, C-12), 133.9 (d, C-3), 141.4 (s, C-2), 143.5 (d, C-5), 143.6 (s, C-10), 167.6 (s, C-1) ppm.

\section{Bafilomycin $B_{1}$ (11b)}

$\mathbf{C}_{44} \mathbf{H}_{65} \mathrm{NO}_{13}(816.01)$ hellgelber Feststoff UV-löschend (254 nm)

Smp.: $129^{\circ}$

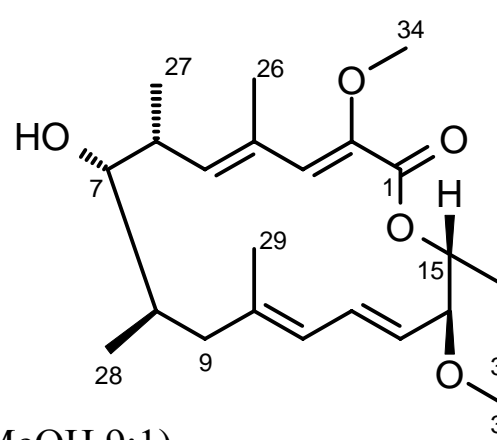

$\mathbf{R}_{\mathbf{f}}=0.53\left(\mathrm{KG}, \mathrm{CHCl}_{3} / \mathrm{MeOH} 9: 1\right)$.

Anfärbeverhalten: bräunlich-violett (Anis).

$[\boldsymbol{\alpha}]_{\mathrm{D}}^{\mathbf{2 0}}=-24^{\circ}(\mathrm{c}=0.10, \mathrm{MeOH})$.

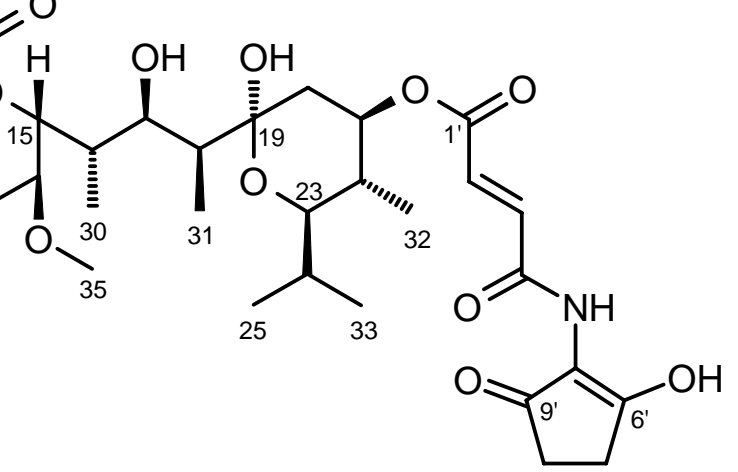

UV $(\mathrm{MeOH}): \lambda_{\max }(\lg \varepsilon)=250(5.34) \mathrm{nm}$,

$(\mathrm{MeOH}, \mathrm{HCl}): \lambda_{\max }(\lg \varepsilon)=248(5.30) \mathrm{nm}$,

$(\mathrm{MeOH}, \mathrm{NaOH}): \lambda_{\max }(\lg \varepsilon)=250(5.36) \mathrm{nm}$. 
IR $(\mathrm{KBr}): \widetilde{v}=3420,3251,3077(\mathrm{sh}), 2967,1724,1614,1553,1458,1362,1244,1170$, $1099,969,943,917,760 \mathrm{~cm}^{-1}$.

${ }^{1} \mathbf{H}-\mathbf{N M R}\left(500 \mathrm{MHz}, \mathrm{CD}_{2} \mathrm{Cl}_{2}\right): \delta=0.79\left(\mathrm{~d}, J=7.0 \mathrm{~Hz}, 3 \mathrm{H}, 33-\mathrm{H}_{3}\right), 0.82(\mathrm{~d}, J=7.0 \mathrm{~Hz}, 3 \mathrm{H}$, $\left.30-\mathrm{H}_{3}\right), 0.83\left(\mathrm{~d}, J=6.5 \mathrm{~Hz}, 3 \mathrm{H}, 32-\mathrm{H}_{3}\right), 0.91$ (d, $\left.J=2.0 \mathrm{~Hz}, 3 \mathrm{H}, 28-\mathrm{H}_{3}\right), 0.93\left(\mathrm{~s}, 3 \mathrm{H}, 25-\mathrm{H}_{3}\right)$, $0.99\left(\mathrm{~d}, J=7.0 \mathrm{~Hz}, 3 \mathrm{H}, 31-\mathrm{H}_{3}\right), 1.04$ (d, $\left.J=8.0 \mathrm{~Hz}, 3 \mathrm{H}, 27-\mathrm{H}_{3}\right), 1.22$ (td, $J=11.5,2.0 \mathrm{~Hz}$, $1 \mathrm{H}, 20-\mathrm{H}_{\mathrm{a}}$ ), 1.63 (m, 1H, H-22), 1.80 (m, 1H, H-18), 1.87 - 1.92 (m, 2H, H-24, H-8), 1.93 (s, $\left.3 \mathrm{H}, 29-\mathrm{H}_{3}\right), 1.94\left(\mathrm{~m}, 1 \mathrm{H}, 9-\mathrm{H}_{\mathrm{a}}\right), 1.98$ (d, J=1.0 Hz, 3H, 26- $\left.\mathrm{H}_{3}\right), 2.09$ (m, 1H, 16-H), 2.11 (m, $\left.1 \mathrm{H}, 9-\mathrm{H}_{\mathrm{b}}\right), 2.33$ (dd, $\left.J=12.0,5.0 \mathrm{~Hz}, 1 \mathrm{H}, 20-\mathrm{H}_{\mathrm{b}}\right), 2.54$ (m, 1H, 6-H), 2.59 (bs, 4H, 7'- $\mathrm{H}_{2}$, $\left.8^{\prime}-\mathrm{H}_{2}\right), 3.23\left(\mathrm{~s}, 3 \mathrm{H}, 35-\mathrm{H}_{3}\right), 3.28(\mathrm{~m}, 1 \mathrm{H}, 7-\mathrm{H}), 3.59(\mathrm{~m}, 1 \mathrm{H}, 23-\mathrm{H}), 3.61\left(\mathrm{~s}, 3 \mathrm{H}, 34-\mathrm{H}_{3}\right), 3.89$ (t, $J=9.0 \mathrm{~Hz}, 1 \mathrm{H}, 14-\mathrm{H}), 4.12(\mathrm{ddd}, J=11.0,4.0,1.5 \mathrm{~Hz}, 1 \mathrm{H}, 17-\mathrm{H}), 4.66$ (d, $J=3.5 \mathrm{~Hz}, 1 \mathrm{H}$, $17-\mathrm{OH}), 4.88(\mathrm{dd}, J=9.0,1.0 \mathrm{~Hz}, 1 \mathrm{H}, 15-\mathrm{H}), 5.00(\mathrm{td}, J=11.0,5.0 \mathrm{~Hz}, 1 \mathrm{H}, 21-\mathrm{H}), 5.14$ (dd, $J=15.0,9.0 \mathrm{~Hz}, 1 \mathrm{H}, 13-\mathrm{H}), 5.46$ (d, $J=2.0 \mathrm{~Hz}, 1 \mathrm{H}, 19-\mathrm{OH}), 5.80$ (m, 2H, 5-H, 11-H), 6.54 (dd, $J=15.0,11.0 \mathrm{~Hz}, 1 \mathrm{H}, 12-\mathrm{H}), 6.69$ (s, 1H, 3-H), 6.86 (d, $J=15.0 \mathrm{~Hz}, 1 \mathrm{H}, 3$ '-H), 7.29 (d, $\left.J=15.0 \mathrm{~Hz}, 1 \mathrm{H}, 2^{\prime}-\mathrm{H}\right), 8.90$ (bs, 1H, NH) ppm.

${ }^{13}$ C-NMR (125.7 MHz, $\mathrm{CD}_{2} \mathrm{Cl}_{2}$ ): $\delta=7.2$ (q, C-31), 10.0 (q, C-30), 12.4 (q, C-32), 14.1 (q, C-26), 14.4 (q, C-33), 17.4 (q, C-27), 20.3 (q, C-29), 21.3 (q, C-25), 21.8 (q, C-28), 14.4 (q, C-24), 26.2 (t, C-7'), 28.4 (d, C-24), 32.6 (t, C-8'), 37.2 (d, C-6), 37.7 (d, C-16), 38.5 (d, C-22), 40.4 (t, C-20), 40.6 (d, C-8), 41.7 (t, C-9), 42.4 (d, C-18), 55.8 (q, C-35), 60.3 (q, C-34), 71.1 (d, C-17), 75.8 (d, C-21), 76.1 (d, C-23), 77.2 (d, C-15), 81.3 (d, C-7), 82.8 (d, C-14), 99.3 (s, C-19), 115.2 (s, C-5'), 125.5 (d, C-11), 127.3 (d, C-13), 133.3 (s, C-4), 133.4 (d, C-2'), 133.6 (d, C-12), 133.8 (d, C-3'), 134.0 (d, C-3), 141.6 (s, C-2), 143.6 (d, C-5), 143.7 (s, C-10), 164.2 (s, C-4'), 164.8 (s, C-1'), 167.7 (s, C-1), 175.6 (s, C-6'), 198.1 (s, C-9’) ppm.

\section{trans-3-Methylthioacrylsäure (29)}

$\mathrm{C}_{4} \mathrm{H}_{6} \mathrm{O}_{2} \mathrm{~S}$ (118.16)

farbloser Feststoff

UV-löschend (254 nm)

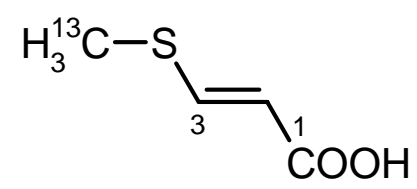

Smp.: $128^{\circ} \mathrm{C}$

$\mathbf{R}_{\mathbf{f}}=0.36\left(\mathrm{KG}, \mathrm{CHCl}_{3} / \mathrm{MeOH} 9: 1\right)$,

0.64 (RP-18, $\mathrm{MeOH} / \mathrm{H}_{2} \mathrm{O}$ 7:3).

EI-MS: $\mathrm{m} / \mathrm{z}(\%)=119(60)[\mathrm{M}]^{+}, 103(74)\left[\mathrm{M}^{13}{ }^{13} \mathrm{CH}_{3}\right]^{+}, 74(32)\left[\mathrm{M}-\mathrm{CO}_{2} \mathrm{H}\right]^{+}, 43(100)$. 
UV (MeOH): $\lambda_{\max }(\lg \varepsilon)=202(4.27), 262(4.74) \mathrm{nm}$, $(\mathrm{MeOH}, \mathrm{HCl}): \lambda_{\max }(\lg \varepsilon)=271(4.82) \mathrm{nm}$.

$(\mathrm{MeOH}, \mathrm{NaOH}): \lambda_{\max }(\lg \varepsilon)=253(4.75) \mathrm{nm}$.

IR (KBr): $\widetilde{v}=3422,3074(\mathrm{sh}), 2965,2828,2599,1665,1576,1420,1333,1300,1269$, $1208,996,929,856,839,688,524 \mathrm{~cm}^{-1}$.

${ }^{1}$ H-NMR $\left(300 \mathrm{MHz}, \mathrm{CD}_{2} \mathrm{Cl}_{2}\right): \delta=2.35\left(\mathrm{~d},{ }^{1} J_{\mathrm{CH}}=141 \mathrm{~Hz}, 3 \mathrm{H}, 4-\mathrm{H}_{3}\right), 5.66(\mathrm{~d}, J=15.0 \mathrm{~Hz}$, $1 \mathrm{H}, 2-\mathrm{H}), 7.85\left(\mathrm{dd}, J=15.0,{ }^{3} J_{\mathrm{CH}}=6.0 \mathrm{~Hz}, 1 \mathrm{H}, 3-\mathrm{H}\right), 9.18(\mathrm{bs}, 1 \mathrm{H}, 1-\mathrm{OH}) \mathrm{ppm}$.

${ }^{13}$ C-NMR (75.5 MHz, $\mathrm{CD}_{2} \mathrm{Cl}_{2}$ ): $\delta=14.6$ (q, C-4), 112.4 (d, C-2), 150.5 (d, C-3), 170.6 (s, C-1) ppm.

\section{Fütterungsexperimente am Concanamycin-Produzenten}

\subsection{Stammhaltung von Streptomyces sp. Stamm Gö 22/15}

Für die Stammhaltung wurden SM-Platten verwendet, die nach Beimpfen sieben Tage bei $28^{\circ} \mathrm{C}$ inkubiert wurden. Stamm Gö 22/15 färbte den Agar braun und bildete weißes Luftmycel aus. Die Lagerung der Platten erfolgte bei $4{ }^{\circ} \mathrm{C}$, für die Langzeitkonservierung dienten in Polypropylenfolie eingeschweißte, gut bewachsene Agarstückchen, welche über flüssigem Stickstoff aufbewahrt wurden.

\subsection{Fermentationsbedingungen}

Alle Fermentationen für Biosyntheseuntersuchungen wurden im Haferkleie-Medium durchgeführt. Für die Vorkulturen wurden $300 \mathrm{~mL}$ Erlenmeyerkolben mit drei Schikanen eingesetzt, welche mit $50 \mathrm{~mL}$ Nährlösung befüllt waren und durch Zugabe eines $1 \mathrm{~cm}^{2}$ großen, gut bewachsenen Agarstückes beimpft wurden. Die Kultivierung erfolgte für 48 Stunden bei $28^{\circ} \mathrm{C}$ und $250 \mathrm{rpm}$. Die Hauptkulturen wurden in einem $2 \mathrm{~L}-F e r m e n t e r$ durchgeführt, welcher mit $540 \mathrm{~mL}$ Nährmedium befüllt war und durch Zugabe von $60 \mathrm{~mL}$ Vorkultur beimpft wurde. Die Kultivierung erfolgte für 72 Stunden bei $28{ }^{\circ} \mathrm{C}$ und $250 \mathrm{rpm}$ bei einer Belüftung von 3.3 vvm unter Verwendung einer $\mathrm{O}_{2}$-Elektrode. 


\subsection{Aufarbeitung der Fermentationsansätze und Isolierung von Concanamycin A (10a)}

Die Aufarbeitung der Fermentationsansätze erfolgte gemäß Abbildung 20 (Kapitel A.II.5.2.) durch Zusatz von Celite und anschließender 20minütiger Zentrifugation bei $3200 \mathrm{rpm}$. Das erhaltene Mycel wurde dreimal mit je $500 \mathrm{~mL}$ Aceton im Ultraschallbad extrahiert und das Lösungsmittel im Vakuum entfernt. Die Isolierung von Concanamycin A (10a) aus dem Mycelextrakt erfolgte durch Flashchromatographie an Kieselgel (Gradient: Chloroform / Methanol 95:5 $\rightarrow$ 90:10) und anschließender Mitteldruckchromatographie an RP-18 (Eluent: Aceton / Wasser 3:1).

\subsection{Durchführung der Fütterungsexperimente}

Die zugefütterten Vorläufer wurden in $40 \mathrm{~mL}$ sterilem Wasser gelöst und kontinuierlich von der 34. bis zur 48. Inkubationsstunde zugepumpt. Zeitgleich mit dem Fütterungsstart wurde eine automatische $\mathrm{pH}-$ Sperre aktiviert, welche den $\mathrm{pH}-$ Wert zwischen 5.5 und 7.4 regulierte. Die Endkonzentrationen der gefütterten Substanzen betrugen: $1.9 \mathrm{mM}$ 2-Hydroxy$\left[1-{ }^{13} \mathrm{C}\right]$ malonyl- $N$-acetylcysteamin $\quad(\mathbf{3 1}), \quad 0.9 \mathrm{mM} \quad$ 2-Methoxy- $\left[1-{ }^{13} \mathrm{C}\right]$ malonyl- $N$-acetylcysteamin (32) und $1.1 \mathrm{mM}\left[1,2-{ }^{13} \mathrm{C}_{2}\right]-s n$-Glycerin (35) sowie $\left[2,3-{ }^{13} \mathrm{C}_{2}\right]$-sn-Glycerin (37). Letztgenannte Verbindungen wurden vor der Zufütterung mit der vierfachen Menge an unmarkiertem Glycerin verdünnt. 


\section{Transformationsversuche an Stamm Gö 22/15}

\section{Resistenztests}

Die Durchführung der Resistenztests an Stamm Gö 22/15 erfolgte auf fünf getrennten R5-Agarplatten. Es wurden folgende Antibiotikakonzentrationen verwendet: $50 \mu \mathrm{g} / \mathrm{mL}$ Apramycin, $15 \mu \mathrm{g} / \mathrm{mL}$ Thiostrepton, $100 \mu \mathrm{g} / \mathrm{mL}$ Gentamicin, $160 \mu \mathrm{g} / \mathrm{mL}$ Kanamycin sowie $10 \mu \mathrm{g} / \mathrm{mL}$ Neomycin. Die Inkubation erfolgte für sechs Tage bei $28^{\circ} \mathrm{C}$.

\section{Kultivierung von $E$. coli}

Die Kultivierung der E. coli-Zellen SCS110, welche über das Plasmid pHGF 7669 verfügen, erfolgte in mehreren Ansätzen zu je $3 \mathrm{~mL}$ LB-Medium unter Zusatz von $50 \mu \mathrm{g} / \mathrm{mL}$ Apramycin in verschließbaren Reagenzgläsern. Zum Beimpfen der Nährlösung wurden $10 \mu \mathrm{L}$ einer Glycerineinlagerung zupipettiert. Die Kultivierung erfolgte für 14 Stunden bei $180 \mathrm{rpm}$ und $37^{\circ} \mathrm{C}$.

\section{Plasmidisolierung aus $E$. coli-Zellen}

Zur Plasmidisolierung wurden $1500 \mu \mathrm{L}$ Zellsuspension bei $1200 \mathrm{rpm}$ für $20 \mathrm{~s}$ zentrifugiert und der Überstand verworfen. Der Rückstand wurde in $150 \mu \mathrm{L}$ P1-Puffer resuspendiert und nacheinander mit $300 \mu \mathrm{L}$ P2-Puffer und $230 \mu \mathrm{L}$ P3-Puffer versetzt. Die Ansätze wurden gut durchmischt und für 10 Minuten auf Eis inkubiert. Nach anschließender 10minütiger Zentrifugation wurde der Überstand abgenommen und in $700 \mu \mathrm{L}$ reinem Ethanol suspendiert. Nach erneuter Inkubation auf Eis und Zentrifugation wurde der Überstand verworfen. Der Rückstand wurde in $700 \mu \mathrm{L} 70 \%$ igem Ethanol aufgenommen und 10 Minuten auf Eis inkubiert. Anschließend wurde überstehendes Ethanol abpipettiert und erneut für eine Minute zentrifugiert. Nach Entfernung des restlichen Ethanols erfolgte eine 30minütige Trocknung bei Raumtemperatur. Die DNA wurde anschließend mit $35 \mu \mathrm{L}$ bidestilliertem Wasser versetzt und bei $-20{ }^{\circ} \mathrm{C}$ gelagert. 


\section{Isolierung des Plasmids pGM9 aus Streptomyces lividans Stamm Tü 32}

Streptomyces lividans Stamm Tü 32 wurde in YEME-Medium unter Zusatz unterschiedlicher Mengen an Antibiotika (Thiostrepton und Kanamycin) bei $30{ }^{\circ} \mathrm{C}$ und $225 \mathrm{rpm}$ in $250 \mathrm{~mL}$ Erlenmeyerkolben mit Schikanen kultiviert. Je $5 \mathrm{~mL}$ der Kulturlösung wurden 10 Minuten bei $1000 \mathrm{xg}$ zentrifugiert und der Rückstand in $500 \mu \mathrm{L}$ TESLR-Puffer aufgenommen. Nach 30minütiger Inkubation bei $37^{\circ} \mathrm{C}$ wurden $250 \mu \mathrm{L} \mathrm{NaOH} / \mathrm{SDS}$ zugegeben und gut durchmischt. Die geöffneten Ansätze wurden bei $55^{\circ} \mathrm{C}$ für 30 Minuten inkubiert und anschließend fünf Minuten auf Eis gelagert. Nach Zugabe von $80 \mu \mathrm{L}$ Phenol / ChloroformLösung (Merck) und guter Durchmischung wurde 10 Minuten zentrifugiert und zum Überstand $50 \mu \mathrm{L} 3 \mathrm{M}$ Natriumacetatlösung und $450 \mu \mathrm{L}$ Isopropanol gegeben. Nach erneuter 10minütiger Zentrifugation wurde der Rückstand mit $700 \mu \mathrm{L}$ eiskaltem $70 \%$ igem Ethanol versetzt und 50 Minuten auf Eis inkubiert. Es wurde zentrifugiert und der Überstand verworfen. Dieser Schritt wurde noch einmal wiederholt, wobei die Inkubation auf Eis diesmal nur für 10 Minuten durchgeführt wurde. Anschließend erfolgte eine 25minutige Trocknung bei Raumtemperatur. Die DNA wurde in $50 \mu \mathrm{L}$ TE-Puffer aufgenommen und bei $20{ }^{\circ} \mathrm{C}$ gelagert.

\section{Transformationsversuche an Streptomyces sp. Stamm Gö 22/15}

Die 43stündige Kultivierung des Stammes Gö 22/15 erfolgte in $25 \mathrm{~mL}$ YEME-Medium bei $28^{\circ} \mathrm{C}$ und $180 \mathrm{rpm}$ in $250 \mathrm{~mL}$ Erlenmyerkolben mit Schikane, wobei zum Animpfen ein $1 \mathrm{~cm}^{2}$ großes Stück einer gut bewachsenen Agarplatte diente. $10 \mathrm{~mL}$ der Kulturlösung wurden entnommen und bei 1000 x g für 10 Minuten zentrifugiert. Der Rückstand wurden in $7.5 \mathrm{~mL}$ $10.3 \%$ iger Sucroselösung resuspendiert und erneut zentrifugiert. Nach Entfernung des Überstandes wurde dieser Schritt noch einmal wiederholt. Die Zellen wurden anschließend mit $2 \mathrm{~mL}$ einer $4 \mathrm{mg} / \mathrm{mL}$ Lysozymlösung in P-Puffer vermischt und bei $30{ }^{\circ} \mathrm{C}$ inkubiert, wobei der Fortschritt der Protoplastierung durch Mikroskopie kontinuierlich verfolgt wurde. Nach 40 Minuten wurde über einen sterilen Baumwollfilter filtriert und die erhaltene Protoplastenlösung für sieben Minuten zentrifugiert. Der Rückstand wurde in $250 \mu \mathrm{L}$ P-Puffer suspendiert und $50 \mu \mathrm{L}$ davon mit $5 \mu \mathrm{L}$ Plasmid-Lösung vermischt. Es wurden $200 \mu \mathrm{L}$ 25 \%ige PEG 1000-Lösung in P-Puffer zugegeben und durch Pipettierung vorsichtig durchmischt. Die Ansätze wurden anschließend auf R5-Medium ausplattiert und bei $30{ }^{\circ} \mathrm{C}$ inkubiert. Nach 18 Stunden wurden die Agarplatten mit $1 \mathrm{~mL}$ einer $1.25 \mathrm{mg} / \mathrm{mL}$ 
Apramycinlösung (bei pHGF7669) bzw. $4 \mathrm{mg} / \mathrm{mL}$ Kanamycinlösung (bei pGM9) überschichtet und für 30 Minuten bei Raumtemperatur getrocknet. Anschließend erfolgte weitere Inkubation bei $30^{\circ} \mathrm{C}$.

\section{Konjugationsversuche mit Streptomyces sp. Stamm Gö 22/15}

Zunächst wurde eine Glycerineinlagerung von Zellen des Stamms Gö 22/15 hergestellt. Zu diesem Zweck wurde $1 \mathrm{~mL}$ einer 48 Stunden alten Kultur (Fermentationsbedingungen siehe Kapitel B.II.2.2.) mit der gleichen Menge einer sterilen, 86 \%igen Glycerinlösung versetzt.

E. coli Stamm ET12567, welcher über die Plasmide pUB307 und pSET152 verfügt, wurde in $3 \mathrm{~mL}$ LB-Medium unter Zusatz von $25 \mu \mathrm{g} / \mathrm{mL}$ Chloramphenicol, $50 \mu \mathrm{g} / \mathrm{mL}$ Apramycin und $50 \mu \mathrm{g} / \mathrm{mL}$ Kanamycin bei $37^{\circ} \mathrm{C}$ und $250 \mathrm{rpm}$ in verschließbaren Reagenzgläsern kultiviert. Nach $12 \mathrm{~h}$ wurden $50 \mu \mathrm{L}$ der Zelllösung entnommen und $\mathrm{zu} 5 \mathrm{~mL}$ frisch angesetztem LBMedium ebenfalls unter Zusatz der Selektionsantibiotika pipettiert. Die Ansätze wurden erneut bei $37^{\circ} \mathrm{C}$ und $250 \mathrm{rpm}$ kultiviert, bis eine optische Dichte $\mathrm{OD}_{600}$ zwischen 0.4 und 0.6 erreicht war (etwa vier Stunden). Anschließend wurde vier Minuten bei $1000 \mathrm{x} g$ zentrifugiert und die Zellen zweimal mit je $5 \mathrm{~mL}$ LB-Medium gewaschen. Der erhaltene Rückstand wurde in $500 \mu \mathrm{L}$ LB-Medium aufgenommen und mit $500 \mu \mathrm{L}$ der Glycerineinlagerung des Mycels von Stamm Gö 22/15 vermischt. Die Ansätze wurden dreimal mit je 5 mL 2 x YT-Medium gewaschen und anschließend drei Minuten bei $3000 \mathrm{rpm}$ zentrifugiert. Der Überstand wurde verworfen und der Rückstand im verbleibenden Medium resuspendiert. Die erhaltene Zellsuspension wurde auf dem Medium SM unter Zusatz von 0.01 mM Magnesiumchlorid ausplattiert und bei $37^{\circ} \mathrm{C}$ für 16 Stunden inkubiert. Anschließend wurden die Platten mit $1 \mathrm{~mL}$ einer Lösung aus $1.3 \mathrm{mg} / \mathrm{mL}$ Apramycin und $1 \mathrm{mg} / \mathrm{mL}$ Nalidixinsäure überschichtet und nach Trocknung weiterhin bei $30^{\circ} \mathrm{C}$ inkubiert. 


\section{Darstellung eines photomarkierten Bafilomycin-Derivats}

\section{2,5-Dibrom-4-[3-(trifluormethyl)-3H-diazirin-3-yl]benzoesäure (43)}

$\mathrm{Zu}$ einer Lösung aus $40 \mathrm{mg}(174 \mu \mathrm{mol}) p$-(Trifluorethyldiazirinyl)benzoesäure (41) in $2 \mathrm{~mL}$ Trifluoressigsäure (TFA) wurden $93 \mathrm{mg}(521 \mu \mathrm{mol}) N$-Bromsuccinimid (NBS) gegeben. Die Lösung wurde für fünf Minuten gerührt und anschließend mit $0.8 \mathrm{~mL}$ konzentrierter Schwefelsäure versetzt. Nach 15stündigem Rühren bei Raumtemperatur wurde das Reaktionsgemisch mit $10 \mathrm{~mL}$ Dichlormethan verdünnt und mit $20 \mathrm{~mL}$ Eiswasser extrahiert. Die wäßrige Phase wurde anschließend fünf Mal mit je $10 \mathrm{~mL}$ Dichlormethan extrahiert, die vereinigten organischen Phasen über Calciumchlorid getrocknet und das Lösungsmittel im Vakuum entfernt. Das erhaltene Produktgemisch $(77 \mathrm{mg})$ wurde ohne weitere Aufreinigung im nächsten Reaktionsschritt eingesetzt.

$\mathrm{C}_{9} \mathrm{H}_{3} \mathrm{Br}_{2} \mathrm{~F}_{3} \mathbf{N}_{2} \mathrm{O}_{2}$ (387.97)

farbloser Feststoff

UV-löschend (254 nm)

Smp.: $88^{\circ} \mathrm{C}$

$\mathbf{R}_{\mathbf{f}}=0.13\left(\mathrm{KG}, \mathrm{CHCl}_{3} / \mathrm{MeOH} 9: 1\right)$,

0.57 (RP-18, $\mathrm{MeOH} / \mathrm{H}_{2} \mathrm{O} 7: 3$ ).

$\mathbf{R}_{\mathbf{t}}=16.5 \min ($ HPLC-MS).

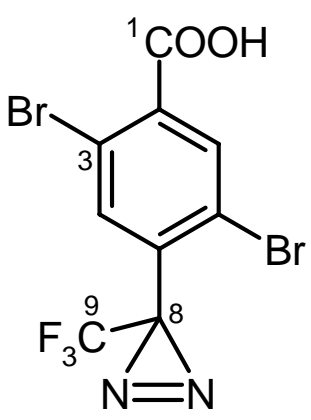

Anfärbeverhalten: hellbraun (Anis).

ESI-MS: $\mathrm{m} / \mathrm{z}=413[\mathrm{M}+\mathrm{Na}]^{+}, 803[2 \mathrm{M}+\mathrm{Na}]^{+}$.

UV (MeOH, Gemisch): $\lambda_{\max }(\lg \varepsilon)=209(5.07) \mathrm{nm}$,

(MeOH, $\mathrm{HCl}): \lambda_{\max }(\lg \varepsilon)=201$ (5.02), 208 (5.08), $298(3.70) \mathrm{nm}$,

$(\mathrm{MeOH}, \mathrm{NaOH}): \lambda_{\max }(\lg \varepsilon)=200$ (4.75), 202 (4.88), $212(5.10) \mathrm{nm}$.

IR (KBr, Gemisch): $\widetilde{v}=3446,3076,2525$ (sh), 2364 (sh), 1773 (sh), 1696, 1619 (sh), 1590 (sh), 1532, 1480, 1404, 1351, 1306, 1198, 1158, 1079, 976, $748 \mathrm{~cm}^{-1}$.

${ }^{1}$ H-NMR $\left(300 \mathrm{MHz}, \mathrm{CD}_{2} \mathrm{Cl}_{2}\right): \delta=7.98(\mathrm{~s}, 1 \mathrm{H}, 6-\mathrm{H}), 8.19$ (s, 1H, 3-H) ppm.

${ }^{13}$ C-NMR (75.5 MHz, $\left.\mathrm{CD}_{2} \mathrm{Cl}_{2}\right): \delta=28.6\left(\mathrm{q},{ }^{2} J_{\mathrm{CF}}=43.5 \mathrm{~Hz}, \mathrm{C}-8\right), 121.8(\mathrm{~s}, \mathrm{C}-3), 124.1(\mathrm{~s}$, C-6), 133.3 (s, C-2), 134.7 (s, C-5), 136.1 (q, $\left.{ }^{1} J_{\mathrm{CF}}=275 \mathrm{~Hz}, \mathrm{C}-9\right), 137.2$ (d, C-4), 139.0 (d, C-7), 168.0 (s, C-1) ppm. 


\section{21-O-(m-Brombenzoyl)bafilomycin $A_{1}$}

\subsection{Darstellung durch Umsatz mit $m$-Brombenzoylchlorid}

$5 \mathrm{mg}(7.9 \mu \mathrm{mol})$ Bafilomycin $\mathrm{A}_{1}$ (11a) wurden in $500 \mu \mathrm{L}$ Pyridin gelöst und mit $21 \mu \mathrm{L}$ (16 $\mu \mathrm{mol}) m$-Brombenzoylchlorid sowie katalytischen Mengen 4- $N, N$-Dimethylaminopyridin (DMAP) versetzt. Das Reaktionsgemisch wurde für drei Stunden bei Raumtemperatur gerührt und anschließend in Dichlormethan aufgenommen. Der Ansatz wurde nacheinander mit Wasser sowie gesättigter Ammoniumchlorid- und Kochsalzlösung extrahiert. Die organische Phase wurde über Natriumsulfat getrocknet und anschließend im Vakuum vom Lösungsmittel befreit. Säulenchromatographische Auftrennung des erhaltenen Rückstands an Sephadex ${ }^{\circledR}$ LH-20 (Eluent: Dichlormethan) lieferte $4.9 \mathrm{mg}(6.1 \mu \mathrm{mol})$ 21- $O$-( $m$-Brombenzoyl)bafilomycin $\mathrm{A}_{1}$, woraus sich eine Reaktionsausbeute von $77 \%$ ergibt.

\subsection{Darstellung durch Veresterung mit $m$-Brombenzoesäure}

Eine Lösung von $6.5 \mathrm{mg}(10.4 \mu \mathrm{mol})$ Bafilomycin $\mathrm{A}_{1}$ (11a) in $200 \mu \mathrm{L}$ wasserfreiem Dichlormethan wurde mit $3.1 \mathrm{mg}(15.7 \mu \mathrm{mol}) m$-Brombenzoesäure, $3.0 \mathrm{mg}(15.7 \mu \mathrm{mol})$ $N$ '-(3-Dimethylaminopropyl)- $N$-ethylcarbo-diimid-hydrochlorid (EDCI) sowie katalytischen Mengen DMAP versetzt. Das Gemisch wurde 24 Stunden bei Raumtemperatur in einer Argonatmosphäre gerührt, wobei der Reaktionsumsatz durch mehrmalige, nachträgliche Gabe von zusätzlicher $m$-Brombenzoesäure sowie EDCI in Richtung des Produkts gedrängt wurde. Anschließend wurde die Reaktionslösung mit Dichlormethan verdünnt und nacheinander mit Wasser sowie gesättigter Ammoniumchlorid- und Kochsalzlösung extrahiert. Nach Trocknung der organischen Phase über Natriumsulfat wurde diese im Vakuum vom Lösungsmittel befreit. Der erhaltene Rückstand (13.5 mg) wurde säulenchromatographisch an Sephadex $^{\circledR}$ LH-20 (Eluent: Dichlormethan) getrennt. Es wurden $5.8 \mathrm{mg}$ (7.2 $\left.\mu \mathrm{mol}\right)$ 21-O-( $m$-Brombenzoyl)-bafilomycin $\mathrm{A}_{1}$ erhalten, was einer Ausbeute von $69 \%$ entspricht. 
21-O-(m-Brombenzoyl)bafilomycin $\mathrm{A}_{1}$

$\mathrm{C}_{42} \mathrm{H}_{61} \mathrm{BrO}_{10}(805.85)$

farbloser Feststoff

UV-löschend (254 nm)

$\mathbf{R}_{\mathbf{f}}=0.63\left(\mathrm{KG}, \mathrm{C}_{6} \mathrm{H}_{12} /\right.$ AcOEt 1:2).

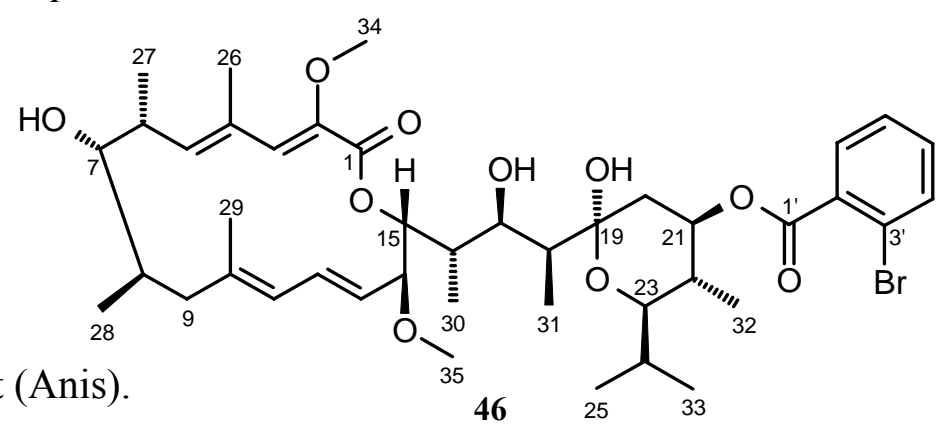

Anfärbeverhalten: bräunlich-violett (Anis).

ESI-MS: $\mathrm{m} / \mathrm{z}=830[\mathrm{M}+\mathrm{Na}]^{+}, 1633[2 \mathrm{M}+\mathrm{Na}]^{+}$.

${ }^{1}$ H-NMR $\left(600 \mathrm{MHz}, \mathrm{CD}_{2} \mathrm{Cl}_{2}\right): \delta=0.80\left(\mathrm{~d}, J=7.0 \mathrm{~Hz}, 3 \mathrm{H}, 33-\mathrm{H}_{3}\right), 0.83(\mathrm{~d}, J=7.0 \mathrm{~Hz}, 3 \mathrm{H}$, $\left.30-\mathrm{H}_{3}\right), 0.92\left(\mathrm{~d}, J=6.5 \mathrm{~Hz}, 3 \mathrm{H}, 32-\mathrm{H}_{3}\right), 0.93\left(\mathrm{~m}, 6 \mathrm{H}, 25-\mathrm{H}_{3}, 28-\mathrm{H}_{3}\right), 1.02(\mathrm{~d}, J=7.0 \mathrm{~Hz}, 1 \mathrm{H}$, $\left.31-\mathrm{H}_{3}\right), 1.04\left(\mathrm{~d}, J=7.0 \mathrm{~Hz}, 3 \mathrm{H}, 27-\mathrm{H}_{3}\right), 1.36$ (td, $\left.J=11.5,2.0 \mathrm{~Hz}, 1 \mathrm{H}, 20-\mathrm{H}_{\mathrm{a}}\right), 1.68$ (bs, 1H, 7-OH), 1.71 (m, 1H, 22-H), 1.81 (q, $J=7.0 \mathrm{~Hz}, 1 \mathrm{H}, 18-\mathrm{H}), 1.87-1.92$ (m, 2H, H-8, H-24), $1.93\left(\mathrm{~s}, 3 \mathrm{H}, 29-\mathrm{H}_{3}\right), 1.94\left(\mathrm{~m}, 1 \mathrm{H}, 9-\mathrm{H}_{\mathrm{a}}\right), 1.98$ (d, $\left.J=1.0 \mathrm{~Hz}, 3 \mathrm{H}, 26-\mathrm{H}_{3}\right), 2.10$ (m, 1H, 16-H), $2.12\left(\mathrm{~m}, 1 \mathrm{H}, 9-\mathrm{H}_{\mathrm{b}}\right), 2.45$ (dd, $\left.J=12.0,5.0 \mathrm{~Hz}, 1 \mathrm{H}, 20-\mathrm{H}_{\mathrm{b}}\right), 2.54(\mathrm{~m}, 1 \mathrm{H}, 6-\mathrm{H}), 3.24$ (s, 3H, 35- $\left.\mathrm{H}_{3}\right), 3.28(\mathrm{~m}, 1 \mathrm{H}, 7-\mathrm{H}), 3.62\left(\mathrm{~s}, 3 \mathrm{H}, 34-\mathrm{H}_{3}\right), 3.66$ (dd, $\left.J=11.0,2.5 \mathrm{~Hz}, 1 \mathrm{H}, 23-\mathrm{H}\right), 3.90$ (t, $J=9.0 \mathrm{~Hz}, 14-\mathrm{H}), 4.14(\mathrm{ddd}, J=11.0,4.0,2.0 \mathrm{~Hz}, 1 \mathrm{H}, 17-\mathrm{H}), 4.66(\mathrm{~d}, J=4.0 \mathrm{~Hz}, 1 \mathrm{H}$, $17-\mathrm{OH}), 4.90(\mathrm{dd}, J=8.5,1.0 \mathrm{~Hz}, 1 \mathrm{H}, 15-\mathrm{H}), 5.12-5.20(\mathrm{~m}, 2 \mathrm{H}, 13-\mathrm{H}, 21-\mathrm{H}), 5.47$ (d, $J=2.0 \mathrm{~Hz}, 1 \mathrm{H}, 19-\mathrm{OH}), 5.78(\mathrm{~d}, J=9.0 \mathrm{~Hz}, 1 \mathrm{H}, 5-\mathrm{H}), 5.82(\mathrm{~d}, J=11 \mathrm{~Hz}, 1 \mathrm{H}, 11-\mathrm{H}), 6.54$ (dd, $J=15.0,11.0 \mathrm{~Hz}, 1 \mathrm{H}, 12-\mathrm{H}), 6.69$ (s, 1H, 3-H), 7.34 (td, $J=7.5,1.5 \mathrm{~Hz}, 1 \mathrm{H}, 6$ '-H), 7.39 (td, $\left.J=7.5,1.0 \mathrm{~Hz}, 1 \mathrm{H}, 5^{\prime}-\mathrm{H}\right), 7.66$ (dd, $\left.J=8.0,1.5 \mathrm{~Hz}, 1 \mathrm{H}, 4^{\prime}-\mathrm{H}\right), 7.73$ (dd, $J=8.0,2.0 \mathrm{~Hz}$, $\left.1 \mathrm{H}, 7^{\prime}-\mathrm{H}\right) \mathrm{ppm}$.

${ }^{13}$ C-NMR (150.8 MHz, $\mathrm{CD}_{2} \mathrm{Cl}_{2}$ ): $\delta=7.1$ (q, C-31), 9.8 (q, C-30), 12.5 (q, C-32), 14.0 (q, C-26), 14.3 (q, C-33), 17.3 (q, C-27), 20.2 (q, C-29), 21.2 (q, C-25), 21.7 (q, C-28), 28.2 (q, C-24), 37.0 (d, C-6), 37.5 (d, C-16), 38.5 (d, C-22), 40.2(t, C-20), 40.5 (d, C-8), 41.5 (t, C-9), 42.2 (d, C-18), 55.7 (q, C-35), 60.2 (q, C-34), 71.0 (d, C-17), 76.0 (d, C-21, C-23), 77.0 (d, C-15), 81.2 (d, C-7), 82.6 (d, C-14), 99.2 (s, C-19), 121.2 (s, C-3'), 125.4 (d, C-11), 127.1 (d, C-13), 127.5 (s, C-7'), 131.1 (s, C-6'), 132.5 (d, C-2'), 133.2 (s, C-4), 133.5 (d, C-4', C-12), 133.9 (d, C-3), 134.4 (s, C-5'), 141.5 (s, C-2), 143.5 (d, C-5), 143.6 (s, C-10), 166.0 (s, C-1'), $167.6(\mathrm{~s}, \mathrm{C}-1) \mathrm{ppm}$. 


\section{21-O-\{2',5'-Dibrom-4'-[3-(trifluormethyl)-3H-diazirin-3-yl]benzoyl\}- bafilomycin $A_{1}$ (44)}

In einem zu B.IV.2.2. analogen Ansatz wurden $50.7 \mathrm{mg}(81.4 \mu \mathrm{mol})$ Bafilomycin $\mathrm{A}_{1}$ (11a) mit $34.5 \mathrm{mg}$ des nach B.IV.1. erhaltenen Produktgemischs sowie $20.7 \mathrm{mg}$ (108 $\mu \mathrm{mol})$ EDCI und katalytischen Mengen DMAP zur Reaktion gebracht. Das nach Aufarbeitung des Ansatzes erhaltene Rohprodukt (109 mg) wurde säulenchromatographisch an Sephadex LH-20 ${ }^{\circledR}$ (Eluent: Dichlormethan) getrennt. Neben $16 \mathrm{mg}(25.7 \mu \mathrm{mol})$ nicht umgesetztem Edukt 11a wurden $23 \mathrm{mg}(23.2 \mu \mathrm{mol}) 44$ erhalten, was einer Ausbeute von $42 \%$ bezogen auf Bafilomycin $\mathrm{A}_{1}$ (11a) entspricht.

$\mathbf{C}_{44} \mathbf{H}_{62} \mathbf{B r}_{2} \mathbf{F}_{3} \mathbf{N}_{2} \mathbf{O}_{10}(992.80)$ farbloser Feststoff

UV-löschend (254 nm)

Smp.: $96^{\circ} \mathrm{C}$

$\mathbf{R}_{\mathbf{f}}=0.13\left(\mathrm{KG}, \mathrm{CHCl}_{3} / \mathrm{MeOH} 9: 1\right)$, 0.57 (RP-18, $\left.\mathrm{MeOH} / \mathrm{H}_{2} \mathrm{O} 7: 3\right)$.

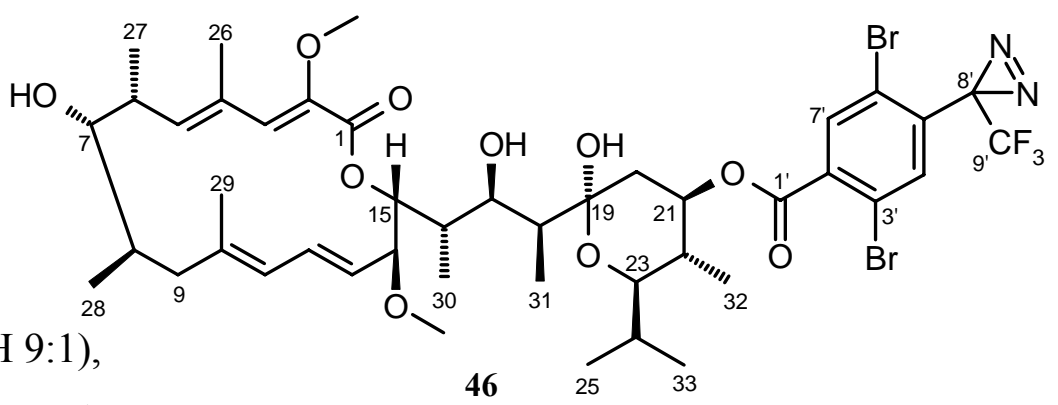

Anfärbeverhalten: hellbraun (Anis).

ESI-MS: $\mathrm{m} / \mathrm{z}=1015[\mathrm{M}+\mathrm{Na}]^{+}, 991[\mathrm{M}-\mathrm{H}]^{-}$.

$[\boldsymbol{\alpha}]_{\mathbf{D}}^{\mathbf{2 0}}=-21^{\circ}(\mathrm{c}=0.10, \mathrm{MeOH})$.

UV $(\mathrm{MeOH}): \lambda_{\max }(\lg \varepsilon)=247$ (5.37), $287(5.01) \mathrm{nm}$,

$(\mathrm{MeOH}, \mathrm{HCl}): \lambda_{\max }(\lg \varepsilon)=246(5.35), 284(4.95) \mathrm{nm}$,

$(\mathrm{MeOH}, \mathrm{NaOH}): \lambda_{\max }(\lg \varepsilon)=246(5.37), 286(5.01) \mathrm{nm}$.

IR (KBr): $\widetilde{v}=3429,2965,2930$ (sh), $2873(\mathrm{sh}), 1687,1646(\mathrm{sh}), 1622(\mathrm{sh}), 1540,1457$, 1385 (sh), 1362, 1245, 1196, 1159, 1100, $967 \mathrm{~cm}^{-1}$.

${ }^{1}$ H-NMR $\left(600 \mathrm{MHz}, \mathrm{CD}_{2} \mathrm{Cl}_{2}\right): \delta=0.78\left(\mathrm{~d}, J=7.0 \mathrm{~Hz}, 3 \mathrm{H}, 33-\mathrm{H}_{3}\right), 0.81(\mathrm{~d}, J=7.0 \mathrm{~Hz}, 3 \mathrm{H}$, $\left.30-\mathrm{H}_{3}\right), 0.88\left(\mathrm{~d}, J=7.0 \mathrm{~Hz}, 3 \mathrm{H}, 32-\mathrm{H}_{3}\right), 0.91$ (d, $\left.J=6.5 \mathrm{~Hz}, 3 \mathrm{H}, 28-\mathrm{H}_{3}\right), 0.92$ (d, $J=7.0 \mathrm{~Hz}$, $\left.3 \mathrm{H}, 25-\mathrm{H}_{3}\right), 1.00\left(\mathrm{~d}, J=7.0 \mathrm{~Hz}, 3 \mathrm{H}, 31-\mathrm{H}_{3}\right), 1.03\left(\mathrm{~d}, J=7.0 \mathrm{~Hz}, 3 \mathrm{H}, 27-\mathrm{H}_{3}\right), 1.34$ (td, $\left.J=11.5,2.5 \mathrm{~Hz}, 1 \mathrm{H}, 20-\mathrm{H}_{\mathrm{a}}\right), 1.65(\mathrm{~d}, J=6.0 \mathrm{~Hz}, 1 \mathrm{H}, 7-\mathrm{OH}), 1.69$ (m, 1H, 22-H), 1.79 (m, $1 \mathrm{H}, 18-\mathrm{H}), 1.85-1.92$ (m, 2H, H-8, H-24), 1.92 (s, 3H, 29- $\left.\mathrm{H}_{3}\right), 1.93$ (m, 1H, 9- $\mathrm{H}_{\mathrm{a}}$ ), 1.97 (d, $\left.J=1.0 \mathrm{~Hz}, 3 \mathrm{H}, 26-\mathrm{H}_{3}\right), 2.09(\mathrm{~m}, 1 \mathrm{H}, 16-\mathrm{H}), 2.12\left(\mathrm{~m}, 1 \mathrm{H}, 9-\mathrm{H}_{\mathrm{b}}\right), 2.41$ (dd, $J=12.0,5.0 \mathrm{~Hz}$, $\left.1 \mathrm{H}, 20-\mathrm{H}_{\mathrm{b}}\right), 2.53(\mathrm{~m}, 1 \mathrm{H}, 6-\mathrm{H}), 3.23\left(\mathrm{~s}, 3 \mathrm{H}, 35-\mathrm{H}_{3}\right), 3.27$ (t, J=6.0 Hz, 1H, 7-H), 3.61 (s, 3H, 34- $\left.\mathrm{H}_{3}\right), 3.63(\mathrm{~m}, 1 \mathrm{H}, 23-\mathrm{H}), 3.89$ (t, $\left.J=9.0 \mathrm{~Hz}, 14-\mathrm{H}\right), 4.12(\mathrm{ddd}, J=11.0,4.5,2.0 \mathrm{~Hz}, 1 \mathrm{H}$, 
17-H), $4.66(\mathrm{~d}, J=6.0 \mathrm{~Hz}, 1 \mathrm{H}, 17-\mathrm{OH}), 4.88(\mathrm{dd}, J=9.0,1.0 \mathrm{~Hz}, 1 \mathrm{H}, 15-\mathrm{H}), 5.13$ (dd, $J=15.0,9.5 \mathrm{~Hz}, 1 \mathrm{H}, 13-\mathrm{H}), 5.17(\mathrm{td}, J=11.0,5.0 \mathrm{~Hz}, 1 \mathrm{H}, 21-\mathrm{H}), 5.49$ (d, $J=2.5 \mathrm{~Hz}, 1 \mathrm{H}$, 19-OH), 5.78 (d, $J=9.0 \mathrm{~Hz}, 1 \mathrm{H}, 5-\mathrm{H}), 5.80$ (d, $J=11 \mathrm{~Hz}, 1 \mathrm{H}, 11-\mathrm{H}), 6.53$ (dd, $J=15.0$, $10.5 \mathrm{~Hz}, 1 \mathrm{H}, 12-\mathrm{H}), 6.68$ (s, 1H, 3-H), 7.93 (s, 1H, 6'-H), 7.96 (s, 1H, 3'-H) ppm.

${ }^{13}$ C-NMR (150.8 MHz, $\mathrm{CD}_{2} \mathrm{Cl}_{2}$ ): $\delta=7.1$ (q, C-31), 9.8 (q, C-30), 12.5 (q, C-32), 14.0 (q, C-26), 14.3 (q, C-33), 17.3 (q, C-27), 20.2 (q, C-29), 21.2 (q, C-25), 21.7 (q, C-28), 28.2 (q, C-24), 28.6 (q, ${ }^{2} J_{\mathrm{CF}}=43.5 \mathrm{~Hz}, \mathrm{C}-8$ '), 37.0 (d, C-6), 37.5 (d, C-16), 38.4 (d, C-22), 40.2(t, C-20), 40.5 (d, C-8), 41.5 (t, C-9), 42.2 (d, C-18), 55.7 (q, C-35), 60.2 (q, C-34), 71.0 (d, C-17), 76.0 (d, C-23), 77.0 (d, C-15), 77.3 (d, C-21), 81.1 (d, C-7), 82.6 (d, C-14), 99.2 (s, C-19), 120.8 (s, C-3'), 124.0 (s, C-6'), 125.3 (d, C-11), 127.0 (d, C-13), 132.2 (s, C-2'), 133.1 (s, C-4), 133.6 (d, C-12), 134.0 (d, C-3), 136.0 (d, C-4'), 137.2 (s, C-5'), 137.4 (q, ${ }^{1} J_{\mathrm{CF}}=275 \mathrm{~Hz}, \mathrm{C}-9$ ') 138.5 (d, C-7'), 141.4 (s, C-2), 143.7 (d, C-5), 143.7 (s, C-10), 163.9 (s, C-1'), 167.7 (s, C-1) ppm. 


\section{Isolierung von Sekundärmetaboliten aus Actinomyceten}

\section{Isolierung der Actinomyceten-Stämme aus Erdproben}

$500 \mathrm{mg}$ Erdprobe wurden mit $4.5 \mathrm{~mL}$ sterilem Wasser durchmischt und 15 Minuten bei Raumtemperatur belassen. Die erhaltene Suspension wurde daraufhin mit sterilem Wasser im Verhältnis 1:100 verdünnt. $0.1 \mathrm{~mL}$ dieses Gemisches wurden auf Sterilfilter mit einer für Actinomycetensporen durchlässigen Porengröße aufgetragen, welche anschließend auf ausschließlich Wasser enthaltende Agarplatten gelegt wurden. Diese wurden zwei Tage bei $28^{\circ} \mathrm{C}$ inkubiert. Die ausgebildeten Kolonien wurden mit einer sterilen Nadel auf frische M2Agarplatten übertragen und weitere fünf Tage inkubiert. Die so erhaltenen Mischkulturen wurden durch wiederholten 3-Feld-Ausstrich so lange vereinzelt, bis reine Bakterienkolonien vorlagen.

\section{Stammhaltung und Langzeitkonservierung}

Alle Actinomyceten-Stämme wurden in Petrischalen auf dem Medium M2 für drei bis sieben Tage bei $28^{\circ} \mathrm{C}$ angezüchtet und anschließend bei $4{ }^{\circ} \mathrm{C}$ maximal drei Monate gelagert. Zur Langzeitkonservierung diente eine Stickstoff-Einlagerung von in Polypropylen-Halmen eingeschweißten, gut bewachsenen Agarstückchen bei $-196^{\circ} \mathrm{C}$.

\section{Durchführung des chemischen Screenings}

Die Kultivierung der zu untersuchenden Stämme wurde in je vier verschiedenen Medien (Hafer, M2, SM und SGG) in $300 \mathrm{~mL}$ Erlenmeyerkolben mit drei Schikanen durchgeführt. Dazu wurden jeweils $50 \mathrm{~mL}$ Nährlösung mit einem $1 \mathrm{~cm}^{2}$ großen Stück einer gut bewachsenen Agarplatte beimpft und die erhaltenen Ansätze bei $28^{\circ} \mathrm{C}$ und $180 \mathrm{rpm}$ inkubiert. Nach $48 \mathrm{~h}$ wurden je $3 \mathrm{~mL}$ dieser Vorkultur entnommen und in $50 \mathrm{~mL}$ des entsprechenden, frisch zubereiteten Mediums übertragen. Die Hauptkulturen wurden unter gleichen Bedingungen $96 \mathrm{~h}$ inkubiert. Pro Nährmedium wurden zwei Kolben angesetzt, welche bei identischem Aussehen und pH-Wert zusammen aufgearbeitet wurden.

Die vereinigten Kulturbrühen $(100 \mathrm{~mL})$ wurden anschließend mit Celite versetzt und filtriert. Das erhaltene Mycel wurde in $30 \mathrm{~mL}$ Aceton suspendiert und im Ultraschallbad für 
15 Minuten extrahiert. Nach erfolgter Abtrennung des Mycels durch Filtration wurde dieser Schritt noch einmal wiederholt. Daraufhin wurde das Lösungsmittel im Vakuum entfernt. Das Kulturfiltrat wurde an Amberlite ${ }^{\circledR}$ XAD-2 $(30 \mathrm{~mL})$ adsorbiert, das Adsorberharz mit $25 \mathrm{~mL}$ Wasser gewaschen und mit $40 \mathrm{~mL}$ Methanol eluiert. Nach Entfernung des Lösungsmittels im Vakuum wurden beide Extrakte (Kulturfiltrat und Mycel) in je $2 \mathrm{~mL}$ eines 9:1-Gemisches aus Methanol und Wasser aufgenommen und $5 \mu \mathrm{L}$ dieser Lösung auf eine HPTLC-Kieselgelplatte aufgetragen. Die Entwicklung der Dünnschichtchromatogramme erfolgte in Chloroform/Methanol 9:1 sowie in n-Butanol/ Eisessig/Wasser 4:1:5. Das Metabolitenmuster wurde im UV-Licht (254 und $366 \mathrm{~nm}$ ) sowie mit Hilfe der Sprühreagenzien Anis, Orcin und Ehrlich analysiert. 


\section{Actinomyces sp. Stamm Gö GS56}

\subsection{Kultivierung und Aufarbeitung}

Stamm Gö GS56 wurde wie unter B.V.3. beschrieben in Schüttelkolben $(250 \mathrm{~mL}$, $20 \times 100 \mathrm{~mL}$ ) in M2-Medium sowie in einem 10 L-Fermenter im selben Medium unter Zusatz von $0.5 \mathrm{~g} / \mathrm{L}$ Glycerin bei $300 \mathrm{rpm}$ und einer Belüftung von 3 vvm kultiviert. Die Aufarbeitung erfolgte durch Korrektur des pH-Wertes auf 5.0, Zusatz von Celite und Filtration. Das Kulturfiltrat wurde an etwa 500 bzw. 3000 mL XAD-2 adsorbiert, das Adsorberharz mit 1 bzw. 6 L Wasser gewaschen und mit 1 bzw. 4 x 1 L Methanol eluiert.

\subsection{Isolierung und Charakterisierung der Metaboliten}

Der Kulturfiltratextrakt des 2 L-Ansatzes wurde durch wiederholte Säulenchromatographie an Kieselgel $\left(\mathrm{CHCl}_{3} / \mathrm{MeOH}\right.$ 19:1 $\rightarrow$ 85:15 $\rightarrow$ 7:1) getrennt. Es wurden $1.8 \mathrm{mg} / \mathrm{L} 45$ erhalten. Der Extrakt des 10 L-Kulturfiltrats wurde flashchromatographisch an Kieselgel $\left(\mathrm{CH}_{2} \mathrm{Cl}_{2} / \mathrm{MeOH}\right.$ 9:1) und anschließend an Sephadex ${ }^{\circledR}$ LH-20 (Eluent: MeOH) gereinigt. Es

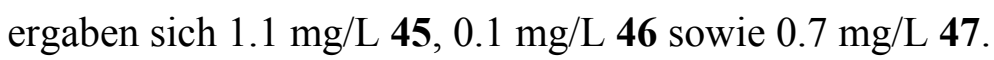

\section{3-Cyanomethyl-6-(2", 3"'-dihydroxy-3"'-methylbutyl)indol (45)}

$\mathbf{C}_{15} \mathbf{H}_{18} \mathbf{N}_{2} \mathbf{O}_{2}(258.32)$

braunes Ö1

UV-löschend (254 nm)

hellblau fluoreszierend $(366 \mathrm{~nm})$

Smp.: $98^{\circ} \mathrm{C}$

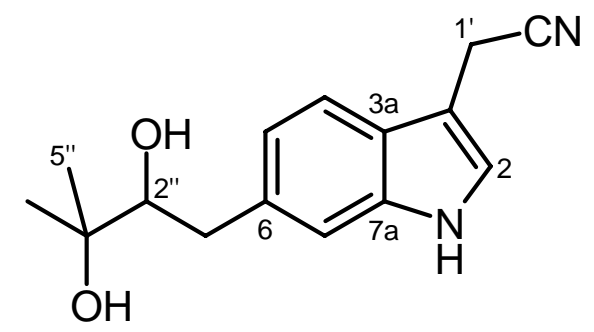

$\mathbf{R}_{\mathbf{f}}=0.24\left(\mathrm{KG}, \mathrm{CHCl}_{3} / \mathrm{MeOH} 9: 1\right)$,

0.59 (RP-18, $\mathrm{MeOH} / \mathrm{H}_{2} \mathrm{O} 7: 3$ ).

Anfärbeverhalten: bräunlich-violett (Anis), violett (Orcin).

ESI-MS: $\mathrm{m} / \mathrm{z}=281[\mathrm{M}+\mathrm{Na}]^{+}, 539[2 \mathrm{M}+\mathrm{Na}]^{+}, 257[\mathrm{M}-\mathrm{H}]^{-}, 515[2 \mathrm{M}-\mathrm{H}]^{-}$.

EI-MS: $m / z(\%)=258(48)[\mathrm{M}]^{+}, 200(25)\left[\mathrm{M}-\mathrm{C}_{2} \mathrm{H}_{4} \mathrm{NO}\right]^{+}, 169(100)\left[\mathrm{M}-\mathrm{C}_{4} \mathrm{H}_{9} \mathrm{O}_{2}\right]^{+}, 130(45)$

$$
\left[\mathrm{M}-\mathrm{C}_{6} \mathrm{H}_{10} \mathrm{O}_{2} \mathrm{~N}\right]^{+} \text {. }
$$

HREI-MS: 258.1368 gefunden wie berechnet für $\mathrm{C}_{15} \mathrm{H}_{18} \mathrm{~N}_{2} \mathrm{O}_{2}$.

$[\boldsymbol{\alpha}]_{\mathrm{D}}^{\mathbf{2 0}}=-17^{\circ}(\mathrm{c}=0.10, \mathrm{MeOH})$. 
UV $(\mathrm{MeOH}): \lambda_{\max }(\lg \varepsilon)=220(5.07), 270(4.38) \mathrm{nm}$.

IR (KBr): $\widetilde{v}=3420,2969,2927,2251,1717$ (sh), 1636, 1456, 1384, 1347 (sh), 1066, $1026,668 \mathrm{~cm}^{-1}$.

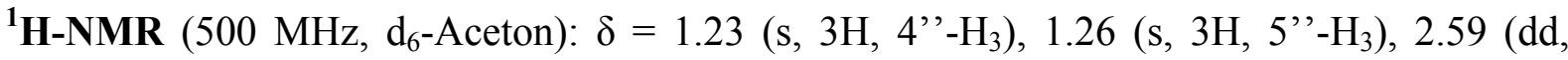
$J=14.0,10.5 \mathrm{~Hz}, 1 \mathrm{H}, 1$ ''- $-\mathrm{H}_{\mathrm{a}}$ ), 3.07 (d, $J=14 \mathrm{~Hz}, 1 \mathrm{H}, 1$ ''- $-\mathrm{H}_{\mathrm{b}}$ ), 3.42 (bs, 2H, 2' $-\mathrm{OH}$, 3' $-\mathrm{OH}), 3.58$ (d, $J=9.0 \mathrm{~Hz}, 1 \mathrm{H}, 2$ '’-H), 3.98 (d, $J=1.0 \mathrm{~Hz}, 2 \mathrm{H}, 1$ ' $\left.-\mathrm{H}_{2}\right), 7.03$ (dd, $J=8.0,1.5$ Hz, 1H, 5-H), 7.31 (m, 1H, 2-H), 7.34 (d, $J<1 \mathrm{~Hz}, 1 \mathrm{H}, 7-\mathrm{H}), 7.52$ (d, $J=8.0 \mathrm{~Hz}, 1 \mathrm{H}, 4-\mathrm{H})$ ppm.

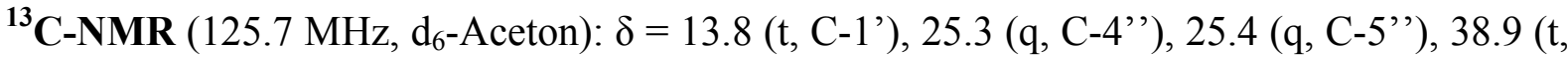
C-1'’), 72.5 (s, C-3'”), 80.5 (d, C-2'’), 104.9 (s, C-3), 112.8 (d, C-7), 118.1 (d, C-4), 119.2 (s, C-9), 121.9 (d, C-5), 123.5 (d, C-2), 125.3 (s, C-3a), 135.4 (s, C-6), 137.7 (s, 7a) ppm.

\section{3,5'-Dimethyluridin (46)}

$\mathbf{C}_{11} \mathbf{H}_{16} \mathbf{N}_{2} \mathbf{O}_{6}(272.26)$

farbloser Feststoff

UV-löschend (254 nm)

Smp.: $>200{ }^{\circ} \mathrm{C}$

$\mathbf{R}_{\mathbf{f}}=0.10\left(\mathrm{KG}, \mathrm{CHCl}_{3} / \mathrm{MeOH} 9: 1\right)$,

0.69 (RP-18, $\mathrm{MeOH} / \mathrm{H}_{2} \mathrm{O}$ 7:3).

Anfärbeverhalten: hellbraun (Anis), violett (Orcin).

ESI-MS: $\mathrm{m} / \mathrm{z}=295[\mathrm{M}+\mathrm{Na}]^{+}, 567[2 \mathrm{M}+\mathrm{Na}]^{+}, 271[\mathrm{M}-\mathrm{H}]^{-}, 543[2 \mathrm{M}-\mathrm{H}]^{-}$.

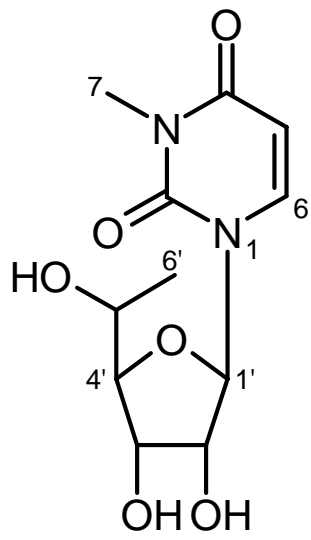

HRESI-MS: 273.1081360 gefunden wie berechnet für $\mathrm{C}_{11} \mathrm{H}_{17} \mathrm{~N}_{2} \mathrm{O}_{6}$.

$[\boldsymbol{\alpha}]_{\mathrm{D}}^{\mathbf{2 0}}=-60^{\circ}(\mathrm{c}=0.025, \mathrm{MeOH})$.

UV $(\mathrm{MeOH}): \lambda_{\max }(\lg \varepsilon)=260(4.24) \mathrm{nm}$,

$(\mathrm{MeOH}, \mathrm{HCl}): \lambda_{\max }(\lg \varepsilon)=261(4.03) \mathrm{nm}$,

$(\mathrm{MeOH}, \mathrm{NaOH}): \lambda_{\max }(\lg \varepsilon)=255(4.23) \mathrm{nm}$.

IR $(\mathrm{KBr}): \widetilde{v}=3422,2927,1700(\mathrm{sh}), 1662,1576,1457,1419,1384,668 \mathrm{~cm}^{-1}$.

${ }^{1}$ H-NMR (500 MHz, CD $\left.3 \mathrm{OD}\right): \delta=1.27\left(\mathrm{~d}, J=6.5 \mathrm{~Hz}, 3 \mathrm{H}, 6{ }^{\prime}-\mathrm{H}_{3}\right), 3.28\left(\mathrm{~s}, 3 \mathrm{H}, 7-\mathrm{H}_{3}\right), 3.82$ (dd, $\left.J=5.0,2.9 \mathrm{~Hz}, 1 \mathrm{H}, 4^{\prime}-\mathrm{H}\right), 3.93\left(\mathrm{qd}, J=6.5,2.9 \mathrm{~Hz}, 1 \mathrm{H}, 5^{\prime}-\mathrm{H}\right), 4.11$ (t, $J=5.0 \mathrm{~Hz}, 1 \mathrm{H}$, 3'-H), 4.17 (t, $\left.J=4.9 \mathrm{~Hz}, 1 \mathrm{H}, 2^{\prime}-\mathrm{H}\right), 5.77$ (d, $\left.J=8.1 \mathrm{~Hz}, 1 \mathrm{H}, 5-\mathrm{H}\right), 5.92$ (d, $J=4.9 \mathrm{~Hz}, 1 \mathrm{H}$, $\left.1^{\prime}-\mathrm{H}\right), 8.12(\mathrm{~d}, J=8.1 \mathrm{~Hz}, 1 \mathrm{H}, 6-\mathrm{H}) \mathrm{ppm}$. 
${ }^{13}$ C-NMR (125.7 MHz, CD 3 OD): $\delta=20.2$ (q, C-6'), 28.0 (q, C-7), 67.7 (d, C-5'), 72.2 (d, C-3’), 75.8 (d, C-2'), 89.2 (d, C-4'), 91.4 (d, C-1'), 101.7 (d, C-5), 140.9 (d, C-6), 152.8 (s, C-2), 165.3 (s, C-4) ppm.

\section{Thioaurin (47)}

$\mathbf{C}_{7} \mathbf{H}_{6} \mathbf{N}_{2} \mathbf{O}_{2} \mathbf{S}_{2}(214.27)$

gelber Feststoff

UV-löschend (254 nm)

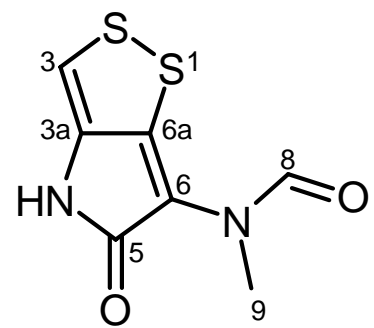

Smp.: $119^{\circ} \mathrm{C}$

$\mathbf{R}_{\mathbf{f}}=0.31\left(\mathrm{KG}, \mathrm{CHCl}_{3} / \mathrm{MeOH} 9: 1\right)$, 0.66 (RP-18, $\mathrm{MeOH} / \mathrm{H}_{2} \mathrm{O}$ 7:3).

Anfärbeverhalten: gelb (Anis).

ESI-MS: $\mathrm{m} / \mathrm{z}=237[\mathrm{M}+\mathrm{Na}]^{+}, 451[2 \mathrm{M}+\mathrm{Na}]^{+}, 213[\mathrm{M}-\mathrm{H}]^{-}, 427[2 \mathrm{M}-\mathrm{H}]^{-}$.

UV $(\mathrm{MeOH}): \lambda_{\max }(\lg \varepsilon)=368(4.75) \mathrm{nm}$,

$(\mathrm{MeOH}, \mathrm{HCl}): \lambda_{\max }(\lg \varepsilon)=367(4.74) \mathrm{nm}$,

$(\mathrm{MeOH}, \mathrm{NaOH}): \lambda_{\max }(\lg \varepsilon)=357(4.74) \mathrm{nm}$.

IR (KBr): $\widetilde{v}=3421,2926(\mathrm{sh}), 1670,1383,1308,1104,817,784,713,629 \mathrm{~cm}^{-1}$.

${ }^{1}$ H-NMR (500 MHz, CD $\left.\mathrm{CD}_{3} \mathrm{OD}\right): \delta$ (Hauptkonformer) = $3.46\left(\mathrm{~s}, 3 \mathrm{H}, 9-\mathrm{H}_{3}\right), 7.26(\mathrm{~s}, 1 \mathrm{H}, 3-\mathrm{H})$, $8.13(\mathrm{~s}, 1 \mathrm{H}, 8-\mathrm{H}) \mathrm{ppm}$.

${ }^{13}$ C-NMR (150.8 MHz, CD 3 OD): $\delta$ (Hauptkonformer) = 34.9 (q, C-9), 114.8 (d, C-3), 115.1 (s, C-6), 134.6 (s, C-3a), 145.7 (s, C-6a), 163.7 (d, C-8), 171.2 (s, C-5) ppm. 


\section{Actinomyces sp. Stamm Gö TS15}

\subsection{Kultivierung und Aufarbeitung}

Stamm Gö TS15 wurde wie unter B.V.4.1. beschrieben in Schüttelkolben $(250 \mathrm{~mL}$, 40 x $100 \mathrm{~mL}$ ) im Medium M2 kultiviert. Die Aufarbeitung erfolgte durch Korrektur des pHWertes auf 5.0, Zusatz von Celite und Filtration. Das Kulturfiltrat wurde an etwa $3000 \mathrm{~mL}$ XAD-2 adsorbiert, das Adsorberharz mit $2 \mathrm{~L}$ Wasser gewaschen und mit 3 x 1 L Methanol eluiert.

\subsection{Isolierung und Charakterisierung der Metaboliten}

Der Kulturfiltratextrakt wurde durch Säulenchromatographie an Sephadex ${ }^{\circledR}$ LH-20 (MeOH) getrennt. Flashchromatographische Trennung $\left(\mathrm{CH}_{2} \mathrm{Cl}_{2} / \mathrm{MeOH}\right.$ 9:1) der erhaltenen Fraktionen ergab $2.3 \mathrm{mg} / \mathrm{L} 56$ sowie $1.1 \mathrm{mg} / \mathrm{L}$ 57. Mitteldruckchromatographie an RP-18 $\left(\mathrm{MeOH} / \mathrm{H}_{2} \mathrm{O}\right.$ 1:1) lieferte $2 \mathrm{mg} / \mathrm{L} \mathbf{5 5}$.

\section{2,3-Dihydroxybenzoesäure (55)}

$\mathbf{C}_{7} \mathbf{H}_{6} \mathbf{O}_{4}(154.12)$

gelbbrauner Feststoff

UV-löschend (254 nm)

Smp.: $>200{ }^{\circ} \mathrm{C}$

$\mathbf{R}_{\mathbf{f}}=0.39\left(\mathrm{KG}, \mathrm{CH}_{2} \mathrm{Cl}_{2} / \mathrm{MeOH} 2: 1\right)$,<smiles>O=C(O)c1cccc(O)c1O</smiles>

0.87 (RP-18, $\mathrm{MeOH} / \mathrm{H}_{2} \mathrm{O} 7: 3$ ).

EI-MS: $\mathrm{m} / \mathrm{z}(\%)=154(45)[\mathrm{M}]^{+}, 136(100)\left[\mathrm{M}-\mathrm{H}_{2} \mathrm{O}\right]^{+}$.

UV (MeOH): $\lambda_{\max }(\lg \varepsilon)=208(4.96), 308(4.06) \mathrm{nm}$,

(MeOH, HCl): $\lambda_{\max }(\lg \varepsilon)=206$ (4.88), $247(4.40), 320(4.06) \mathrm{nm}$,

$(\mathrm{MeOH}, \mathrm{NaOH}): \lambda_{\max }(\lg \varepsilon)=209$ (4.90), 313 (4.03) nm.

IR (KBr): $\widetilde{v}=3422,2925,2853$ (sh), 2726, 1636 (sh), 1605, 1559, 1482, 1383, 1271, $1081,840,782,753,636 \mathrm{~cm}^{-1}$

${ }^{1}$ H-NMR $\left(500 \mathrm{MHz}, \mathrm{CD}_{3} \mathrm{OD}\right): \delta=6.60(\mathrm{t}, J=7.8 \mathrm{~Hz}, 1 \mathrm{H}, 6-\mathrm{H}), 6.85(\mathrm{~d}, J=7.8 \mathrm{~Hz}, 1 \mathrm{H}$, 4-H), 7.35 (d, $J=7.8 \mathrm{~Hz}, 1 \mathrm{H}, 6-\mathrm{H}) \mathrm{ppm}$. 
${ }^{13}$ C-NMR (125.7 MHz, CD $\left.{ }_{3} \mathrm{OD}\right): \delta=118.2$ (C-2), 119.0 (C-5), 120.0 (C-1), 122.4 (C-6), 146.4 (C-3), 151.3 (C-2), 167.6 (C-7) ppm.

\section{Hydroxymethylmaltol (56)}

$\mathbf{C}_{6} \mathbf{H}_{6} \mathbf{O}_{4}(142.11)$

farbloser Feststoff

UV-löschend (254 nm)

Smp.: $128^{\circ} \mathrm{C}$<smiles>O=c1ccoc(CO)c1O</smiles>

$\mathbf{R}_{\mathbf{f}}=0.20\left(\mathrm{KG}, \mathrm{CHCl}_{3} / \mathrm{MeOH} 9: 1\right)$,

$0.82\left(\mathrm{RP}-18, \mathrm{MeOH} / \mathrm{H}_{2} \mathrm{O} 7: 3\right)$.

Anfärbeverhalten: rot (Orcin).

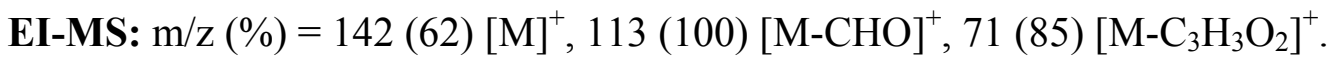

UV (MeOH): $\lambda_{\max }(\lg \varepsilon)=216(4.73), 277(4.68) \mathrm{nm}$,

$(\mathrm{MeOH}, \mathrm{HCl}): \lambda_{\max }(\lg \varepsilon)=215$ (4.74), $276(4.69) \mathrm{nm}$,

$(\mathrm{MeOH}, \mathrm{NaOH}): \lambda_{\max }(\lg \varepsilon)=225(4.90), 322(4.59) \mathrm{nm}$.

IR (KBr): $\widetilde{v}=3319,3079(\mathrm{sh}), 2924$ (sh), 2868 (sh), 2747 (sh), 2628 (sh), 1651, 1611, 1552, 1483, 1446, 1401, 1300, 1269, 1245, 1189, 1045, 1008, 928, 849, $826,668(\mathrm{sh}), 625,517 \mathrm{~cm}^{-1}$.

${ }^{1}$ H-NMR (500 MHz, CD $\left.{ }_{3} \mathrm{OD}\right): \delta=4.60\left(\mathrm{~s}, 2 \mathrm{H}, 7-\mathrm{H}_{2}\right), 6.40(\mathrm{~d}, J=5.5 \mathrm{~Hz}, 1 \mathrm{H}, 5-\mathrm{H}), 8.00$ (d, $J=5.5 \mathrm{~Hz}, 1 \mathrm{H}, 6-\mathrm{H}) \mathrm{ppm}$.

${ }^{13}$ C-NMR (75.5 MHz, CD 3 OD): $\delta=57.0$ (t, C-7), 114.5 (d, C-5), 144.7 (s, C-3), 152.0 (s, C-2), 156.8 (d, C-6), 176.1 (s, C-4) ppm.

\section{2-Aminobenzoesäureamid (57)}

$\mathbf{C}_{7} \mathbf{H}_{8} \mathbf{N}_{2} \mathbf{O}(136.15)$

farbloser Feststoff

UV-löschend (254 nm)

hellblau fluoreszierend $(366 \mathrm{~nm})$

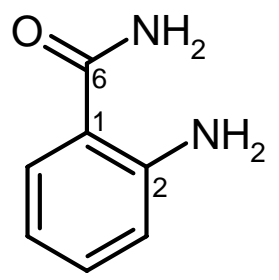

Smp.: $75^{\circ} \mathrm{C}$

$\mathbf{R}_{\mathbf{f}}=0.30\left(\mathrm{KG}, \mathrm{CHCl}_{3} / \mathrm{MeOH} 9: 1\right)$,

0.71 (RP-18, $\mathrm{MeOH} / \mathrm{H}_{2} \mathrm{O}$ 7:3).

Anfärbeverhalten: gelb (Ehrlich).

EI-MS: $\mathrm{m} / \mathrm{z}(\%)=136(96)[\mathrm{M}]^{+}, 119(100)\left[\mathrm{M}-\mathrm{NH}_{3}\right]^{+}, 92(46)\left[\mathrm{M}-\mathrm{CH}_{2} \mathrm{NO}\right]^{+}$. 
UV $(\mathrm{MeOH}): \lambda_{\max }(\lg \varepsilon)=214(4.97), 248(4.47), 330(4.17) \mathrm{nm}$,

$(\mathrm{MeOH}, \mathrm{HCl}): \lambda_{\max }(\lg \varepsilon)=202(4.73), 221(4.65) \mathrm{nm}$,

$(\mathrm{MeOH}, \mathrm{NaOH}): \lambda_{\max }(\lg \varepsilon)=216$ (4.95), $248(4.48), 331(4.20) \mathrm{nm}$.

IR (KBr): $\widetilde{v}=3411,3324$ (sh), 3200 (sh), 2925, 2834 (sh), 1658, 1627, 1586, 1544, 1403, $1317,1259,743 \mathrm{~cm}^{-1}$.

${ }^{1}$ H-NMR $\left(500 \mathrm{MHz}, \mathrm{CD}_{3} \mathrm{OD}\right): \delta=6.59(\mathrm{ddd}, J=8.0,7.8,1.0 \mathrm{~Hz}, 1 \mathrm{H}, 5-\mathrm{H}), 6.73(\mathrm{dd}, J=8.2$, $1.0 \mathrm{~Hz}, 1 \mathrm{H}, 3-\mathrm{H}), 7.17$ (ddd, $J=8.2,7.8,1.7 \mathrm{~Hz}, 1 \mathrm{H}, 4-\mathrm{H}), 7.49$ (dd, $J=8.0,1.7 \mathrm{~Hz}, 1 \mathrm{H}, 6-\mathrm{H})$ ppm.

${ }^{13}$ C-NMR (125.7 MHz, CD $\left.{ }_{3} \mathrm{OD}\right): \delta=115.9$ (s, C-1), 117.1 (d, C-3), 118.3 (d, C-5), 129.7 (d, C-6), 133.6 (d, C-4), 151.1 (s, C-2), 174.6 (s, C-7) ppm. 


\section{Actinomyces sp. Stamm Gö TS17}

\subsection{Kultivierung und Aufarbeitung}

Stamm Gö TS17 wurde wie unter B.V.5.1. beschrieben in Schüttelkolben $(250 \mathrm{~mL}$, 50 x $100 \mathrm{~mL}$, Hafermedium) kultiviert und aufgearbeitet.

\subsection{Isolierung und Charakterisierung der Metaboliten}

Der Kulturfiltratextrakt wurde durch Säulenchromatographie an Sephadex ${ }^{\circledR}$ LH-20 (MeOH) getrennt. Anschließende flashchromatographische Reinigung an Kieselgel $\left(\mathrm{CH}_{2} \mathrm{Cl}_{2} / \mathrm{MeOH}\right.$ 97:3) ergab 0.8 mg/L 58. Der Mycelextrakt von Stamm Gö TS17 wurde analog bearbeitet. Säulenchromatographie an Kieselgel $\left(\mathrm{CHCl}_{3} / \mathrm{MeOH}\right.$ 98:2) sowie $\mathrm{RP}-18(\mathrm{MeOH})$ und anschließende Trennung mittels semipräparativer HPLC (Programm 2) lieferten 0.2 mg/L 59.

\section{Maltol (58)}

$\mathrm{C}_{6} \mathrm{H}_{6} \mathrm{O}_{3}(126.11)$

farbloser Feststoff

UV-löschend (254 nm)

Smp.: $110{ }^{\circ} \mathrm{C}$

$\mathbf{R}_{\mathbf{f}}=0.49\left(\mathrm{KG}, \mathrm{CHCl}_{3} / \mathrm{MeOH} 9: 1\right)$,<smiles>O=c1ccoc(I)c1O</smiles>
0.64 (RP-18, $\mathrm{MeOH} / \mathrm{H}_{2} \mathrm{O}$ 7:3).

Anfärbeverhalten: hellbraun (Anis), violett (Orcin, verschwindet beim Erhitzen).

EI-MS: $\mathrm{m} / \mathrm{z}(\%)=126(100)[\mathrm{M}]^{+}, 71(35)\left[\mathrm{M}-\mathrm{C}_{3} \mathrm{H}_{3} \mathrm{O}\right]^{+}$.

UV $(\mathrm{MeOH}): \lambda_{\max }(\lg \varepsilon)=203$ (4.50), $275(4.10) \mathrm{nm}$, $(\mathrm{MeOH}, \mathrm{HCl}): \lambda_{\max }(\lg \varepsilon)=204$ (4.40), $278(4.13) \mathrm{nm}$,

$(\mathrm{MeOH}, \mathrm{NaOH}): \lambda_{\max }(\lg \varepsilon)=217(4.44), 318(3.94) \mathrm{nm}$.

IR $(\mathrm{KBr}): \widetilde{v}=3421,3260,2927,1654,1622,1560,1459,1258,1201 \mathrm{~cm}^{-1}$.

${ }^{1}$ H-NMR $\left(300 \mathrm{MHz}, \mathrm{CD}_{2} \mathrm{Cl}_{2}\right): \delta=2.33(\mathrm{~s}, 3 \mathrm{H}, 7-\mathrm{H}), 6.35(\mathrm{~d}, J=5.5 \mathrm{~Hz}, 1 \mathrm{H}, 5-\mathrm{H}), 7.71(\mathrm{~d}$, $J=5.5 \mathrm{~Hz}, 1 \mathrm{H}, 6-\mathrm{H}) \mathrm{ppm}$.

${ }^{13}$ C-NMR (75.5 MHz, $\mathrm{CD}_{2} \mathrm{Cl}_{2}$ ): $\delta=14.4$ (q, C-7), 113.0 (d, C-5), 143.3 (s, C-3), 148.9 (s, C-2), 154.8 (d, C-6), 173.1 (s, C-4) ppm. 


\section{Grincamycin (59)}

$\mathbf{C}_{49} \mathbf{H}_{62} \mathbf{O}_{18}$ (939.03)

gelber Feststoff

UV-löschend (254 nm)

Smp.: $140{ }^{\circ} \mathrm{C}$

$\mathbf{R}_{\mathbf{f}}=0.85\left(\mathrm{KG}, \mathrm{CHCl}_{3} / \mathrm{MeOH} 9: 1\right)$.

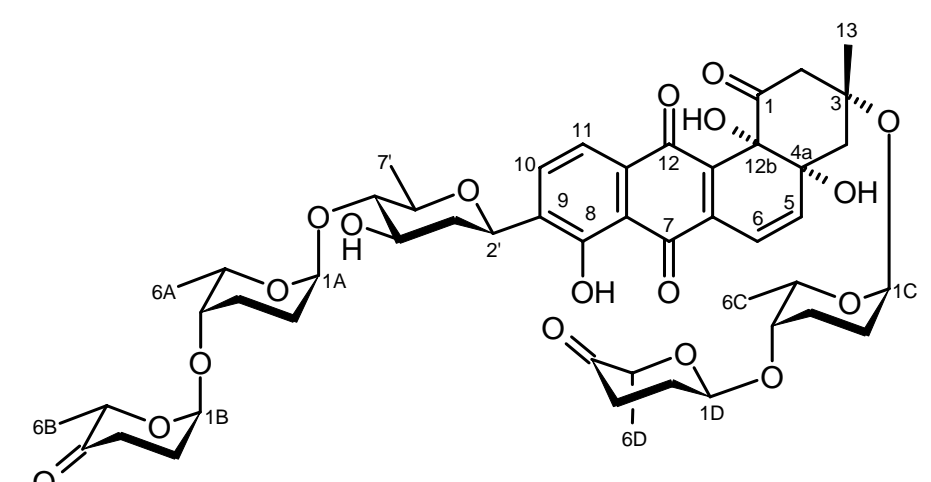

Anfärbeverhalten: hellbraun (Anis).

ESI-MS: $\mathrm{m} / \mathrm{z}=962[\mathrm{M}+\mathrm{Na}]^{+}, 937[\mathrm{M}-\mathrm{H}]^{-}$.

HRESI-MS: 959.4273250 gefunden wie berechnet für $\mathrm{C}_{49} \mathrm{H}_{66} \mathrm{NO}_{18}$.

$[\boldsymbol{\alpha}]_{\mathbf{D}}^{\mathbf{2 0}}=-35^{\circ}(\mathrm{c}=0.04, \mathrm{MeOH})$.

UV (MeOH): $\lambda_{\max }(\lg \varepsilon)=201$ (5.13), $217(5.12), 428(4.39) \mathrm{nm}$,

$(\mathrm{MeOH}, \mathrm{HCl}): \lambda_{\max }(\lg \varepsilon)=201$ (5.10), $218(5.08), 436(4.40) \mathrm{nm}$,

$(\mathrm{MeOH}, \mathrm{NaOH}): \lambda_{\max }(\lg \varepsilon)=203(5.22), 275(4.91) \mathrm{nm}$.

IR $(\mathrm{KBr}): \widetilde{v}=3432,2931,1734,1700,1684,1653$ (sh), 1636, 1118, 1086, 1040, $1011 \mathrm{~cm}^{-1}$.

${ }^{1}$ H-NMR $\left(600 \mathrm{MHz}, \mathrm{CD}_{2} \mathrm{Cl}_{2}\right): \delta=1.20\left(\mathrm{~d}, J=6.5 \mathrm{~Hz}, 3 \mathrm{H}, 6 \mathrm{C}-\mathrm{H}_{3}\right), 1.21(\mathrm{~d}, J=7.0 \mathrm{~Hz}, 3 \mathrm{H}$, 6A-H $\left.\mathrm{H}_{3}\right), 1.22\left(\mathrm{~d}, J=7.0 \mathrm{~Hz}, 3 \mathrm{H}, 6 \mathrm{~B}-\mathrm{H}_{3}\right), 1.23\left(\mathrm{~d}, J=7.0 \mathrm{~Hz}, 3 \mathrm{H}, 6 \mathrm{D}-\mathrm{H}_{3}\right), 1.33(\mathrm{~d}, J=6 \mathrm{~Hz}$, $\left.3 \mathrm{H}, 7^{\prime}-\mathrm{H}_{3}\right), 1.37\left(\mathrm{~s}, 3 \mathrm{H}, 13-\mathrm{H}_{3}\right), 1.36\left(\mathrm{~m}, 1 \mathrm{H}, 3^{\prime}-\mathrm{H}_{\mathrm{a}}\right), 1.42\left(\mathrm{~m}, 1 \mathrm{H}, 2 \mathrm{C}-\mathrm{H}_{\mathrm{a}}\right), 1.64(\mathrm{~m}, 1 \mathrm{H}$, $\left.2 \mathrm{~A}-\mathrm{H}_{\mathrm{a}}\right), 1.83\left(\mathrm{~d}, J=15.5 \mathrm{~Hz}, 1 \mathrm{H}, 4-\mathrm{H}_{\mathrm{a}}\right), 1.84\left(\mathrm{~m}, 1 \mathrm{H}, 2 \mathrm{C}-\mathrm{H}_{\mathrm{b}}\right), 1.86\left(\mathrm{~m}, 2 \mathrm{H}, 3 \mathrm{~A}-\mathrm{H}_{\mathrm{a}}, 3 \mathrm{C}-\mathrm{H}_{\mathrm{a}}\right)$, $2.04\left(\mathrm{~m}, 1 \mathrm{H}, 2 \mathrm{~A}-\mathrm{H}_{\mathrm{b}}\right), 2.06\left(\mathrm{~m}, 4 \mathrm{H}, 3 \mathrm{~A}-\mathrm{H}_{\mathrm{b}}, 3 \mathrm{C}-\mathrm{H}_{\mathrm{b}}, 2 \mathrm{~B}-\mathrm{H}_{\mathrm{a}}, 2 \mathrm{D}-\mathrm{H}_{\mathrm{a}}\right), 2.25(\mathrm{dd}, J=15.5 \mathrm{~Hz}$, $\left.3.0 \mathrm{~Hz}, 1 \mathrm{H}, 4-\mathrm{H}_{\mathrm{b}}\right), 2.32\left(\mathrm{~m}, 2 \mathrm{H}, 2 \mathrm{~B}-\mathrm{H}_{\mathrm{b}}, 2 \mathrm{D}-\mathrm{H}_{\mathrm{b}}\right), 2.45\left(\mathrm{~m}, 5 \mathrm{H}, 3^{\prime}-\mathrm{H}_{\mathrm{b}}, 3 \mathrm{~B}-\mathrm{H}_{\mathrm{a}}, 3 \mathrm{~B}-\mathrm{H}_{\mathrm{b}}, 3 \mathrm{D}-\mathrm{H}_{\mathrm{a}}\right.$, 3D-H $\left.\mathrm{H}_{\mathrm{b}}\right), 2.50\left(\mathrm{~d}, J=13.5 \mathrm{~Hz}, 1 \mathrm{H}, 2-\mathrm{H}_{\mathrm{a}}\right), 3.03(\mathrm{t}, J=8.8 \mathrm{~Hz}, 1 \mathrm{H}, 5$ '-H), 3.09 (dd, $J=13.5$, $\left.3.5 \mathrm{~Hz}, 1 \mathrm{H}, 2-\mathrm{H}_{\mathrm{b}}\right), 3.53$ (dq, $\left.J=9.5,6.2 \mathrm{~Hz}, 1 \mathrm{H}, 6^{\prime}-\mathrm{H}\right), 3.63$ (bs, 1H, 4C-H), 3.66 (bs, 1H, 4A-H), 3.77 (ddd, $\left.J=11.0,8.5,5.5 \mathrm{~Hz}, 1 \mathrm{H}, 4^{\prime}-\mathrm{H}\right), 4.15$ (qd, $\left.J=6.5,1.3 \mathrm{~Hz}, 1 \mathrm{H}, 5 \mathrm{C}-\mathrm{H}\right), 4.18$ $(\mathrm{m}, 1 \mathrm{H}, 5 \mathrm{~A}-\mathrm{H}), 4.28^{\mathrm{a}}(\mathrm{q}, J=6.9 \mathrm{~Hz}, 1 \mathrm{H}, 5 \mathrm{~B}-\mathrm{H}), 4.30^{\mathrm{a}}(\mathrm{q}, J=6.9 \mathrm{~Hz}, 1 \mathrm{H}, 5 \mathrm{D}-\mathrm{H}), 4.86(\mathrm{dd}$, $\left.J=11.5,1.5 \mathrm{~Hz}, 1 \mathrm{H}, 2^{\prime}-\mathrm{H}\right), 4.94$ (bs, 1H, 1A-H), 5.06 (t, $\left.J=5.5 \mathrm{~Hz}, 2 \mathrm{H}, 1 \mathrm{~B}-\mathrm{H}, 1 \mathrm{D}-\mathrm{H}\right), 5.20$ (d, $J=4 \mathrm{~Hz}, 1 \mathrm{H}, 1 \mathrm{C}-\mathrm{H}), 7.59$ (d, $J=8.0 \mathrm{~Hz}, 1 \mathrm{H}, 11-\mathrm{H}), 7.87(\mathrm{dd}, J=8 \mathrm{~Hz},<1 \mathrm{~Hz}, 1 \mathrm{H}, 10-\mathrm{H})$ ppm. 
${ }^{13}$ C-NMR (150.8 MHz, $\mathrm{CD}_{2} \mathrm{Cl}_{2}$ ): $\delta=14.9$ (q, C-6B, C-6D), 17.0 (q, C-6A), 17.2 (q, C-6C), 18.5 (q, C-7'), 24.7 (t, C-3A), 25.0 (t, C-3C), 25.1 (t, C-2C), 25.5 (t, C-2A), 25.6 (q, C-13), 28.7 (t, C-2B, C-2D), 33.8 (t, C-3B), 33.9 (t, C-3D), 39.1 (t, C-3'), 44.6 (t, C-4), 50.5 (t, C-2), 67.4 (d, C-5D), 68.3 (d, C-5A), 71.2 (d, C-2'), 71.3 (d, C-5B, C-5D), 71.6 (d, C-4'), 74.8 (d, C-6'), 74.9 (d, C-4A), 75.0 (d, C-4C), 80.3 (s, C-4a), 82.7 (s, C-3), 89.2 (d, C-5'), 92.8 (d, C-1C), 99.3 (d, C-1B, C-1D), 99.9 (d, C-1A), 117.4 (d, C-6), 119.7 (d, C-11), 130.8 (s, C-11a), 133.8 (d, C-10), 138.9 (s, C-9), 139.1 (s, C-12a, C-6a), 146.1 (d, C-5), 158.3 (s, C-8), 182.5 (s, C-12), 188.7 (s, C-7), 205.4 (s, C-1), 210.9 (s, C-4B), 211.1 (

a,b,c Signale sind untereinander austauschbar. 


\section{Actinomyces sp. Stamm Gö TS18}

\subsection{Kultivierung und Aufarbeitung}

Stamm Gö TS18 wurde in einem 10 L-Fermenter im Medium M2 bei $300 \mathrm{rpm}$ und einer Belüftung von 1 vvm kultiviert. Zum Beimpfen dienten $800 \mathrm{~mL}$ einer 48 Stunden alten Vorkultur im selben Medium. Die Aufarbeitung wurde wie unter B.V.5.1 beschrieben durchgeführt.

\subsection{Isolierung und Charakterisierung der Metaboliten}

Der Kulturfiltratextrakt wurde durch Flashchromatographie an Kieselgel $\left(\mathrm{CH}_{2} \mathrm{Cl}_{2} / \mathrm{MeOH}\right.$ 95:5 $\rightarrow$ 9:1) getrennt. Anschließende Chromatographie an Sephadex ${ }^{\circledR}$ LH-20 (MeOH) und RP-18 (MeOH / $\mathrm{H}_{2} \mathrm{O}$ 7:3) ergab $1.5 \mathrm{mg} / \mathrm{L}$ 62, $0.6 \mathrm{mg} / \mathrm{L} \mathrm{64}, 1.4 \mathrm{mg} / \mathrm{L} \mathrm{65}, 1 \mathrm{mg} / \mathrm{L} 66$ sowie $0.7 \mathrm{mg} / \mathrm{L}$ 67. 63 wurde durch zusätzliche Trennung an Kieselgel (Cyclohexan/Essigester $/ \mathrm{MeOH}$ 5:10:2) in einer Ausbeute von $0.2 \mathrm{mg} / \mathrm{L}$ erhalten.

\section{Virginiamycin $\mathrm{M}_{1}(62)$}

$\mathrm{C}_{28} \mathrm{H}_{35} \mathbf{N}_{3} \mathbf{O}_{7}(525.61)$

farbloser Feststoff

UV-löschend (254 nm)

Smp.: $81^{\circ} \mathrm{C}$

$\mathbf{R}_{\mathbf{f}}=0.26\left(\mathrm{KG}, \mathrm{CHCl}_{3} / \mathrm{MeOH} 9: 1\right)$,

$0.70\left(\mathrm{RP}-18, \mathrm{MeOH} / \mathrm{H}_{2} \mathrm{O}\right.$ 7:3).

Anfärbeverhalten: rosa (Anis),<smiles>C/C=C(C)/C=C/CNC(=O)/C=C/[C@@H](C)[C@H](OC(=O)C1=CCCN1C(=O)c1coc(CC(=O)C[C@@H](O)C=C(C)C)n1)C(C)C</smiles>

$\operatorname{rot}($ Ehrlich).

ESI-MS: $\mathrm{m} / \mathrm{z}=548[\mathrm{M}+\mathrm{Na}]^{+}, 1073[2 \mathrm{M}+\mathrm{Na}]^{+}, 524[\mathrm{M}-\mathrm{H}]^{+}, 1071[2 \mathrm{M}+\mathrm{Na}-2 \mathrm{H}]^{-}$.

$[\boldsymbol{\alpha}]_{\mathbf{D}}^{\mathbf{2 0}}=-10^{\circ}(\mathrm{c}=0.04, \mathrm{MeOH})$.

UV (MeOH): $\lambda_{\max }(\lg \varepsilon)=204$ (5.38), $214(5.36), 261(4.87) \mathrm{nm}$,

(MeOH, $\mathrm{HCl}): \lambda_{\max }(\lg \varepsilon)=203$ (5.35), 216 (5.32), $262(4.81) \mathrm{nm}$,

$(\mathrm{MeOH}, \mathrm{NaOH}): \lambda_{\max }(\lg \varepsilon)=202$ (5.05), 207 (5.35), 280 (4.85), 289 (4.84) nm.

IR (KBr): $\widetilde{v}=3346,2929(\mathrm{sh}), 1655,1604,1513,1436,1384,1269,1160,1117,1030$, $747 \mathrm{~cm}^{-1}$. 
${ }^{1}$ H-NMR $\left(600 \mathrm{MHz}, \mathrm{CD}_{2} \mathrm{Cl}_{2}\right): \delta=0.94\left(\mathrm{~d}, J=6.5 \mathrm{~Hz}, 3 \mathrm{H}, 31-\mathrm{H}_{3}\right), 0.97(\mathrm{~d}, J=6.9 \mathrm{~Hz}, 3 \mathrm{H}$, 30- $\left.\mathrm{H}_{3}\right), 1.09$ (d, J=7.0 Hz, 3H, 32- $\left.\mathrm{H}_{3}\right), 1.55$ (s, 3H, 33- $\left.\mathrm{H}_{3}\right), 2.01$ (m, 1H, 29-H), 2.69 (m, 3H, $\left.4-\mathrm{H}, 15-\mathrm{H}_{\mathrm{a}}, 25-\mathrm{H}_{\mathrm{a}}\right), 2.89$ (dtd, $\left.J=16.8,9.8,2.5 \mathrm{~Hz}, 1 \mathrm{H}, 25-\mathrm{H}_{\mathrm{b}}\right), 3.13\left(\mathrm{~m}, 1 \mathrm{H}, 15-\mathrm{H}_{\mathrm{b}}\right), 3.68$ (dt, $\left.J=13.4,3.5 \mathrm{~Hz}, 1 \mathrm{H}, 17-\mathrm{H}_{\mathrm{a}}\right), 3.85\left(\mathrm{~m}, 1 \mathrm{H}, 9-\mathrm{H}_{\mathrm{a}}\right), 3.94$ (d, $\left.J=13.5 \mathrm{~Hz}, 1 \mathrm{H}, \mathrm{H}-17_{\mathrm{b}}\right), 4.17$ (m, $\left.1 \mathrm{H}, 9-\mathrm{H}_{\mathrm{b}}\right), 4.31\left(\mathrm{~m}, 2 \mathrm{H}, 24-\mathrm{H}_{\mathrm{a}}, 24-\mathrm{H}_{\mathrm{b}}\right), 4.78(\mathrm{~m}, 1 \mathrm{H}, 14-\mathrm{H}), 4.87(\mathrm{~d}, J=9.0 \mathrm{~Hz}, 1 \mathrm{H}, 13-\mathrm{H})$, $4.90(\mathrm{dd}, J=11.2,1.9 \mathrm{~Hz}, 1 \mathrm{H}, 3-\mathrm{H}), 5.57$ (ddd, $J=16.0,6.0,3.5 \mathrm{~Hz}, 1 \mathrm{H}, 10-\mathrm{H}), 5.80$ (d, $J=16.0 \mathrm{~Hz}, 1 \mathrm{H}, 11-\mathrm{H}), 5.94$ (d, $J=16.5 \mathrm{~Hz}, 1 \mathrm{H}, 6-\mathrm{H}), 6.15$ (t, $J=2.5 \mathrm{~Hz}, 1 \mathrm{H}, 26-\mathrm{H}), 6.57$ (dd, $J=16.5,7.5 \mathrm{~Hz}, 1 \mathrm{H}, 5-\mathrm{H}), 7.51$ (bs, 1H, 8-H), 7.78 (s, 1H, 20-H) ppm.

${ }^{13}$ C-NMR (150.8 MHz, $\mathrm{CD}_{2} \mathrm{Cl}_{2}$ ): $\delta=12.1$ (q, C-32), 12.5 (q, C-33), 18.6 (q, C-30), 19.3 (q, C-31), 29.9 (d, C-29), 30.2 (t, C-25), 37.6 (d, C-4), 40.2 (t, C-9), 45.6 (t, C-17), 47.6 (t, C-15), 50.6 (t, C-24), 65.8 (d, C-14), 81.2 (d, C-3), 123.2 (d, C-26), 125.1 (d, C-6), 126.3 (d, C-10), 131.1 (d, C-13), 133.5 (d, C-11), 134.4 (s, C-12), 135.9 (s, C-21), 136.9 (s, C-27), 143.2 (d, C-5), 145.3 (d, C-20), 156.2 (s, C-18), 160.2 (s, C-22), 160.8 (s, C-1), 167.0 (s, C-7), 200.9 (s, C-16) ppm.

\section{6-Dihydro-Virginiamycin $M_{1}(63)$}

$\mathrm{C}_{28} \mathrm{H}_{37} \mathrm{~N}_{3} \mathrm{O}_{7}$ (527.62)

farbloser Feststoff

UV-löschend (254 nm)

Smp.: $>200^{\circ} \mathrm{C}$

$\mathbf{R}_{\mathbf{f}}=0.15\left(\mathrm{KG}, \mathrm{CHCl}_{3} / \mathrm{MeOH} 9: 1\right)$, 0.40 (RP-18, $\mathrm{MeOH} / \mathrm{H}_{2} \mathrm{O}$ 7:3).

Anfärbeverhalten: blau (Anis),

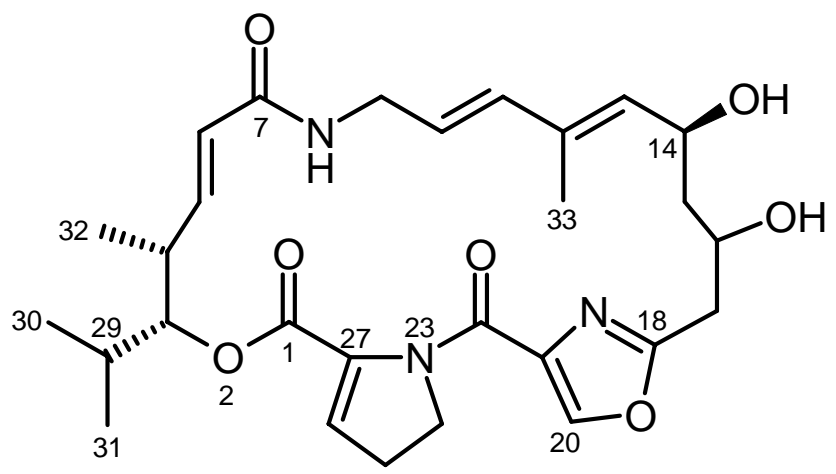
$\operatorname{rot}($ Ehrlich).

ESI-MS: $\mathrm{m} / \mathrm{z}=550[\mathrm{M}+\mathrm{Na}]^{+}, 1077[2 \mathrm{M}+\mathrm{Na}]^{+}$.

UV $(\mathrm{MeOH}): \lambda_{\max }(\lg \varepsilon)=212(5.02) \mathrm{nm}$.

IR (KBr): $\widetilde{v}=3420,2967,2929,1734,1653$ (sh), 1623, 1559 (sh), 1541, 1420, 1384, $1317,1225,1180,1112,988 \mathrm{~cm}^{-1}$. 
${ }^{1}$ H-NMR $\left(600 \mathrm{MHz}, \mathrm{CD}_{2} \mathrm{Cl}_{2}\right): \delta=0.93\left(\mathrm{~d}, J=6.5 \mathrm{~Hz}, 3 \mathrm{H}, 31-\mathrm{H}_{3}\right), 0.96(\mathrm{~d}, J=7.0 \mathrm{~Hz}, 3 \mathrm{H}$, $\left.30-\mathrm{H}_{3}\right), 1.10\left(\mathrm{~d}, J=7.0 \mathrm{~Hz}, 3 \mathrm{H}, 32-\mathrm{H}_{3}\right), 1.74$ (d, $\left.J=1 \mathrm{~Hz}, 3 \mathrm{H}, 33-\mathrm{H}_{3}\right), 1.89$ (m, 2H, 15- $\mathrm{H}_{\mathrm{a}}$, $\left.15-\mathrm{H}_{\mathrm{b}}\right), 2.00(\mathrm{~m}, 1 \mathrm{H}, 29-\mathrm{H}), 2.74\left(\mathrm{~m}, 3 \mathrm{H}, 4-\mathrm{H}, 25-\mathrm{H}_{\mathrm{a}}, 25-\mathrm{H}_{\mathrm{b}}\right), 2.88(\mathrm{dd}, J=15.0,4.5 \mathrm{~Hz}, 1 \mathrm{H}$, $\left.17-\mathrm{H}_{\mathrm{a}}\right), 2.98\left(\mathrm{dd}, J=15.0,8.5 \mathrm{~Hz}, 1 \mathrm{H}, 17-\mathrm{H}_{\mathrm{b}}\right), 3.92\left(\mathrm{~m}, 2 \mathrm{H}, 9-\mathrm{H}_{\mathrm{a}}, 16-\mathrm{H}\right), 4.03(\mathrm{dtd}, J=17.0$, $6.5,<1 \mathrm{~Hz}, 1 \mathrm{H}, \mathrm{H}-9 \mathrm{~b}), 4.15$ (ddd, $\left.J=11.5,10.0,5.8 \mathrm{~Hz}, 1 \mathrm{H}, 24-\mathrm{H}_{\mathrm{a}}\right), 4.25$ (ddd, $J=11.5$, 10.0, 8.0 Hz, 1H, 24-H $), 4.63$ (td, $J=9.0,5.5 \mathrm{~Hz}, 1 \mathrm{H}, 14-\mathrm{H}), 4.88$ (dd, $J=10.0,2.0 \mathrm{~Hz}, 1 \mathrm{H}$, 3-H), $5.04(\mathrm{~d}, J=9.0 \mathrm{~Hz}, 1 \mathrm{H}, 13-\mathrm{H}), 5.62(\mathrm{ddd}, J=16.0,7.0,4.0 \mathrm{~Hz}, 1 \mathrm{H}, 10-\mathrm{H}), 5.89$ (dd, $J=16.5,1.5 \mathrm{~Hz}, 1 \mathrm{H}, 6-\mathrm{H}), 5.98(\mathrm{~d}, J=16.0 \mathrm{~Hz}, 1 \mathrm{H}, 11-\mathrm{H}), 6.16$ (t, $J=6.0 \mathrm{~Hz}, 1 \mathrm{H}, 26-\mathrm{H})$, 6.59 (dd, $J=16.5,7.0 \mathrm{~Hz}, 1 \mathrm{H}, 5-\mathrm{H}), 6.88$ (bs, 1H, 8-H), 7.94 (s, 1H, 20-H) ppm.

${ }^{13}$ C-NMR (150.8 MHz, $\mathrm{CD}_{2} \mathrm{Cl}_{2}$ ): $\delta=12.2$ (q, C-32), 13.5 (q, C-33), 19.0 (q, C-30), 19.6 (q, C-31), 30.2 (d, C-29), 30.5 (t, C-25), 37.0 (t, C-17), 37.9 (d, C-4), 40.9 (t, C-9), , 44.5 (t, C-15), 51.4 (t, C-24), 67.3 (d, C-14), 67.9 (d, C-16), 81.3 (d, C-3), 124.4 (d, C-26), 125.0 (d, C-6), 125.8 (d, C-10), 133.4 (d, C-13), 134.8 (d, C-11), 134.8 (s, C-12), 135.8 (s, C-21), 137.4 (s, C-27), 144.0 (d, C-20), 144.2 (d, C-5), 161.0 (s, C-22), 161.1 (s, C-1), 162.0 (s, C-18), 167.0 (s, C-7) ppm.

\section{3-(4'-Dimethylaminophenyl)-2-hydroxypropionsäureamid (64)}

$\mathrm{C}_{11} \mathrm{H}_{16} \mathbf{N}_{2} \mathbf{O}_{2}$ (208.26)

farbloser Feststoff

UV-löschend (254 nm)

Smp.: $75^{\circ} \mathrm{C}$

$\mathbf{R}_{\mathbf{f}}=0.30\left(\mathrm{KG}, \mathrm{CHCl}_{3} / \mathrm{MeOH} 9: 1\right)$,

0.56 (RP-18, $\mathrm{MeOH} / \mathrm{H}_{2} \mathrm{O} 7: 3$ ).

Anfärbeverhalten: schwach rosa (Anis), schwach gelb (Ehrlich).

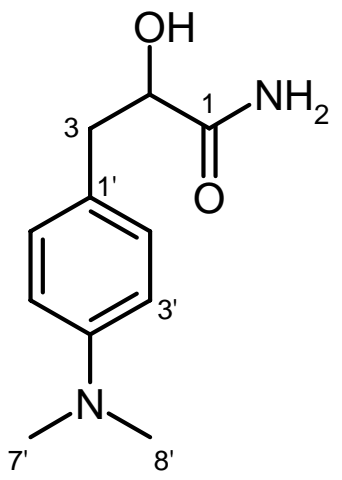

ESI-MS: $\mathrm{m} / \mathrm{z}=209[\mathrm{M}+\mathrm{H}]^{+}, 231[\mathrm{M}+\mathrm{Na}]^{+}, 439[2 \mathrm{M}+\mathrm{Na}]^{+}$.

EI-MS: $\mathrm{m} / \mathrm{z}(\%)=208(16)[\mathrm{M}]^{+}, 134(100)\left[\mathrm{M}-\mathrm{C}_{2} \mathrm{H}_{4} \mathrm{NO}_{2}\right]^{+}$.

HREI-MS: 208.1218 gefunden wie berechnet für $\mathrm{C}_{11} \mathrm{H}_{16} \mathrm{~N}_{2} \mathrm{O}_{2}$.

$[\boldsymbol{\alpha}]_{\mathbf{D}}^{\mathbf{2 0}}=+12^{\circ}(\mathrm{c}=0.05, \mathrm{MeOH})$.

UV $(\mathrm{MeOH}): \lambda_{\max }(\lg \varepsilon)=205$ (4.89), $257(4.65) \mathrm{nm}$,

$(\mathrm{MeOH}, \mathrm{HCl}): \lambda_{\max }(\lg \varepsilon)=202$ (4.74), $280(4.11) \mathrm{nm}$,

$(\mathrm{MeOH}, \mathrm{NaOH}): \lambda_{\max }(\lg \varepsilon)=208(4.81), 256(4.66) \mathrm{nm}$.

IR (KBr): $\widetilde{v}=3308,3170,2944(\mathrm{sh}), 2915,2808,1879,1669,1616,1525,1449,1359$, $1235,1047,820,806 \mathrm{~cm}^{-1}$. 
${ }^{1}$ H-NMR $\left(300 \mathrm{MHz}, \mathrm{CD}_{3} \mathrm{OD}\right): \delta=2.72\left(\mathrm{dd}, J=14.0,8.0 \mathrm{~Hz}, 1 \mathrm{H}, 3-\mathrm{H}_{\mathrm{a}}\right), 2.85\left(\mathrm{~s}, 6 \mathrm{H}, 7{ }^{\prime}-\mathrm{H}_{3}\right.$, 8'- $\left.-\mathrm{H}_{3}\right), 2.99$ (dd, $\left.J=14.0,4.0 \mathrm{~Hz}, 1 \mathrm{H}, 3-\mathrm{H}_{\mathrm{b}}\right), 4.14$ (dd, $J=8.0,2.0 \mathrm{~Hz}, 1 \mathrm{H}, 2$ '-H), 6.72 (d, $\left.J=8.5 \mathrm{~Hz}, 2 \mathrm{H}, 3^{\prime}-\mathrm{H}, 5^{\prime}-\mathrm{H}\right), 7.11$ (d, $\left.J=8.5 \mathrm{~Hz}, 2 \mathrm{H}, 2^{\prime}-\mathrm{H}, 6^{\prime}-\mathrm{H}\right) \mathrm{ppm}$.

${ }^{13}$ C-NMR (75.5 MHz, CD 3 OD): $\delta=40.9$ (t, C-3), 41.4 (q, C-7', C-8'), 74.2 (d, C-2), 114.5 (d, C-3', C-5'), 127.8 (s, C-1'), 131.2 (d, C-2', C-6'), 151.1 (s, C-4'), 179.9 (s, C-1) ppm.

\section{Phenylacetamid (65)}

$\mathrm{C}_{8} \mathrm{H}_{9} \mathrm{NO}(135.17)$

farbloser Feststoff

UV-löschend (254 nm)

Smp.: $140{ }^{\circ} \mathrm{C}$

$\mathbf{R}_{\mathbf{f}}=0.36\left(\mathrm{KG}, \mathrm{CHCl}_{3} / \mathrm{MeOH} 9: 1\right)$, 0.67 (RP-18, $\mathrm{MeOH} / \mathrm{H}_{2} \mathrm{O}$ 7:3).

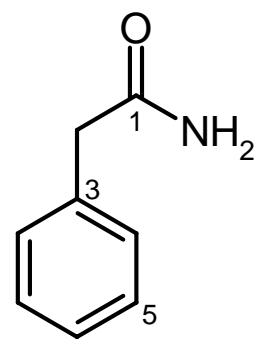

Anfärbeverhalten: hellbraun (Anis).

ESI-MS: $\mathrm{m} / \mathrm{z}=158[\mathrm{M}+\mathrm{Na}]^{+}, 293[2 \mathrm{M}+\mathrm{Na}]^{+}$.

EI-MS: $\mathrm{m} / \mathrm{z}(\%)=135(32)[\mathrm{M}]^{+}, 92(100)[\mathrm{M}-\mathrm{CHNO}]^{+}, 91(99)\left[\mathrm{M}-\mathrm{CH}_{2} \mathrm{NO}\right]^{+}$.

UV $(\mathrm{MeOH}): \lambda_{\max }(\lg \varepsilon)=202(4.65), 265(3.68) \mathrm{nm}$.

IR $(\mathrm{KBr}): \widetilde{v}=3359,3176,2802,1638,1578(\mathrm{sh}), 1497,1454,1418,1290,747,700$, $582 \mathrm{~cm}^{-1}$.

${ }^{1}$ H-NMR $\left(600 \mathrm{MHz}, \mathrm{CD}_{3} \mathrm{OD}\right): \delta=3.49$ (s, 2H, 2H, 2-H $)$, 7.29-7.88 (m, 5H, H-4, H-5, H-6, H-7, H-8) ppm.

${ }^{13}$ C-NMR (75.5 MHz, CD 3 OD): $\delta=43.4$ (t, C-2), 127.8 (d, C-6), 129.5 (d, C-5, C-7), 130.1 (d, C-4, C-8), 136.9 (s, C-3) 177.0 (s, C-1) ppm.

\section{2'-O-Methyluridin (66)}

$\mathrm{C}_{10} \mathrm{H}_{14} \mathbf{N}_{2} \mathbf{O}_{6}(258.23)$

gelbes Ö1

UV-löschend (254 nm)

Smp.: $76^{\circ} \mathrm{C}$

$\mathbf{R}_{\mathbf{f}}=0.12\left(\mathrm{KG}, \mathrm{CHCl}_{3} / \mathrm{MeOH} 9: 1\right)$, 0.84 (RP-18, $\mathrm{MeOH} / \mathrm{H}_{2} \mathrm{O}$ 7:3).

Anfärbeverhalten: hellbraun (Anis), grün (Orcin).<smiles>COC1C(O)[C@@H]2O[C@H]1C2n1ccc(=O)[nH]c1=O</smiles> 
ESI-MS: $\mathrm{m} / \mathrm{z}=259[\mathrm{M}+\mathrm{H}]^{+}, 281[\mathrm{M}+\mathrm{Na}]^{+}, 539[2 \mathrm{M}+\mathrm{Na}]^{+}$.

$[\boldsymbol{\alpha}]_{\mathbf{D}}^{\mathbf{2 0}}=+6^{\circ}(\mathrm{c}=0.05, \mathrm{MeOH})$.

UV $(\mathrm{MeOH}): \lambda_{\max }(\lg \varepsilon)=201(4.80), 262(4.50) \mathrm{nm}$,

$(\mathrm{MeOH}, \mathrm{HCl}): \lambda_{\max }(\lg \varepsilon)=201$ (4.78), $263(4.46) \mathrm{nm}$,

$(\mathrm{MeOH}, \mathrm{NaOH}): \lambda_{\max }(\lg \varepsilon)=207(4.75), 253(4.43) \mathrm{nm}$.

IR $(\mathrm{KBr}): \widetilde{v}=3397,2935,1676,1464,1385,1269,1112,1086,1060,818,766$, $706 \mathrm{~cm}^{-1}$.

${ }^{1}$ H-NMR (300 MHz, CD $\left.{ }_{3} \mathrm{OD}\right): \delta=3.51\left(\mathrm{~s}, 3 \mathrm{H}, 6^{\prime}-\mathrm{H}_{3}\right), 3.74\left(\mathrm{dd}, J=12.3,3.0 \mathrm{~Hz}, 1 \mathrm{H}, 5^{\prime}-\mathrm{H}_{\mathrm{a}}\right)$, $3.84\left(\mathrm{dd}, J=6.0,3.5 \mathrm{~Hz}, 1 \mathrm{H}, 2^{\prime}-\mathrm{H}\right), 3.87\left(\mathrm{dd}, J=12.3,3.0 \mathrm{~Hz}, 5^{\prime}-\mathrm{H}_{\mathrm{b}}\right), 3.97(\mathrm{dt}, J=6.0,3.0$ $\left.\mathrm{Hz}, 1 \mathrm{H}, 4^{\prime}-\mathrm{H}\right), 4.24\left(\mathrm{t}, J=6.0 \mathrm{~Hz}, 1 \mathrm{H}, 3^{\prime}-\mathrm{H}\right), 5.68$ (d, $\left.J=8.1 \mathrm{~Hz}, 1 \mathrm{H}, 5-\mathrm{H}\right), 5.93$ (d, $\left.J=3.5 \mathrm{~Hz}, 1 \mathrm{H}, 1^{\prime}-\mathrm{H}\right), 8.08$ (d, $\left.J=8.1 \mathrm{~Hz}, 1 \mathrm{H}, 6-\mathrm{H}\right) \mathrm{ppm}$.

${ }^{13}$ C-NMR (75.5 MHz, CD 3 OD): $\delta=58.8$ (q, C-6'), 61.6 (t, C-5'), 69.7 (d, C-3'), 85.0 (d, C-2'), 86.0 (d, C-4'), 88.8 (d, C-1'), 102.5 (d, C-5), 142.4 (d, C-6), 155.1 (s, C-2), 166.2 (s, C-4) ppm.

\section{4-Aminobenzoesäureamid (67)}

$\mathbf{C}_{7} \mathbf{H}_{8} \mathbf{N}_{2} \mathbf{O}(136.15)$

farbloser Feststoff

UV-löschend (254 nm)

Smp.: $151^{\circ} \mathrm{C}$

$\mathbf{R}_{\mathbf{f}}=0.12\left(\mathrm{KG}, \mathrm{CHCl}_{3} / \mathrm{MeOH} 9: 1\right)$, 0.83 (RP-18, $\mathrm{MeOH} / \mathrm{H}_{2} \mathrm{O}$ 7:3).

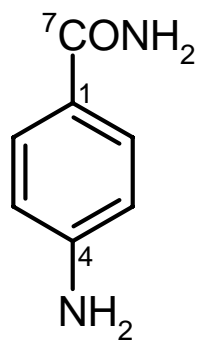

Anfärbeverhalten: gelb (Anis), gelb (Ehrlich).

ESI-MS: $\mathrm{m} / \mathrm{z}=159[\mathrm{M}+\mathrm{Na}]^{+}, 295[2 \mathrm{M}+\mathrm{Na}]^{+}$.

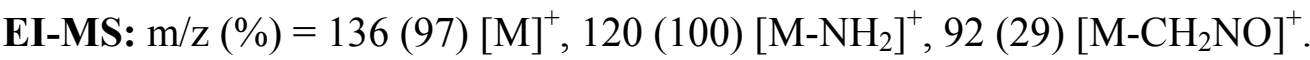

UV $(\mathrm{MeOH}): \lambda_{\max }(\lg \varepsilon)=203(4.87), 282(4.77) \mathrm{nm}$,

(MeOH, HCl): $\lambda_{\max }(\lg \varepsilon)=202$ (4.85), 220 (4.68), $277(4.08) \mathrm{nm}$,

$(\mathrm{MeOH}, \mathrm{NaOH}): \lambda_{\max }(\lg \varepsilon)=207$ (4.84), $283(4.76) \mathrm{nm}$.

IR $(\mathrm{KBr}): \widetilde{v}=3466,3331,3223,1652(\mathrm{sh}), 1614,1565,1519,1435,1395,1292,851$, $779,584,531 \mathrm{~cm}^{-1}$.

${ }^{1}$ H-NMR (300 MHz, CD 3 OD): $\delta=6.65$ (m, 2H, 3-H, 5-H), 7.63 (m, 2H, 2-H, 6-H) ppm.

${ }^{13}$ C-NMR (75.5 MHz, CD $\left.{ }_{3} \mathrm{OD}\right): \delta=114.6(\mathrm{~d}, \mathrm{C}-3, \mathrm{C}-5), 122.2(\mathrm{~s}, \mathrm{C}-1), 130.5$ (d, C-2, C-6), 153.5 (s, C-4), 172.8 (s, C-7) ppm. 


\section{Actinomyces sp. Stamm Gö TS19}

\subsection{Kultivierung und Aufarbeitung}

Stamm Gö TS19 wurde wie unter B.V.5.1. beschrieben in Schüttelkolben $(250 \mathrm{~mL}$, $40 \times 100 \mathrm{~mL}$, Medium M2) kultiviert und aufgearbeitet. Zusätzlich wurde eine Kultivierung im 50 L-Fermenter im selben Medium bei $250 \mathrm{rpm}$ und einer Belüftung von $1.8 \mathrm{vvm}$ durchgeführt. Hier kam es zu einem Ausfall der Temperaturkontrolle, was zu einem kontinuierlichen Abfall von anfänglich $28{ }^{\circ} \mathrm{C}$ auf Raumtemperatur führte. Die Aufarbeitung erfolgte analog B.V.5.1., wobei das Kulturfiltrat in zwei Portionen an XAD-2 adsorbiert wurde.

\subsection{Isolierung und Charakterisierung der Metaboliten}

Der Kulturfiltratextrakt der 4 L-Fermentation wurde durch Säulenchromatographie an Sephadex ${ }^{\circledR}$ LH-20 (MeOH) und Flashchromatographie an Kieselgel $\left(\mathrm{CH}_{2} \mathrm{Cl}_{2} / \mathrm{MeOH}\right.$ 6:1 bzw. $\mathrm{CH}_{2} \mathrm{Cl}_{2} / \mathrm{MeOH}$ 9:1) getrennt. Durch nachfolgende Chromatographie an Sephadex ${ }^{\circledR}$ LH20 (Aceton bzw. $\mathrm{MeOH}$ ) wurden $61 \mathrm{mg} / \mathrm{L} 68$ bzw. $0.4 \mathrm{mg} / \mathrm{L} 77$ erhalten. Der Extrakt des Kulturfiltrats der 50 L-Fermentation wurde säulenchromatographisch an Sephadex ${ }^{\circledR}$ LH-20 $(\mathrm{MeOH})$ getrennt. Anschließende Flashchromatographie an Kieselgel $\left(\mathrm{CH}_{2} \mathrm{Cl}_{2} / \mathrm{MeOH}\right.$ $9: 1 \rightarrow 1: 1)$ lieferte $0.1 \mathrm{mg} / \mathrm{L}$ 69. Verbindung 70 wurde durch Mitteldruckchromatographie einer weiteren Fraktion an RP-18 $\left(\mathrm{MeOH} / \mathrm{H}_{2} \mathrm{O}\right.$ 7:3) in einer Ausbeute von $0.1 \mathrm{mg} / \mathrm{L}$ erhalten.

\section{Okaspirodiol (68)}

(3-(S)-Hydroxymethyl-4-(S)-hydroxy-7-(S)-methyl-1,6-(S)-dioxaspiro[4.5]decan)

$\mathbf{C}_{10} \mathrm{H}_{18} \mathbf{O}_{4}(202.25)$

farbloser Feststoff

Smp.: $86^{\circ} \mathrm{C}$

$\mathbf{R}_{\mathbf{f}}=0.52\left(\mathrm{KG}, \mathrm{CHCl}_{3} / \mathrm{MeOH} 9: 1\right)$,

$0.55\left(\mathrm{RP}-18, \mathrm{MeOH} / \mathrm{H}_{2} \mathrm{O} 7: 3\right)$.

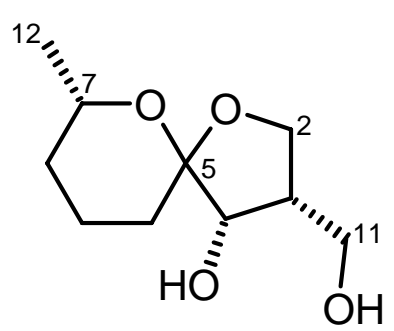

Anfärbeverhalten: grün-braun (Anis), grün-gelb (Orcin).

ESI-MS: $\mathrm{m} / \mathrm{z}=225[\mathrm{M}+\mathrm{Na}]^{+}$. 
DCI-MS: $\mathrm{m} / \mathrm{z}(\%)=203[\mathrm{M}+\mathrm{H}]^{+}, 220\left[\mathrm{M}+\mathrm{NH}_{4}\right]^{+}, 405[2 \mathrm{M}+\mathrm{H}]^{+}, 422\left[2 \mathrm{M}+\mathrm{NH}_{4}\right]^{+}$.

HRESI-MS: 225.1097460 gefunden wie berechnet für $\mathrm{C}_{10} \mathrm{H}_{18} \mathrm{O}_{4} \mathrm{Na}$.

$[\boldsymbol{\alpha}]_{\mathbf{D}}^{\mathbf{2 0}}=-29^{\circ}(\mathrm{c}=0.10, \mathrm{MeOH})$.

UV $(\mathrm{MeOH}): \lambda_{\max }(\lg \varepsilon)=254(2.70), 202(3.24) \mathrm{nm}$.

IR (KBr): $\widetilde{v}=3446,3391(\mathrm{sh}), 2968$ (sh), 2934, 2741, 1634, 1441, 1386, 1243, 1224, $1128,1078,1020$ (sh), 997, 954, 847, 729, $536 \mathrm{~cm}^{-1}$.

${ }^{1}$ H-NMR (500 MHz, CD $\left.3 \mathrm{OD}\right): \delta=1.14\left(\mathrm{~d}, J=6.5 \mathrm{~Hz}, 3 \mathrm{H}, 12-\mathrm{H}_{3}\right), 1.21(\mathrm{qd}, J=12.0,3.8 \mathrm{~Hz}$, $\left.1 \mathrm{H}, 8-\mathrm{H}_{\mathrm{a}}\right), 1.48\left(\mathrm{~m}, 1 \mathrm{H}, 10-\mathrm{H}_{\mathrm{a}}\right), 1.58\left(\mathrm{~m}, 1 \mathrm{H}, 8-\mathrm{H}_{\mathrm{b}}\right), 1.67\left(\mathrm{~m}, 1 \mathrm{H}, 9-\mathrm{H}_{\mathrm{a}}\right), 1.73\left(\mathrm{~m}, 1 \mathrm{H}, 10-\mathrm{H}_{\mathrm{b}}\right)$, $1.80\left(\mathrm{~m}, 1 \mathrm{H}, 9-\mathrm{H}_{\mathrm{b}}\right), 2.49(\mathrm{~m}, 1 \mathrm{H}, 3-\mathrm{H}), 3.69\left(\mathrm{~m}, 1 \mathrm{H}, 11-\mathrm{H}_{\mathrm{a}}\right), 3.74\left(\mathrm{~m}, 1 \mathrm{H}, 11-\mathrm{H}_{\mathrm{b}}\right), 3.76(\mathrm{~m}$, $1 \mathrm{H}, 2-\mathrm{H}_{\mathrm{a}}$ ), 3.84 (d, $\left.J=9.0 \mathrm{~Hz}, 1 \mathrm{H}, 4-\mathrm{H}\right), 3.93$ (quintd, $\left.J=6.5,2.1 \mathrm{~Hz}, 1 \mathrm{H}, 7-\mathrm{H}\right), 3.98$ (t, $\left.J=8.5 \mathrm{~Hz}, 1 \mathrm{H}, 2-\mathrm{H}_{\mathrm{b}}\right) \mathrm{ppm}$.

${ }^{13}$ C-NMR (125.7 MHz, CD 3 OD): $\delta=21.0$ (t, C-9), 22.0 (q, C-12), 31.4 (t, C-10), 33.4 (t, C-8), 43.2 (d, C-3), 62.1 (t, C-11), 68.0 (d, C-7), 68.9 (t, C-2), 77.8 (d, C-4), 103.9 (s, C-5) ppm.

\section{Adenosin (77)}

$\mathrm{C}_{10} \mathrm{H}_{13} \mathbf{N}_{5} \mathbf{O}_{4}(267.25)$

farbloser Feststoff

UV-löschend (254 nm)

Smp.: $188^{\circ} \mathrm{C}$

$\mathbf{R}_{\mathbf{f}}=0.14\left(\mathrm{KG}, \mathrm{CH}_{2} \mathrm{Cl}_{2} / \mathrm{MeOH} 6: 1\right)$,

0.78 (RP-18, $\left.\mathrm{MeOH} / \mathrm{H}_{2} \mathrm{O} 7: 3\right)$.

Anfärbeverhalten: hellbraun (Anis), blau (Orcin).

ESI-MS: $\mathrm{m} / \mathrm{z}=268[\mathrm{M}+\mathrm{H}]^{+}, 290[\mathrm{M}+\mathrm{Na}]^{+}, 557[2 \mathrm{M}+\mathrm{Na}]^{+}$.

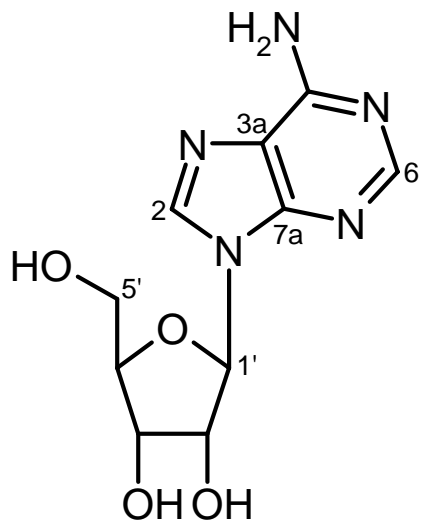

$[\boldsymbol{\alpha}]_{\mathbf{D}}^{20}=-48^{\circ}(\mathrm{c}=0.05, \mathrm{MeOH})$.

UV $(\mathrm{MeOH}): \lambda_{\max }(\lg \varepsilon)=207(4.88), 259(4.70) \mathrm{nm}$.

IR (KBr): $\widetilde{v}=3431,2925,1637,1384,1086 \mathrm{~cm}^{-1}$.

${ }^{1}$ H-NMR $\left(500 \mathrm{MHz}, \mathrm{CD}_{3} \mathrm{OD}\right): \delta=3.74\left(\mathrm{dd}, J=12.5,2.5 \mathrm{~Hz}, 1 \mathrm{H}, 5\right.$ '- $\left.\mathrm{H}_{\mathrm{a}}\right), 3.88(\mathrm{dd}$, $\left.J=12.5,2.5 \mathrm{~Hz}, 1 \mathrm{H}, 5-\mathrm{H}_{\mathrm{b}}\right), 4.16$ (q, $\left.J=2.5 \mathrm{~Hz}, 1 \mathrm{H}, 4^{\prime}-\mathrm{H}\right), 4.32$ (dd, $J=5.0,2.8 \mathrm{~Hz}, 1 \mathrm{H}, 3$ 'H), 4.73 (dd, $\left.J=6.5,5.0 \mathrm{~Hz}, 1 \mathrm{H}, 2^{\prime}-\mathrm{H}\right), 5.96$ (d, $\left.J=6.5 \mathrm{~Hz}, 1 \mathrm{H}, \mathrm{H}-1^{\prime}\right), 8.17$ (s, 1H, 2-H), 8.30 (s, 1H, 6-H) ppm. 


\section{3-Amino-4-chlorbenzoesäureamid (78)}

$\mathbf{C}_{7} \mathbf{H}_{7} \mathbf{N}_{2} \mathbf{O C l}(170.60)$

farbloser Feststoff

UV-löschend (254 nm)

hellblau fluoreszierend (366 nm)

Smp.: $71^{\circ} \mathrm{C}$

$\mathbf{R}_{\mathbf{f}}=0.18\left(\mathrm{KG}, \mathrm{CHCl}_{3} / \mathrm{MeOH} 9: 1\right)$,

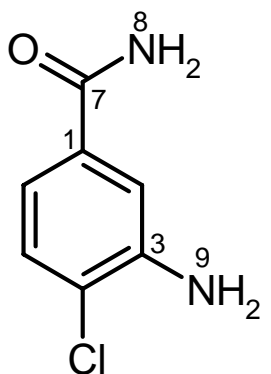

0.64 (RP-18, $\mathrm{MeOH} / \mathrm{H}_{2} \mathrm{O}$ 7:3).

Anfärbeverhalten: hellbraun (Anis), gelb (Ehrlich).

EI-MS: $\mathrm{m} / \mathrm{z}(\%)=170(100)[\mathrm{M}]^{+}, 154(100)\left[\mathrm{M}-\mathrm{NH}_{2}\right]^{+}, 126(45)\left[\mathrm{M}-\mathrm{CH}_{2} \mathrm{NO}\right]^{+}, 90(50)$ $\left[\mathrm{M}-\mathrm{CH}_{3} \mathrm{NOCl}\right]^{+}$.

HREI-MS: 170.0247 gefunden wie berechnet für $\mathrm{C}_{7} \mathrm{H}_{7} \mathrm{~N}_{2} \mathrm{OCl}$.

UV $(\mathrm{MeOH}): \lambda_{\max }(\lg \varepsilon)=219(4.83), 314(3.95) \mathrm{nm}$,

$(\mathrm{MeOH}, \mathrm{HCl}): \lambda_{\max }(\lg \varepsilon)=202$ (4.72), 224 (4.64), $316(3.65) \mathrm{nm}$,

$(\mathrm{MeOH}, \mathrm{NaOH}): \lambda_{\max }(\lg \varepsilon)=202$ (4.60), $220(4.83), 316(3.94) \mathrm{nm}$.

IR $(\mathrm{KBr}): \widetilde{v}=3428,2926,1654,1616,1570,1438,1384,1091,1035,762 \mathrm{~cm}^{-1}$.

${ }^{1}$ H-NMR (300 MHz, d 6 -Aceton): $\delta=5.09$ (bs, 2H, 9- $\mathrm{H}_{2}$ ), 6.53 (bs, 1H, 8- $\mathrm{H}_{\mathrm{a}}$ ), 7.12 (dd, $J=8.5,2 \mathrm{~Hz}, 1 \mathrm{H}, 6-\mathrm{H}), 7.25$ (d, $J=8.5 \mathrm{~Hz}, 1 \mathrm{H}, \mathrm{H}-5), 7.29$ (bs, 1H, 8- $\left.\mathrm{H}_{\mathrm{b}}\right), 7.41$ (d, $J=2 \mathrm{~Hz}$, 1H, 2-H) ppm.

${ }^{13}$ C-NMR (150.8 MHz, CD $\left.{ }_{3} \mathrm{OD}\right): \delta=115.9(\mathrm{~d}, \mathrm{C}-2), 117.7$ (d, C-6), 123.1 (s, C-4), $130.2(\mathrm{~d}$, C-5), 134.6 (s, C-1), 145.7 (s, C-3), 172.1 (s, C-7) ppm.

\section{$N_{\beta}$-Acetyltryptamin (70)}

$\mathbf{C}_{12} \mathbf{H}_{14} \mathbf{N}_{2} \mathbf{O}(202.26)$

farbloser Feststoff

UV-löschend (254 nm)

hellblau fluoreszierend $(366 \mathrm{~nm})$

Smp.: $187^{\circ} \mathrm{C}$

$\mathbf{R}_{\mathbf{f}}=0.33\left(\mathrm{KG}, \mathrm{CHCl}_{3} / \mathrm{MeOH} 9: 1\right)$,

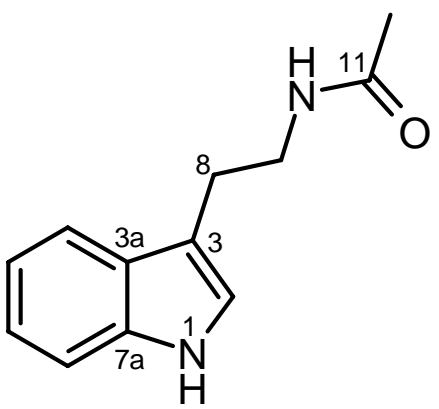

$0.51\left(\mathrm{RP}-18, \mathrm{MeOH} / \mathrm{H}_{2} \mathrm{O}\right.$ 7:3).

Anfärbeverhalten: rot-braun (Anis).

ESI-MS: $\mathrm{m} / \mathrm{z}=203[\mathrm{M}+\mathrm{H}]^{+}, 225[\mathrm{M}+\mathrm{Na}]^{+}, 427[2 \mathrm{M}+\mathrm{Na}]^{+}$. 
UV $(\mathrm{MeOH}): \lambda_{\max }(\lg \varepsilon)=221(5.03), 281(4.34) \mathrm{nm}$.

IR $(\mathrm{KBr}): \widetilde{v}=3404,3290,2927,1653,1541,1457,1536,1365,1340,1292,1098$, $744 \mathrm{~cm}^{-1}$.

${ }^{1}$ H-NMR (300 MHz, CD $\left.{ }_{3} \mathrm{OD}\right): \delta=1.90\left(\mathrm{~s}, 3 \mathrm{H}, 12-\mathrm{H}_{3}\right), 2.92\left(\mathrm{t}, J=7.0 \mathrm{~Hz}, 2 \mathrm{H}, 8-\mathrm{H}_{2}\right), 3.45$ (t, $\left.J=7.0 \mathrm{~Hz}, 2 \mathrm{H}, 9-\mathrm{H}_{2}\right), 7.03(\mathrm{~m}, 3 \mathrm{H}, 2-\mathrm{H}, 5-\mathrm{H}, 6-\mathrm{H}), 7.31$ (td, $\left.J=8.0,1.0 \mathrm{~Hz}, 1 \mathrm{H} ; 4-\mathrm{H}\right), 7.54$ (td, $J=8.0,1.0 \mathrm{~Hz}, 1 \mathrm{H}, 7-\mathrm{H}) \mathrm{ppm}$.

${ }^{13}$ C-NMR (75.5 MHz, CD $\left.{ }_{3} \mathrm{OD}\right): \delta=22.6$ (q, C-12), 26.2 (t, C-8), 41.6 (t, C-9), 112.2 (d, C-4), 113.2 (s, C-3), 119.2 (d, C-7), 119.6 (d, C-6), 122.3 (d, C-2), 123.3 (d, C-5), 128.8 (s, C-7a), 138.2 (s, C-3a), 173.3 (s, C-11) ppm. 


\section{Endosymbionten aus Aplidium lenticulum}

\section{Streptomyces sp. Stamm JP90}

\subsection{Kultivierung und Aufarbeitung}

Der Stamm JP90 wurde wie unter B.V.5.1. beschrieben in Schüttelkolben $(250 \mathrm{~mL}$, $40 \times 100 \mathrm{~mL}$, Medium SGG) kultiviert und aufgearbeitet. Der Kulturfiltratextrakt wurde durch Flashchromatographie an Kieselgel $\left(\mathrm{CHCl}_{3} / \mathrm{MeOH}\right.$ 9:1) getrennt.

\subsection{Isolierung und Charakterisierung der Metaboliten}

\section{Desferrioxamin E (79)}

79 fiel in Form schwerlöslicher Kristalle an, welche durch wiederholtes Auswaschen mit Methanol gereinigt wurden. Es ergaben sich $12 \mathrm{mg} / \mathrm{L} 79$.

$\mathrm{C}_{27} \mathrm{H}_{48} \mathrm{~N}_{6} \mathbf{O}_{9}$ (600.72)

farbloser Feststoff

UV-löschend (254 nm)

Smp.: $173^{\circ} \mathrm{C}$

$\mathbf{R}_{\mathbf{f}}=0.15\left(\mathrm{KG}, \mathrm{CHCl}_{3} / \mathrm{MeOH} 9: 1\right)$,

0.60 (RP-18, $\left.\mathrm{MeOH} / \mathrm{H}_{2} \mathrm{O} 7: 3\right)$.

ESI-MS: $\mathrm{m} / \mathrm{z}=623[\mathrm{M}+\mathrm{Na}]^{+}, 599[\mathrm{M}+\mathrm{H}]^{-}$.

UV $(\mathrm{MeOH}): \lambda_{\max }(\lg \varepsilon)=203(5.04) \mathrm{nm}$,

$(\mathrm{MeOH}, \mathrm{HCl}): \lambda_{\max }(\lg \varepsilon)=203(5.06) \mathrm{nm}$,

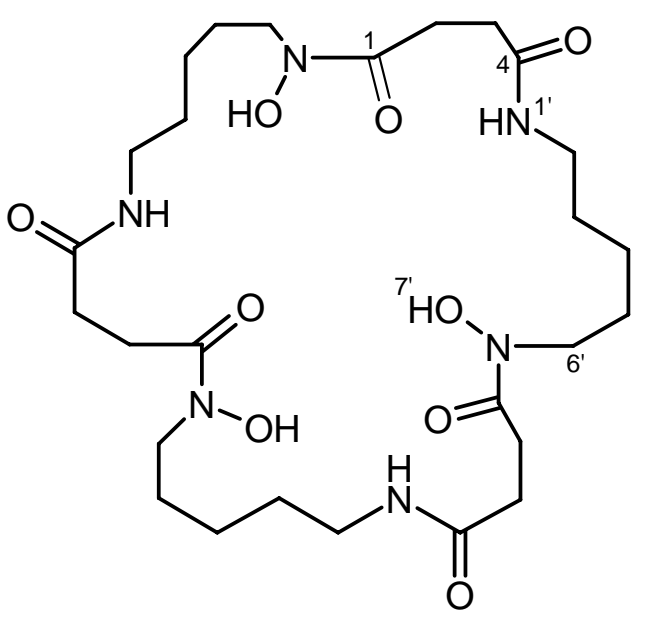

$(\mathrm{MeOH}, \mathrm{NaOH}): \lambda_{\max }(\lg \varepsilon)=201$ (4.60), 206 (4.87), 238 (4.74) nm.

IR $(\mathrm{KBr}): \widetilde{v}=3341,3163,2935,1650,1556,1454,1422,1251,1225,1198,1180,1154$, $1022,960,732(\mathrm{sh}), 701 \mathrm{~cm}^{-1}$.

${ }^{1}$ H-NMR (300 MHz, d 6 -DMSO): $\delta=1.20$ (m, 6H, 4'-H), 1.37 (quint, $J=5.5 \mathrm{~Hz}, 6 \mathrm{H}, 3^{\prime}-\mathrm{H}_{2}$ ), 1.49 (quint, $J=7.0 \mathrm{~Hz}, 6 \mathrm{H}, 5$ '- $\left.\mathrm{H}_{2}\right), 2.28\left(\mathrm{t}, J=6.5 \mathrm{~Hz}, 6 \mathrm{H}, 3-\mathrm{H}_{2}\right), 2.58(\mathrm{t}, J=6.5 \mathrm{~Hz}, 6 \mathrm{H}, 2-$ $\mathrm{H}_{2}$ ), 3.00 (q, $\left.J=5.5 \mathrm{~Hz}, 6 \mathrm{H}, 2^{\prime}-\mathrm{H}_{2}\right), 3.45$ (m, 6H, 6'- $\left.\mathrm{H}_{2}\right), 7.69$ (t, $\left.J=5.5 \mathrm{~Hz}, 3 \mathrm{H}, 1^{\prime}-\mathrm{H}\right), 9.62$ (bs, 3H, 7'-H) ppm.

${ }^{13}$ C-NMR (75.5 MHz, d 6 -DMSO): $\delta=23.2$ (t, C-4'), 25.9 (t, C-5'), 27.6 (t, C-2), 28.6 (t, C-3'), 30.2 (t, C-3), 38.4 (t, C-2'), 47.0 (t, C-6'), $171.7^{\mathrm{a}}$ (s, C-4), 172.2 (s, C-1) ppm.

${ }^{a}$ Signale sind untereinander austauschbar. 
(E)-3-(4-Aminomethoxyphosphoryloxyphenyl)acrylsäuremethylester (80a) bzw.

(E)-3-(4-Hydroxymethoxyphosphoryloxyphenyl)acrylimidsäuremethylester (80b)

80 wurde nach Säulenchromatographie an Sephadex ${ }^{\circledR}$ LH-20 (MeOH) und RP-18 $\left(\mathrm{MeOH} / \mathrm{H}_{2} \mathrm{O} 7: 3\right)$ in einer Ausbeute von $1.2 \mathrm{mg} / \mathrm{L}$ erhalten.

$\mathrm{C}_{11} \mathrm{H}_{14} \mathrm{NO}_{5} \mathrm{P}(271.21)$

farbloses Ö1

UV-löschend (254 nm)

Smp.: $93{ }^{\circ} \mathrm{C}$

$\mathbf{R}_{\mathbf{f}}=0.35\left(\mathrm{KG}, \mathrm{CHCl}_{3} / \mathrm{MeOH} 9: 1\right)$,

$0.52\left(\mathrm{RP}-18, \mathrm{MeOH} / \mathrm{H}_{2} \mathrm{O} 7: 3\right)$.

ESI-MS: $\mathrm{m} / \mathrm{z}=294[\mathrm{M}+\mathrm{Na}]^{+}, 565[2 \mathrm{M}+\mathrm{Na}]^{+}$.
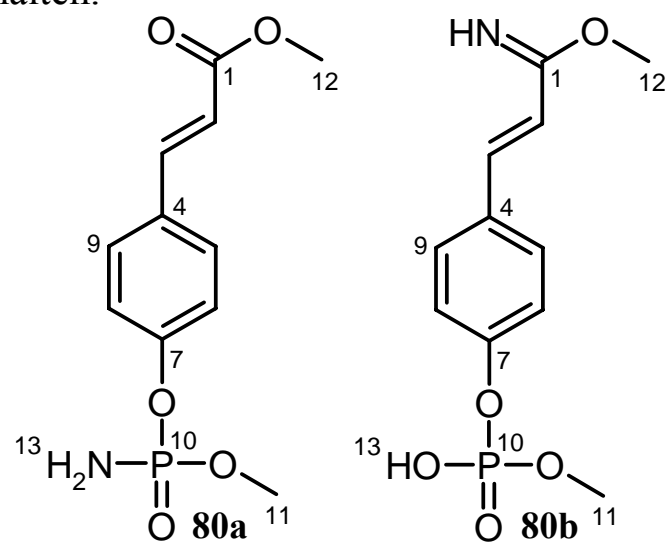

HRESI-MS: 272.0681240 gefunden wie berechnet für $\mathrm{C}_{11} \mathrm{H}_{15} \mathrm{NO}_{5} \mathrm{P}$.

$[\boldsymbol{\alpha}]_{\mathrm{D}}^{\mathbf{2 0}}=-5.2^{\circ}(\mathrm{c}=0.25, \mathrm{MeOH})$.

UV $(\mathrm{MeOH}): \lambda_{\max }(\lg \varepsilon)=204(4.75), 217(4.70), 283(4.86) \mathrm{nm}$,

$(\mathrm{MeOH}, \mathrm{HCl}): \lambda_{\max }(\lg \varepsilon)=205$ (4.80), $217(4.73), 316(4.87) \mathrm{nm}$,

$(\mathrm{MeOH}, \mathrm{NaOH}): \lambda_{\max }(\lg \varepsilon)=240(4.42), 359(4.96) \mathrm{nm}$.

IR (KBr): $\widetilde{v}=3417,2953,1716,1637,1602,1508,1437,1326,1226,1171,1053,1014$, $982,925,836,796 \mathrm{~cm}^{-1}$.

${ }^{1}$ H-NMR $\left(600 \mathrm{MHz}, \mathrm{CD}_{2} \mathrm{Cl}_{2}\right): \delta=3.76\left(\mathrm{~s}, 3 \mathrm{H}, 12-\mathrm{H}_{3}\right), 3.79\left(\mathrm{~d}, J=11.8 \mathrm{~Hz}, 3 \mathrm{H}, 11-\mathrm{H}_{3}\right), 6.37$ $(\mathrm{d}, J=16.0 \mathrm{~Hz}, 1 \mathrm{H}, 2-\mathrm{H}), 7.23(\mathrm{~d}, J=8.5 \mathrm{~Hz}, 2 \mathrm{H}, 6-\mathrm{H}, 8-\mathrm{H}), 7.50(\mathrm{~d}, J=8.5 \mathrm{~Hz}, 2 \mathrm{H}, 5-\mathrm{H}$, 9-H), $7.62(\mathrm{~d}, J=16.0 \mathrm{~Hz}, 1 \mathrm{H}, 3-\mathrm{H}) \mathrm{ppm}$.

${ }^{13}$ C-NMR (75.5 MHz, $\left.\mathrm{CD}_{2} \mathrm{Cl}_{2}\right): \delta=51.8(\mathrm{q}, \mathrm{C}-12), 53.9\left(\mathrm{qd},{ }^{2} J_{\mathrm{C}-\mathrm{P}}=5.8 \mathrm{~Hz}, \mathrm{C}-11\right), 117.9(\mathrm{~d}$, C-2), $121.0\left(\mathrm{dd},{ }^{3} J_{\mathrm{C}-\mathrm{P}}=4.5 \mathrm{~Hz}, \mathrm{C}-6, \mathrm{C}-8\right), 128.6$ (s, C-4), 129.8 (d, C-5, C-9), 143.7 (d, C-3), $152.7\left(\mathrm{dd},{ }^{2} J_{\mathrm{C}-\mathrm{P}}=11.3 \mathrm{~Hz}, \mathrm{C}-7\right), 167.4$ (s, C-1) ppm.

${ }^{31}$ P-NMR $\left(121.5 \mathrm{MHz}, \mathrm{CD}_{2} \mathrm{Cl}_{2}\right): \delta=6.1(\mathrm{~s}, \mathrm{P}-10) \mathrm{ppm}$. 


\section{6-Hydroxy-6-methyl-heptansäure (81)}

81 wurde durch nachfolgende Säulenchromatographie an Sephadex ${ }^{\circledR}$ LH-20 (MeOH), Kieselgel (Cyclohexan / Essigester/ $\mathrm{MeOH}$ 5:10:2) und RP-18 (MeOH / $\mathrm{H}_{2} \mathrm{O}$ 6:4) in einer Ausbeute von $1.2 \mathrm{mg} / \mathrm{L}$ erhalten.

$\mathbf{C}_{8} \mathbf{H}_{16} \mathbf{O}_{3}(160.21)$

farbloser Feststoff

Smp.: $>200{ }^{\circ} \mathrm{C}$

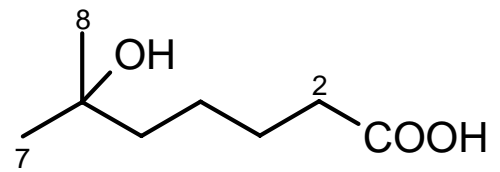

$\mathbf{R}_{\mathbf{f}}=0.16\left(\mathrm{KG}, \mathrm{CHCl}_{3} / \mathrm{MeOH} 9: 1\right)$,

0.69 (RP-18, $\mathrm{MeOH} / \mathrm{H}_{2} \mathrm{O} 7: 3$ ).

Anfärbeverhalten: violett (Anis).

ESI-MS: $\mathrm{m} / \mathrm{z}=183[\mathrm{M}+\mathrm{Na}]^{+}, 343[2 \mathrm{M}+\mathrm{Na}]^{+}, 365[2 \mathrm{M}-\mathrm{H}+2 \mathrm{Na}]^{+}, 159[\mathrm{M}-\mathrm{H}]^{-}, 319[2 \mathrm{M}-\mathrm{H}]^{-}$.

HRESI-MS: 183.0992290 gefunden wie berechnet für $\mathrm{C}_{8} \mathrm{H}_{16} \mathrm{O}_{3} \mathrm{Na}$.

UV $(\mathrm{MeOH}): \lambda_{\max }(\lg \varepsilon)=201(4.95) \mathrm{nm}$.

IR $(\mathrm{KBr}): \widetilde{v}=3425,2970,2361,1712,1559,1466,1381,1251,1196,1150,1125$, $903 \mathrm{~cm}^{-1}$.

${ }^{1}$ H-NMR (600 MHz, CD $\left.{ }_{3} \mathrm{OD}\right): \delta=1.16\left(\mathrm{~s}, 3 \mathrm{H}, 7-\mathrm{H}_{3}, 8-\mathrm{H}_{3}\right), 1.40\left(\mathrm{~m}, 2 \mathrm{H}, 4-\mathrm{H}_{2}\right), 1.46(\mathrm{~m}, 2 \mathrm{H}$, $\left.5-\mathrm{H}_{2}\right), 1.59$ (q, $\left.J=7.5 \mathrm{~Hz}, 2 \mathrm{H}, 3-\mathrm{H}_{2}\right), 2.29$ (t, $\left.J=7.5 \mathrm{~Hz}, 2 \mathrm{H}, 2-\mathrm{H}_{2}\right) \mathrm{ppm}$.

${ }^{13}$ C-NMR (150.8 MHz, CD 3 OD): $\delta=25.0$ (t, C-4), 26.8 (t, C-3), 29.1 (q, C-7, C-8), 35.2 (t, C-2), 44.5 (t, C-5), 71.3 (s, C-6), 178.0 (s, C-1) ppm.

\section{Rosiridol (82)}

82 wurde nach Chromatographie an Sephadex ${ }^{\circledR}$ LH-20 (MeOH) und Kieselgel $\left(\mathrm{CH}_{2} \mathrm{Cl}_{2} / \mathrm{MeOH} 4: 1\right)$ in einer Ausbeute von $2 \mathrm{mg} / \mathrm{L}$ erhalten.

$\mathbf{C}_{10} \mathrm{H}_{18} \mathbf{O}_{2}(170.25)$

farbloser Feststoff

Smp.: $150{ }^{\circ} \mathrm{C}$

$\mathbf{R}_{\mathbf{f}}=0.31\left(\mathrm{KG}, \mathrm{CHCl}_{3} / \mathrm{MeOH} 9: 1\right)$, 0.36 (RP-18, $\mathrm{MeOH} / \mathrm{H}_{2} \mathrm{O}$ 7:3).

Anfärbeverhalten: violett (Anis).<smiles>CC(C)=CCC(O)C(Br)=CCO</smiles>

DCI-MS: $\mathrm{m} / \mathrm{z}=188\left[\mathrm{M}+\mathrm{NH}_{4}\right]^{+}, 170\left[\mathrm{M}-\mathrm{H}_{2} \mathrm{O}+\mathrm{NH}_{4}\right]^{+}$.

$[\boldsymbol{\alpha}]_{\mathbf{D}}^{\mathbf{2 0}}=-8^{\circ}(\mathrm{c}=0.05, \mathrm{MeOH})$. 
UV $(\mathrm{MeOH}): \lambda_{\max }(\lg \varepsilon)=203(4.65) \mathrm{nm}$,

$(\mathrm{MeOH}, \mathrm{HCl}): \lambda_{\max }(\lg \varepsilon)=203(4.68) \mathrm{nm}$,

$(\mathrm{MeOH}, \mathrm{NaOH}): \lambda_{\max }(\lg \varepsilon)=206(4.47) \mathrm{nm}$.

IR $(\mathrm{KBr}): \widetilde{v}=3405,2968(\mathrm{sh}), 2922,1669,1438,1384,1001 \mathrm{~cm}^{-1}$.

${ }^{1}$ H-NMR $\left(300 \mathrm{MHz}, \mathrm{CD}_{3} \mathrm{OD}\right): \delta=1.62\left(\mathrm{~m}, 3 \mathrm{H}, 9-\mathrm{H}_{3}\right), 1.63\left(\mathrm{~m}, 3 \mathrm{H}, 10-\mathrm{H}_{3}\right), 1.69(\mathrm{~m}, 3 \mathrm{H}$, 8- $\left.\mathrm{H}_{3}\right), 2.22\left(\mathrm{~m}, 2 \mathrm{H}, 5-\mathrm{H}_{2}\right), 3.92(\mathrm{t}, J=7.0 \mathrm{~Hz}, 1 \mathrm{H}, 4-\mathrm{H}), 4.12\left(\mathrm{~d}, J=7.0 \mathrm{~Hz}, 2 \mathrm{H}, 1-\mathrm{H}_{2}\right), 5.10$ (thept, $J=7.0,1.5 \mathrm{~Hz}, 1 \mathrm{H}, 6-\mathrm{H}), 5.52$ (tdq, $J=7.0,1.5,1.2 \mathrm{~Hz}, 1 \mathrm{H}, 2-\mathrm{H}) \mathrm{ppm}$.

${ }^{13}$ C-NMR (75.5 MHz, CD ${ }_{3} \mathrm{OD}$ ): $\delta=11.8$ (q, C-10), 18.0 (q, C-9), 26.0 (q, C-8), 34.8 (t, C-5), 59.2 (t, C-1), 78.1 (d, C-4), 121.7 (d, C-6), 126.2 (d, C-2), 134.0 (s, C-7), 140.6 (s, C-3) ppm.

\section{Cyclo(tyrosylprolyl) (83)}

Nach Säulenchromatographie an Sephadex ${ }^{\circledR}$ LH-20 (MeOH), Kieselgel $\left(\mathrm{CH}_{2} \mathrm{Cl}_{2} / \mathrm{MeOH}\right.$ 4:1), RP-18 (MeOH/ $\mathrm{H}_{2} \mathrm{O}$ 6:4) und Kieselgel (Cyclohexan/Essigester/MeOH 5:10:2) wurden $2.5 \mathrm{mg} / \mathrm{L} 83$ erhalten.

$\mathbf{C}_{14} \mathbf{H}_{16} \mathbf{N}_{2} \mathbf{O}_{3}(260.30)$

farbloser Feststoff

UV-löschend (254 nm)

Smp.: $94^{\circ} \mathrm{C}$

$\mathbf{R}_{\mathbf{f}}=0.31\left(\mathrm{KG}, \mathrm{CHCl}_{3} / \mathrm{MeOH} 9: 1\right)$,<smiles>O=C1NC(Cc2ccc(O)cc2)C(=O)N2CCCC12</smiles>

$0.72\left(\mathrm{RP}-18, \mathrm{MeOH} / \mathrm{H}_{2} \mathrm{O}\right.$ 7:3).

ESI-MS: $\mathrm{m} / \mathrm{z}=261[\mathrm{M}+\mathrm{H}]^{+}, 283[\mathrm{M}+\mathrm{Na}]^{+}, 543[2 \mathrm{M}+\mathrm{Na}]^{+}, 259[\mathrm{M}-\mathrm{H}]^{-}, 519[2 \mathrm{M}-\mathrm{H}]^{-}$.

$[\boldsymbol{\alpha}]_{\mathrm{D}}^{\mathbf{2 0}}=-94^{\circ}(\mathrm{c}=0.10, \mathrm{MeOH})$.

UV (MeOH): $\lambda_{\max }(\lg \varepsilon)=204$ (4.88), 224 (4.66), 277 (3.96) nm,

(MeOH, HCl): $\lambda_{\max }(\lg \varepsilon)=202$ (4.94), 224 (4.68), $277(3.98) \mathrm{nm}$,

$(\mathrm{MeOH}, \mathrm{NaOH}): \lambda_{\max }(\lg \varepsilon)=208$ (4.91), 245 (4.65), 294 (3.99) nm.

IR $(\mathrm{KBr}): \widetilde{v}=3384,2956,1885,1653,1615(\mathrm{sh}), 1594(\mathrm{sh}), 1515,1447,1269(\mathrm{sh}), 1233$, 1174 (sh), 1114, $825 \mathrm{~cm}^{-1}$. 
${ }^{1}$ H-NMR (600 MHz, CD ${ }_{3} \mathrm{OD}$ ): $\delta=1.20$ (quintd, $J=11.0,1.8 \mathrm{~Hz}, 1 \mathrm{H}, 12-\mathrm{H}_{\mathrm{a}}$ ), $1.79(\mathrm{~m}, 2 \mathrm{H}$, $\left.13-\mathrm{H}_{\mathrm{a}}, 13-\mathrm{H}_{\mathrm{b}}\right), 2.08\left(\mathrm{~m}, 1 \mathrm{H}, 12-\mathrm{H}_{\mathrm{b}}\right), 3.01\left(\mathrm{dd}, J=14.5,4.5 \mathrm{~Hz}, 1 \mathrm{H}, 3-\mathrm{H}_{\mathrm{a}}\right), 3.08(\mathrm{dd}, J=14.5$, $\left.5.0 \mathrm{~Hz}, 1 \mathrm{H}, 3-\mathrm{H}_{\mathrm{b}}\right), 3.34$ (quint, $\left.J=6.5 \mathrm{~Hz}, 1 \mathrm{H}, 14-\mathrm{H}_{\mathrm{a}}\right), 3.54\left(\mathrm{~m}, 1 \mathrm{H}, 14-\mathrm{H}_{\mathrm{b}}\right), 4.03(\mathrm{~m}, 1 \mathrm{H}$, 11-H), 4.35 (m, 1H, 2-H), 6.69 (d, $J=8.5 \mathrm{~Hz}, 2 \mathrm{H}, 6-\mathrm{H}, 8-\mathrm{H}), 7.03$ (d, $J=8.5 \mathrm{~Hz}, 2 \mathrm{H}, 5-\mathrm{H}$, 9-H) ppm.

${ }^{13}$ C-NMR (150.8 MHz, CD $\left.{ }_{3} \mathrm{OD}\right): \delta=22.7$ (t, C-13), 29.4 (t, C-12), 37.6 (t, C-3), 45.9 (t, C-14), 57.9 (d, C-11), 60.0 (d, C-2), 116.2 (d, C-6, C-8), 127.6 (s, C-4), 132.1 (d, C-5, C-9), 157.7 (s, C-7), 166.9 (s, C-10), 170.8 (s, C-1) ppm.

\section{$N$-Acetyltyramin (84)}

84 wurde durch nachfolgende Säulenchromatographie an Sephadex ${ }^{\circledR}$ LH-20 (MeOH) und $\mathrm{RP}-18\left(\mathrm{MeOH} / \mathrm{H}_{2} \mathrm{O}\right.$ 6:4) in einer Ausbeute von $16.6 \mathrm{mg} / \mathrm{L}$ erhalten.

$\mathrm{C}_{10} \mathrm{H}_{13} \mathrm{NO}_{2}(179.22)$

farbloser Feststoff

UV-löschend (254 nm)

Smp.: $119^{\circ} \mathrm{C}$

$\mathbf{R}_{\mathbf{f}}=0.25\left(\mathrm{KG}, \mathrm{CHCl}_{3} / \mathrm{MeOH} 9: 1\right)$,

$0.71\left(\mathrm{RP}-18, \mathrm{MeOH} / \mathrm{H}_{2} \mathrm{O}\right.$ 7:3).

ESI-MS: $\mathrm{m} / \mathrm{z}=202[\mathrm{M}+\mathrm{Na}]^{+}, 381[2 \mathrm{M}+\mathrm{Na}]^{+}, 178[\mathrm{M}-\mathrm{H}]^{-}$.

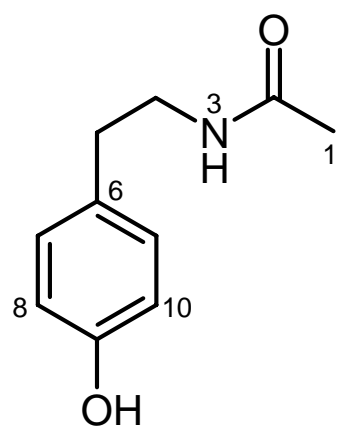

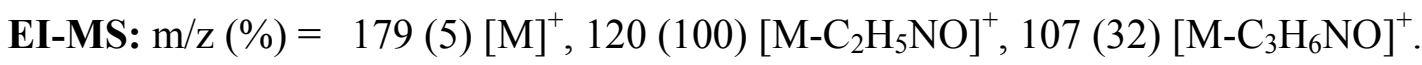

UV $(\mathrm{MeOH}): \lambda_{\max }(\lg \varepsilon)=202$ (4.71), $224(4.56), 278(3.84) \mathrm{nm}$,

$(\mathrm{MeOH}, \mathrm{HCl}): \lambda_{\max }(\lg \varepsilon)=202$ (4.77), $224(4.58), 278(3.91) \mathrm{nm}$,

$(\mathrm{MeOH}, \mathrm{NaOH}): \lambda_{\max }(\lg \varepsilon)=207$ (4.64), 241 (4.52), 286 (3.86) nm.

IR (KBr): $\widetilde{v}=3334,3101,3044,3013,2970,2934,2809,2700,2628$ (sh), 2512 (sh), $1882,1634,1595,1569,1514,1460,1435,1386,1362,1308,1247,1105$, $857,831,812,602 \mathrm{~cm}^{-1}$.

${ }^{1}$ H-NMR $\left(300 \mathrm{MHz}, \mathrm{CD}_{3} \mathrm{OD}\right): \delta=1.83\left(\mathrm{~s}, 3 \mathrm{H}, 1-\mathrm{H}_{3}\right), 2.60\left(\mathrm{t}, J=7.5 \mathrm{~Hz}, 2 \mathrm{H}, 5-\mathrm{H}_{2}\right), 3.25$ (t, $\left.J=7.5 \mathrm{~Hz}, 2 \mathrm{H}, 4-\mathrm{H}_{2}\right), 6.65(\mathrm{~d}, J=8.5 \mathrm{~Hz}, 2 \mathrm{H}, 8-\mathrm{H}, 10-\mathrm{H}), 6.95(\mathrm{~d}, J=8.5 \mathrm{~Hz}, 2 \mathrm{H}, 7-\mathrm{H}$, 11-H) ppm.

${ }^{13}$ C-NMR (75.5 MHz, CD 3 OD): $\delta=22.6$ (q, C-1), 35.6 (t, C-5), 42.4 (t, C-4), 116.3 (d, C-8, C-10), 130.7 (d, C-7, C-11), 131.2 (s, C-6), 156.9 (s, C-9), 173.2 (s, C-2) ppm. 


\section{Indol-3-carbonsäure (85)}

85 wurde durch Mitteldruckchromatographie an RP-18 $\left(\mathrm{MeOH} / \mathrm{H}_{2} \mathrm{O}\right.$ 6:4) in einer Ausbeute von $4.2 \mathrm{mg} / \mathrm{L}$ erhalten.

$\mathrm{C}_{9} \mathrm{H}_{7} \mathrm{NO}_{2}(161.16)$

farbloser Feststoff

UV-löschend (254 nm)

hellblau fluoreszierend (366 nm)

Smp.: $155^{\circ} \mathrm{C}$

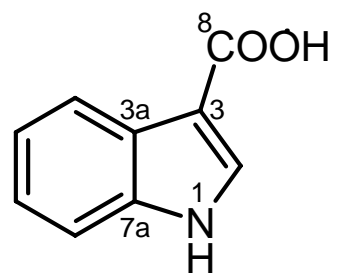

$\mathbf{R}_{\mathbf{f}}=0.25\left(\mathrm{KG}, \mathrm{CHCl}_{3} / \mathrm{MeOH} 9: 1\right)$,

$0.58\left(\mathrm{RP}-18, \mathrm{MeOH} / \mathrm{H}_{2} \mathrm{O}\right.$ 7:3).

Anfärbeverhalten: gelb (Anis).

EI-MS: $\mathrm{m} / \mathrm{z}(\%)=161(100)[\mathrm{M}]^{+}, 144(75)[\mathrm{M}-\mathrm{OH}]^{+}, 117$ (26) $\left[\mathrm{M}-\mathrm{CO}_{2}\right]^{+}, 89$ (16) $\left[\mathrm{M}-\mathrm{C}_{3} \mathrm{H}_{4} \mathrm{O}_{2}\right]^{+}$.

UV $(\mathrm{MeOH}): \lambda_{\max }(\lg \varepsilon)=213(5.05), 280(4.54) \mathrm{nm}$.

IR $(\mathrm{KBr}): \widetilde{v}=3398,2928,1653,1527,1444,1195,1126,754 \mathrm{~cm}^{-1}$.

${ }^{1}$ H-NMR (300 MHz, CD 3 OD): $\delta=7.14(\mathrm{~m}, 2 \mathrm{H}, 5-\mathrm{H}, 6-\mathrm{H}), 7.40$ (m, 1H, 7-H), $7.88(\mathrm{~s}, 1 \mathrm{H}$, 2-H), $8.10(\mathrm{~m}, 1 \mathrm{H}, 4-\mathrm{H}) \mathrm{ppm}$.

${ }^{13}$ C-NMR (150.8 MHz, CD 3 OD): $\delta=110.0$ (s, C-3), 112.8 (d, C-7), 122.1 (d, C-4, C-5), 123.4 (d, C-6), 127.7 (s, C-3a), 132.9 (s, C-2), 138.2 (s, C-7a), 170.3 (s, C-8) ppm. 


\section{LITERATURVERZEICHNIS}

1 J. D. Watson, F. H. C. Crick, Nature 1953, 171, 737-738.

2 S. D. Bentley et al., Nature 2002, 417, 141-147.

3 T. Sasaki et al., Nature 2002, 420, 312-316.

4 International Human Genome Sequencing Consortium, Nature 2001, 409, 860-921.

5 The Celera Genomics Sequencing Team, Science 2001, 291, 1304-1351.

6 W. Hampe, M. Rezgaoui, I. Hermans-Borgmeyer, H. C. Schaller, Hum. Genet. 2001, 108, 529-536.

7 R. F. Service, Science 2004, 303, 1796-1799.

8 J. C. Reader, Curr. Top. Med. Chem. 2004, 4, 671-686.

9 R. Breinbauer, I. R. Vetter, H. Waldmann, Angew. Chem. 2002, 114, 3002-3015.

10 T. Henkel, R. M. Brunne, H. Müller, F. Reichel, Angew. Chem. 1999, 111, 688-691.

11 D. J. Newman, G. M. Cragg, K. M. Snader, J. Nat. Prod. 2003, 66, 1022-1037.

12 J. B. Harborne, H. Baxter, G. P. Moss (Eds.), Phytochemical Dictionary, Taylor \& Francis, London, Philadelphia, 1999.

13 S. Grabley, R. Thiericke (Eds.), Drug Discovery from Nature, Springer, Berlin, Heidelberg, 1999.

14 T. Carlomagno, M. J. J. Blommers, J. Meiler, W. Jahnke, T. Schupp, F. Petersen, D. Schinzer, K.-H. Altmann, C. Griesinger, Angew. Chem. 2003, 115, 2615-2619.

15 U. Rix, C. Fischer, L. L. Remsing, J. Rohr, Nat. Prod. Rep. 2002, 19, 542-580.

16 J. Staunton, K. Weissman, Nat. Prod. Rep. 2000, 18, 380-416.

17 B. Shen, Curr. Opin. Chem. Biol. 2003, 7, 285-295.

18 D. Schwarzer, R. Finking, M. A. Marahiel, Nat. Prod. Rep. 2003, 20, 275-287.

19 D. A. Hopwood, F. Malpartida, H. M. Kieser, H. Ikeda, J. Duncan, I. Fujii, B. A. M. Rudds, H. G. Floss, S. Omura, Nature 1985, 314, 642-644.

20 K. A. Reynolds, Proc. Natl. Acad. Sci. USA 1998, 95, 12744-12746.

21 L. Du, C. Sánchez, B. Shen, Met. Eng. 2001, 3, 78-95.

22 B. S. Moore, C. Hertweck, Nat. Prod. Rep. 2002, 19, 70-99.

23 U. Rix, C. Fischer, L. L. Remsing, J. Rohr, Nat. Prod. Rep. 2002, 19, 542-580.

24 M. Oliynyk, M. J. B. Brown, J. Cortés, J. Staunton, P. F. Leadlay, Chem. Biol. 1996, 3, 833-839.

25 X. Ruan, A. Perada, D. L. Stassi, D. Zeidner, R. G. Summers, M. Jackson, A. Shivakumar, S. Kakavas, M. J. Staver, S. Donadio, L. Katz, J. Bacteriol. 1997, 179, 6416-6425.

26 A. F. A. Marsden, B. Wilkinson, J. Cortés, N. J. Dunster, J. Staunton, P. F. Leadlay, Science 1998, 279, 199202.

27 L. Liu, H. F. Thamchaipenet, M. Betlach, G. Ashley, J. Am. Chem. Soc. 1997, 119, 10553-10554.

28 R. McDaniel, A. Thamchaipenet, C. Gustafsson, H. Fu, M. Betlach, G. Ashley, Proc. Natl. Acad. Sci. USA 1999, 96, 1846-1851.

29 H. Petkovic, R. E. Lill, R. M. Sheridan, B. Wilkinson, E. L. McCormick, H. A. I. McArthur, J. Staunton, P. F. Leadlay, S. G. Kendrew, J. Antibiot. 2003, 56, 543-551. 
30 B. Wilkinson, G. Foster, B. A. M. Rudd, N. L. Taylor, A. P. Blackaby, P. J. Siedbottom, D. J. Cooper, M. J. Dawson, A. D. Buss, S. Gaisser, I. U. Böhm, C. J. Rowe, J. Cortés, P. F. Leadlay, J. Staunton, Chem. Biol. 2000, 7, 111-117.

31 C. J. Rowe, I. U. Böhm, I. P. Thomas, B. Wilkinson, B. A. M. Rudd, G. Foster, A. P. Blackaby, P. J. Sidebottom, Y. Roddis, A. D. Buss, J. Staunton, P. F. Leadlay, Chem. Biol. 2001, 8, 475-485.

32 S. J. Moss, C. J. Martin, B. Wilkinson, Nat. Prod. Rep. 2004, 21, 575-593.

33 H. B. Bode, Dissertation, Universität Göttingen, 2000.

34 S. Dröse, C. Boddien, M. Gassel, G. Ingenhorst, A. Zeeck, K. Altendorf, Biochemistry 2001, 40, $2816-2825$.

35 G. Ingenhorst, K. U. Bindseil, C. Boddien, S. Dröse, M. Gaßel, K. Altendorf, A.Zeeck, Eur. J. Org. Chem. 2001, 4525-4532.

36 N. Czempinski, Diplomarbeit, Universität Göttingen 2003.

37 K. U. Bindseil, A. Zeeck, Liebigs Ann. Chem. 1994, 305-312.

38 H. Kinashi, K. Someno, K. Sakaguchi, Tetrahedron Lett. 1981, 22, 3857-3860.

39 H. Kinashi, K. Someno, K. Sakaguchi, T. Higashijima, T. Miyazawa, Tetrahedron Lett. 1981, 22, 3861-3864.

40 J.-T. Woo, C. Shinohara, K. Sakai, K. Hasumi, A. Endo, J. Antibiot. 1992, 45, 1108-1116.

41 Y. Hayakawa, K. Takaku, K. Furihata, K. Nagai, H. Seto, J. Antobiot. 1991, 44, 1294-1299.

42 S. Omura, N. Imamura, K. Hinotozawa, K. Otoguro, G. Lukacs, R. Faghih, R. Tolmann, B. H. Arison, J. L. Smith, J. Antibiot. 1983, 36, 1783-1786.

43 G. Werner, H. Hagenmaier, K. Albert, H. Kohlshorn. H. Drautz, Tetrahedron Lett. 1983, 24, 5193-5196.

44 G. H. Baker, P. J. Brown, R. J. J. Dorgan, J. R. Everett, S. V. Ley, A. M. Z. Slawin, D. J. Williams, Tetrahedron Lett. 1987, 28, 5565-5568.

45 H. Seto, H. Akao, K. Furihata, N. Otake, Tetrahedron Lett. 1982, 23, 2667-2670.

46 M. Iharashi, H. Nakamura, H. Naganawa, T. Takeuchi, J. Antibiot. 1997, 50, 932-936.

47 K. Neupert-Laves, M. Dobler, Helv. Chim. Acta 1982, 65, 262-267.

48 K. Frobel, E. Bischoff, H. Mueller, O. Salcher, A. de Jong, F. Berschauer, M. Scheer, Ger. Pat. DE 85$3511753,1986$.

49 G. Werner, H. Hagenmaier, H. Drautz, A. Baumgartner, H. Zähner, J. Antibiot. 1984, 37, 110-117.

50 E. J. Bowman, A. Siebers, Altendorf, Proc. Natl. Acad. Sci. USA 1988, 85, 7972-7976.

51 S. Dröse, K. U. Bindseil, E. J. Bowman, A. Siebers, A. Zeeck, K. Altendorf, Biochemistry 1993, 32, $3902-$ 3906.

52 J. A. Beutler, T. C. McKee, Curr. Med. Chem. 2003, 10, 787-796.

53 S. Dröse, K. Altendorf, J. Exp. Biol. 1997, 200, 1-8.

54 S. Dröse, C. Boddien, M. Gassel, G. Ingenhorst, A. Zeeck, K. Altendorf, Biochemistry 2001, 40, $2816-2825$.

55 M. Huss, G. Ingenhorst, S. König, M. Gaßel, S. Dröse, A. Zeeck, K. Altendorf, H. Wieczorek, J. Biol. Chem. 2002, 277, 40544-40548.

56 B. J. Bowman, E. J. Bowman, J. Biol. Chem. 2002, 277, 3965-3972.

57 E. J. Bowman, L. A. Graham, T. H. Stevens, B. J. Bowman, J. Biol. Chem. 2004, 279, 33131-33138.

58 K. Tanigaki, S. Sasaki, S. Okhuma, FEBS Letters 2003, 537, 79-84.

59 F. E. Karet, K. E. Finberg, R. D. Nelson, A. Nayir, H. Mocan, S. A. Sanjad, J. Rodriguez-Soriano, F. Santos, C. W. Cremers, A. di Pietro, B. I. Hoffbrand, J. Winiarski, A. Bakkaloglu, S. Ozen, R. Dusunsel, P. Goodyer, 
S. A. Hulton, D. K. Wu, A. B. Skvorak, C. C. Morton, M. J. Cunningham, V. Jha, R. P. Lifton, Nat. Genet. 1999, 21, 84-90.

60 T. Torigoe, H. Izumi, T. Ise, T. Murakami, H. Uramoto, H. Ishiguchi, Y. Yoshida, M. Tanabe, M. Nomoto, K. Kohno, Anticancer Drugs 2002, 13, 237-243.

61 H. C. Blair, S. L. Teitelbaum, R. Ghiselli, S. Gluck, Science 1989, 245, 855-857.

62 G. Stenbeck, M. A. Horton, J. Cell. Sci. 2004, 117, 827-836.

63 C. Farina, S. Gagliardi, DDT 1999, 4, 163-172.

64 C. Farina, S. Gagliardi, Exp. Opin. Ther. Patents 1999, 9, 157-168.

65 C. Farina, S. Gagliardi, Current Pharmaceutical Design 2002, 8, 2033-2048.

66 aus: M. Huß, Dissertation, Universität Osnabrück, 2001.

67 K. Toshima, T. Jyojima, H. Yamaguchi, Y. Noguchi, T. Yoshida, H. Murase, M. Nakata, S. Matsumura, J. Org. Chem. 1997, 62, 3271-3284.

68 K. A. Scheidt, A. Tasaka, T. D. Bannister, M. D. Wendt, W. R. Roush, Angew. Chem. 1999, 111, 1760-1762.

69 S. Hanessian, J. Ma, W. Wang, J. Am. Chem. Soc. 2001, 123, 10200-10206.

70 W. R. Roush, T. D. Bannister, M. D. Wendt, J. A. Jablonowski, K. A. Scheidt, J. Org. Chem. 2002, 67, 42754283.

71 F. Eustache, P. I. Dalko, J. Cossy, J. Org. Chem. 2003, 68, 9994-10002.

72 E. Quéron, R. Lett, Tetrahedron Lett. 2004, 45, 4539-4543.

73 K. Toshima, Curr. Org. Chem. 2004, 8, 185-210.

74 H. G. Floss, J. Ind. Microbiol. Biotechnol. 2001, 27, 183-194.

75 S. Grond, I. Papastavrou, A. Zeeck, Eur. J. Org. Chem. 2000, 1875-1881.

76 A. I. Scott, C. A. Townsend, K. Okada, M. Kajiwara, R. J. Cushley, P. J. Whitman, J. Am. Chem. Soc. 1974, 96, 8069-8080.

77 K. Hatano, E. Mizuta, S. Akiyama, E. Higashide, Y. Nakao, Agric. Biol. Chem. 1985, 49, 327-333.

78 S. Omura, A. Nakagawa, H. Takeshima, K. Atusmi, J. Miyazawa, F. Piriou, G. Lukacs, J. Am. Chem. Soc. 1975, 97, 6600-6602.

79 A. Haber, R. D. Johnson, K. L. Rinehart Jr., J. Am. Chem. Soc. 1977, 99, 3541-3544.

80 K. M. Byrne, A. Shafiee, J. B. Nielsen, B. H. Arison, R. L. Monaghan, L. Kaplan, in Developments in Industrial Microbiology Series, Vol. 32, Ed.: R. Hamill, Wm. C. Brown Publisher, Dubuque, Iowa, 1993, 29.

81 A. M. Hill, J. P. Harris, A. P. Siskos, J. Chem. Soc., Chem. Commun. 1998, 2361-2362.

82 E. A. Stohl, J. L. Milner, J. Handelsman, Gene 1999, 237, 403-411.

83 B. J. Carroll, S. J. Moss, L. Bai, Y. Kato, S. Toelzer, T.-W. Yu, H. G. Floss, J. Am. Chem. Soc. 2002, 124, 4176-4177.

84 E. J. Corey, J. W. Ponder, Tetrahedron Lett. 1984, 39, 4325-4328.

85 A. Nakagawa, T.-S. Wu, P. J. Keller, J. P. Lee, S. Omura, H. G. Floss, J. Chem. Soc., Chem. Commun. 1985, 519-521.

${ }^{86}$ R. Thiericke, A. Zeeck, A. Nakagawa, S. Omura, R. E. Herrold, S. T. S. Wu, J. M. Beale, H. G. Floss, J. Am. Chem. Soc. 1990, 112, 3979-3987.

87 J. M. Beale, J. P. Lee, A. Nakagawa, S. Omura, H. G. Floss, J. Am. Chem. Soc. 1986, 108, 331-332.

88 G. Michal (Hrsg.), Biochemical Pathways, Spektrum Akademischer Verlag, Heidelberg, Berlin, 1999. 
O. Wagner, Dissertation, Universität Göttingen, 2000.

90 R. Surette, L. C. Vining, J. Antibiot. 1976, 29, 646-652.

91 D. Voet, J. G. Voet, C. W. Pratt, Lehrbuch der Biochemie, Wiley-VCH, Weinheim, 2002.

92 C. Khosla, D. E. Cane, F. Kudo, K. Kinoshita, Chem. Biol. 2003, 9, 131-142.

93 Y. Kato, L. Bai, Q. Xue, W. P. Revill, T.-W. Yu, H. G. Floss, J. Am. Chem. Soc. 2002, 124, 5268-5269.

94 K. Watanabe, C. Khosla, R. M. Stroud, S.-C. Tsai, J. Mol. Biol. 2003, 334, 435-444.

95 J. W. Westley, C.-M. Liu, L. H. Sello, R. H. Evans, N. Troupe, J. F. Blount, A. M. Chiu, L. J. Todaro, P. A. Miller, J. Antibiot. 1984, 37, 1738-1740.

96 K. U. Bindseil, Dissertation, Universität Göttingen, 1993.

97 C. Boddien, Dissertation, Universität Göttingen, 1995.

98 M. K. Wassef, J. Sarner, M. Kates, Can. J. Biochem. 1970, 48, 69-73.

99 S. Kornfeld, L. Glaser, Biochim. Biophys. Acta 1960, 42, 548-550.

${ }^{100}$ S.-W. Yang, G. A. Cordell, J. Nat. Prod. 1996, 59, 828-833.

101 B. Ewing, P. Green, Genome Res. 1998, 8, 186-194.

102 B. Ewing, L. Hillier, M. C. Wendl, P. Green, Genome Res. 1998, 8, 175-185.

${ }^{103}$ D. Gordon, C. Abajian, P. Green, Genome Res. 1998, 8, 195-202.

104 J. H. Badger, G. J. Olsen, Mol. Biol. Evol. 1999, 16, 512-524.

${ }^{105}$ K. Rutherford, J. Parkhill, J. Crook, T. Horsnell, P. Rice, M. A. Rajandream, B. Barrell, Bioinformatics 2000, 16, 944-945.

${ }^{106}$ S. F. Altschul, W. Gish, W. Miller, E. W. Myers, D. J. Lipman, J. Mol. Biol. 1990, 215, 403-410.

${ }^{107}$ S. R. Eddy, HMMer: Profile hidden Markov models for biological sequence analysis, http://hmmer.wustl.edu, 2001.

${ }^{108}$ T. Weber, persönliche Mitteilung, 2004.

109 J. Felsenstein, Phyllip, http://evolution.genetics.washington.edu/phylip.html, 2004.

${ }^{110}$ S. F. Haydock, J. F. Aparicio, I. Molnár, T. Schwecke, L. E. Khaw, A. König, A. F. A. Marsden, I. S. Galloway, J. Staunton, P. F. Leadlay, FEBS Letters 1995, 374, 246-248.

111 K. Wu, L. Chung, W. P. Revill, L. Katz, C. D. Reeves, Gene 2000, 251, 81-90.

112 S. Omura, A. Nakagawa, Y. Tanaka, J. Org. Chem. 1982, 47, 5415-5416.

113 S. Omura, A. Nakagawa, N. Imamura, K. Kushida, C.-M. Liu, L. H. Sello, J. W. Westley, J. Antibiot. 1986, $38,674-676$.

114 Y. Xue, L. Zhao, H.-W. Liu, D. H. Sherman, Proc. Natl. Acad. Sci USA 1998, 95, 12111-12116.

${ }^{115}$ E. Künzel, B. Faust, C. Oelkers, U. Weissbach, D. W. Bearden, G. Weitnauer, L. Westrich, A. Bechthold, J. Rohr, J. Am. Chem. Soc. 1999, 121, 11058-11062.

${ }^{116}$ L. Zhao, J. Ahlert, Y. Xue, J. S. Thorson, D. H. Sherman, H.-W. Liu, J. Am. Chem. Soc. 1999, 121, $9881-$ 9882.

117 T. Kieser, M. J. Bibb, M. J. Buttner, K. F. Chater, D. A. Hopwood, Practical Streptomyces Genetics, John Innes Foundation, Norwich, 2000.

118 P. Mazodier, R. Petter, C. Thompson, J. Bacteriol. 1989, 171, 3583-3585.

${ }^{119}$ F. Kotzyba-Hibert, I. Kapfer, M. Goeldner, Angew. Chem. 1995, 107, 1391-1408.

${ }^{120}$ S. A. Fleming, Tetrahedron 1995, 46, 12479-12520. 
121 D. C. Chiara, J. C. Trinidad, D. Wang, M. R. Ziebell, D. Sullivan, J. Cohen, Biochemistry 2003, 42, 271-283.

122 M. T. Mas, J. K. Wang, P. A. Hargrave, Biochemistry 1980, 19, 684.

123 Y.-Z. Li, J. P. Kirby, M. W. George, M. Poliakoff, G. B. Schuster, J. Am. Chem. Soc. 1988, 110, 8092-8098.

124 J. Brunner, H. Senn, F. M. Richards, J. Biol. Chem. 1980, 255, 3313-3318.

125 M. Nassal, Liebigs Ann. Chem. 1983, 1510-1523.

126 A. Rühmann, A. K. E. Köpke, F. M. Drautzenberg, J. Spiess, Proc. Natl. Acad. Sci. USA 1996, 93, 1060910613.

127 Y. Ambroise, F. Pillon, C. Miokowski, A. Valleix, B. Rousseua, Eur. J. Org. Chem. 2001, 3961-3964.

${ }^{128}$ N. Kanoh, S. Kumashiro, S. Simizu, Y. Kondoh, S. Hatakeyama, H. Tashiro, H. Osada, Angew. Chem. Int. Ed. 2003, 42, 5584-5587.

129 J. Duan, L. H. Zhang, W. R. Dolbier Jr., Synlett 1999, 8, 1245-1246.

130 P. A. Gatti, S. Gagliardi, A. Cerri, M. Visconti, C. Farina, J. Org. Chem. 1996, 61, 7185-7188.

131 M. Huss, S. Bockelmann and H. Wieczorek, unpublished results.

132 S. Umezawa, T. Tsuchiya, K. Tatsuna, Y. Horiychi, T. Usi, H. Umezawa, M. Hamada, A. Yagi, J. Antibiot. 1970, 23, 20-27.

${ }^{133}$ H. Zähner, H. Drautz, W. Weber, in Bioactive Microbial Product-Search and Discovery, Eds.: J. D. Bullock, L. J. Nisbet, D. J. Winstley, Academic Press, London, New York, 1982, 51-70.

134 S. Breiding-Mack, A. Zeeck, J. Antibiot. 1987, 40, 953-960.

135 H. B. Bode, B. Bethe, R. Höfs, A. Zeeck, ChemBioChem 2002, 3, 619-627.

${ }^{136}$ H. O. Kalinowski, S. Berger, S. Braun, ${ }^{13} C$-NMR-Spektroskopie, Georg Thieme Verlag, Stuttgart, New York, 1984.

${ }^{137}$ B. Böhlendorf, E. Forche, N. Bedorf, K. Gerth, H. Irschik, R. Jansen, B. Kunze, W. Trowitzsch-Kienast, H. Reichenbach, G. Höfle, Liebigs Ann. 1996, 49-53.

${ }^{138}$ H. Achenbach, C. Renner, R. Waibel, Liebigs Ann. 1995, 1327-1337.

139 M. Rohmer, Nat. Prod. Rep. 1999, 16, 565-574.

${ }^{140}$ C. J. Pouchert, J.Behnke, The Aldrich Library of ${ }^{13} C$ and ${ }^{1} H$ FTNMR Spectra, Edition I, Aldrich Chemical Company Inc. 1993.

141 F. E. Hruska, W. J. P. Blonski, Can. J. Chem. 1982, 60, 3026-3032.

142 J. Hovinen, Helv. Chim. Acta. 1997, 80, 851-855.

143 A. S. B. Prasad, T. M. Stevenson, J. R. Citineni, V. Nyzam, P. Knochel, Tetrahedron 1997, 53, 7237-7254.

144 R. L. Hamill, M. M. Hoehn, J. Antibiot. 1973, 26, 463-465.

145 M. J. Yebra, J. Sanchez, C. G. Martin, C. Hardisson, C. Barbes, J. Antibiot. 1991, 44, 1141-1147.

146 A. Takatsuki, K. Arima, G. Tamura, J. Antibiot. 1971, 24, 215-223.

147 B. C. Tsvetanova, D. J. Kiemle, N. P. J. Price, J. Biol. Chem. 2002, 277, 35289-35296.

${ }^{148}$ H. Laatsch, Naturstoffdatenbank AntiBase, Version 2002, Chemical Concepts, Weinheim, 2000.

149 W. L. Bolhofer, R. A. Machlowitz, J. Charney, Antibiot. \& Chemoth. 1953, 3, 382-384.

${ }^{150}$ B. Jensen, J. Antibiot. 1969, 22, 231-232.

151 W. von Daehne, W. O. Godtfredsen, L. Tybring, K. Schaumburg, J. Antibiot. 1969, 22, 233-236.

${ }^{152}$ F. Conti, W. von Philipsborn, Helv. Chim. Acta 1967, 50, 603-607.

153 R. C. Neuman Jr., V. Jonas, J. Am. Chem. Soc. 1968, 90, 1970-1975. 
154 A. Pines, M. Rabinovitz, Tetrahedron Lett. 1968, 31, 3529-3532.

155 A. R. Katritzky, K. W. Law, Magn. Reson. Chem. 1988, 26, 129-133.

156 M. Speitling, Dissertation, Universität Göttingen, 1998.

157 R. Höfs, Dissertation, Universität Göttingen, 1999.

158 A. Schulze, Dissertation, Universität Göttingen, 2003.

159 G. Terui, T. Enatzu, S. Tabota, J. Ferment. Technol. 1961, 39, 224.

${ }^{160}$ F. Arcamone, E. B. Chain, A. Ferretti, P. Pannella, Nature 1961, 192, 552-553.

161 P. V. Subbarao, K. Moore, G. H. N. Towers, Biochem. Biophys. Res. Commun. 1967, 28, 1008.

${ }^{162}$ V. E. Tyler Jr., K. Mothes, D. Gröger, H. G. Floss, Tetrahedron Lett. 1964, 11, 593-598.

163 J. R. Dyer, H. Heding, C. P. Schaffner, J. Org. Chem. 1964, 29, 2802-2803.

164 C. Ratledge, Nature 1964, 203, 428-429.

165 J. L. Corbin, W. A. Bulen, Biochemistry 1969, 8, 757-762.

166 I. G. Young, G. B. Cox, F. Gibson, Biochim. Biophys. Acta 1967, 141, 319.

167 I. G. Young, L. M. Jackman, F. Gibson, Biochim. Biophys. Acta 1967, 148, 313.

${ }^{168}$ K.-I. Hayashi, K. Suzuki, M. Kawaguchi, T. Nakajima, T. Suzuki, M. Numata, T. Nakamura, Biosci. Biotech. Biochem. 1995, 59, 319-320.

169 W. A. Ayer, J. S. Racok, Can. J. Chem. 1990, 68, 2095-2101.

${ }^{170}$ F. Huth, Dissertation, Universität Göttingen, 1999.

171 Y. Hayakawa, T. Iwakiri, K. Imamura, H. Seto, N. Otake, J. Antibiot. 1987, 40, 1785-1787.

172 H. Drautz, H. Zähner, J. Rohr, A. Zeeck, J. Antibiot. 1986, 39, 1657-1669.

173 J. Rohr, R. Thiericke, Nat. Prod. Rep. 1992, 9, 103-137

174 K. Krohn, J. Rohr, Top. Curr. Chem. 1997, 188, 127-195.

175 J. Schimana, H.-P. Fiedler, I. Groth, R. Süssmuth, W. Beil, M. Walker, A. Zeeck, J. Antibiot. 2000, 53, 779-787.

${ }^{176}$ M. Holzenkämpfer, M. Walker, A. Zeeck, J. Schimana, H.-P. Fiedler, J. Antibiot. 2002, 55, 301-307.

177 K. Ströch, Dissertation, Universität Göttingen, 2003.

178 A. Kawashima, Y. Kishimura, M. Tamai, K. Hanada, Chem. Pharm. Bull. 1989, 37, 3429-3431.

179 T. Uchida, M. Imoto, Y. Watanabe, K. Miura, T. Dobashi, N. Matsuda, T. Sawa, H. Naganawa, M. Hamada, T. Takeuchi, H. Umezawa, J. Antibiot. 1985, 38, 1171-1181.

180 D. G. I. Kingston, L. Todd, D. H. Williams, J. Chem. Soc. C 1966, 1669-1676.

181 J. W. LeFevre, T. E. Glass, M. X. Kolpak, D. G. I. Kingston, J. Nat. Prod. 1983, 46, 475-480.

${ }^{182}$ W. Witte, in Antibiotics Resistance: Origins, Evolution, Selection and Spread, Ciba Foundation Symposium 207, Wiley, Chichester, 1997, 61-75.

$183 \mathrm{http}: / / w w w . a p v m a . g o v . a u / c h e m r e v / v i r g i n i a m y c i n . p d f$

184 J. Falbe, M. Regnitz, Römpp Lexikon Chemie T-Z, 10. Auflage, Georg Thieme Verlag, Stuttgart, 1999.

185 D. G. I. Kingston, M. X. Kolpak, J. W. LeFevre, I. Borup-Grochtmann, J. Am. Chem. Soc. 1983, 105, 51065110 .

186 C. Walsh, Antibiotics, ASM Press, Washington, 2003.

187 L. Du, C. Sánchez, B. Shen, Metabolic Engineering 2001, 3, 78-95. 
${ }^{188}$ Y. K. T. Lam, P. Dai, D. L. Zink, A. J. Smith, N. W. Lee, S. Freedman, M. J. Salvatore, J. Antibiot. 1993, 46, 623-630.

189 V. M. Dembitsky, I. Shkrob, O. Lev, J. Chem. Ecol. 2000, 26, 1359-1366.

190 R. Veluri, I. Oka, I. Wagner-Döbler, H. Laatsch, J. Nat. Prod. 2003, 66, 1520-1523.

191 H. Cramer, W. Pfleiderer, Helv. Chim. Acta 1996, 79, 2114-2136.

192 M. Hesse, H. Meier, B. Zeeh, Spektroskopische Methoden in der organischen Chemie, Thieme, Stuttgart, New York, 2002.

193 T. Bender, Diplomarbeit, Universität Göttingen, 2004.

194 K. Eckardt, D. Tresselt, W. Ihn, J. Antibiot. 1978, 31, 970-973.

195 H. Brockmann, K. H. Renneberg, Naturwissenschaften 1953, 40, 59-60.

196 T. Ueno, H. Takahashi, M. Oda, M. Mizunuma, A. Yokoyama, Y. Goto, Y. Mizushina, K. Sakaguchi, H. Hayashi, Biochemistry 2000, 39, 5995-6002.

197 A. Li, J. Piel, Chem. Biol. 2002, 9, 1017-1026.

198 S. Sakuda, A. Higashi, S. Tanaka, T. Nihira, Y. Yamada, J. Am. Chem. Soc. 1992, 114, 663-668.

199 E. Pretsch, P. Bühlmann, C. Affolter, M. Badertscher, Spektroskopische Methoden zur Strukturaufklärung organischer Verbindungen, Springer-Verlag, Berlin, Heidelberg, 2001, S. 223.

200 S. Meyer, Dissertation, Universität Göttingen, 2003.

201 R. N. Asolkar, D. Schröder, R. Heckmann, S. Lang, I. Wagner-Döbler, H. Laatsch, J. Antibiot. 2004, 57, $17-$ 23.

202 J. Piel, Nat. Prod. Rep. 2004, 21, 519-538.

${ }^{203}$ H. Bickel, R. Bosshardt, E. Gäumann, P. Reusser, E. Vischer, W. Voser, A. Wettstein, H. Zähner, Helv. Chim. Acta 1960, 43, 2118-2128.

204 B. Girmann, Dissertation, Universität Göttingen, 2002.

${ }^{205}$ H. Wang, S. L. Yeo, J. Xu, X. Xu, H. He, F. Ronca, A. E. Ting, Y. Wang, V. C. Yu, M. M. Sim, J. Nat. Prod. 2002, 65, 721-724.

${ }^{206}$ G. Winkelmann, H. Drechsel, in: Biotechnology, Vol. 7, Eds.: H.-J. Rehm et al., Wiley-VCH, Weinheim, 1997, 199-246.

207 M. P. Neu, J. H. Matonic, C. E. Ruggiero, B. L. Scott, Angew. Chem. 2000, 112, 1501-1503.

208 V. A. Kurkin, G. G. Zapesochnaya, A. N. Shchavlinskii, Khim. Prir. Soedin. 1985, 5, 632-635.

209 P. T. Northcote, J. Andersen, J. Am. Chem. Soc. 1989, 111, 6276-6280.

${ }^{210}$ G. S. Jayatilake, M. P. Thornton, A. C. Leonard, J. E. Grimwalde, B. J. Baker, J. Nat. Prod. 1996, 59, $293-$ 296.

211 A. C. Stierle, J. H. Cardellina II, G. A. Strobel, Proc. Natl. Acad. Sci. USA 1988, 85, 8008-8011.

212 B. Bethe, Dissertation, Universität Göttingen, 1994.

213 M. Holzenkämpfer, Dissertation, Universität Göttingen, 2001.

${ }^{214}$ D. R. Houston, B. Synstad, V. G. H. Eijsink, M. J. R. Stark, I. M. Eggleston, D. M. F. van Aalten, J. Med. Chem. 2004, 47, 5713-5720.

215 J. Comin, W. Keller-Schierlein, Helv. Chim. Acta 1959, 42, 1730-1732.

216 S. Kunimoto, C.-Z. Xu, H. Naganawa, M. Hamada, T. Masuda, T. Takeuchi, H. Umezawa, J. Antibiot. 1987, $40,1651-1652$. 
217 W.-S. Sun, H.-S. Lee, J.-M. Park, S.-H. Kim, J.-H. Yu, J.-H. Kim, J. Antibiot. 2001, 54, 827-7830.

${ }^{218}$ W. S. Sun, Y. S. Park, J. Yoo, K. D. Park, S. H. Kim, J.-H. Kim, H-J. Park, J. Med. Chem. 2003, 46, 56195627.

219 G. Habermehl, P. Hammann, Naturstoffchemie, Springer-Verlag, Berlin, 1992, S. 151.

${ }^{220}$ X. Fu, F. J. Schmitz, R. S. Tanner, J. Nat. Prod. 1995, 58, 1950-1954.

221 T. Schuhmann, S. Grond, J. Antibiot. 2004, 57, 655-661.

${ }^{222}$ W. C. Still, M. Kahn, A. Mitra, J. Org. Chem. 1978, 43, 2923-2925.

${ }^{223}$ Merck, Anfärbereagenzien für die Dünnschichtchromatographie, Darmstadt, 1980. 


\section{Danksagung}

Mein ganz besonderer Dank gilt Hans-Jörg Langer, dessen exzellente experimentelle Mitarbeit eine große Hilfe beim Zustandekommen dieser Arbeit war und der den Alltag im Labor mit vielen wertvollen Diskussionen und Späßen ungemein bereichert hat.

Für die gute Zusammenarbeit bei den Biosyntheseuntersuchungen danke ich Prof. Dr. H.-G. Floss. PD Dr. Udo Wehmeier und Dr. Tilmann Weber möchte ich für die gute Kooperation im BMBF-Projekt danken. Bei Dr. Markus Huss bedanke ich mich für die engagierte Zusammenarbeit bei den V-ATPase-Untersuchungen.

Carola Zolke, Christiane Siebert und Martin Weitemeyer danke ich für das Messen zahlreicher NMR-Spektren. Bei Herrn Reinhard Machinek möchte ich mich für die Hilfe bei NMRtechnischen Problemen bedanken. Aus unserer Abteilung danke ich Stephanie Grond, Olli Schlörke, Sven Meier, Diana Wolff, Frank Surup, Inken Plitzko und Jens Bitzer für das viele Messen.

Bei Dr. Holm Frauendorf und Györgyi Udvarnoki bedanke ich mich für die Aufnahme der Massenspektren.

Besonderer Dank gilt Hans-Peter Kroll für die unermüdliche Isolierung von Bafi $\mathrm{A}_{1}$, Kerstin Vogel für das Destillieren der Lösungsmittel und Jutta Gerber-Nolte für die Bereitstellung der Testplatten.

Jens Bitzer, Gerald Thormann, Marko Gentzsch und Patricio Lopez danke ich für die Hilfe bei so manchem Problem mit Rechnern und Netzwerken.

Für das gründliche, schnelle Korrekturlesen und die konstruktive Kritik möchte ich Jens Bitzer, Markus Radzom, Tilmann Weber, Luise Hoffmann und Frank Surup danken. Bei Tobias Bender bedanke ich mich für alles rund ums Okaspirodiol.

Allen Mitgliedern der Abteilungen Grond und Zeeck danke ich herzlich für das wunderbare Arbeitsklima und die vielen angenehmen Stunden bei Kuchen, Tee und sonstigen Anlässen.

Mein ganz besonderer Dank gilt meinen Eltern, die immer ihr möglichstes getan haben, um mich zu unterstützen.

Mein allergrößter Dank gilt meiner Frau Imelda, die immer für mich da ist und die mein Leben auch in schwierigen Zeiten lebenswert macht. 


\section{Lebenslauf}

Am 29.05.1975 wurde ich als erstes Kind von Waltraud Schuhmann, geb. Turini, und Siegfried Schuhmann in Marktredwitz geboren.

Von August 1981 bis Juli 1985 besuchte ich die Grundschule in Marktredwitz und von September 1986 bis Juni 1994 das Otto-Hahn-Gymnasium in Marktredwitz, welches ich mit der Allgemeinen Hochschulreife verließ.

Von Oktober 1994 bis Februar 1995 leistete ich Grundwehrdienst bei der Luftwaffe in Bayreuth und Feuchtwangen, den ich von Februar 1995 bis Dezember 1995 als Wehrersatzdienst am Kreisund Stadtkrankenhaus Wunsiedel-Marktredwitz fortsetzte.

Im Wintersemester 1995/96 begann ich mit dem Studium der Chemie an der Universität Bayreuth, legte im Dezember 1997 die Diplom-Chemiker-Vorprüfung und im September 2000 die Diplom-Chemiker-Hauptprüfung ab.

In der Zeit von Dezember 2000 bis September 2001 fertigte ich im Arbeitskreis von Prof. Dr. C. Unverzagt (Universität Bayreuth) meine Diplomarbeit mit dem Titel „Untersuchungen zur Synthese von 2-( $\alpha$-Mannopyranosyl)-L-Tryptophan“ an.

Seit Januar 2002 arbeite ich unter Anleitung von Dr. S. Grond und Prof. Dr. A. Zeeck an der vorliegenden Dissertation. 